OSCAR D. ACOSTA LOPERA

HYDRODYNAMIC ANALYSIS OF INLAND VESSEL SELF-PROPULSION FOR CARGO TRANSPORT FOR NAVIGABILITY IN THE MAGDALENA RIVER 

OSCAR D. ACOSTA LOPERA

\section{HYDRODYNAMIC ANALYSIS OF INLAND VESSEL SELF-PROPULSION FOR CARGO TRANSPORT FOR NAVIGABILITY IN THE MAGDALENA RIVER}

Master thesis presented to the Polytechnic

School of the University of São Paulo for the degree of Master of Science. 

OSCAR D. ACOSTA LOPERA

\section{HYDRODYNAMIC ANALYSIS OF INLAND VESSEL SELF-PROPULSION FOR CARGO TRANSPORT FOR NAVIGABILITY IN THE MAGDALENA RIVER}

Master thesis presented to the Polytechnic School of the University of São Paulo for the degree of Master of Science.

Research area:

Naval and Oceanic Engineering

Advisor:

Prof. Ph.D. Kazuo Nishimoto 

Autorizo a reprodução e divulgação total ou parcial deste trabalho, por qualquer meio convencional ou eletrônico, para fins de estudo e pesquisa, desde que citada a fonte.

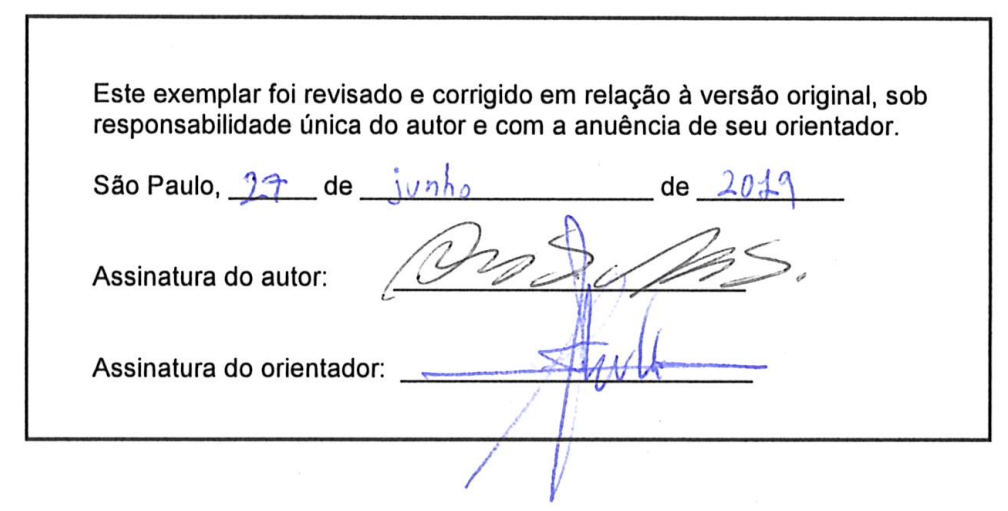

Catalogação-na-publicação

Acosta Lopera, Oscar D.

Hydrodynamic Analysis of Inland Vessel Self-Propulsion for Cargo Transport for Navigability in The Magdalena River / O. D. Acosta Lopera -versão corr. -- São Paulo, 2019.

$134 \mathrm{p}$.

Dissertação (Mestrado) - Escola Politécnica da Universidade de São Paulo. Departamento de Engenharia Naval e Oceânica.

1.Fluvial Transport 2.Shallow water 3.Inland vessel 4.CFD 5.Magdalena river I.Universidade de São Paulo. Escola Politécnica. Departamento de Engenharia Naval e Oceânica II.t. 
The directives of the University of São Paulo, the qualifying bank and the faculty are not responsible for the criteria and ideas presented in this document. These correspond only to the author.

The author has made every effort to ensure that the addresses of the web pages referred to in this work are correct and active at the time of publication. However, it is not responsible for the content of these web pages and can not guarantee that a page remains active or that its content remains relevant, ethical or opportune. 
Dedicated to Rose Costa 



\section{ACKNOWLEDGMENTS}

Acknowledgments to Technological Research Institute of the Sate of São Paulo (IPT, acronym in Portuguese) and Carlo Padovezi for send me the experimental results of the 2700 TDW inland vessel made in the 1970s. Also, to the professor Kazuo Nishimoto, general coordinator of the Numerical Offshore Tank (TPN, acronym in Portuguese) for let me use the software $S T A R-C C M+$ and the cluster; and for the opportunity in work as a MSc. candidate at the Polytechnic School (EP, acronym in Portuguese) of the University of São Paulo (USP). Acknowledgments to Benedito Moraes (TPN, USP) for share me the clusters' properties. Acknowledgments to the Library of Congress of the United States for send me some bibliographical resources. Acknowledgments to Guilherme Feitosa (Argonautica) and the professor Claudio Mueller (USP) for solve me the difficulties and doubts that I had during the development of my project.

Acknowledgments to COTECMAR for believe me and support on this project. Acknowledgments to Jairo H. Cabrera Tovar (my maste, UTB) for teach me with all knowledge of the naval engineer and recommend me for the opportunity in study at the EP of the USP.

Personally, acknowledgments to my family, specially to my aunt Rosario. And finally, I thanks to my friends in São Paulo, specially to Cristiana to check my English redaction on this work. 

"Why do we fall? So that we can learn to pick ourselves back up"

"Our greatest glory is not in ever falling, but in rising every time we fall"

-- Bruce Wayne 



\section{RESUMO}

É apresentado um estudo para determinar a resistência de uma barcaça empregada no transporte de carga que poderia operar no setor baixo do rio Magdalena. Os efeitos hidrodinâmicos de um navio em águas rasas são muito diferentes, comparados a esses efeitos em águas com profundidade infinita.

A análise hidrodinâmica é realizada numericamente usando a Dinâmica dos Fluidos Computacional (CFD, acrônimo em inglês). A solução das equações de Navier-Stokes (NS) junto com a decomposição do Reynolds (RANS, acrônimo em inglês) é aplicada para simular os efeitos viscosos e de pressão em torno de um tanque e de uma embarcação em um tanque confinado que é caracterizado pelos efeitos do fundo e das paredes. Para efeitos de turbulência, o modelo realizado $k-\varepsilon$ é usado. O movimento da embarcação do rio provoca elevações da superfície livre que são capturadas usando o método do Volume de Fluido (VOF, acrônimo em inglês). Para a discretização do domínio de fluxo, o Método dos Volumes Finitos (FVM, acrônimo em inglês) é utilizado. O movimento dos fluidos é atualizado para cada intervalo de tempo o que permite o cálculo da resistência atuando no casco.

Os resultados da simulação numérica são comparados com dados experimentais obtidos pelo Instituto de Pesquisas Tecnológicas do Estado de São Paulo (IPT), juntamente com os métodos empíricos existentes para esse tipo de casos.

Palavras-Chave: Águas rasas, Barcaça, CFD, FVM, Modelo de turbulência $k-\varepsilon$, Resistencia, RANS, Rio Magdalena, VOF. 



\section{ABSTRACT}

The subject of this study is the determination of the resistance of an inland vessel engaged in cargo transport in the lower course of the Magdalena River, considering that the hydrodynamic effects in shallow water navigation are very different compared to the effects in deep water navigation.

The hydrodynamic analysis is realized numerically using Computational Fluid Dynamics (CFD). The Reynolds-Averaging Navier-Stokes equation (RANS) solver is applied to simulate viscous and pressure effects around a tank and a hull in confined tank considering the wall bottom and side effects in shallow water navigation. For turbulence effects, realizable $k-\varepsilon$ model is used. The motion of the vessel causes elevations of the free surface, in which, is captured using the Volume of Fluid method (VOF). For discretization of flow domain, the Finite Volume Method (FVM) is applied. The motion of the fluids is updated for each time step that allows the calculation of the resistance acting on the hull.

The numerical simulation results are compared with experimental data obtained by the Technological Research Institute of the State of São Paulo (IPT, acronym in Portuguese) together with the existing empirical methods for this type of cases.

Keywords: CFD, Free surface flow, FVM, Inland vessel, $k-\varepsilon$ turbulence model, Magdalena River, RANS, Resistance, Restricted waterways, VOF. 



\section{LIST OF FIGURES}

1.1 Hydrography of the Magdalena River . . . . . . . . . . . . . . . . . 3

1.2 Disciplines involved in CFD . . . . . . . . . . . . . . 3

1.3 CFD complement the theoretical analysis and experimental test . . . . . 4

1.4 Evolution of computer performance from the $1950 \mathrm{~s} \ldots \ldots \ldots$

2.1 Overview of computational domain . . . . . . . . . . . . . . 13

2.2 Grid structure around ship and bottom in shallow waters . . . . . . . . . . 13

3.1 Basic resistance components . . . . . . . . . . . . . . . . . 16

3.2 Frictional and pressure forces; wave pattern and wake . . . . . . . . . . 17

3.3 Specific components of resistance . . . . . . . . . . . . . . . . . 17

3.4 Subcritical and supercritical wave patterns . . . . . . . . . . . . . . 21

3.5 Changes of divergent wave angle . . . . . . . . . . . . . . . . 21

3.6 Influence of shallow water on the resistance curve . . . . . . . . . . . . 22

3.7 Amplification of wave-making resistance . . . . . . . . . . . . . . . 22

3.8 Effect of shallow water on wave-making resistance . . . . . . . . . . . . 23

3.9 Distribution of the velocity and the pressure of a fluid . . . . . . . . . 23

3.10 Sub-critical and super-critical operating regions . . . . . . . . . . . 24

3.11 Models available depending on the situation and the vessel . . . . . . . 25

3.12 Determination of shallow water resistance by Schlichting's method . . . . . 26

3.13 Curves of velocity ratios for the calculation of the resistance in shallow water 26

3.14 Schlichting's chart . . . . . . . . . . . . . . . . . . 27

3.15 Different cross-section of the channels for Landweber's method . . . . . . . 29

3.16 Loss in velocity in shallow water . . . . . . . . . . . . . . . 29

3.17 Karvop's diagrams . . . . . . . . . . . . . . . . . . . . 30 


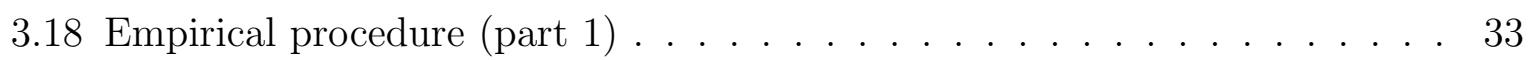

3.19 Empirical procedure $($ part 2) . . . . . . . . . . . . . . 34

4.1 Notation for stresses . . . . . . . . . . . . . . . . . . . . 38

4.2 Behavior of shear stress for Newtonian and non-Newtonian fluids . . . . . . 38

4.3 Time-averaging for stationary turbulence . . . . . . . . . . . . . . . . 41

4.4 Example of VOF method . . . . . . . . . . . . . . . . . . . . . . . 44

4.5 Domain boundary to impose the boundary conditions . . . . . . . . . . . 45

4.6 Calculation of distance $y_{Q}$ between node $Q$ and the surface on the wall B . 47

4.7 Velocity distribution near a solid wall . . . . . . . . . . . . . . . 48

4.8 Positions of the variables for each cell in a structured mesh . . . . . . . . 50

4.9 Positions of the variables of a cell in 2D . . . . . . . . . . . . 50

4.10 Interpolation profile of the 2 nd Order Upwind Scheme . . . . . . . . . . 52

4.11 Numerical procedure in the $S T A R-C C M+$ solver $\ldots \ldots \ldots \ldots$. . . . . 54

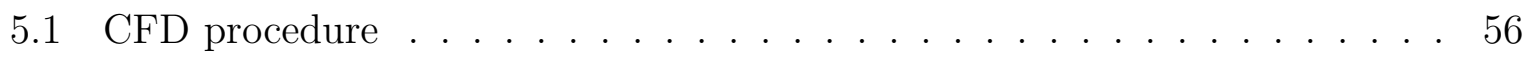

5.2 General methodology . . . . . . . . . . . . . . . . . . . . 57

5.3 Resistance test in shallow water condition at Ghent University . . . . . . . 57

5.4 Example of geometric similarity in model testing . . . . . . . . . . . . . 58

5.5 Example of kinematic similarity in model testing . . . . . . . . . . . . . . . 58

5.6 Example of dynamic similarity in model testing . . . . . . . . . . . . 59

5.7 Example of a lines-plan . . . . . . . . . . . . . . . . . . . . . 60

5.82700 TDW hull modeled by author . . . . . . . . . . . . . . . 61

5.9 Lines-plan of 2700 TDW modeled by author . . . . . . . . . . . . . 61

5.10 Boundary conditions of the domain . . . . . . . . . . . . . . 62

5.11 Refined mesh zones in the computational domain . . . . . . . . . . . . 63

5.12 Overview of the mesh in the computational domain . . . . . . . . . . . 64

5.13 Grid structure around the vessel . . . . . . . . . . . . . . . . . . . 64 
5.14 Representation of prismatic mesh for boundary layer . . . . . . . . . . 65

5.15 Prism layer mesh . . . . . . . . . . . . . . . . . . 65

5.16 Free surface in flat state . . . . . . . . . . . . . . . . . 66

5.17 Numerical damping on $S T A R-C C M+\ldots \ldots \ldots . \ldots . \ldots . \ldots 67$

5.18 Physical time simulation of the 2700 TDW inland vessel performed on $S T A R-C C M+$ at $v=0.576 \mathrm{~m} / \mathrm{s} \ldots \ldots \ldots 68$

5.19 Plot of residuals of the 2700 TDW inland vessel performed on STAR-CCM+ at $v=0.921 \mathrm{~m} / \mathrm{s} \ldots \ldots \ldots \ldots \ldots \ldots$

5.20 TPN clusters . . . . . . . . . . . . . . . . . 70

5.21 Comparison of methods with 2700 TDW inland vessel . . . . . . . . . . . 71

5.22 Total resistance results of 2700 TDW inland vessel calculated numerically . 73

5.23 Convergence of the total resistance with grid refinement of the 2700 TDW inland vessel . . . . . . . . . . . . . . . . . . . . . . . 74

5.24 Cross sections at different $x, y$ and $z$ coordinates axis used in the illustrations of the results. . . . . . . . . . . . . . . . 76

5.25 Contour plots of the pressure coefficient on the inland vessel hull. . . . . . 76

5.26 Longitudinal cross section of the pressure coefficient on the inland vessel hull 77

5.27 Transverse cross section of the pressure coefficient on the inland vessel hull 77

5.28 Contour plots of the skin friction coefficient on the inland vessel hull . . . . 78

5.29 Longitudinal cross section of the skin friction coefficient on the inland vessel hull . . . . . . . . . . . . . . . . . . . 78

5.30 Transversal cross section of the skin friction coefficient on the inland vessel hull . . . . . . . . . . . . . . . . . . . . 79

5.31 Contour plots of the dimensionless wall distance $y+$ on the inland vessel hull 79

5.32 Longitudinal cross section of the dimensionless wall $y+$ on the inland vessel hull ........................... . . 80

5.33 Transverse cross section of the dimensionless wall $y+$ on the inland vessel hull ........................... . . 80

5.34 Wave pattern generated by 2700 TDW inland vessel . . . . . . . . . . . . 81 
5.35 Longitudinal cross section of the wave height generated by 2700 TDW inland self-propelled vessel . . . . . . . . . . . . . . . . . . . . . . 81

5.36 Velocity magnitude of the air and water on the computational domain (symmetry view $) \ldots \ldots \ldots \ldots$. . . . . . . . . . . . . 82

5.37 Velocity magnitude of the water on the computational domain (top view) . 82

5.38 Pressure distribution of the computational domain (symmetry view) . . . . 82

5.39 Pressure distribution of the water generated by 2700 TDW inland vessel (top view $) \ldots \ldots \ldots \ldots$. . . . . . . . . . . . . . . . . . . . . . . . . .

5.40 Longitudinal cross section of the velocity and the pressure distribution between the hull and wall bottom . . . . . . . . . . . . . . . . 83

5.41 Wetted surface area of the 2700 TDW inland self-propelled vessel . . . . . 84

A.1 Residuary resistance coefficient versus length Froude number for different values of longitudinal prismatic coefficient. $M=4.0 \ldots \ldots$. . . . . . 96

A.2 Residuary resistance coefficient versus length Froude number for different values of longitudinal prismatic coefficient. $M=4.5 \ldots \ldots$. . . . . . . 97

A.3 Residuary resistance coefficient versus length Froude number for different values of longitudinal prismatic coefficient. $M=5.0 \ldots \ldots$. . . . . . 98

A.4 Residuary resistance coefficient versus length Froude number for different values of longitudinal prismatic coefficient. $M=5.5 \ldots \ldots$. . . . . . . 99

A.5 Residuary resistance coefficient versus length Froude number for different values of longitudinal prismatic coefficient. $M=6.0 \ldots \ldots$. . . . . . . 100

A.6 Residuary resistance coefficient versus length Froude number for different values of longitudinal prismatic coefficient. $M=6.5$. . . . . . . . . 101

A.7 Residuary resistance coefficient versus length Froude number for different values of longitudinal prismatic coefficient. $M=7.0$. . . . . . . . . . 102

A.8 Residuary resistance coefficient versus length Froude number for different values of longitudinal prismatic coefficient. $M=7.5 \ldots \ldots$. . . . . . . 103

A.9 Residuary resistance coefficient versus length Froude number for different values of longitudinal prismatic coefficient. $M=8.0$. . . . . . . . . . 104

B.1 2700 TDW inland vessel original lines-plan (stern view) . . . . . . . . . . . 110 
B.2 2700 TDW inland vessel original lines-plan (bow view) . . . . . . . . . 111

B.3 Schlichting's curves applied to the 2700 TDW inland vessel . . . . . . . . . 112

B.4 Loss in velocities by empirical method for large rivers applied to 2700 TDW inland vessel . . . . . . . . . . . . . . . . . . . . . . . . 112

B.5 Coefficient forces for large rivers of the 2700 TDW inland vessel . . . . . . 113

B.6 Total resistance using Schlichting's method in comparison with Froude hypothesis ship resistance of the 2700 TDW inalnd vessel . . . . . . . . . . . 113

B.7 Karvop's diagrams for 2700 TDW inland vessel . . . . . . . . . . . . . . . 114

B.8 Coefficient forces for middle rivers of the 2700 TDW inland vessel . . . . . 114

B.9 Total forces for middle rivers of the 2700 TDW inland vessel . . . . . . . . 115 



\section{LIST OF TABLES}

1.1 Comparison of approaches ...................... 4

3.1 Residuary resistance coefficient corrections $\Delta C_{r}$ for different channels . . . 31

3.2 Velocity relations $v^{\prime} / v_{\infty}$ for a model in different channels . . . . . . . . . 31

5.1 Comparison of model hulls . . . . . . . . . . . . . . . . . . . 60

5.2 Dimensions of the computational domain geometry . . . . . . . . . . 62

5.3 Dimensions of refined regions f . . . . . . . . . . . . . . . 63

5.4 Configuration of the mesh in refined regions . . . . . . . . . . . . . . 64

5.5 Parameters of the prism layer of the mesh . . . . . . . . . . . 66

5.6 Properties of Flat VOF Wave on STAR-CCM+ . . . . . . . . . . . . . 66

5.7 Boundary conditions properties configured on $S T A R-C C M+\ldots \ldots 7$

5.8 Definition of residuals . . . . . . . . . . . . . . . . . . . . . . . 69

5.9 SGI cluster specifications on TPN . . . . . . . . . . . . . . 70

5.10 Sun microsystems (Oracle) cluster specifications on TPN . . . . . . . . 70

5.11 Comparison of numerical and empirical method with experimental results . 72

5.12 Number of cell in the meshes of the 2700 TDW inland vessel . . . . . . . . 73

5.13 Grid convergence parameters . . . . . . . . . . . . . . . 75

A.1 Equations for approximation by Georgakaki and Sorenson (2004) . . . . . . 95

B.1 Characteristics of 2700 TDW inland vessel in full and in model scale . . . . 105

B.2 Characteristics of experimental test . . . . . . . . 105

B.3 Experimental results of 2700 TDW inland vessel resistance test . . . . . . 106

B.4 Offset of 2700 TDW inland vessel . . . . . . . . . . . . . . . 109 



\section{LIST OF SYMBOLS}

\section{Latin symbols}

\section{Symbol Term}

A Surface area vector

$\mathbf{A}_{f} \quad$ Area of the cell face

$A_{c} \quad$ Sectional area of the channel or river

$A_{\text {ims }} \quad$ Immersed midship area of the ship

$A_{0} \quad$ Function (equation 3.9)

$A_{1} \quad$ Function (equation 3.10)

a Any point on the free surface

$B \quad$ Beam of the vessel

$B_{c} \quad$ Width of the channel or river

$B_{1} \quad$ Function (equation 3.13)

$B_{2} \quad$ Function (equation 3.14 )

$B_{3} \quad$ Function (equation 3.15 )

b Position of vector of the face centroid

$C_{a} \quad$ Correlation allowance coefficient

$C_{f} \quad$ Frictional resistance coefficient

$C_{o} \quad$ Courant number

$C_{r} \quad$ Residuary resistance coefficient

$C_{t} \quad$ Total resistance coefficient

$C_{1} \quad$ Function (equation 4.40)

$C_{1 \varepsilon} \quad k-\varepsilon$ model constant

$C_{\mu} \quad k-\varepsilon$ model constant

$c \quad$ Critical velocity

$d_{m} \quad$ Dimensional length of the model

$d_{p} \quad$ Dimensional length of the prototype

E Center of the coordinates adjacent to east cell in a control volume

E Empirical constant

$E_{r} \quad$ Relative error

$E_{1} \quad$ Function (equation 3.8)

e Point of the east center face of a control volume

$e_{a}^{21} \quad$ Approximate relative error for medium-fine grid mesh used for GCI

$e_{a}^{32}$

$e_{\text {ext }}^{21}$

$e_{\mathrm{ext}}^{32}$

$F_{b} \quad$ Body force

$F_{\mathrm{CFD}} \quad$ Force of the numerical results

$F_{i} \quad$ Components of the force vector

$F_{m} \quad$ Force of the experimental test results

$F_{s} \quad$ Surface force

$F r_{h} \quad$ Depth Froude number

$F r_{L} \quad$ Length Froude number 


\begin{tabular}{|c|c|}
\hline Symbol & Term \\
\hline$G$ & Function (equation 3.12) \\
\hline$G C I_{\text {fine }}^{21}$ & Fine-grid convergence index equation \\
\hline$g$ & Gravity \\
\hline$\vec{g}$ & Gravity vector \\
\hline$H$ & Function (equation 3.16) \\
\hline$h$ & Local depth \\
\hline $\mathbf{I}$ & Identity matrix \\
\hline$I$ & Turbulence intensity \\
\hline$K$ & Function (equation 3.17) \\
\hline$k$ & Turbulent Kinetic Energy \\
\hline$k_{\text {in }}$ & Turbulent Kinetic Energy at inlet boundary condition \\
\hline$k_{\text {out }}$ & Turbulent Kinetic Energy at outlet boundary condition \\
\hline$k_{\mathrm{sym}}$ & Turbulent Kinetic Energy at symmetry boundary condition \\
\hline$k_{\text {wall }}$ & Turbulent Kinetic Energy at wall boundary condition \\
\hline$L_{\mathrm{WL}}$ & Length of the vessel in waterline \\
\hline$L_{\text {mod }}$ & Length of the inland vessel model \\
\hline$M$ & Function (equation 3.18) \\
\hline$\dot{m}$ & Mass flow rate \\
\hline $\mathrm{N}$ & Center of the coordinates adjacent to north cell in a control volume \\
\hline$N_{i}$ & Mesh number \\
\hline$N_{\text {faces }}$ & Number of faces enclosing the bcell \\
\hline$N_{\text {fluids }}$ & Number of fluids \\
\hline$N_{1}$ & Function (equation 3.11) \\
\hline $\mathbf{n}$ & Normal vector \\
\hline $\mathrm{n}$ & Point of the north center face of a control volume \\
\hline$n_{j}$ & Components of the normal vector \\
\hline$O$ & Center of the cell in a control volume \\
\hline$P$ & Mean pressure \\
\hline $\bar{P}$ & Time averaged mean pressure \\
\hline$P_{k}$ & Generation of TKE \\
\hline$P_{k-\text { wall }}$ & Generation of TKE on the wall boundary condition \\
\hline$p$ & Pressure \\
\hline$p_{\text {in }}$ & Pressure on inlet boundary condition \\
\hline$p_{\text {out }}$ & Pressure on outlet boundary condition \\
\hline$p_{0}$ & Pressure with the gradient due to gravitational force \\
\hline$p^{*}$ & Balanced pressure \\
\hline$p^{\prime}$ & Fluctuating pressure \\
\hline$\overline{p^{\prime}}$ & Time averaged fluctuating pressure \\
\hline$q$ & Designation of the fluid for $\alpha$ \\
\hline$q_{s}$ & Wetted girth of the hull \\
\hline$R_{f}$ & Frictional resistance \\
\hline$R_{p}$ & Pressure resistance \\
\hline$R_{r}$ & Residuary resistance \\
\hline$R_{t}$ & Total resistance \\
\hline Re & Reynolds number \\
\hline$R e_{L}$ & Reynolds number of the inland vessel model \\
\hline$R e_{t}$ & Turbulent Reynolds number \\
\hline
\end{tabular}




\begin{tabular}{|c|c|}
\hline Symbol & Term \\
\hline$R w$ & Wave-making resistance \\
\hline$R w_{d}$ & Wave-making resistance in deep water \\
\hline$R w_{h}$ & Wave-making resistance in depth water \\
\hline$r_{h}$ & Hydraulic radius \\
\hline$r_{k}$ & Refinement ratio used for GCI \\
\hline S & Center of the coordinates adjacent to south cell in a control volume \\
\hline$S_{1}$ & Function (equation 4.40) \\
\hline$S_{i j}$ & Strain-rate tensor \\
\hline$S_{k}$ & User-defined source term \\
\hline$S_{\text {mat }}$ & Material surface \\
\hline$S_{w s}$ & Wetted surface area the of the vessel \\
\hline$S_{\varepsilon}$ & User-defined source term \\
\hline$S_{\varphi}$ & Source of $\varphi$ \\
\hline $\mathrm{s}$ & Point of the south center face of a control volume \\
\hline$T$ & Draft of the vessel \\
\hline$T_{s}$ & Characteristic time scale \\
\hline$t$ & Time \\
\hline$u_{Q}^{+}$ & $\begin{array}{l}\text { Dimensionless velocity from the centroid of the wall-adjacent cell to the } \\
\text { wall } B\end{array}$ \\
\hline$u_{Q}^{*}$ & Dimensionless velocity for $k-\varepsilon$ turbulence model \\
\hline$U_{i}$ & Mean velocity \\
\hline$U_{Q}$ & Mean velocity of the fluid at the wall-adjacent cell centroid $Q$ \\
\hline $\mathbf{U}_{\text {in }}$ & Mean velocity vector at inlet boundary condition \\
\hline $\mathbf{U}_{\text {out }}$ & Mean velocity vector at outlet boundary condition \\
\hline $\mathbf{U}_{\text {sym }}$ & Mean velocity vector at symmetry boundary condition \\
\hline $\mathrm{U}_{\text {wall }}$ & Mean velocity vector at wall boundary condition \\
\hline$\overline{U_{i}}$ & Time averaged mean velocity \\
\hline $\mathbf{u}$ & Flow velocity in vector notation \\
\hline $\mathbf{u}_{f}$ & Flow velocity vector field through the face cell \\
\hline$u_{i}$ & Flow velocity in tensor notation \\
\hline$u_{i}^{\prime}$ & Fluctuating velocity \\
\hline$\overline{u_{i}^{\prime}}$ & Time averaged fluctuating velocity \\
\hline$u_{\tau}$ & Friction or shear velocity \\
\hline$V$ & Volume \\
\hline$\dot{V}$ & Volume flow rate \\
\hline$V_{q}$ & Volume of the designed fluid \\
\hline W & Center of the coordinates adjacent to west cell in a control volume \\
\hline $\mathrm{w}$ & Point of the west center face of a control volume \\
\hline $\mathbf{x}$ & Position vector in tensor notation \\
\hline$x_{i}$ & Position vector in vector notation \\
\hline$y$ & Distance of the boundary thickness \\
\hline$y+$ & Dimensionless distance on the wall \\
\hline$y_{Q}$ & Distance from the centroid of the wall-adjacent cell to the wall $B$ \\
\hline$y_{Q}^{+}$ & $\begin{array}{l}\text { Dimensionless distance from the centroid of the wall-adjacent cell to the } \\
\text { wall } B\end{array}$ \\
\hline$y_{Q}^{*}$ & $\begin{array}{l}\text { Dimensionless distance from the centroid of the wall-adjacent cell to the } \\
\text { wall } B \text { for } k-\varepsilon \text { turbulence model }\end{array}$ \\
\hline
\end{tabular}




\section{Greek symbols}

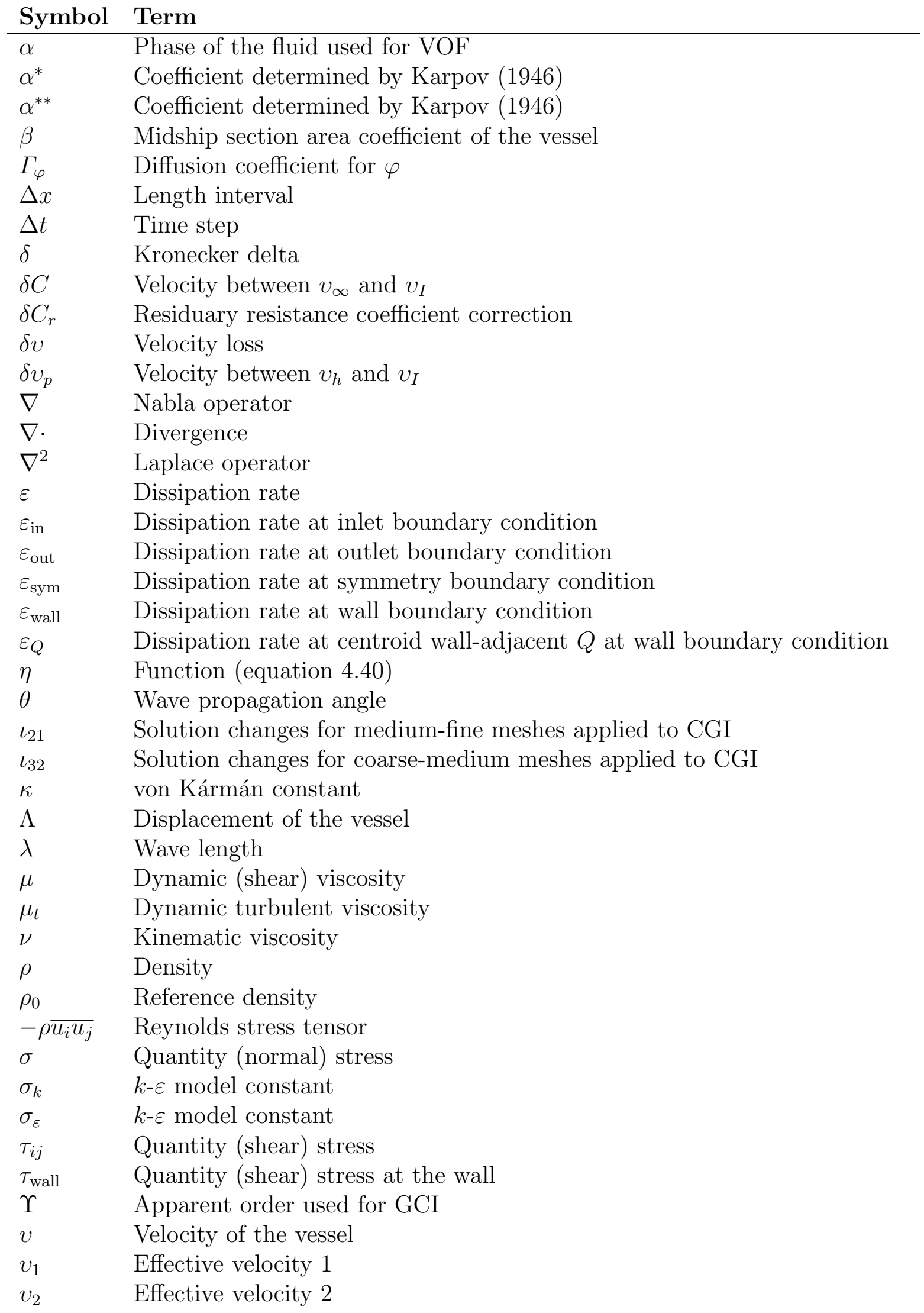




\begin{tabular}{ll} 
Symbol & Term \\
\hline$v_{\infty}$ & Velocity of the vessel in deep water \\
$v_{h}$ & Velocity of vessel in shallow or depth water \\
$v_{I}$ & Intermediate velocity of vessel \\
$\Phi$ & Prismatic coefficient of the vessel \\
$\phi_{1}$ & Solution for fine mesh applied in GCI \\
$\phi_{2}$ & Solution for medium mesh applied in GCI \\
$\phi_{3}$ & Solution for coarse mesh applied in GCI \\
$\phi_{\text {ext }}$ & Extrapolated value used for GCI \\
$\varphi$ & Scalar quantity \\
$\varphi_{f}$ & Value of scalar quantity convected through face \\
\hline
\end{tabular}

\section{Abbreviations}

\begin{tabular}{|c|c|}
\hline Acronym & Name \\
\hline AIAA & American Institute of Aeronautics and Astronautics \\
\hline ANSYS & Analysis System \\
\hline ASME & American Society of Mechanical Engineers \\
\hline BSL & Baseline for $k-\omega$ \\
\hline CAD & Computer-Aided Design \\
\hline CD-adapco & $\begin{array}{l}\text { Computational Dynamics-Analysis \& Design Application } \\
\text { Company Ltd. }\end{array}$ \\
\hline CFD & Computational Fluid Dynamics \\
\hline CNR (in French) & Rhone National Company \\
\hline Cormagdalena (in Spanish) & Magdalena Great River Corporation \\
\hline DTMB & David Taylor Model Basin \\
\hline DTU (in Danish) & Technical University of Denmark \\
\hline EDUSP (in Portuguese) & Publisher of the University of São Paulo \\
\hline EP (in Portuguese) & The Polytechnic School \\
\hline FDM & Finite Difference Method \\
\hline FEM & Finite Element Method \\
\hline FVM & Finite Volume Method \\
\hline GCI & Grid Convergence Index \\
\hline GDP & Gross Domestic Product \\
\hline HRN & High Reynolds Number \\
\hline $\mathrm{ICCM}$ & International Conference on Computational Methods \\
\hline IHTC & International Heat Transfer Conference \\
\hline IITK & Indian Institute of Technology Kanpur \\
\hline IPT (in Portuguese) & Technological Research Institute of the State of São Paulo \\
\hline ITTC & International Towing Tank Conference \\
\hline LRN & Low Reynolds Number \\
\hline MAC & Marker-and-cell method \\
\hline MASHCON (In German) & $\begin{array}{l}\text { International Conference on Ship Maneuvering in Shallow } \\
\text { and Confined Water with Special Focus on Ship Bottom } \\
\text { Interaction }\end{array}$ \\
\hline MATLAB & Matrix Laboratory \\
\hline
\end{tabular}




\begin{tabular}{ll} 
Acronym & Name \\
\hline NS & Navier-Stokes \\
PDE & Partial Differential Equations \\
PIANC & $\begin{array}{l}\text { Permanent International Association of Navigation Con- } \\
\text { gresses }\end{array}$ \\
RANS or RANSE & Reynolds Averaging Navier-Stokes equation \\
RE & Richardson Extrapolation \\
RNG & Re-Normalization Group method for $k-\varepsilon$ \\
SIMPLE & Semi-Implicit Method for Pressure Linked Equations \\
SNAME & Society of Naval Architects and Marine Engineers \\
SST & Shear-Stress Transport for $k$ - $\omega$ \\
TDR & Turbulent Dissipation Rate \\
TKE & Turbulence Kinetic Energy \\
TPN (in Portuguese) & Numerical Offshore Tank \\
USP (in Portuguese) & The University of São Paulo \\
UTB (in Spanish) & The Technological of Bolivar University \\
UTC (in French) & University of Technology of Compiègne \\
VOF & Volume of Fluid \\
\hline
\end{tabular}




\section{CONTENTS}

1 Introduction 1

1.1 Presentation of the problem ..................... 4

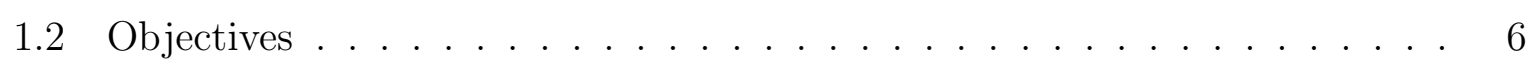

2 Bibliographic review $\quad 9$

2.1 Important references . . . . . . . . . . . . . . . . . . 11

2.1.1 Celik et al. (2008) . . . . . . . . . . . . . . . 11

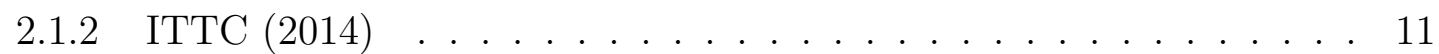

2.1 .3 Ji et al. (2012) . . . . . . . . . . . . . . . . . . 12

2.1.4 Linde et al. (2017) . . . . . . . . . . . . . . . . 12

2.1.5 Liu et al. $(2017) \ldots \ldots \ldots \ldots \ldots$. . . . . . . . . . . . . . . . . . . .

3 Fundamentals on ship resistance $\quad 15$

3.1 Components of resistance . . . . . . . . . . . . . . . . 15

3.2 Shallow water effects . . . . . . . . . . . . . . . 20

3.2 .1 Large rivers . . . . . . . . . . . . . . . . . 24

3.2 .2 Medium rivers . . . . . . . . . . . . . . . . . . . . . 28

3.3 Empirical procedure . . . . . . . . . . . . . . . . . . . 32

3.4 Hypothesis . . . . . . . . . . . . . . . . . . . . . . . 32

4 Numerical simulation by CFD 35

4.1 Hypotheses . . . . . . . . . . . . . . . . . . 35

4.2 Conservation of mass . . . . . . . . . . . . . . . . . . 35

4.3 Conservation of momentum . . . . . . . . . . . . . 36

4.3 .1 Newtonian fluid . . . . . . . . . . . . . . . . . . . . . . . 38 
4.3 .2 The Navier-Stokes equation _. . . . . . . . . . . . . . . 39

4.4 Reynolds-Averaging . . . . . . . . . . . . . . . . . . . . 40

4.5 Reynolds-Averaged Navier-Stokes equation . . . . . . . . . . . . . . . . 41

4.6 Turbulence modeling . . . . . . . . . . . . . . . . . . . . . . . . . . . 42

4.6.1 Realizable $k-\varepsilon$ model . . . . . . . . . . . . . . . . . . . . . . . . . . 42

4.7 Volume of Fluid method . . . . . . . . . . . . . . . . . . . . . 43

4.8 Implementation of boundary conditions . . . . . . . . . . . . . . . . . . . 44

4.8.1 Inlet boundary condition . . . . . . . . . . . . . . . . . . . . 44

4.8.2 Outlet boundary condition . . . . . . . . . . . . . . 46

4.8.3 Wall boundary condition . . . . . . . . . . . . . . . . 46

4.8.4 Symmetry boundary condition . . . . . . . . . . . . . . . . . 48

4.9 Finite Volume Method . . . . . . . . . . . . . . . . . . . . . . . . 49

4.9.1 Transient term . . . . . . . . . . . . . . . . 51

4.9 .2 Convection term . . . . . . . . . . . . . . . . . 51

4.9.2.1 2nd order upwind scheme . . . . . . . . . . . 51

4.9 .3 Diffusion term . . . . . . . . . . . . . . . . . . . . 52

4.10 Numerical procedure . . . . . . . . . . . . . . . . . . 53

5 Application to the self-propelled inland vessel intended for the operation in the Magdalena river low course

5.1 Methodology . . . . . . . . . . . . . . . . 55

5.2 Experimental test in model scale . . . . . . . . . . . . . . . . 55

5.2 .1 Geometric similarity . . . . . . . . . . . . . 57

5.2 .2 Kinematic similarity . . . . . . . . . . . . . . . . 58

5.2 .3 Dynamic similarity . . . . . . . . . . . . . . . . 58

5.3 Hull modeling . . . . . . . . . . . . . . . . . . . . . . . . . . . . . . . . 59

5.4 Geometry and mesh . . . . . . . . . . . . . . . . . . . . 60 
5.4 Mesh .......................... 62

5.4.1.1 Boundary layer mesh . . . . . . . . . . . . . . . . . 64

5.5 Boundary conditions . . . . . . . . . . . . . . . . 66

5.6 Solver parameters, monitoring and plotting . . . . . . . . . . . . 67

5.6 .1 Cluster specifications . . . . . . . . . . . . . . . . 70

5.7 Results . . . . . . . . . . . . . . . . . . 71

5.7 .1 Verification of results . . . . . . . . . . . . . . . . 72

5.7 .2 Calculation of the properties . . . . . . . . . . . 75

5.7.2.1 Pressure coefficient . . . . . . . . . . . . 75

5.7.2.2 Skin friction coefficient . . . . . . . . . . . . 77

5.7.2.3 Dimensionless wall distance $y+\ldots \ldots . \ldots 78$

5.7 .2 .4 Wave pattern . . . . . . . . . . . . . 79

5.7.2.5 Velocity and pressure distribution . . . . . . . . . 80

5.7.2.6 Wetted surface of the hull . . . . . . . . . . . . 84

6 Conclusions $\quad 85$

6.1 Future analysis . . . . . . . . . . . . . . . . 86

$\begin{array}{lr}\text { References } & 87\end{array}$

$\begin{array}{ll}\text { Appendix A - Graphics and tables } & 95\end{array}$

Appendix B - Results of the 2700 TDW inland vessel resistance in shallow $\begin{array}{ll}\text { waters } & 105\end{array}$

$\begin{array}{ll}\text { Appendix C - Codes } & 117\end{array}$

C.1 Schlichting's method . . . . . . . . . . . . . . . 117

C.2 Karpov's and Artjuskov's method . . . . . . . . . . . . . . . . . . . . . . 124

C.3 Total prism layer calculation . . . . . . . . . . . . . . . . . . 131 



\section{INTRODUCTION}

"A universal constant has been the development of people, civilizations and diverse cultures around the main river, which dispenses gift and natural resources, provides identity, offering its landscape, becomes a witness to its history and is a generator of life", Bernal Duffo (2013).

At the time of the European conquest of the Americas, the Spanish arrived at the Colombian territory. The Magdalena river was discovered and named by Rodrigo de Bastidas at the beginning of 16th century (specifically on April 1st in 1501) and gained great importance as a main access route. During the colonization period, the river served as a single route between Santa Fé de Bogotá (actually Bogotá) and the port of Cartagena (Bernal Duffo, 2013).

During the independence period, the patriotic armies used the river to dominate the Spanish colony. Gabriel Garcia Marquez described these events in his historical novel The General in His Labyrinth.

As far as the logistics are concerned, the fluvial transport was used from the colonial period until the middle of 19th century for the transport of commercial products which were transported in keel-boats. In 1822, steamboats were introduced, and the harvest of tobacco in 1850s made the river transport more profitable. Nevertheless in 20th century, the commercial activities of the river for the transport of commercial goods started to decline due to the air services, the railway transport and mainly, the road transportation (Encyclopædia Britannica, 2015d).

With the aim of increasing the activities of the river, the Colombian Constitution of 1991 created the Magdalena Grand River Corporation (Cormagdalena, acronym in Spanish) and since then, the fluvial transport has been recovering due to projects developed or being developed that imply the navigability of the river that includes, the construction of ports, dredging works and the maintenance of the river. Nowadays, the cargoes are transported in convoys, each of which consists of a tugboat and a maximum of six barges 
organized in series and/or in parallel.

In 2017, 3.67 million tons of a large variety of goods, including hydrocarbons and dry cargoes such as coal and cement, were mobilized by the river. This signify an increase of $68.5 \%$ compared to the numbers of the previous year (Ministry of Transport - Colombia, 2018).

There are different types of inland vessel (Bureau Voorlichting Binnenvaart, n.d.): dry-cargo carriers, well barges, tank vessels, push/tugboats and ro-ro.

The Magdalena River is the most important in the country with an extension of 1,497 km and its birthplace is located in the Páramo de las Papas (placed in the Andes mountain range). This river is divided in three courses: upper, middle and lower (Figure 1.1), crossing 128 municipalities and 11 departments. The river receives the affluents of the San Jorge, Cesar and Cauca rivers, increasing its flow. Finally, the river mouths in the Caribbean Sea and close to Barranquilla city (ACOSTA-LOPERA; CABRERA-TOVAR, 2014; Encyclopædia Britannica, 2015d). The area under the influence of the Magdalena river is responsible for $80 \%$ of GDP of the country, $70 \%$ of the hydraulic energy, $95 \%$ of the thermoelectricity, $70 \%$ of agricultural production, $50 \%$ of freshwater fishing (Castro Pinzón, 2017).

Compared to other countries, the Netherlands is a pioneer in this type of transport, since its canal system is based on large natural rivers. For example, to transport a cargo of 16,000 tons, 660 trucks are needed for road transport, while only one inland barge can transport the total of that cargo and the Dutch operators take advantage of these numbers as the riverboats under the Dutch flag that is represented around $50 \%$ of the entire Western European fleet. Furthermore, the importance of the rivers in Netherlands is obvious as $6,000 \mathrm{~km}$ of a total of 24,709 $\mathrm{km}$ of the European waterways are Dutch, where $500 \mathrm{~km}$ are main routes (Bureau Voorlichting Binnenvaart, 2011; ACOSTA-LOPERA; CABRERA-TOVAR, 2014; Encyclopædia Britannica, 2015a).

The fluid mechanics allow the study of the fluids at rest (stationary) and, mainly, in motion (dynamic). The last term is called Fluid Dynamics. The fundamental mathematical equations describe the physical characteristics of the fluid motion. The solution of the math equations is converted in a high-level computer programming language into computer programs applying numerical methods and is called computer science. These disciplines integrate the branch of the Computational Fluid Dynamics (CFD), illustrated in the Figure 1.2 (TU; YEOH; LIU, 2008).

The numerical methods imply the comparison and the validation of the experimen- 


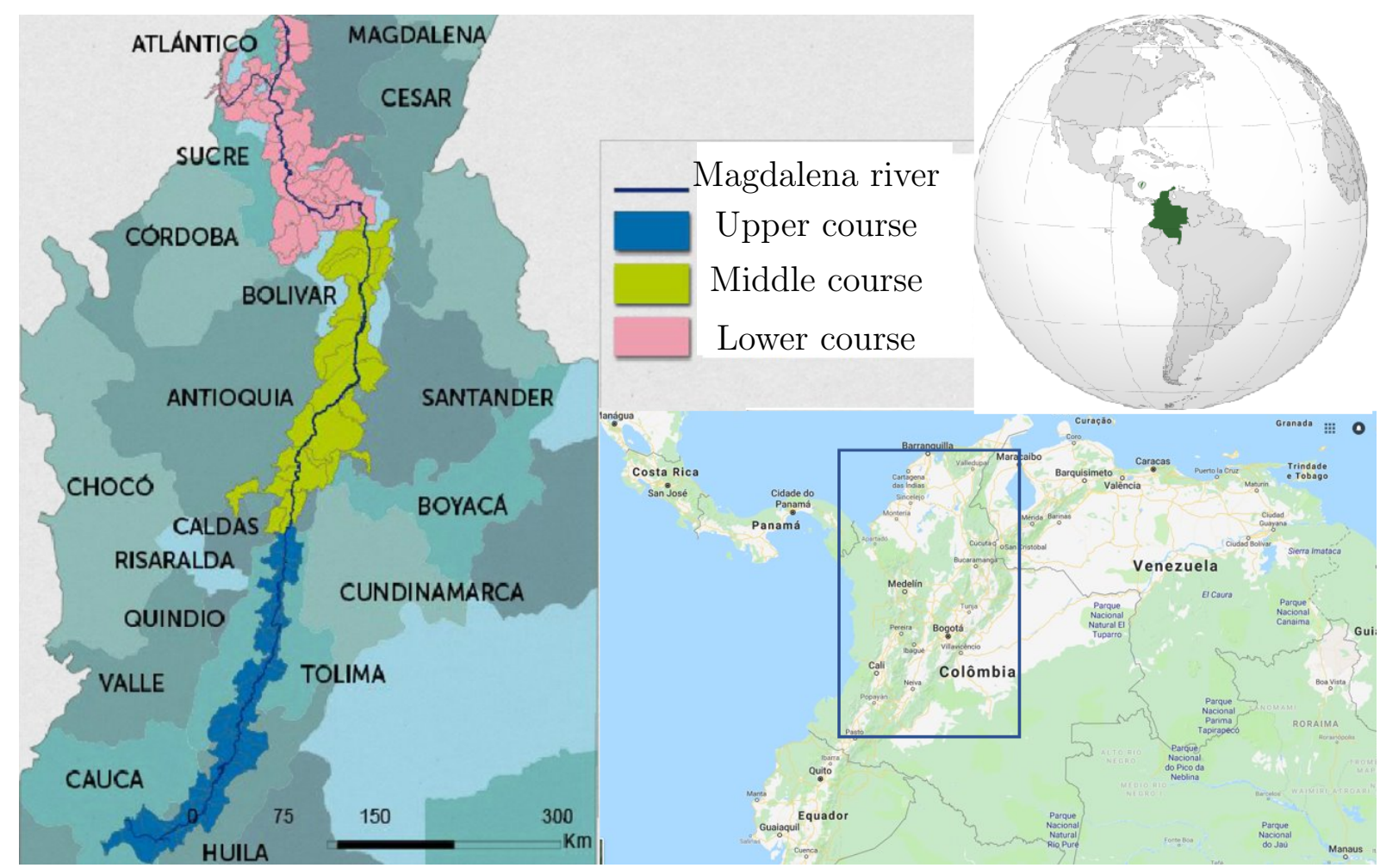

Figure 1.1: Hydrography of the Magdalena River, divided in upper (blue), middle (yellow) and lower (pink) courses. Source: Acosta-Lopera and Cabrera-Tovar (2014), Google, Wikipedia.

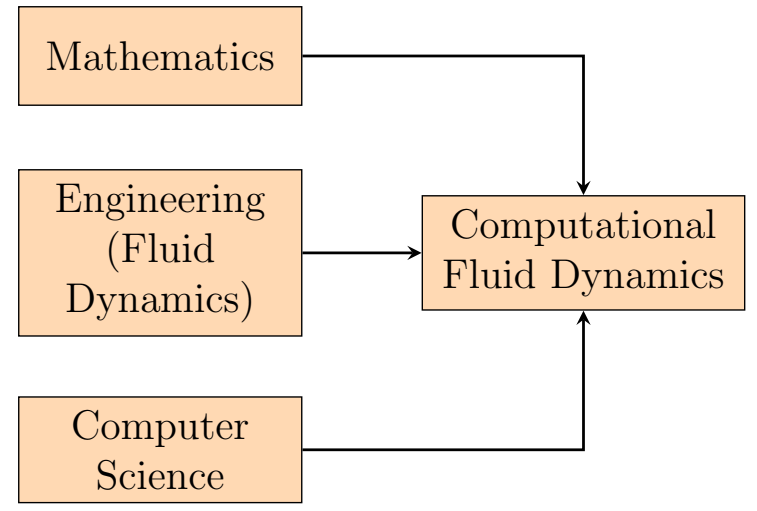

Figure 1.2: Different disciplines involved in CFD. Source: Tu, Yeoh and Liu (2008).

tal test and theoretical analysis, indicated in the Figure 1.3. The theoretical analysis allows the designer predicts the behavior for a case. The experimental test simulates the environmental and physical conditions in reduced scale. In the Table 1.1, extracted from Pletcher, Tannehill and Anderson (2013), the strategies to solve problems of fluid mechanics are compared. Over the years, the speed of computer processing has been increasing contrary to computational costs, illustrated in the Figure 1.4. This makes them more efficient, therefore, has generated interest for the application in CFD. The computer performance is measured in Gflop/s. 


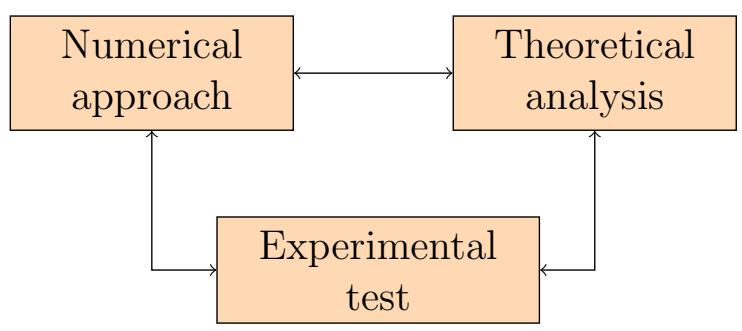

Figure 1.3: CFD complement the theoretical analysis and experimental test. Source: Tu, Yeoh and Liu (2008), Fortuna (2012).

\begin{tabular}{|c|c|c|}
\hline Approach & Advantages & isadvantage \\
\hline Experimental & $\begin{array}{l}\text { - Capable of being most realis- } \\
\text { tic }\end{array}$ & $\begin{array}{l}\text { - Equipment required } \\
\text { - Scaling problems } \\
\text { - Tunnel corrections } \\
\text { - Measurement difficulties } \\
\text { - Operating cost }\end{array}$ \\
\hline $\begin{array}{l}\text { Theoretical (ana- } \\
\text { lytic) }\end{array}$ & $\begin{array}{l}\text { - Simple basic general informa- } \\
\text { tion, which is usually in for- } \\
\text { mula form }\end{array}$ & $\begin{array}{l}\text { - Restricted to simple geometry } \\
\text { and physics } \\
\text { - Usually restricted to linear } \\
\text { problems }\end{array}$ \\
\hline Computational & $\begin{array}{l}\text { - No restriction to linearity } \\
\text { - Complicated physics can be } \\
\text { treated } \\
\text { - Time evolution of flow can be } \\
\text { obtained }\end{array}$ & $\begin{array}{l}\text { - Truncation errors } \\
\text { - Boundary condition problems } \\
\text { - Computer cost }\end{array}$ \\
\hline
\end{tabular}

Table 1.1: Comparison of approaches. Source: Fortuna (2012), Pletcher, Tannehill and Anderson (2013).

Despite the advantages and disadvantages offered by CFD, it still cannot resolve a lot of problems, i.e., turbulent flow cases. When the Navier-Stokes equations are used numerically, the turbulent behavior is not represented directly, therefore the need for the adoption of turbulent models from the original equations. However, there are exist turbulence models that allow resolve this type of flows.

\subsection{Presentation of the problem}

The need to improve efficiency of cargo transport sector had motivated the increase in the number of self-propelled vessels in the main river of the country, allowing the direct access of companies located inland to the main ports of the Colombian northern regions.

Despite the economic advantages of cargo transport by river for the national econ- 


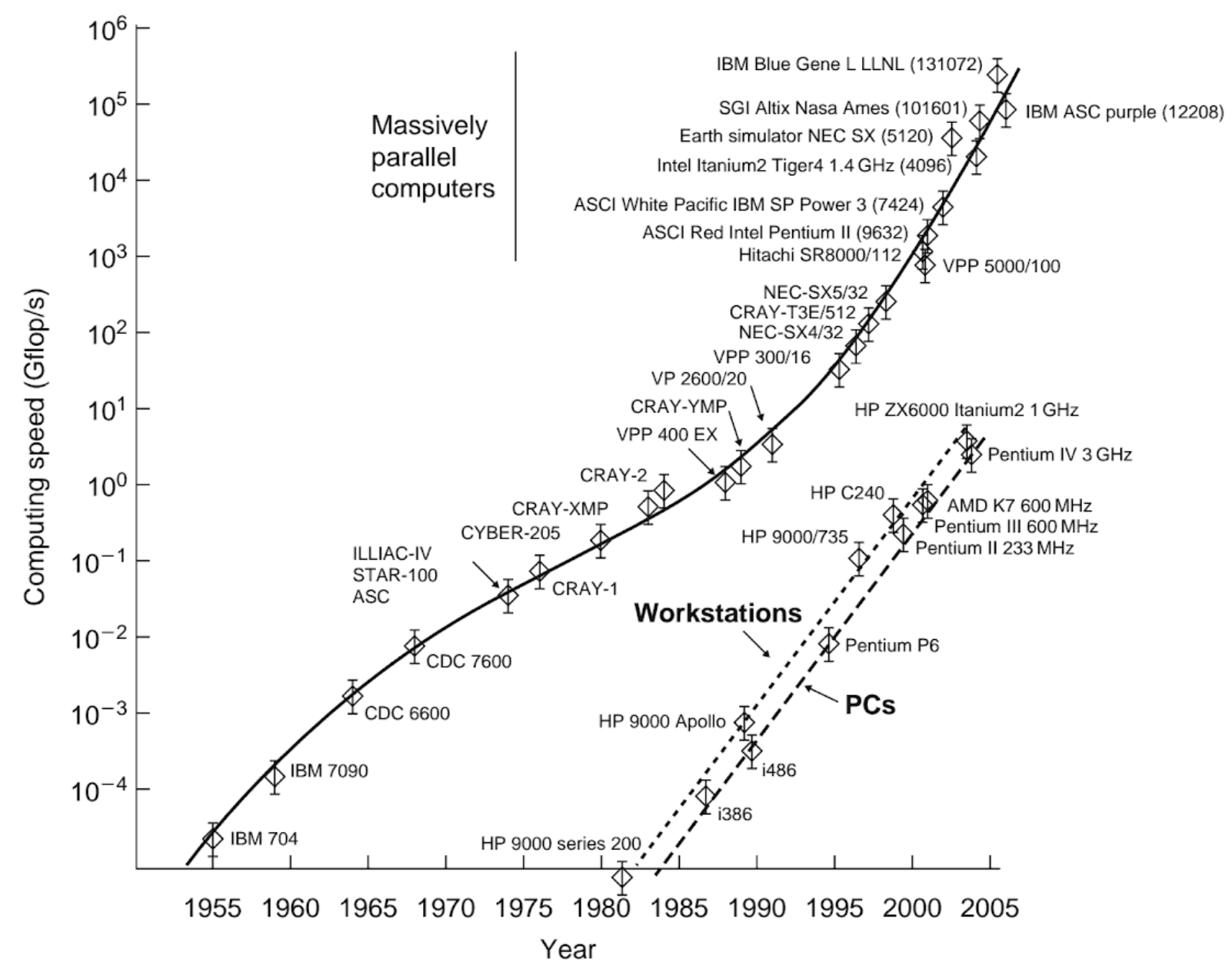

Figure 1.4: Evolution of computer performance from the 1950s. Source: Hirsch (2007).

omy, resulted from the reduction of freight rates and costs of exportation, the road transportation remains the main transport system in Colombia where factors, such as poor conservation and the weather conditions makes this transport mode very expensive and inefficient.

The elaboration of inland vessel projects ends up being a local regional or national problem since it depends on the conditions in the waterway, the route and the market in which the vessel will operate, as well as, other factors such as mission, cargo capacity and autonomy. The physical characteristics of the river and the aspects of the shallow water effects (as draft and beam restrictions, crossing ships in restricted spaces, radius of curvature of the river, locks) are important for the execution of the project. In this project, the type of inland vessel will be designed for dry-cargo carrier, well barge and tank vessel. 


\subsection{Objectives}

The objective of this work is the study of the resistance of a 2700 TDW inland vessel self-propelled by CFD numerical simulation and the validation and comparison of the numerical results with the existing empirical formulas and the experimental test results.

The following specific objectives are proposed during development of this objective:

- Understanding of the phenomena involving fluid flow along the inland vessel hull in shallow waters;

- Modeling of the 2700 TDW inland vessel hull using the CAD software FREE!Ship and Rhinoceros;

- Evaluation of the hull resistance using empirical formulas;

- Numerical simulation of the 2700 TDW inland vessel hull using CFD software STAR$C C M+$.

- Application of the grid convergence criteria for the choosing the number of elements that it will simulate the resistance and calculation of the properties of the inland vessel.

The study is divided in 6 chapters:

- Chapter 1 is the introduction of this study, where the presentation of the problem and the objectives are presented.

- Chapter 2 presents the state of art, including important references.

- Chapter 3 explains the empirical method for the estimation of the inland vessel resistance. For this purpose, the empirical formulations for the velocity loss calculation of the vessel in shallow water using Schlichting, Landweber, Lackenby for large rivers, as well as, the empirical formulations for middle rivers, where the effective velocities calculation applying the Karpov's diagrams and the correction of wall effect by Artjushkov are used.

- The resistance estimation applying CFD is the main topic of the chapters 4 and 5, where the equations for the numerical calculation, the procedure and the methodology, applied to inland vessels, are explained. Finally, the numerical results are compared to the experimental results for validation purposes. 
- Chapter 6 presents the conclusions and the future work of the project. The next chapter, the references consulted are listed. The appendices present the calculations concerning the shallow water effects and others results, including the experimental results, and codes used in this study. 


\section{BIBLIOGRAPHIC REVIEW}

The calculation of the resistance is based on Froude Hypothesis that is composed by frictional and residual resistances, where are expressed by the frictional and residual coefficients, wetted surface of the hull, velocity of the vessel and water density. ITTC (1957) established an equation for the frictional resistance coefficient. Guldhammer and Harvald (1974) created diagrams for the calculation of the residuary resistance coefficient. Georgakaki and Sorenson (2004) demonstrated that the resistance coefficient can be extrapolated providing reasonable results.

Considering the effects of shallow waters, Molland, Turnock and Hudson (2011) explained the wave generating phenomena for the resistance calculation. Latorre, Luthra and Tang (1982) presented the empirical methods of study for inland vessels applied to European and American vessels. ITTC (1987) considered some typical parameters to estimate the waterway restriction in shallow water. Pompée (2015) reviewed many empirical methods to determine the resistance of the ship depending on the type of vessel (pushed convoy or self-propelled), as well as, the physical conditions of a river (small, medium and large). In this study is explained only empirical formulations for medium and large rivers.

For large rivers and sea access channels, Schlichting (1934) presented the analysis of shallow water effects through experimental test and theoretical considerations, without influence of walls in a towing tank. Landweber (1939) improved this work, proposing the hydraulic radius. Lackenby (1963) simplified the semi-empirical formula of the velocity loss proposed by Schlichting.

In case of medium rivers, the effects of the shallow water are different. Karpov (1946) interpreters these phenomena with effective velocities for frictional and residual resistances that can be determined through two diagrams proposed by him. Artjushkov (1968) improved this work correcting the wall effects. Georgakaki and Sorenson (2004) demonstrated that these diagrams and the correction of the wall effects would be extrapolated, and they proposed equations for the approximation of these parameters. 
For small rivers, the calculation of the inland vessel resistance is associated with the existence of a limited velocity in restricted waterways that cannot exceed, where could be caused by a steep ship resistance rise. Schijf (1949) studied this limit velocity that corresponds for lower critical velocity (also called subcritical velocity). Pompée (2015) made the analytical theories for confined waters using two methods: energy method by Schijf (1949, 1953); and quantity of movement methods by Bouwmeester et al. (1977) and CNR (SAVEY, 1977; TENAUD, 1977; POMMIER; SELMI, 1981). These analytical theories are complemented for the Schlichting's formulation.

The numerical calculation of the hydrodynamic flow of the inland vessel was based on references that influenced this study. From the conservation of mass to the conservation of momentum, the Navier-Stokes (NS) equations are the basis of the description of fluid motion. Euler (1755) initiated this work for incompressible fluids and non-friction flows, Navier (1822) analyzed the friction effects for viscous fluids and Stokes (1845) improved this work completing the solution.

Reynolds (1895) introduced the time-averaging of the flow for turbulent effects, defining the decomposition of a mean and fluctuating parts of a variable. This is applied to the NS equations and is called Reynolds-Averaging Navier-Stokes equations (RANS). The choice of the turbulence model is necessary. Launder and Spalding (1972) were the first to introduce the standard $k-\varepsilon$ model. This model was refined and is called RNG (Re-Normalization Group methods) $k-\varepsilon$ model, and it was developed by Yakhot et al. (1992). Later, Shih et al. (1995) improved the turbulence model and is called Realizable $k-\varepsilon$. Wilcox (1988) published another turbulent model denominated standard $k-\omega$. To improve $k$ - $\omega$ model, Menter (1993) developed the baseline (BSL, also called BSL $k-\omega$ model) which was later refined for the transport of the turbulence shear stress and is called Shear Stress Transport (SST) $k-\omega$ model.

Noh and Woodward (1976), and Hirt and Nichols (1981) developed the Volume of Fluid method (VOF) to track and locate the free-surface. This method is based on Marker-and-cell method (MAC).

The interpolation of the convection term is used in the transport equation applied to Finite Volume Method (FVM). Courant, Isaacson and Rees (1952), and independently, Gentry, Martin and Daly (1966); Barakat and Clark (1966); and Runchal and Wolfshtein (1969) introduced the 1st order upwind scheme. Another type of interpolation is the 2nd order upwind scheme, started by Warming and Beam (1976), and Hodge, Stone and Miller (1979) for finite difference discretization. 
Patankar and Spalding (1972) introduced the iterative method called the The SemiImplicit Method for Pressure Linked Equations (SIMPLE) algorithm to resolve the linear pressure-velocity couple.

\section{$2.1 \quad$ Important references}

The following references are of high importance in this study.

\subsubsection{Celik et al. (2008)}

Their work resulted in the development of the Grid Convergence Index (GCI) that is used in the estimation and report of uncertainty results in CFD applications. The method is based on the Richardson (1910) Extrapolation (RE) and is only applied to unstructured volume domain. The authors justified that, if the user chooses to use it, this method shall not be questioned. On the other hand, if the user chooses another method, this method shall be judged in the review process. However, the authors do not desire to discourage further development of new methods. This method is simple, justified and accepted, and is used in this study for the validation of the simulation results.

\subsubsection{ITTC (2014)}

The ITTC creates a guideline, comprising of recommendations and practices regarding the applications of CFD methods that is divided in three steps: pre-processing, computation, and post-processing. The geometry of the hull, the volume domain and the computational grid are defined during the pre-processing step. At computational step, the governing equations to be solved are chosen. The visualization, analysis, verification and validation of the results belong to the post-processing step.

In this study, some of the values recommended in the guideline are adopted and applied to the equations. One of these recommended values is the wall $y+$, applied on the wall of the hull for the creation of the boundary layer in the grid mesh, which the ITTC provides a range of possible options, among which the user shall choose the specific for the purpose of the study. Later, the distance $y$ of the first layer is calculated. The ITTC (1957) established the formulation for the frictional resistance coefficient that is explained in the next chapter.

According to ITTC (2014), this is important because the value of wall $y+$ should be 
checked a posteriori once the solution is obtained. In this project, the wall $y+$ is simulated for the wall hull surface and the wall bottom plane in the computational domain.

\subsubsection{Ji et al. (2012)}

Their work is the study of prediction of the relationship between the geometrical and the kinematic parameters of the convoy and the amplitude of ship generated waves in restricted waterways. The authors used numerical simulations, solving the 3-D NavierStokes, along with the standard $k-\varepsilon$ for turbulent.

In this paper, the calculation of the grid size in $x$ direction is defined and the transversal wave length $\lambda$ is estimated. Once is done, the value of $\lambda$ is divided by 10 points, as the authors recommend, obtaining the grid size.

\subsubsection{Linde et al. (2017)}

Their work consists in the evaluation of the ship resistance in restricted waterways with effects of ship sinkage and trim. The RANS solver coupled with a quasi-Newton approach is used to find the equilibrium position and the calculation of the ship sinkage. The numerical simulation results are validated with towing tank tests and some empirical models.

In this study, the GCI method for grid convergence will be used with a constant refinement ratio

$$
r_{k}=\sqrt{2}
$$

\subsubsection{Liu et al. (2017)}

The authors evaluated the inland vessel resistance in confined waters. The effect of squat is analyzed. They used the RANS equations to simulate the viscous flow around the hull in a confined tank characterized by shallow sea bottom and close side walls.

In this study, computational domain is adopted, as illustrated in the Figure 2.1. Dimensions extend by $1.5 L_{\mathrm{WL}}$ from the bow to the inlet plane, $3.5 L_{\mathrm{WL}}$ from stern to the outlet plane and $0.33 L_{\mathrm{WL}}$ from the free surface to the top plane. Additionally, the meshing volume is configured and modified, as shown in Figure 2.2. The grid mesh in the vicinity of the free surface, hull, the tank bottom and the banks are refined. The prism layer is used at the bottom boundary condition, with wall $y+$ larger than 30 ; at the hull 
surface, wall $y+$ is smaller than 1 in order to obtain a more precise flow field simulation near the vessel.

Some configurations of the boundary conditions are adopted. The velocity inlet is set on the inlet and top plane. The pressure outlet is set on the outlet plane. The symmetry condition is set on the symmetry plane. The wall condition is set on the rest of the planes, including the hull.

For the estimation of the numerical error and uncertainty about the results following the grid discretization, the GCI is only applied to grid convergence with a constant refinement ration defined in the equation (2.1).

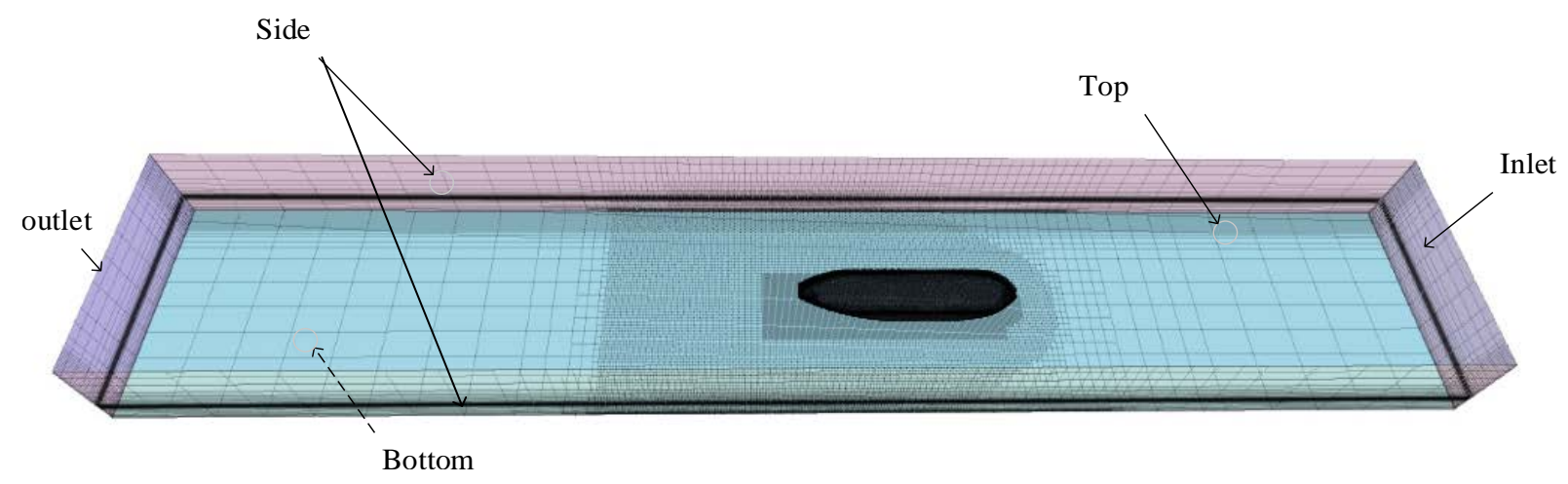

Figure 2.1: Overview of computational domain. Source: Liu et al. (2017).
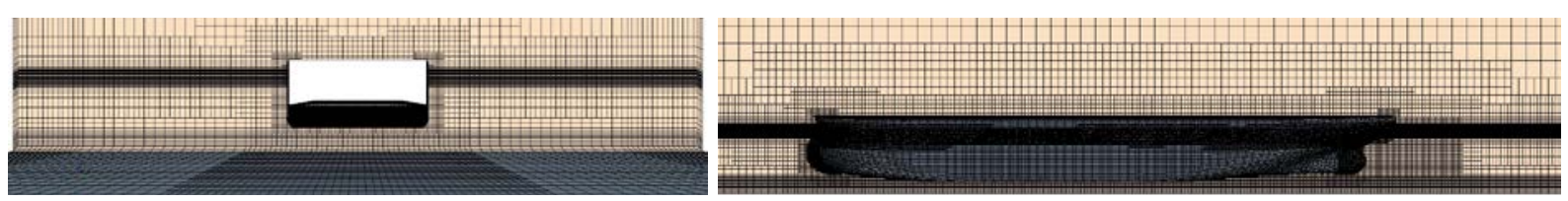

Figure 2.2: Grid structure around ship and bottom in shallow waters. Cross section at mid-ship (left) and longitudinal section at symmetry (right). Source: Liu et al. (2017). 


\section{FUNDAMENTALS ON SHIP RESISTANCE}

The vessel resistance is a force acting on the vessel during navigation at a given velocity. The direction of this force is opposite to the direction of the motion. The total resistance can be obtained through theoretical, experimental and computational calculations. This chapter will define the basic components of the resistance. Following, the resistance calculation methods will be described. Later, the shallow water effects will be described considering that the resistance in depth water is different to the resistance in deep water. Finally, the existing empirical methods will be contextualized.

\subsection{Components of resistance}

The total resistance is divided in basic components (shown in the Figures 3.1 and 3.2) (HARVALD, 1983; MOLLAND; TURNOCK; HUDSON, 2011):

- Frictional resistance: frictional forces between water and hull surface due to tangential shear forces in direction of motion.

- Pressure resistance: pressure force of water (normal forces) acting in the direction of motion.

- Viscous resistance: is associated with the energy expended due to viscous effects.

- Wave-making resistance: is associated with the energy generated by gravity waves during navigation.

- Viscous pressure resistance: is obtained by the integration of the components of the normal stresses acting on the hull due to viscosity and turbulence.

The following list contains additional resistance components:

- Residuary resistance: Considering the Froude's approach, the residuary resistance can be obtained by subtracting the skin friction resistance from the total resistance. 
- Wave-pattern resistance: is the resistance (deduced from measurements of wave elevations) where the wave pattern at a point remote from the vessel or model, is related, through a linearized theory, to the ship's or model's subsurface velocity field and, therefore, the momentum of the fluid. This resistance does not include wave-breaking resistance.

- Wave-breaking resistance: is associated with the breakdown of the vessel bow wave.

- Spray resistance: is associated with the energy loss resulting from the spray generation.

- Air resistance: is the resistance caused by the incident of wind/air on the vessel during navigation.

- Steering resistance: is the resistance caused by the rudder.

These specific components are shown in the Figure 3.3, where is represented in total resistance coefficient $C_{t}$ giving as function of length Froude number $F r_{L}$.

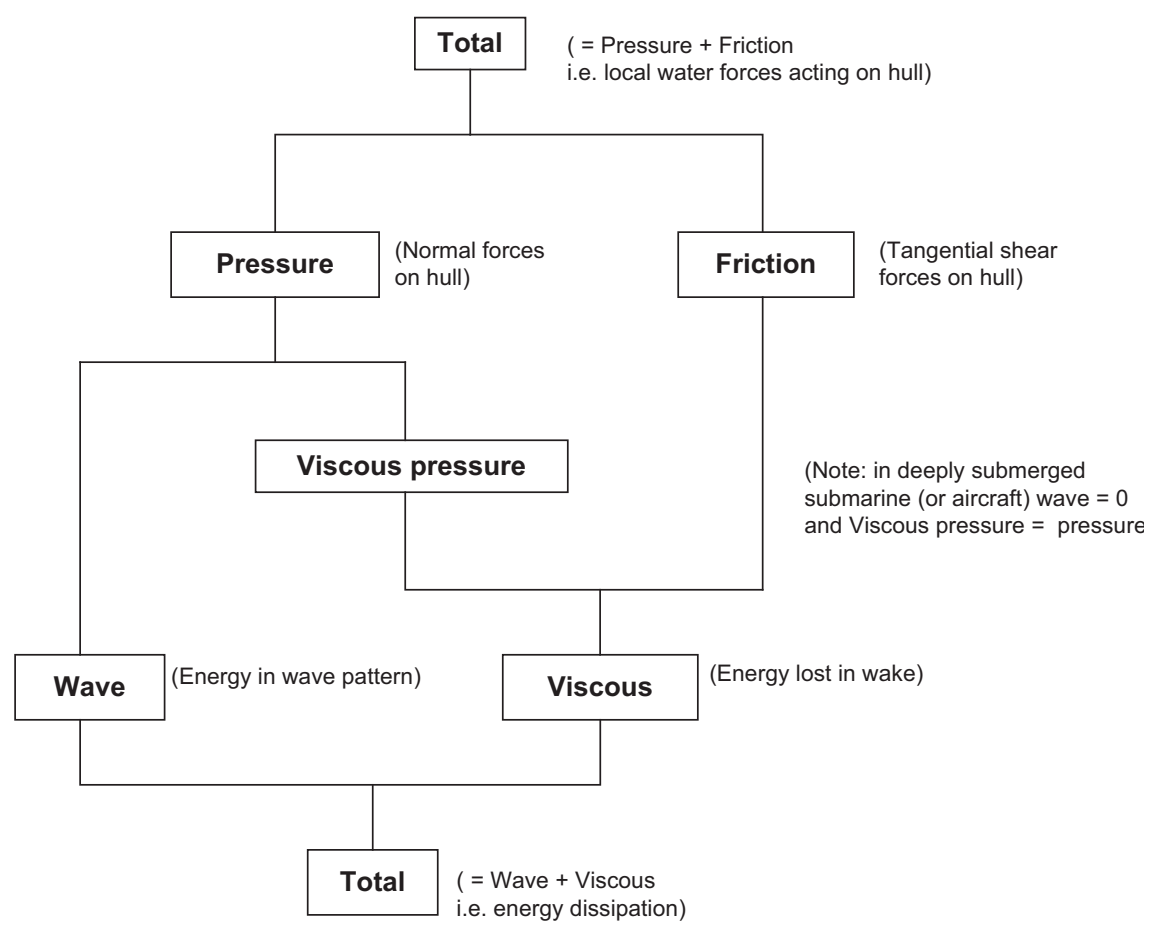

Figure 3.1: Basic resistance components. Source: Molland, Turnock and Hudson (2011).

According to Froude hypothesis, the total resistance is represented by the following formula

$$
R_{t}=R_{r}+R_{f}=\frac{1}{2} \rho S_{w s} v^{2} C_{t}
$$




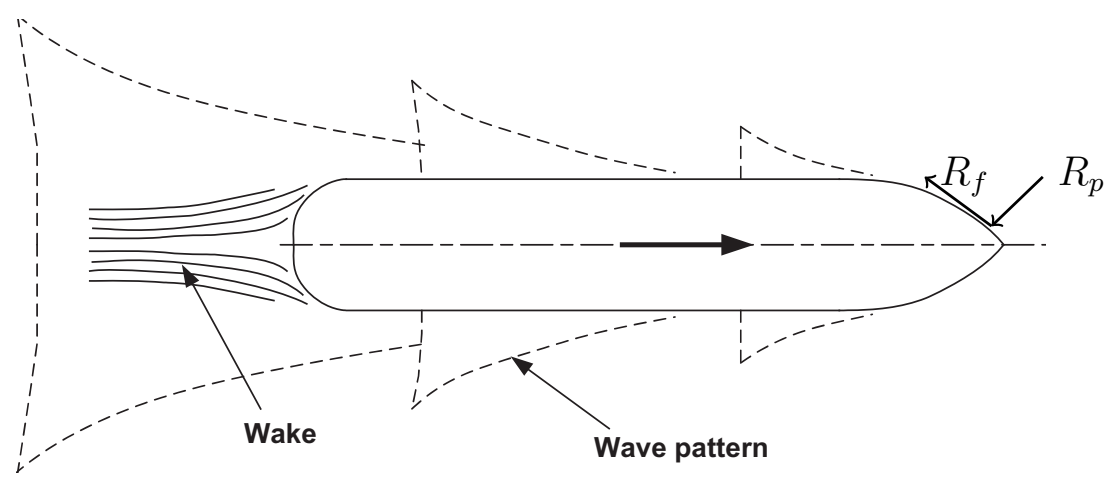

Figure 3.2: Frictional $\left(R_{f}\right)$ and pressure $\left(R_{p}\right)$ forces; wave pattern and wake. Source: Molland, Turnock and Hudson (2011).

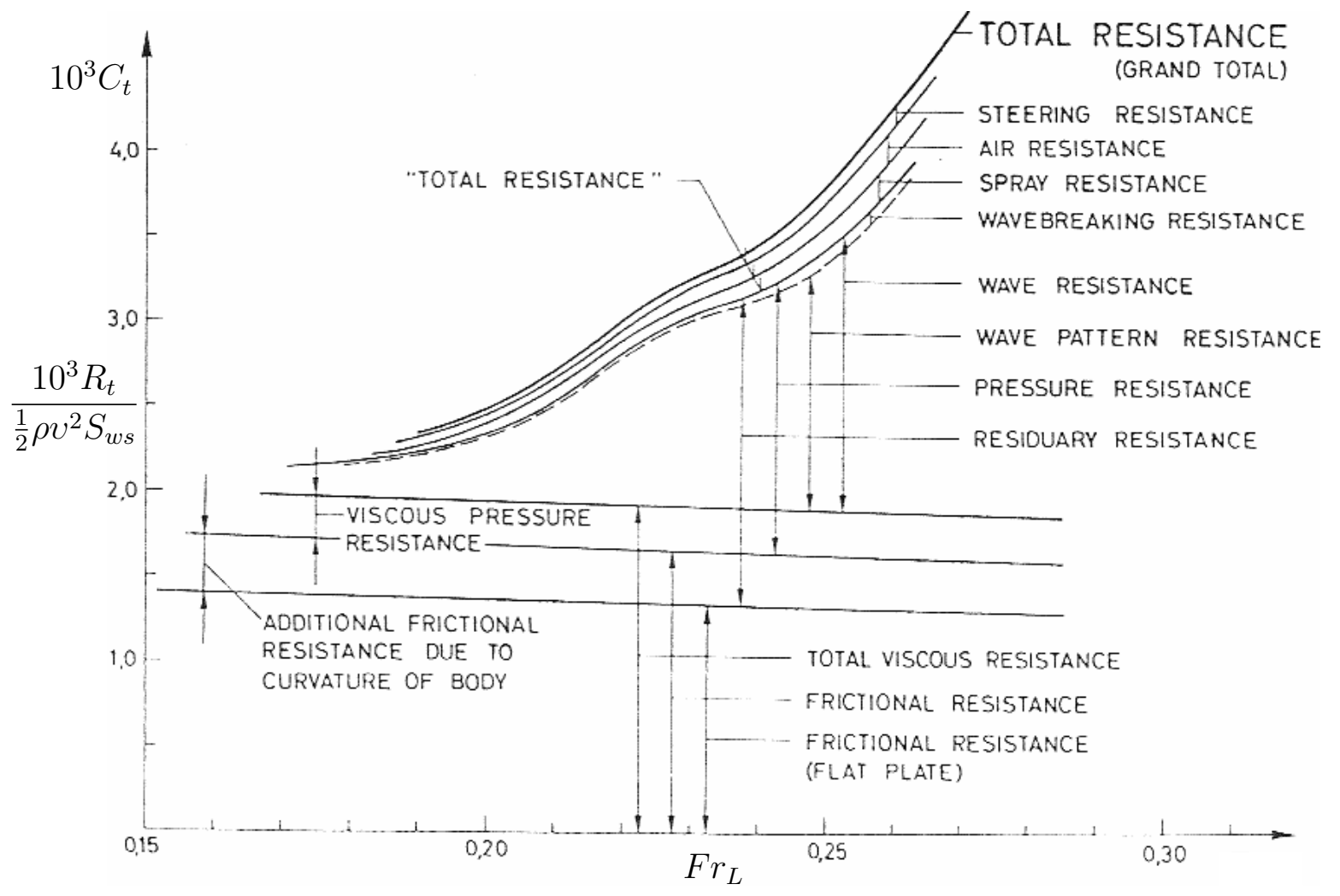

Figure 3.3: Specific components of resistance. Source: Harvald (1983).

where $R_{r}$ is the residuary resistance, $R_{f}$ is the frictional resistance, $\rho$ is the density of water, $S_{w s}$ is the wetted surface area of the vessel, $v$ is the velocity of the vessel, and $C_{t}$ is the total resistance coefficient. $C_{t}$ is defined as

$$
C_{t}=C_{r}+C_{f}
$$

where $C_{f}$ and $C_{r}$ are the frictional and the residuary resistance coefficients.

The International Towing Tank Conference (ITTC) studied proposals in order to determine the frictional resistance coefficient (HARVALD, 1983). ITTC (1957) proposed 
the Model-ship correlation line providing great accuracy. This coefficient is formulated as

$$
C_{f}=\frac{0.075}{\left[\log _{10}(R e)-2\right]^{2}},
$$

where $R e$ is the Reynolds number.

Reynolds (1883) studied the characterization of the fluid motion in which used flow criteria that indicate whether the flow is laminar, turbulent or at transition stage (Encyclopædia Britannica, 2015f). The Reynolds number is given by

$$
R e=\frac{L_{\mathrm{WL}} v}{\nu}
$$

where $L_{\mathrm{WL}}$ is the length of the vessel in waterline and $\nu$ is kinematic viscosity of water, represented as

$$
\nu=\frac{\mu}{\rho}
$$

where $\mu$ is the dynamic viscosity.

The residuary resistance coefficient is calculated according to Guldhammer's and Harvald's method (1974)

$$
C_{r}=f\left(F r_{L}, \frac{L_{\mathrm{WL}}}{\Lambda^{\frac{1}{3}}}, \Phi\right), \quad \text { if } \frac{B}{T}=2.5,
$$

where $F r_{L}$ is the length Froude number, $\Lambda$ is the vessel's displacement, $\Phi$ is the prismatic coefficient of the vessel, $B$ is the vessel's beam, and $T$ is the vessel's draft. This coefficient can be determined by nine diagrams (see the Figures from A.1 to A.9) for $L_{\mathrm{WL}} / \Lambda$ ratios ranging from 4 to 8 at intervals of 0.5 . Additionally, each diagram provides the mean curves of $C_{r}$ for $\Phi$ between 0.5 and 8.0. The values of $F r_{L}$ are between 0.15 and 0.45 . The diagrams refer to a $B / T$ ratio equal to 2.5 and were obtained through experimental tests corresponding to ship models.

Georgakaki and Sorenson (2004) mentioned that the Guldhammer's and Harvald's curves can extrapolate the values of $C_{r}$. In case of $F r_{L}$ lower than 0.15 , is equal to the $C_{r}$ value for $F r_{L}$ equal to 0.15 . The formulation involved is

$$
10^{3} C_{r}=E_{1}+G+H+K
$$

where

$$
\begin{aligned}
& E_{1}=\left(A_{0}+1.5 F r_{L}^{1.8}+A_{1}+F r_{L}^{N_{1}}\right)\left[0.98+\frac{2.5}{(M-2)^{4}}\right]+(M-5)^{4}\left(F r_{L}-0.1\right)^{4}, \\
& A_{0}=1.35-0.23 M+0.012 M^{2}
\end{aligned}
$$




$$
\begin{aligned}
A_{1} & =0.0011 M^{9.1} \\
N_{1} & =2 M-3.7 \\
G & =\frac{B_{1} B_{2}}{B_{3}} \\
B_{1} & =7-0.09 M^{2} \\
B_{2} & =(5 \Phi-2.5)^{2} \\
B_{3} & =\left[600\left(F r_{L}-0.315\right)^{2}+1\right]^{1.5} \\
H & =\exp \left\{80\left[F r_{L}-(0.04+0.59 \Phi)\right]-[0.015(M-5)]\right\} \\
K & =180 F r_{L}^{3.7} \exp (20 \Phi-16), \\
M & =\frac{L}{\Lambda^{\frac{1}{3}}} .
\end{aligned}
$$

The equation (3.7) is applicable to self-propelled vessels and convoys but does not applied to pushed convoys.

The Froude number $\mathrm{Fr}$ is the dimensionless quantity that indicates the influence of gravity on fluid motion (Encyclopædia Britannica, 2015c). In marine hydrodynamic applications, this is important to calculate the ship resistance using length Froude number. For shallow waters, is applied the depth Froude number that will be explained in the next subsection. The length Froude number is determined by

$$
F r_{L}=\frac{v}{\sqrt{g L_{\mathrm{WL}}}},
$$

where $g$ is the gravitational acceleration. The prismatic coefficient is given by

$$
\Phi=\frac{\Lambda}{L_{\mathrm{WL}} B T \beta},
$$

where $\beta$ is the midship section area coefficient of the vessel, represented by

$$
\beta=\frac{A_{i m s}}{B T},
$$

where $A_{i m s}$ is the immersed midship area of the vessel.

The correction of the residuary resistance coefficient for vessels with beam to draft ratio of value higher or lower than 2.5 is determined by

$$
10^{3} C_{r}=10^{3} C_{r_{\frac{B}{T}=2.5}}+0.16\left(\frac{B}{T}-2.5\right) .
$$




\subsection{Shallow water effects}

The performance of a ship engaged in sea transport is different to the performance of an inland vessel due to aspects such as cruising velocities, maneuverability, stability and river's/channel's geographic morphology and infrastructure. The term "shallow water" refers to the boundaries close to the ship in vertical and horizontal direction.

The principal effects of shallow waters are (MOLLAND; TURNOCK; HUDSON, 2011):

- Effective increase in velocity and backflow;

- Decrease in pressure under the hull;

- Significant changes in sinkage and trim;

- Increases in skin friction drag and wave resistance.

Shallow water effects are characterized by depth Froude number, related to the velocity of the vessel $v_{\infty}$ and the local depth of the river $h$, obtained by

$$
F r_{h}=\frac{v_{\infty}}{\sqrt{g h}}
$$

The vessel produces system waves which travel with velocities that depends on the water depth $h$ and the wave length $\lambda$. In deep water, when $h / \lambda$ ratio is large, the wave velocity is defined as

$$
c=\sqrt{\frac{g \lambda}{2 \pi}} \quad \text { if } \frac{h}{\lambda} \geq \frac{1}{20} .
$$

In shallow water, when the value of this relationship is small,

$$
c=\sqrt{g h} \quad \text { if } \frac{h}{\lambda}<\frac{1}{20} .
$$

The waves travel at the same velocity $c$ as the velocity of the ship. In this case, $c$ is known as the critical velocity (MOLLAND; TURNOCK; HUDSON, 2011).

In the Figure 3.4, shows the wave patterns. The propagation of the transversal waves system and divergent waves system occurs away from the vessel for subcritical values $\left(F r_{h}<1\right)$, producing an angle of $35^{\circ}$. At critical velocity $\left(F r_{h}=1\right)$ the wave angle is perpendicular to the track of ship, generating an angle of $0^{\circ}$. At supercritical velocities $\left(F r_{h}>1\right)$, there is no transversal waves and the divergent waves produce wave with a 
propagation angle

$$
\theta=\cos ^{-1}\left(\frac{1}{F r_{h}}\right)
$$

because a gravity wave cannot travel at $c>\sqrt{g h}$. These observations can be visualized in the Figure 3.5, and are the result of the experimental test according to Molland, Wilson and Taunton (2004).

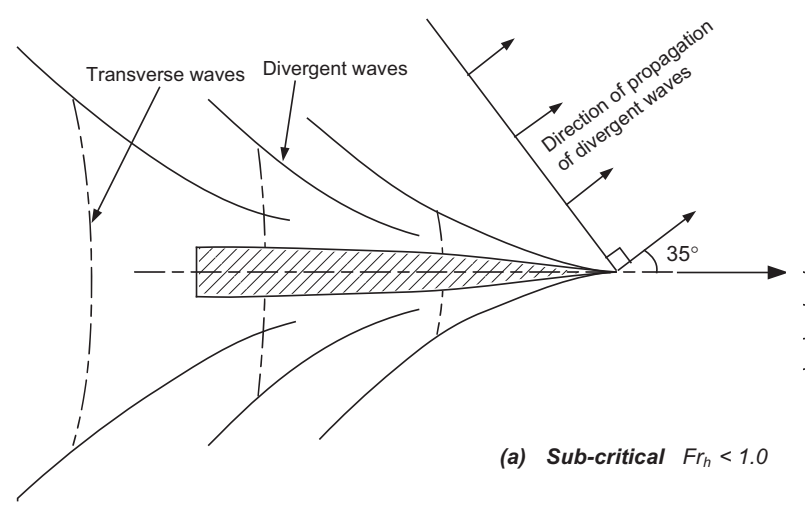

(a) Subcritical $\left(F r_{h}<1\right)$

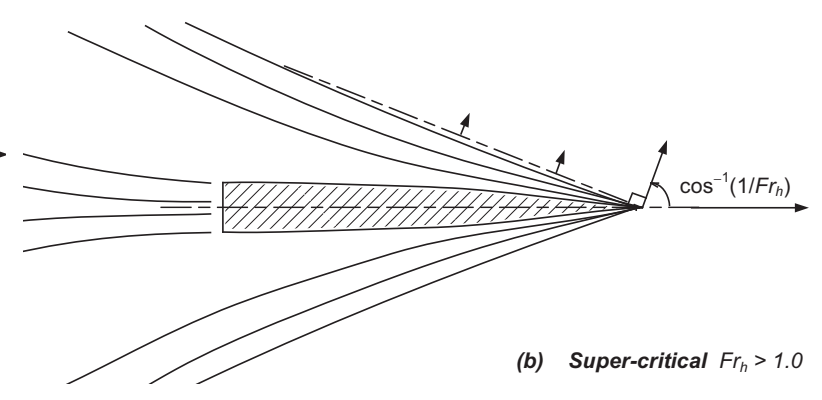

(b) Supercritical $\left(F r_{h}>1\right)$

Figure 3.4: Subcritical and supercritical wave patterns. Source: Molland, Turnock and Hudson (2011).

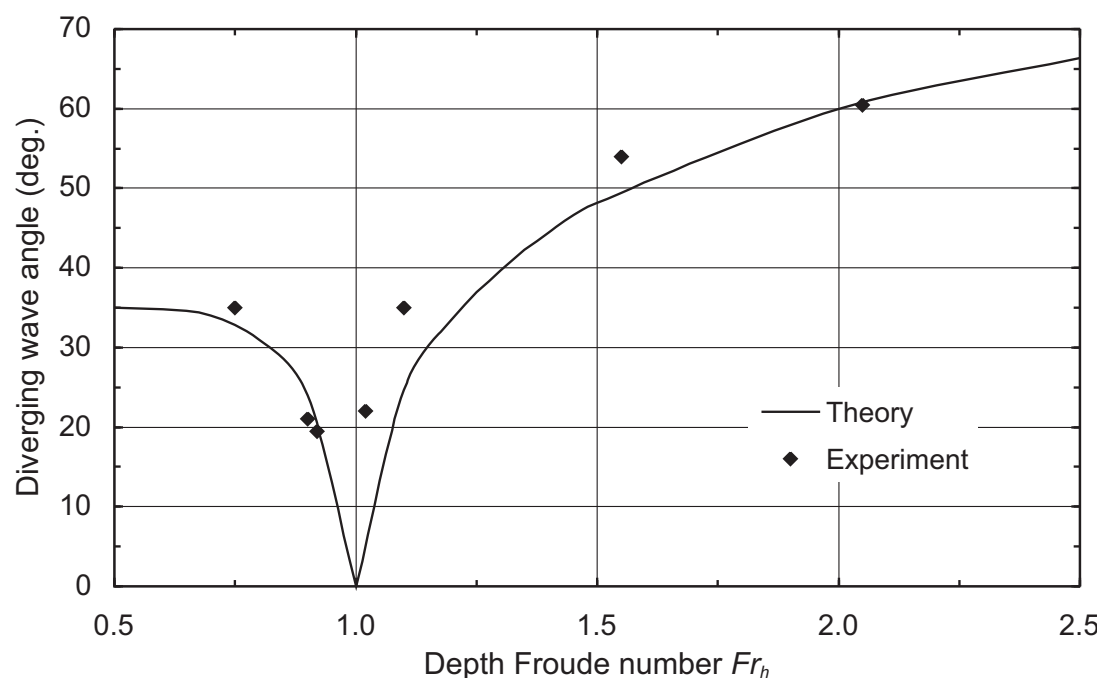

Figure 3.5: Changes of divergent wave angle in function of depth Froude number. Source: Molland, Wilson and Taunton (2004); Molland, Turnock and Hudson (2011).

Molland, Turnock and Hudson (2011) show the performance of the resistance, described in the Figure 3.6, displaying great variation of the resistance in shallow water. When the velocity is greater than critical, the value of $R_{t}$ in shallow waters reduces again and and becomes a little lower than the $R_{t}$ in deep water navigation. The ratio of shallow to deep water wave-making resistances $R w_{h} / R w_{D}$ is illustrated in the Figure 3.7, where 
the maximum value is 4.0, typically, when $F r_{h}$ is approximately 1.0 (in general in the range of 0.96 to 0.98 ) implying the decrease of the propeller efficiency. These effects (described in the Figure 3.8) show a lower value of $h / L_{\mathrm{WL}}$ ratio and $R w$ peaks with a high value. The ratio marked as $\infty$ is for deep water. The value of 0.75 for the $h / L_{\mathrm{WL}}$ ratio corresponds to the critical velocity.

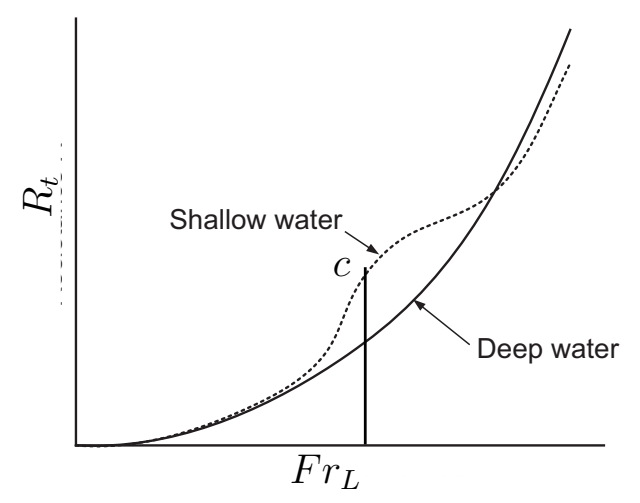

Figure 3.6: Influence of shallow water on the resistance curve. Source: Molland, Turnock and Hudson (2011).

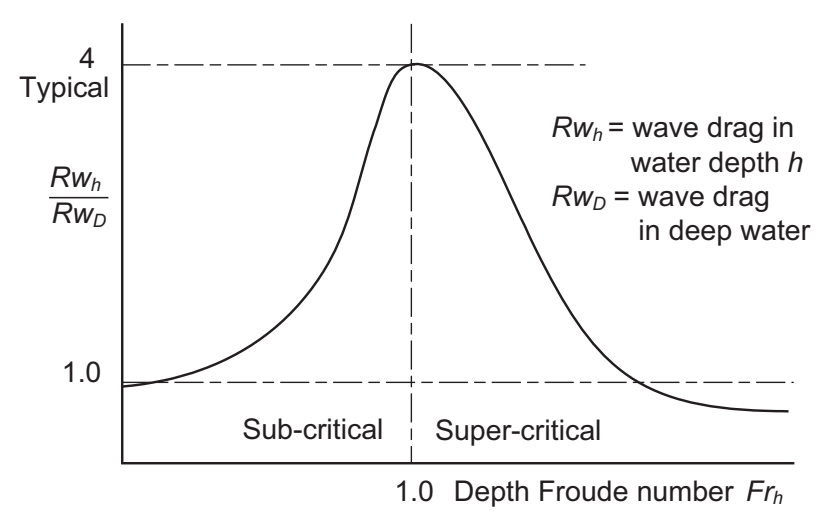

Figure 3.7: Amplification of wave-making resistance. Source: Molland, Turnock and Hudson (2011).

In the Figure 3.9 shows the distribution of the pressure and the velocity of a fluid around a symmetric body. The flow is slower at the bow and the stern of the ship, and faster at midship. Before the flow touches the hull, the velocity is constant and no pressure. When the flow is in contact in the bow and the stern, its velocity is zero and its pressure is high. At the middle of the body, the velocity of the flow is higher, and its pressure is lower according to Bernoulli's principle. The boundary layer of a body increases significantly the viscous resistance. The pressure and the velocity distribution can be altered due to vortex formation that occurs close to the hull surface (BERTRAM, 2000). 


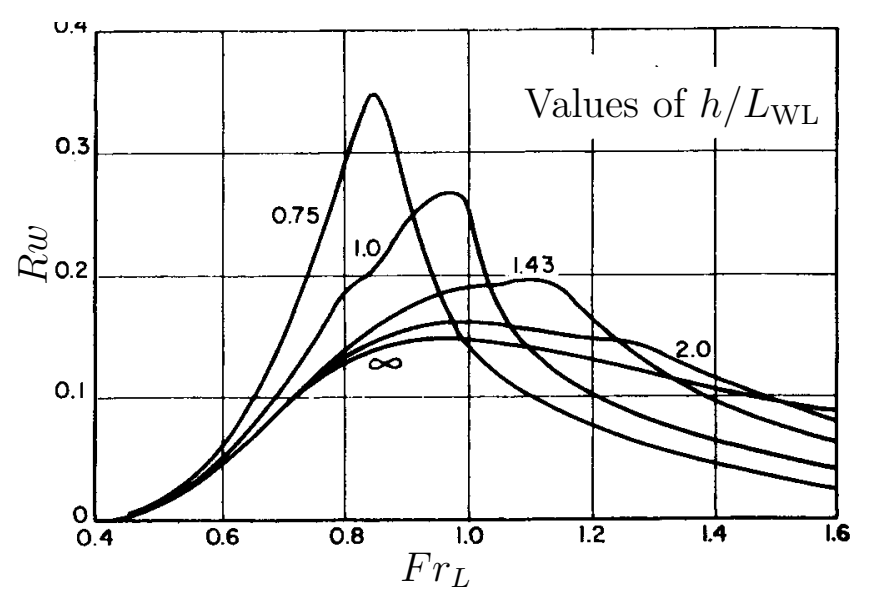

Figure 3.8: Effect of shallow water on wave-making resistance. Source: Lewis (1988).

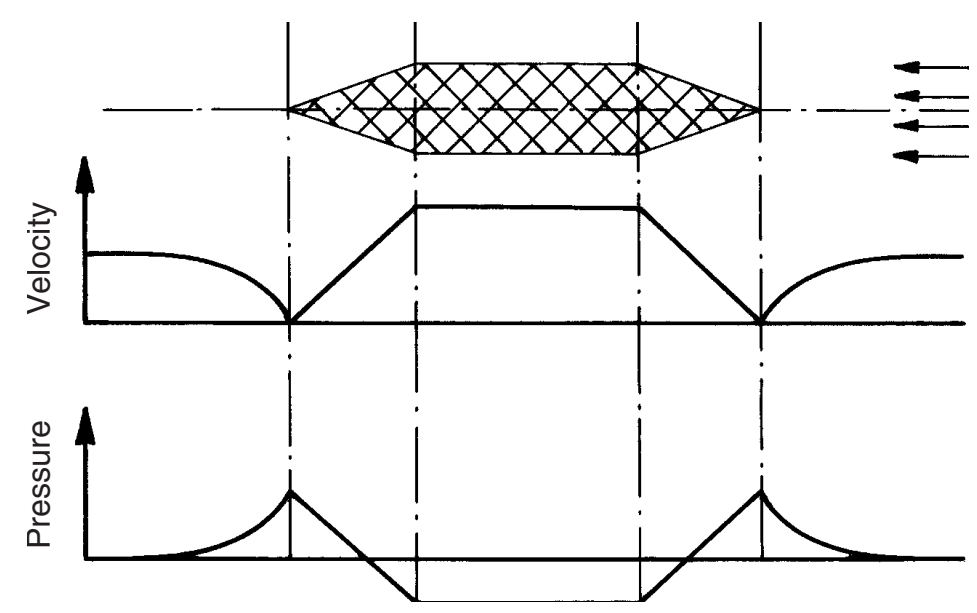

Figure 3.9: Distribution of the velocity and the pressure of a fluid around a symmetry body. Source: Bertram (2000).

It is highly important to define whether the vessel's velocity, during navigation in certain local depths, is super-critical, sub-critical or critical, as illustrated in the Figure 3.10 .

According to ITTC (1987), some typical parameters and their values must be considered so as to estimate the river restrictions, e.g.,

- The depth Froude number $F r_{h}$ influences on wave resistance $\left(F r_{h}>0.7\right)$;

- The water-depth to draught ratio $h / T$ influences the flow around the hull, independent of the $F r_{h}$ value (if $h / T<4$ );

- For river width to vessel's beam ratio $B_{c} / B$, the flow around the hull changes (if $\left.B_{c} / B<4\right)$;

- The relationship between the river section area and the immerse midship section 


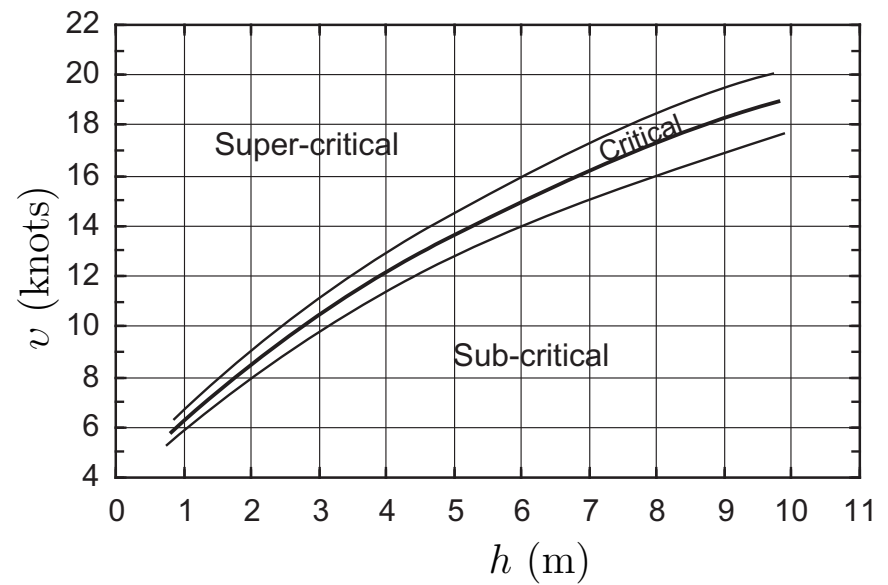

Figure 3.10: Sub-critical and super-critical operating regions. Source: Molland, Turnock and Hudson (2011).

area $A_{c} / A_{i m s}$ is the beginning of the restriction waterway (if $A_{c} / A_{i m s}<15$ ).

Pompée (2015) established models to estimate the inland vessel's resistance, depending on the type of vessels (self-propelled or pushed convoys) and the characteristics of the river as shown in the Figure 3.11. The traditional shallow water methods for large rivers (as Danube) are based on velocities of Schlichting (1934), Landweber (1939) and Lackenby (1963). The diagrams by Karpov (1946) and the correction of the wall effect by Artjushkov (1968) for middle rivers (as Rhine and Rhone) are used.

\subsubsection{Large rivers}

Schlichting (1934) carried out the analysis of shallow water effects based on theoretical considerations and model experiments. In model tests, the author only took into account the reduction of the water depth and did not consider the increasing influence of the banks (tank width) in a towing tank.

In the Figure 3.12 is shown the frictional $R_{f}$ and total $R_{t}$ resistance curves in deep and shallow water to a base of velocity. The ship generates a wave pattern giving a wave length $\lambda$ for velocity $v_{\infty}$ in deep water

$$
v_{\infty}^{2}=\frac{g \lambda}{2 \pi}
$$

The same wave length $\lambda$ would be generated at some lower or intermediate velocity $v_{I}$ in a specific water depth $h$, and is expressed as

$$
v_{I}^{2}=\frac{g \lambda}{2 \pi} \tanh \left(\frac{2 \pi h}{\lambda}\right) .
$$




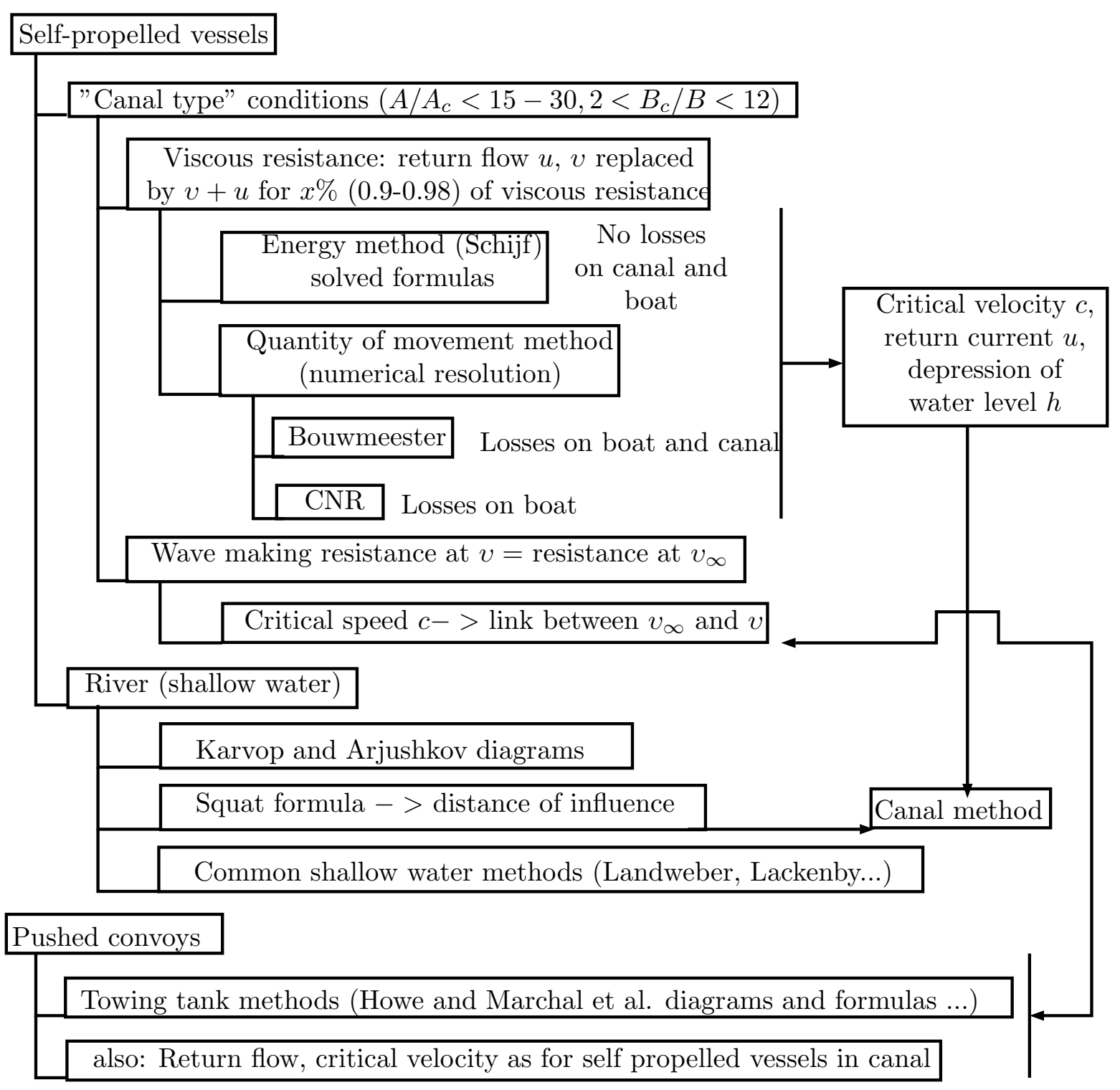

Figure 3.11: Models available depending on the situation and the vessel. Source: Pompée (2015).

The ratio between these two velocities is

$$
\frac{v_{I}}{v_{\infty}}=\sqrt{\tanh \left(\frac{g h}{v_{\infty}^{2}}\right)}=\sqrt{\tanh \left[\left(\frac{\sqrt{g h}}{v_{\infty}}\right)^{2}\right]}=\sqrt{\tanh \left(\frac{2 \pi h}{\lambda}\right)} .
$$

and is plotted a curve to a base of $v_{\infty} / \sqrt{g h}$ in the Figure 3.13. The values less of 0.4 , the shallow water effect on the wake-making resistance $R w$ is unimportant. The difference between these velocities is (Figure 3.12)

$$
v_{\infty}-v_{I}=\delta C
$$

and the Schlichting's assumption is that the wave-making resistance $R w$ in shallow waters 
at velocity $v_{I}$ (line $\mathrm{BF}$ ) would be the same as that velocity $v_{\infty}$ in deep water (line $\mathrm{AE}$ ). In the point $\mathrm{B}$ is located the total resistance at velocity $v_{I}$ adding $R w$ in deep water and $R_{f}$ in depth water. The line AB is parallel to EF (LEWIS, 1988).

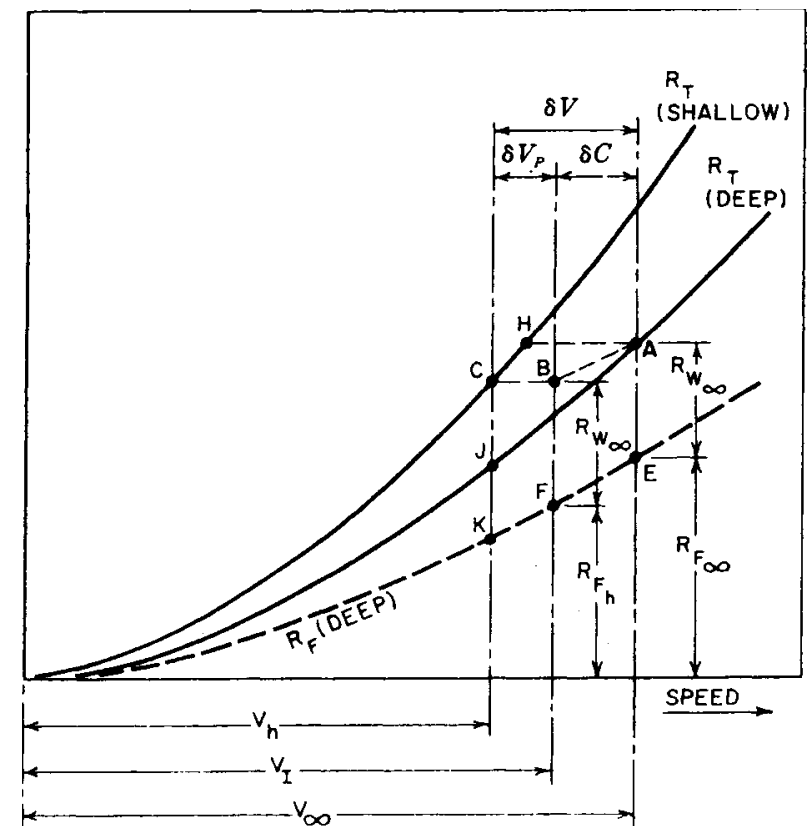

Figure 3.12: Determination of shallow water resistance by Schlichting's method. Source: Lewis (1988).

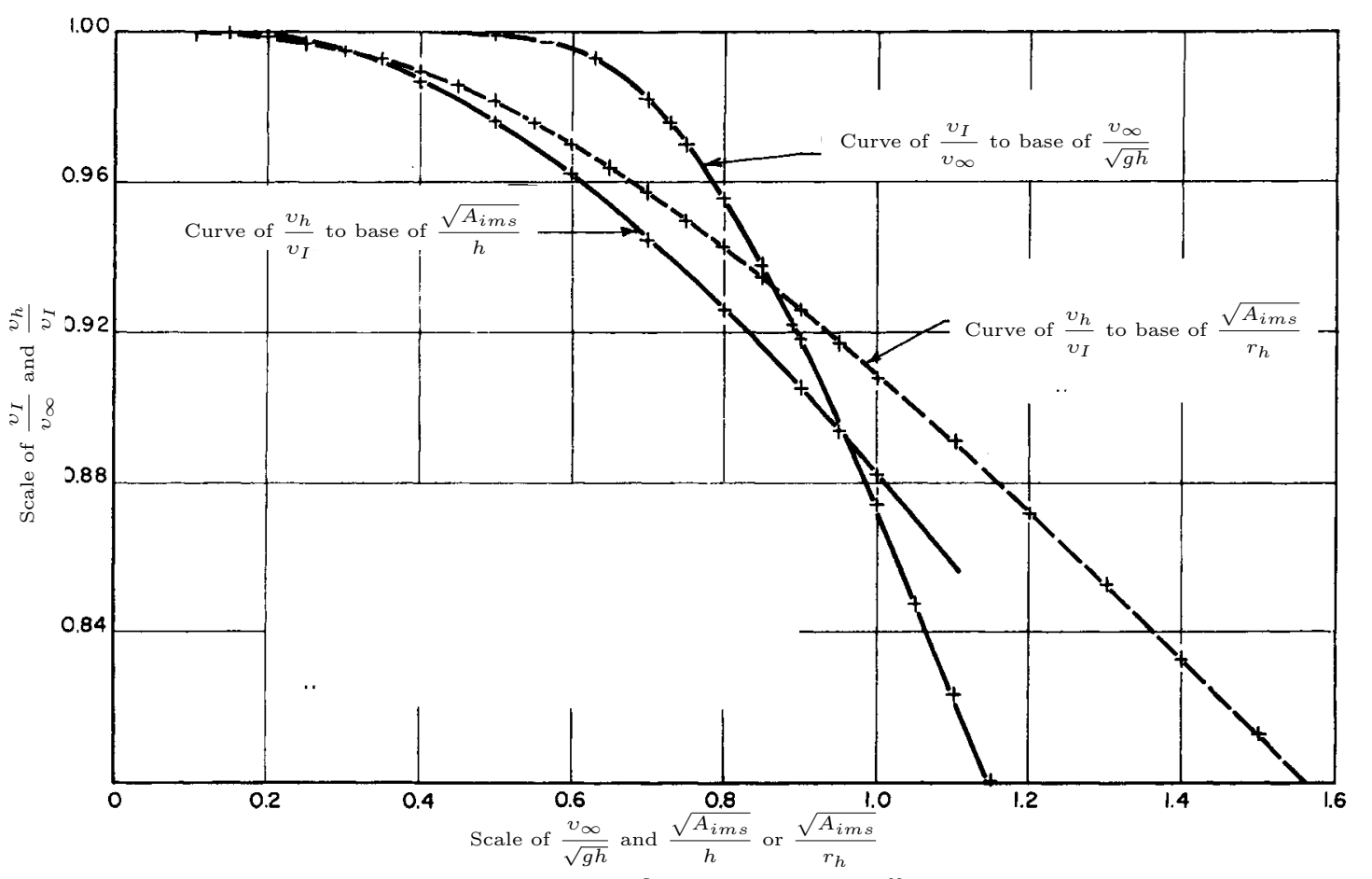

Figure 3.13: Curves of velocity ratios for the calculation of the resistance in shallow water. Source: Lewis (1988). 
The increase in potential or displacement flow around the hull due to the restriction of area by the proximity of the bottom generate a further loss in velocity $\delta v_{p}$, giving

$$
v_{h}=v_{I}-\delta v_{p}
$$

Later, Schlichting investigated this reduction of the velocity of the vessel in shallow waters, and found that the factor to control further loss in velocity was the ratio

$$
\frac{\sqrt{A_{i m s}}}{h}
$$

In the Figure 3.13 is plotted the curves of $v_{h} / v_{I}$ in function of the equation 3.32. In the Figure 3.12, the distance of $\delta v_{p}$ is parallel to the line $\mathrm{BC}$, and the point $\mathrm{C}$ is the curve of total resistance in shallow waters at velocity $v_{h}$.

The total velocity loss is determined as

$$
\delta v=\delta C-\delta v_{p}
$$

which can be expressed in percentage terms

$$
\frac{\delta v}{v_{\infty}} \times 100=\frac{v_{\infty}-v_{h}}{v_{\infty}} \times 100=f\left(\frac{v_{\infty}^{2}}{g h}, \frac{\sqrt{A_{m s}}}{h}\right) .
$$

The above are given in contour form, illustrated in the Figure 3.14.

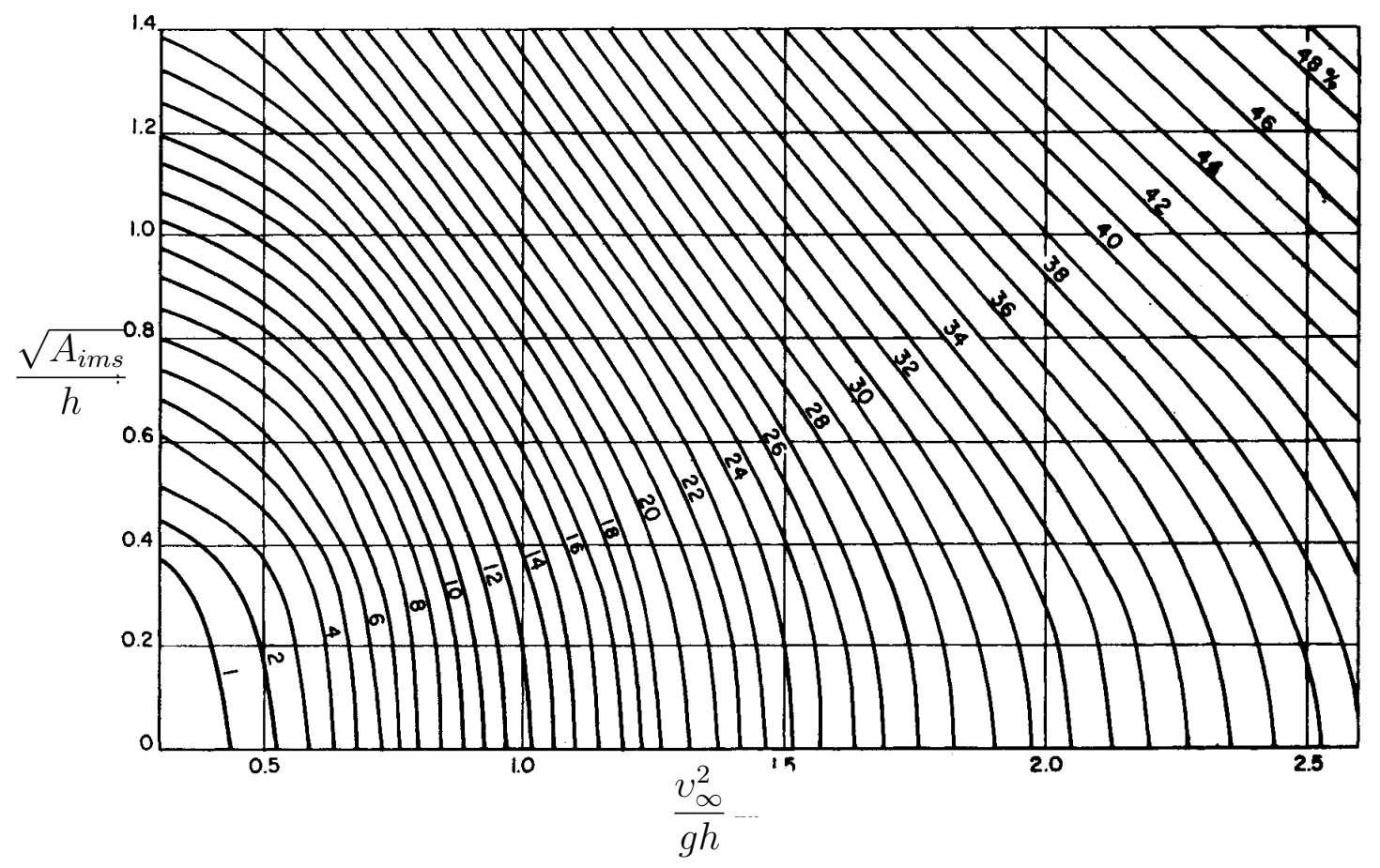

Figure 3.14: Schlichting's chart for calculate the loss in velocity of the vessel. Source: Lewis (1988). 
Landweber (1939) analysed the Schlichting's method for the prediction of the resistance shallow water in case of restricted channels. He proposed a hydraulic radius that can be determined by the ratio of the cross-section area of the channel to the wetted perimeter (Figure 3.15)

$$
r_{h}= \begin{cases}\frac{B_{c} h}{B_{c}+2 h} & \text { (a) for rectangular channel of } B_{c} \text { and } h, \\ h & \text { (b) when } b \text { becomes very large, } \\ \frac{B_{c} h-A_{i m s}}{B_{c}+2 h+q_{s}} & \text { (c) model is in a rectangular channel. }\end{cases}
$$

where $B_{c}$ is the width of the channel and $q_{s}$ is the wetted girth of the hull that is determined as:

$$
q_{s}=B+2 T \text {. }
$$

Introducing $B_{c}$ in the equation (3.32), $h$ is replaced by $r_{h}$, and is expressed as

$$
\frac{\sqrt{A_{i m s}}}{r_{h}}
$$

Lackenby (1963) presented a semi-empirical formula as a complement to Schlichting's method

$$
\frac{d v}{v_{\infty}} \times 100=\left[0.1242\left(\frac{A_{i m s}}{h^{2}}-0.05\right)+1-\sqrt{\tanh \left(\frac{g h}{v_{\infty}^{2}}\right)}\right] \times 100 \quad \text { if } \frac{A_{i m s}}{h^{2}}>0.05
$$

which is given in contour form illustrated in the Figure 3.16. He observed some points of interest. In the area ABCD there is no shallow water effect. In BEFC, there is a "backflow" effect. In DCHJ there is wave-retardation. In CFGH back-flow and wave-retardation are significant.

The methods for large rives must be limited to the range of the diagram shown in the Figure 3.13, i.e.

$$
\frac{v_{\infty}}{\sqrt{g h}} \leq 1.14846, \quad \frac{\sqrt{A_{i m s}}}{h} \leq 1.3, \quad \frac{\sqrt{A_{i m s}}}{r_{h}} \leq 1.558 .
$$

\subsubsection{Medium rivers}

According to Karpov (1946), the vessel resistance in shallow water divided into the frictional and residuary resistance as a function of, instead of cruising velocity, the two 


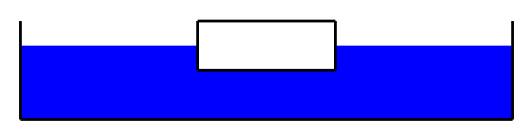

(a) Rectangular channel

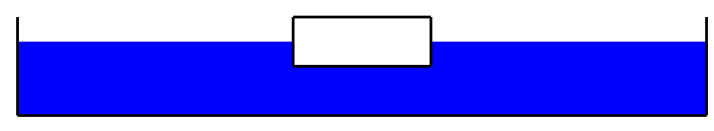

(b) When $b$ becomes very large

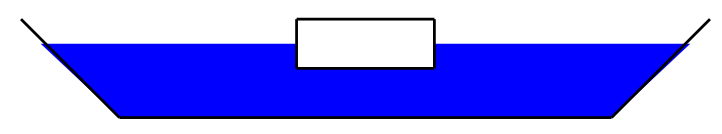

(c) When the model is in a rectangular channel

Figure 3.15: Different cross-section of the channels for Landweber's method. Source: Author.

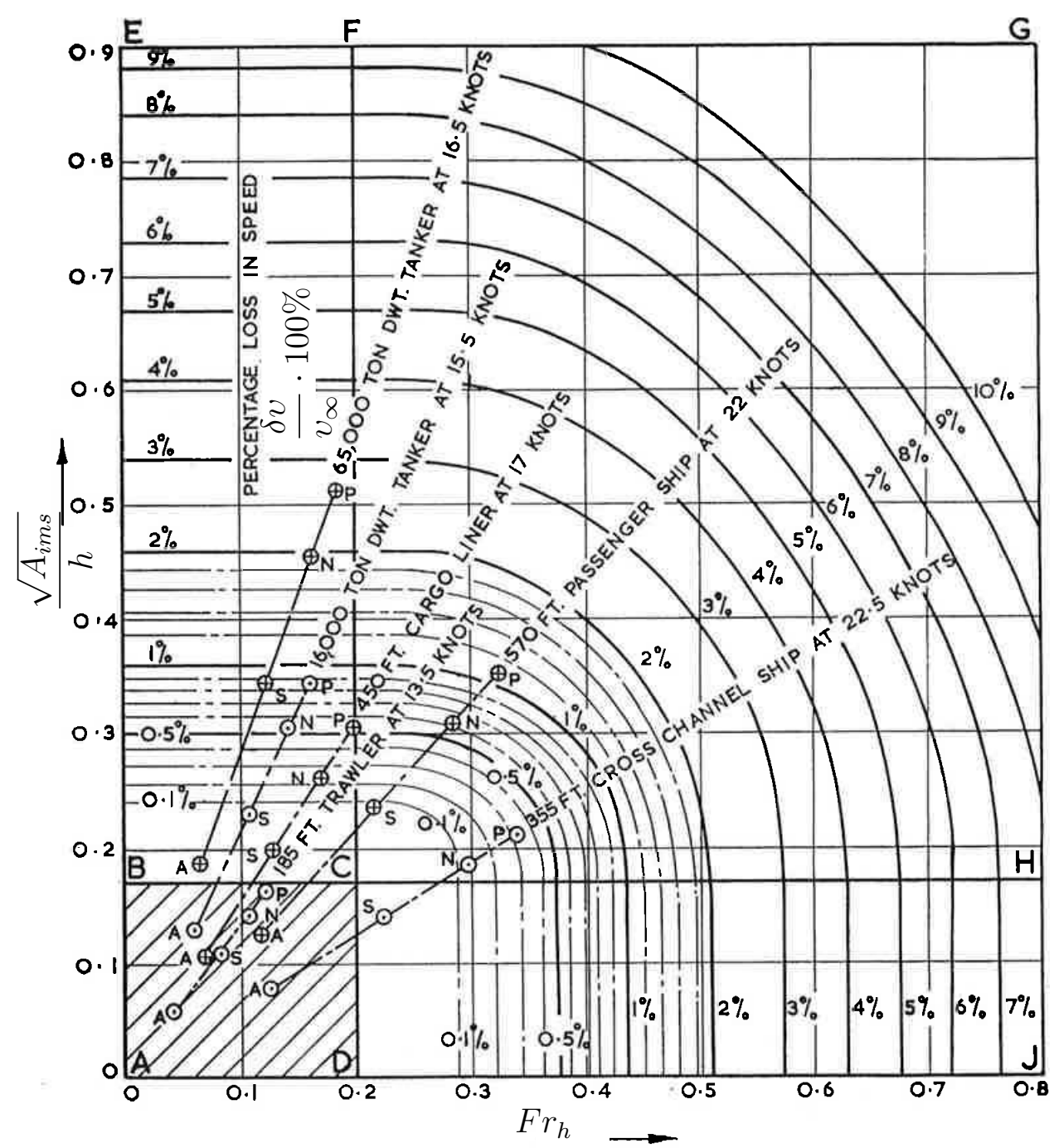

Figure 3.16: Loss in velocity in shallow water. Source: Lackenby (1963).

different velocities velocities $v_{1}$ and $v_{2}$ operating in waterways with a local depth $h$

$$
R_{t}\left(v_{\infty}\right)=\frac{1}{2} \rho S_{w s}\left[\left(C_{f}+C_{a}\right) v_{1}^{2}+C_{r} v_{2}^{2}\right]
$$

where $C_{a}$ is the correlation allowance that is used for the calculation of the total resistance of the vessel in full scale, otherwise, is zero. The effective velocities $v_{1}$ and $v_{2}$ are expressed 
as

$$
v_{1}=\frac{v_{\infty}}{\alpha^{*}}, \quad v_{2}=\frac{v_{\infty}}{\alpha^{* *}}
$$

where $\alpha^{*}$ and $\alpha^{* *}$ are coefficients that can be determined from the diagrams shown in the Figure 3.17. These values depend on the $h / T$ ratio curves and $F r_{h}$.

The correlation allowance is applied to the correction of the vessel's frictional coefficient. The value varies depending on the ship length and, rarely, the displacement. According to Harvald (1983) this coefficient has been fixed at 0.0004. This variable is not applied in this study because only the model scale of the vessel is calculated.

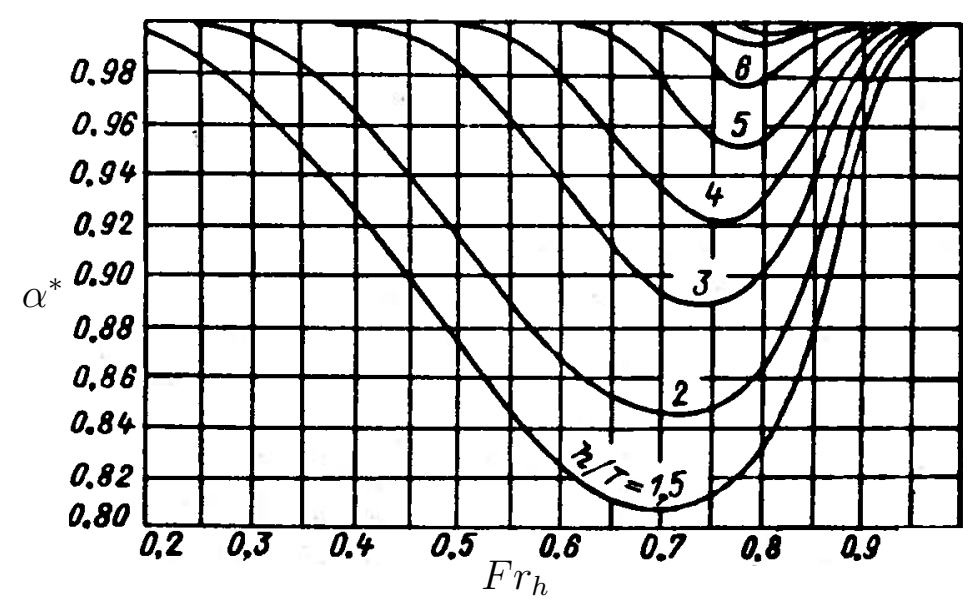

(a) $\alpha^{*}$

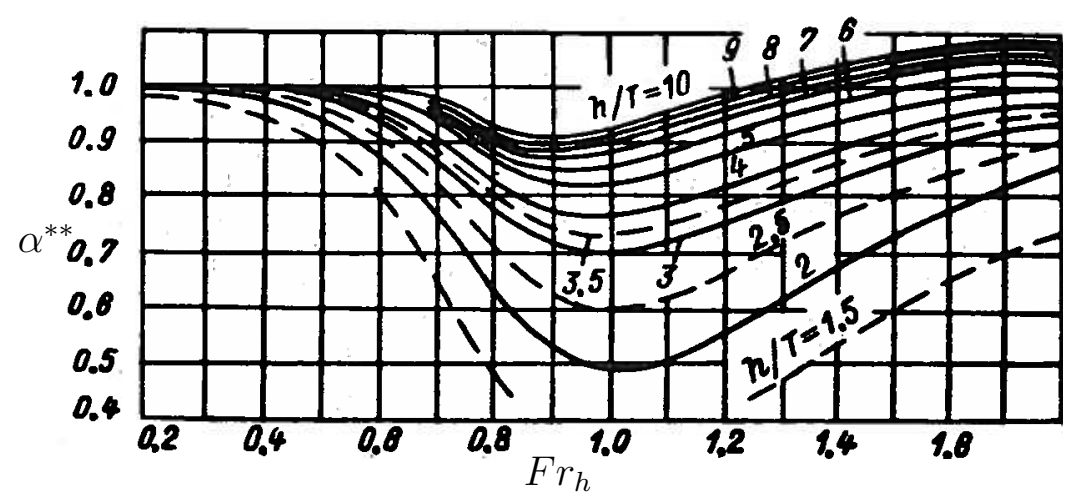

(b) $\alpha^{* *}$

Figure 3.17: Karpov's diagrams for the determination of the coefficients $\alpha^{*}$ and $\alpha^{* *}$. Source: Latorre, Luthra and Tang (1982).

Artjushkov (1968) improved the Karpov's analysis by including a correction for the width effect on the residuary resistance coefficient, this correction composed of two terms, the first, is the residuary resistance coefficient correction $\Delta C_{r}$; and second, the velocity ratio $v^{\prime} / v_{\infty}$. This terms are determined in the Tables 3.1 and 3.2. 
The total resistance in shallow waters determined by Karpov and Artjushkov is calculated as

$$
R_{t}\left(v_{\infty}\right)=\frac{1}{2} \rho S_{w s}\left\{\left[C_{f}+C_{a}\right] v_{1}^{2}+\left[C_{r}\left(\frac{v}{v^{\prime}}\right)^{2}+\Delta C_{r}\right] v_{2}^{2}\right\} .
$$

Finally, Georgakaki and Sorenson proposed the equations for the approximation of the variables $\alpha^{*}, \alpha^{* *}, \Delta C_{r}$ and $v^{\prime} / v_{\infty}$, and these are shown in the Table A.1. Also, they recommend limit the diagrams and the tables above within the parameters, i.e.,

$$
1.5 \leq \frac{h}{T} \leq 10.0, \quad F r_{h} \leq 0.6 \text { to } 0.7, \quad 0.04 \leq \frac{B}{B_{c}} \leq 0.30 .
$$

\begin{tabular}{r|ccccccc} 
& \multicolumn{7}{|c}{$B / B_{c}$} \\
\hline$h / T$ & 0.040 & 0.080 & 0.120 & 0.160 & 0.200 & 0.250 & 0.300 \\
\hline 1.500 & 0.040 & 0.097 & 0.161 & 0.247 & 0.348 & 0.482 & - \\
2.000 & 0.034 & 0.081 & 0.137 & 0.203 & 0.279 & 0.386 & 0.570 \\
2.500 & 0.028 & 0.067 & 0.112 & 0.162 & 0.218 & 0.300 & 0.418 \\
3.000 & 0.023 & 0.054 & 0.089 & 0.127 & 0.166 & 0.225 & 0.302 \\
3.500 & 0.018 & 0.041 & 0.068 & 0.096 & 0.125 & 0.168 & 0.223 \\
4.000 & 0.013 & 0.030 & 0.050 & 0.072 & 0.094 & 0.126 & 0.172 \\
5.000 & 0.008 & 0.016 & 0.028 & 0.042 & 0.057 & 0.082 & 0.115 \\
6.000 & 0.005 & 0.011 & 0.020 & 0.032 & 0.043 & 0.062 & 0.089 \\
8.000 & 0.003 & 0.007 & 0.011 & 0.019 & 0.028 & 0.045 & 0.066 \\
10.000 & 0.003 & 0.007 & 0.011 & 0.018 & 0.026 & 0.038 & 0.055 \\
\hline
\end{tabular}

Table 3.1: Residuary resistance coefficient corrections $\Delta C_{r}$ for different channels by Artjushkov. Source: Artjushkov (1968), Latorre, Luthra and Tang (1982).

\begin{tabular}{r|ccccccc} 
& \multicolumn{7}{|c}{$B / B_{c}$} \\
\hline$h / T$ & 0.040 & 0.080 & 0.120 & 0.106 & 0.200 & 0.250 & 0.300 \\
\hline 1.500 & 0.968 & 0.933 & 0.894 & 0.849 & 0.795 & 0.699 & - \\
2.000 & 0.978 & 0.950 & 0.921 & 0.886 & 0.843 & 0.780 & 0.685 \\
2.500 & 0.982 & 0.962 & 0.938 & 0.913 & 0.885 & 0.846 & 0.796 \\
3.000 & 0.986 & 0.970 & 0.952 & 0.934 & 0.915 & 0.889 & 0.859 \\
3.500 & 0.989 & 0.977 & 0.965 & 0.952 & 0.938 & 0.918 & 0.895 \\
4.000 & 0.992 & 0.983 & 0.974 & 0.946 & 0.953 & 0.937 & 0.916 \\
5.000 & 0.996 & 0.990 & 0.983 & 0.976 & 0.968 & 0.957 & 0.941 \\
6.000 & 0.997 & 0.993 & 0.989 & 0.983 & 0.977 & 0.967 & 0.954 \\
8.000 & 0.999 & 0.996 & 0.994 & 0.989 & 0.985 & 0.977 & 0.965 \\
10.000 & 0.999 & 0.996 & 0.994 & 0.990 & 0.987 & 0.980 & 0.971 \\
\hline
\end{tabular}

Table 3.2: Velocity relations $v^{\prime} / v_{\infty}$ for a model in different channels by Artjushkov. Source: Artjushkov (1968), Latorre, Luthra and Tang (1982). 


\subsection{Empirical procedure}

This chapter is summarized with a flowchart in two parts. In the Figure 3.18 shows the empirical part in case of inland vessel accomplish inside of the parameters represented in the equation (3.39). Otherwise, in the Figure 3.19 describes the Karpov's and Artjushkov's methods if the inland ship accomplish within the parameters, shown in the equation (3.43).

\subsection{Hypothesis}

The empirical methods for the calculation of the vessel's resistance, used in this paper, are based on models applicable to middle rivers for shallow water navigation. The hypotheses are numerated as follows:

- The inland vessel is self-propelled;

- The type of waterway is a middle river;

- There is a restriction of the river width. 


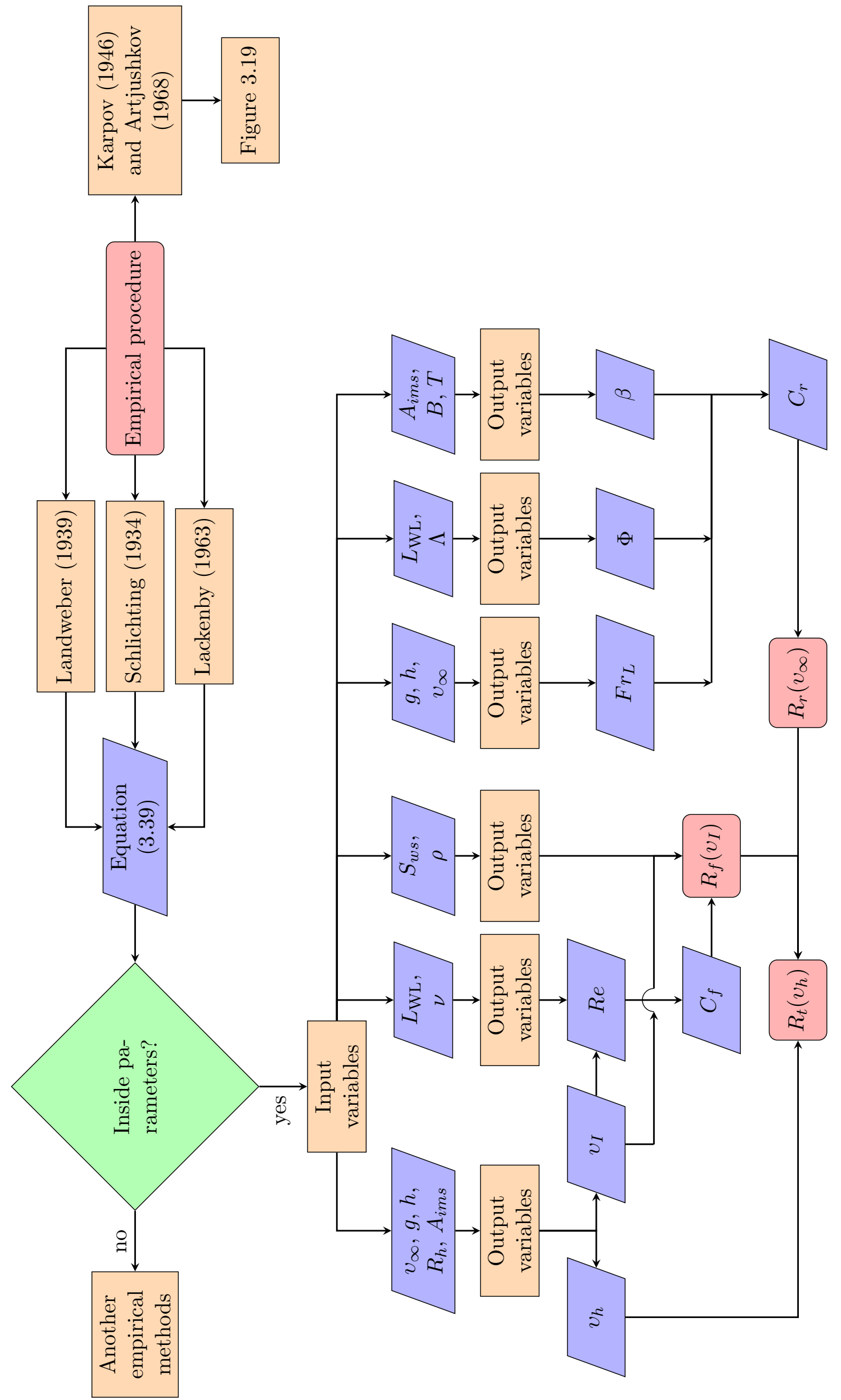

Figure 3.18: Empirical procedure (part 1). Source: Author. 


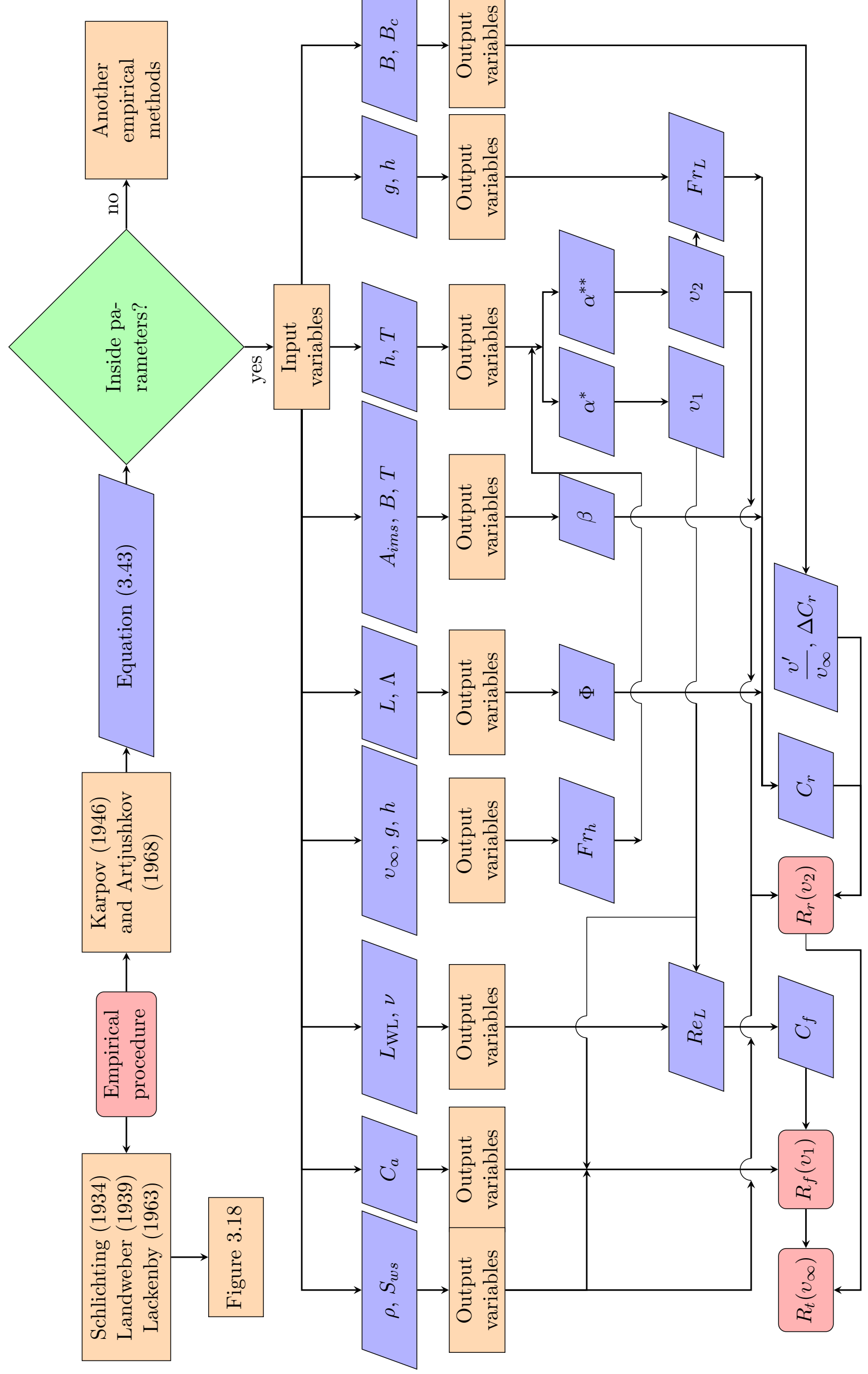

Figure 3.19: Empirical procedure (part 2). Source: Author. 


\section{NUMERICAL SIMULATION BY CFD}

This chapter provides a systematic review of the main fundamentals regarding the Computational Fluid Dynamics (CFD). For this purpose, the equations that govern the motions of the fluids are presented. First, the Navier-Stokes (NS) equation is used to obtain the Reynolds-Averaging Navier-Stokes (RANS) equation by means of Reynolds decomposition. The Realizable $k-\varepsilon$ turbulence model and the Finite Volume Method (FVM) are applied in order to simulate the turbulent flow and in order to calculate values at specific points/small areas in a cell or element of a mesh, respectively. For tracking and locating the free surface between air and water, the Volume of Fluid (VOF) method is used. Additionally, the implementation of the boundary conditions is explained.

\subsection{Hypotheses}

The computational methods, used in this paper, are based on the RANS equations in three dimensions applying the realizable $k-\varepsilon$ turbulence model. For the solution of the problem, the following hypotheses are adopted:

- The fluids (air and water) are incompressible and Newtonian;

- The flows are three-dimensional and non-stationary;

- The surface tension between air and water is ignored;

- The calculation of the inland vessel's sinkage and trim will not be applied.

\subsection{Conservation of mass}

Is the principle in which the mass of an object, set of objects or any closed system does not remains unchanged over time. Its equation is represented mathematically by the 
following equation

$$
\frac{\partial}{\partial t} \int_{V} \rho d V=-\int_{A} \rho \mathbf{u} \cdot \mathbf{n} d A
$$

where $A$ is the closed surface area that encloses a volume $V$ (fixed in the space), $\mathbf{u}$ is the flow velocity vector and $\mathbf{n}$ is the normal vector. The left term is the rate of change of mass and the right term is the net inflow of mass (BATCHELOR, 1967). The equation must be written as ${ }^{1}$,

$$
\int_{V}\left[\frac{\partial \rho}{\partial t}+\nabla \cdot(\rho \mathbf{u})\right] d V=0
$$

and the integrand is identically zero everywhere in the fluid. This relation is valid for any volume domain. Thus,

$$
\frac{\partial \rho}{\partial t}+\nabla \cdot(\rho \mathbf{u})=0
$$

where $\rho$ is the fluid density, $t$ is time and $\nabla \cdot$ is the divergence operator.

The equation above is called equation of continuity and is one of the fundamental equations of the fluid mechanics. In Cartesian coordinates, is expressed as

$$
\frac{\partial \rho}{\partial t}+\frac{\partial}{\partial x_{i}}\left(\rho u_{i}\right)=0, \quad i=1,2,3,
$$

where $x_{i}$ are components of Cartesian coordinates and $u_{i}$ are components of velocity vector. If the fluid is considered incompressible, the equation is reduced to a simpler condition

$$
\nabla \cdot \mathbf{u}=0
$$

in Cartesian coordinates,

$$
\frac{\partial u_{i}}{\partial x_{i}}=0
$$

\subsection{Conservation of momentum}

Is associated with Newton's second law where, in a closed system, the total momentum is constant. For fluids, where the material surface $S_{\text {mat }}$ encloses the volume, the momentum is estimated by

$$
\int_{V} \rho \mathbf{u} d V
$$

and its rate of change is

\footnotetext{
${ }^{1}$ Using the divergence theorem, the net inflow of mass is expressed by

$$
-\int_{A} \rho \mathbf{u} \cdot \mathbf{n} d A=-\int_{V} \nabla \cdot(\rho \mathbf{u}) d V
$$
}




$$
\begin{aligned}
\frac{d}{d t} \int_{V} \rho \mathbf{u} d V=\int_{V} \frac{D \mathbf{u}}{D t} \rho d V & =\int_{V} \rho F_{i} d V+\int_{S_{\mathrm{mat}}} \tau_{i j} n_{j} d S_{\mathrm{mat}} \\
& =\int_{V} \rho F_{i} d V+\int_{V} \frac{\partial \tau_{i j}}{\partial x_{j}} d V
\end{aligned}
$$

where $n_{j}$ are components of the normal vector to the surface. The integrand is identically zero everywhere in the fluid. Hence ${ }^{2}$

$$
\begin{aligned}
\rho \frac{D \mathbf{u}}{D t} & =\rho F_{i}+\frac{\partial \tau_{i j}}{\partial x_{j}}, \\
\frac{\partial}{\partial t}(\rho \mathbf{u})+\rho(\mathbf{u} \cdot \nabla \mathbf{u}) & =F_{b}+F_{s}
\end{aligned}
$$

where $F_{b}$ are the body forces, $F_{s}$ are the surface forces and $\nabla$ is the nabla operator.

The body forces are those that are applied to the entire mass of the fluid element, such as the gravity force. These forces are expressed as

$$
F_{b}=\rho F_{i}=\rho g
$$

where $F_{i}$ are components of the force vector and $g$ is the vector acceleration of gravity. The surface forces are those that act across the surface, shown in the Figure 4.1, and are given by

$$
F_{s}=\frac{\partial \tau_{i j}}{\partial x_{j}}=\nabla \cdot \tau_{i j},
$$

where $\tau_{i j}$ are components of the tensor stress.

Replacing the equations (4.11) and (4.12) into the equation (4.9), the Newton's second law for fluids now becomes (WHITE, 1991)

$$
\rho \frac{\partial \mathbf{u}}{\partial t}+\rho(\mathbf{u} \cdot \nabla \mathbf{u})=\rho g+\nabla \cdot \tau_{i j}
$$

in Cartesian coordinates,

$$
\frac{\partial}{\partial t}\left(\rho u_{i}\right)+\frac{\partial}{\partial x_{j}}\left(\rho u_{i} u_{j}\right)=\rho g+\frac{\partial \tau_{i j}}{\partial x_{j}} .
$$

\footnotetext{
${ }^{2}$ The left term is expressed in material derivative as

$$
\frac{D \mathbf{u}}{D t} \equiv \frac{\partial \mathbf{u}}{\partial t}+\mathbf{u} \cdot \nabla \mathbf{u}
$$
}




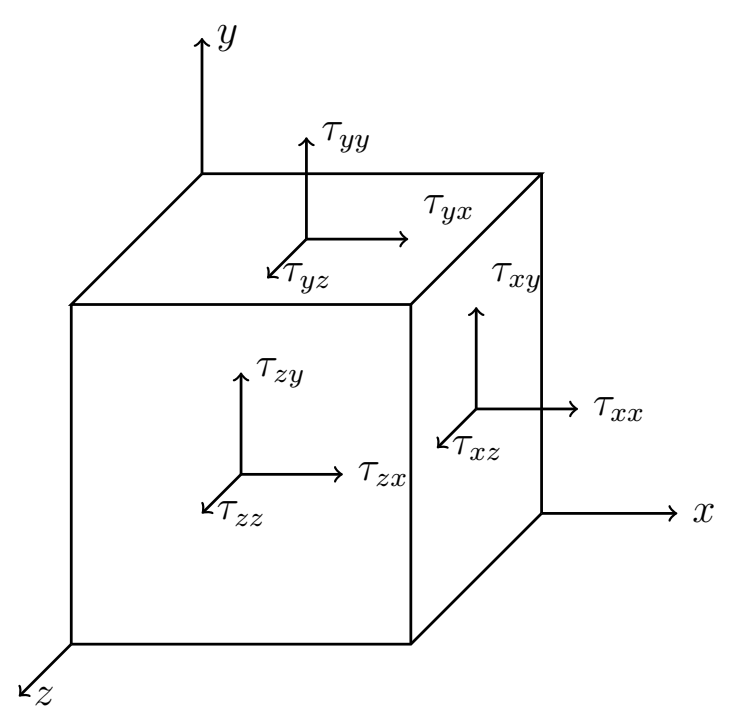

Figure 4.1: Notation for stresses. Source: White (1991).

\subsubsection{Newtonian fluid}

Newtonian fluids are characterized by a constant viscosity, independently of time and shear stresses (Encyclopædia Britannica, 2015b). Moreover, the shear and strain rates are linearly related in these cases. On the other hand, non-Newtonian fluids do not follow Newtonian's law of viscosity. As a matter of fact, their viscosity is dependent of shear rate and/or shear rate viscosity. In the Figure 4.2 shows the characteristics of $\tau$, described above, for Newtonian and non-Newtonian fluids.

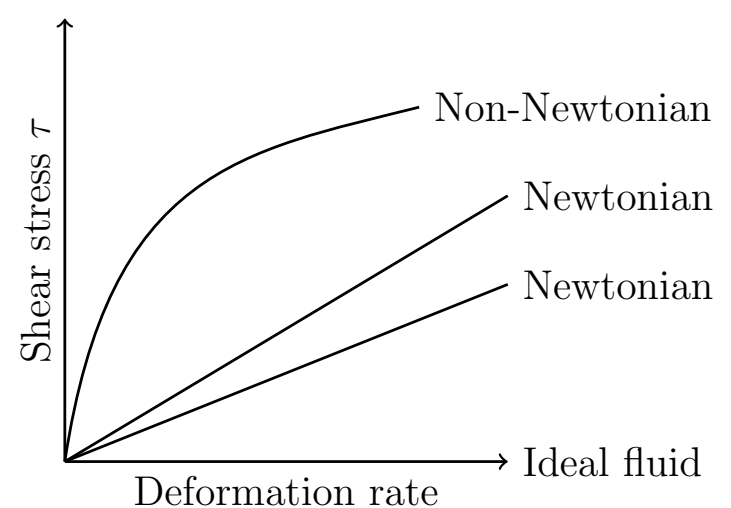

Figure 4.2: Behavior of shear stress for Newtonian and non-Newtonian fluids according to deformation rate. Source: Fortuna (2012).

Mathematically, Sir Isaac Newton proposes a simple relation

$$
\tau_{i j}=\mu \frac{d u_{i}}{d x_{j}} \quad \text { if } i \neq j,
$$

where $\mu$ is the dynamic (shear) viscosity of the fluid and $\frac{d u_{i}}{d x_{j}}$ is the velocity gradient 
perpendicular to the direction to the plane. This equation stands for an incompressible Newtonian fluid.

The constitutive relation of the shear stresses with the pressure $p$ and the viscous friction in Newtonian fluid, is prescribed $a^{3}$

$$
\tau_{i j}=-p \delta_{i j}+\mu\left[\nabla \mathbf{u}+(\nabla \mathbf{u})^{T}-\frac{2}{3} \delta_{i j}(\nabla \cdot \mathbf{u}) \mathbf{I}\right], \quad \text { if } i=j \quad \tau_{i i}=\sigma_{i i}
$$

in Cartesian coordinates

$$
\tau_{i j}=-p \delta_{i j}+\mu\left(\frac{\partial u_{i}}{\partial x_{j}}+\frac{\partial u_{j}}{\partial x_{i}}-\frac{2}{3} \delta_{i j} \frac{\partial u_{i}}{\partial x_{i}}\right), \quad \text { if } i=j \quad \tau_{i i}=\sigma_{i i}
$$

where $\delta_{i j}$ is the Kronecker delta, $\mathbf{I}$ is the identity matrix, and $\sigma_{i i}$ is the normal stress. The equation is the result of deformation law and it was introduced by Stokes $(1845)^{4}$.

\subsubsection{The Navier-Stokes equation}

The Navier-Stokes (NS) equation is a partial differential equation that describes the motion of the viscous fluid. Euler was the first to describe the ideal equation for incompressible and frictionless fluids. His works was devised in 17th century and published in 1755. Navier (1822) introduced the friction (element viscosity) for more realistic problems of viscous fluids. Stokes (1845) improved on this work although the complete solutions were obtained only for the case of simple two-dimensional flows (Encyclopædia Britannica, $2015 \mathrm{e})$.

Substituting the equation (4.16) into the equation (4.13),

$$
\rho \frac{\partial \mathbf{u}}{\partial t}+\rho(\mathbf{u} \cdot \nabla \mathbf{u})=\rho g-\nabla p+\nabla \cdot\left\{\mu\left[\nabla \mathbf{u}+(\nabla \mathbf{u})^{T}-\frac{2}{3} \delta_{i j}(\nabla \cdot \mathbf{u}) \mathbf{I}\right]\right\} .
$$

The equation (4.18) is simplified by means of balancing the pressure gradient $\nabla p^{*}$ and gravitational forces $g$ (STULL, 2000; FIELDING, 2005). Defining

$$
\nabla p^{*}=\nabla p-\nabla p_{0}, \quad \frac{1}{\rho} \nabla p_{0}=g,
$$

the following is obtained by

$$
\rho \frac{\partial \mathbf{u}}{\partial t}+\rho(\mathbf{u} \cdot \nabla \mathbf{u})=-\nabla p^{*}+\nabla \cdot\left\{\mu\left[\nabla \mathbf{u}+(\nabla \mathbf{u})^{T}-\frac{2}{3} \delta_{i j}(\nabla \cdot \mathbf{u}) \mathbf{I}\right]\right\}
$$

\footnotetext{
${ }^{3}$ Only in this case, $T$ is the transpose.

${ }^{4}$ For more details about the constitutive relation, see Deformation Law for a Newtonian Fluid in White (1991), pp. 65-68.
} 
in Cartesian coordinates,

$$
\frac{\partial}{\partial t}\left(\rho u_{i}\right)+\frac{\partial}{\partial x_{j}}\left(\rho u_{i} u_{j}\right)=-\frac{\partial p^{*}}{\partial x_{i}}+\frac{\partial}{\partial x_{j}}\left[\mu\left(\frac{\partial u_{i}}{\partial x_{j}}+\frac{\partial u_{j}}{\partial x_{i}}-\frac{2}{3} \delta_{i j} \frac{\partial u_{i}}{\partial x_{i}}\right)\right] .
$$

If the fluid is incompressible, the equation is reduced in simple terms,

$$
\rho \frac{\partial \mathbf{u}}{\partial t}+\rho(\mathbf{u} \cdot \nabla \mathbf{u})=-\nabla p^{*}+\mu \nabla^{2} \mathbf{u}
$$

in Cartesian coordinates,

$$
\frac{\partial}{\partial t}\left(\rho u_{i}\right)+\frac{\partial}{\partial x_{j}}\left(\rho u_{i} u_{j}\right)=-\frac{\partial p^{*}}{\partial x_{i}}+\mu\left(\frac{\partial^{2} u_{i}}{\partial x_{i}^{2}}\right),
$$

where $\nabla^{2}$ is the Laplace operator.

\subsection{Reynolds-Averaging}

In Reynolds averaging or Reynolds decomposition, introduced in 1895, a quantity is decomposed into a mean (ensemble-averaged or time-averaged) and a fluctuating parts. Consider a stationary turbulent flow. For the velocity components is decomposed by

$$
u_{i}(\mathbf{x}, t)=U_{i}(\mathbf{x})+u_{i}^{\prime}(\mathbf{x}, t)
$$

where $U_{i}(\mathbf{x})$ is the mean velocity, $u_{i}^{\prime}(\mathbf{x}, t)$ is the fluctuating velocity and $\mathbf{x}$ is the position vector in vector notation.

The mean velocity is defined by

$$
U_{i}(\mathbf{x})=\lim _{T_{s} \rightarrow \infty} \frac{1}{T_{s}} \int_{t}^{t+T_{s}} u_{i}(\mathbf{x}, t) d t
$$

where $T_{s}$ is a long time to relevant period of the fluctuations in $u_{i}$. The equation (4.25) is again the same time-averaged value,

$$
\overline{U_{i}}(\mathbf{x})=\lim _{T_{s} \rightarrow \infty} \frac{1}{T_{s}} \int_{t}^{t+T_{s}} U_{i}(\mathbf{x}) d t=U_{i}(\mathbf{x}),
$$

where an overbar is shorthand for the time average. The time-averaging of the fluctuating velocity is

$$
\overline{u_{i}^{\prime}}(\mathbf{x})=\lim _{T_{s} \rightarrow \infty} \frac{1}{T_{s}} \int_{t}^{t+T_{s}}\left[u_{i}(\mathbf{x}, t)-U_{i}(\mathbf{x})\right] d t=U_{i}(\mathbf{x})-\overline{U_{i}}(\mathbf{x})=0 .
$$

This behavior is illustrated in the Figure 4.3 (WILCOX, 1998). 


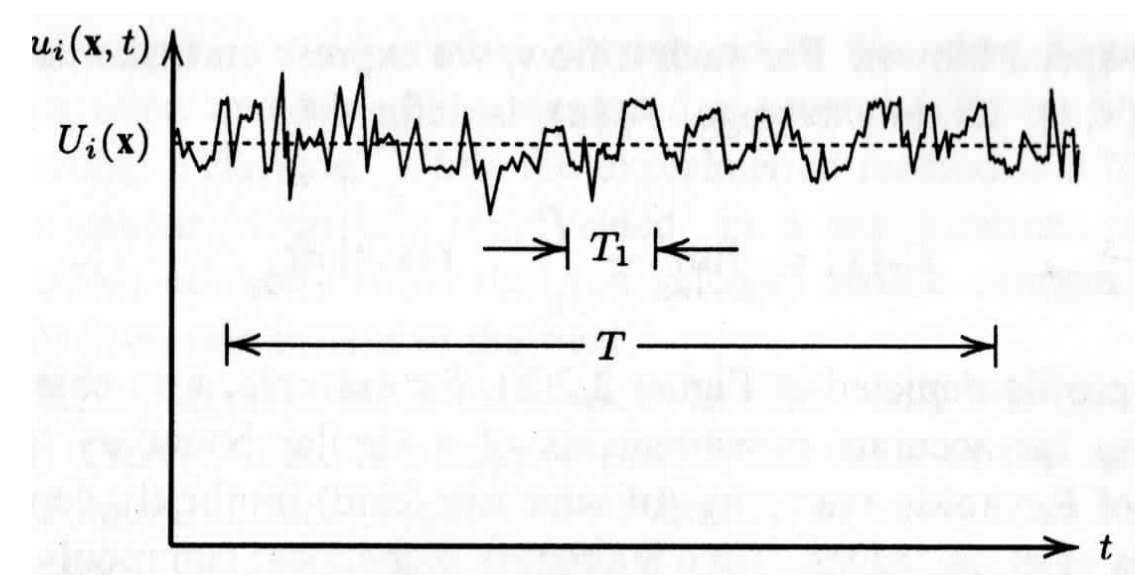

Figure 4.3: Time-averaging for stationary turbulence. Source: Wilcox (1998).

\subsection{Reynolds-Averaged Navier-Stokes equation}

Aiming at the description of the turbulent flow motions, the Reynolds decomposition is introduced to be applied in the NS equation. First, the velocity components and the pressure are time-averaged,

$$
u_{i}=U_{i}+u_{i}^{\prime}, \quad u_{j}=U_{j}+u_{j}^{\prime}, \quad p^{*}=P+p^{\prime},
$$

and are replaced in the equation (4.21), expressed by

$$
\begin{aligned}
& \frac{\partial}{\partial t}\left[\rho\left(U_{i}+u_{i}^{\prime}\right)\right]+\frac{\partial}{\partial x_{j}}\left[\rho\left(U_{i}+u_{i}^{\prime}\right)\left(U_{j}+u_{j}^{\prime}\right)\right]= \\
& -\frac{\partial}{\partial x_{j}}\left(P+p^{\prime}\right)+\frac{\partial}{\partial x_{j}}\left\{\mu\left[\frac{\partial}{\partial x_{j}}\left(U_{i}+u_{i}^{\prime}\right)+\frac{\partial}{\partial x_{i}}\left(U_{j}+u_{j}^{\prime}\right)-\frac{2}{3} \delta_{i j} \frac{\partial}{\partial x_{i}}\left(U_{i}+u_{i}^{\prime}\right)\right]\right\}
\end{aligned}
$$

Time-averaging again the NS equation

$$
\begin{aligned}
& \frac{\partial}{\partial t}\left[\rho \overline{\left(U_{i}+u_{i}^{\prime}\right)}\right]+\frac{\partial}{\partial x_{j}}\left[\rho \overline{\left(U_{i}+u_{i}^{\prime}\right)\left(U_{j}+u_{j}^{\prime}\right)}\right]= \\
& -\frac{\partial}{\partial x_{j}} \overline{\left(P+p^{\prime}\right)}+\frac{\partial}{\partial x_{j}}\left\{\mu\left[\frac{\partial}{\partial x_{j}} \overline{\left(U_{i}+u_{i}^{\prime}\right)}+\frac{\partial}{\partial x_{i}} \overline{\left(U_{j}+u_{j}^{\prime}\right)}-\frac{2}{3} \delta_{i j} \frac{\partial}{\partial x_{i}} \overline{\left(U_{i}+u_{i}^{\prime}\right)}\right]\right\} .
\end{aligned}
$$

In the previous section it was explained that the fluctuating quantity with overbar is equal to zero. The following rules of averaging are determined by

$$
\begin{aligned}
\overline{U_{i}+u_{i}^{\prime}} & =\overline{U_{i}}+\overline{u_{i}^{\prime}}, \\
\overline{P+p^{\prime}} & =\bar{P}+\overline{p^{\prime}}, \\
\overline{U_{i} u_{i}^{\prime}} & =0, \\
\overline{u_{i} u_{j}} & =\overline{\left(U_{i}+u_{i}^{\prime}\right)\left(U_{j}+u_{j}^{\prime}\right)}=U_{i} U_{j}+\overline{u_{i}^{\prime} u_{j}^{\prime}},
\end{aligned}
$$


and are applied in the equation (4.30). Hence,

$$
\frac{\partial}{\partial t}\left(\rho U_{i}\right)+\frac{\partial}{\partial x_{j}}\left(\rho U_{i} U_{j}\right)=-\frac{\partial P}{\partial x_{j}}+\frac{\partial}{\partial x_{j}}\left[\mu\left(\frac{\partial U_{i}}{\partial x_{j}}+\frac{\partial U_{j}}{\partial x_{i}}-\frac{2}{3} \delta_{i j} \frac{\partial U_{i}}{\partial x_{i}}\right)\right]+\frac{\partial}{\partial x_{j}}\left(-\rho \overline{u_{i}^{\prime} u_{j}^{\prime}}\right) .
$$

The equation is usually referred to as the Reynolds-Averaged Navier-Stokes equation (RANS or RANSE).

The term $-\rho \overline{u_{i}^{\prime} u_{j}^{\prime}}$ is the Reynolds stress tensor and must be modeled. The Boussinesq hypothesis is the method employed to relate the Reynolds stresses to the mean velocity gradients,

$$
-\rho \overline{u_{i}^{\prime} u_{j}^{\prime}}=\mu_{t}\left(\frac{\partial U_{i}}{\partial x_{j}}+\frac{\partial U_{j}}{\partial x_{i}}\right)-\frac{2}{3}\left(\rho k+\mu_{t} \frac{\partial U_{i}}{\partial x_{i}}\right) \delta_{i j},
$$

where $\mu_{t}$ is the dynamic turbulent viscosity and $k$ is the Turbulent Kinetic Energy (TKE).

The equation (4.36) is replaced in the equation (4.35) which, finally, is expressed by

$$
\frac{\partial}{\partial t}\left(\rho U_{i}\right)+\frac{\partial}{\partial x_{j}}\left(\rho U_{i} U_{j}\right)=-\frac{\partial P}{\partial x_{j}}+\frac{\partial}{\partial x_{j}}\left[\left(\mu+\mu_{t}\right)\left(\frac{\partial U_{i}}{\partial x_{j}}+\frac{\partial U_{j}}{\partial x_{i}}-\frac{2}{3} \delta_{i j} \frac{\partial U_{i}}{\partial x_{i}}\right)\right]-\frac{2}{3} \frac{\partial}{\partial x_{j}}(\rho k) .
$$

\subsection{Turbulence modeling}

There are several approaches that allow the estimation of these effects. SpalartAllmaras, $k-\varepsilon$ and $k-\omega$ are common models that employ the Boussinesq hypothesis. In this study, the realizable $k-\varepsilon$ turbulence model is adopted.

\subsubsection{Realizable $k-\varepsilon$ model}

Is a two-equation turbulence model widely adopted. Initially is developed by Launder and Spalding (1972) in standard form and is based on the model transport equations for TKE and the dissipation rate $\varepsilon$. Later, Yakhot et al. (1992) refined this model (called RNG $k-\varepsilon$ ). Finally, this model was improved by Shih et al. (1995), called Realizable $k-\varepsilon$, and is described by

$$
\begin{aligned}
& \frac{\partial}{\partial t}(\rho k)+\frac{\partial}{\partial x_{j}}\left(\rho k U_{j}\right)=\frac{\partial}{\partial x_{j}}\left[\left(\mu+\frac{\mu_{t}}{\sigma_{k}}\right) \frac{\partial k}{\partial x_{j}}\right]+P_{k}+P_{b}-\rho \varepsilon-Y_{M}+S_{k}, \\
& \frac{\partial}{\partial t}(\rho \varepsilon)+\frac{\partial}{\partial x_{j}}\left(\rho \varepsilon U_{j}\right)=\frac{\partial}{\partial x_{j}}\left[\left(\mu+\frac{\mu_{t}}{\sigma_{\varepsilon}}\right) \frac{\partial \varepsilon}{\partial x_{j}}\right]+\rho C_{1} S \varepsilon-\rho C_{2} \frac{\varepsilon^{2}}{k+\sqrt{\nu \epsilon}}+C_{1 \varepsilon} \frac{\varepsilon}{k} C_{3 \varepsilon} P_{b}+S_{\varepsilon}
\end{aligned}
$$


where

$$
C_{1}=\max \left[0.43, \frac{\eta}{\eta+5}\right], \quad \eta=S_{1} \frac{k}{\varepsilon}, \quad S_{1}=\sqrt{2 S_{i j} S_{i j}} .
$$

$P_{k}$ represents the generation of TKE due to the mean velocity gradients, $Y_{M}$ represents the contribution of the fluctuating dilatation in compressible turbulence to the overall dissipation rate, $S_{k}$ and $S_{\varepsilon}$ are user-defined source terms. $P_{k}$ and $\mu_{t}$ are given by

$$
\begin{aligned}
& \mu_{t}=\rho C_{\mu} \frac{k^{2}}{\varepsilon}, \\
& P_{k}=-\rho \overline{u_{i}^{\prime} u_{j}^{\prime}} \frac{\partial U_{j}}{\partial x_{i}} .
\end{aligned}
$$

The physic interpretation of $C_{\mu}, Y_{M}$ and the constant $C_{3 \varepsilon}$ are given in Shih et al. (1995) and ANSYS (2017). The model constants $C_{1 \varepsilon}, C_{2}, \sigma_{k}$ and $\sigma_{\varepsilon}$ have the following default values: $C_{1 \varepsilon}=1.44, C_{2}=1.9, \sigma_{k}=1.0$ and $\sigma_{\varepsilon}=1.2$.

\subsection{Volume of Fluid method}

The Volume of Fluid (VOF) is a method that can model immiscible ${ }^{5}$ fluids for tracking and locating the free surface. Initially, the method was developed by Noh and Woodward (1976) and later by Hirt and Nichols (1981).

In the Figure 4.4a shows an example of a interface between two fluids with an actual shape and the Figure 4.4b is illustrated an approximation to the reconstruction of interface of the fluids in a grid mesh of a computational domain. Each cell indicates the fill rate of a fluid (material 1). The volume fraction of a fluid $q$ is denoted by $\alpha_{q}$ and is defined as

$$
\alpha_{q}=\frac{V_{q}}{V}
$$

where $V_{q}$ is the volume of a fluid in the cell and $V$ is the volume of the cell. The volume fractions of two fluids in a cell must sum up to one

$$
\sum_{q=1}^{N_{\text {fluids }}} \alpha_{q}=1
$$

where $N_{\text {fluids }}$ is the total number of fluids.

For each cell of the volume fraction follows three conditions:

- $\alpha_{q}=0$, the cell is empty (of the $q^{\text {th }}$ fluid);

\footnotetext{
${ }^{5}$ Incapable of mixing or attaining homogeneity (Merriam-Webster, 2004).
} 


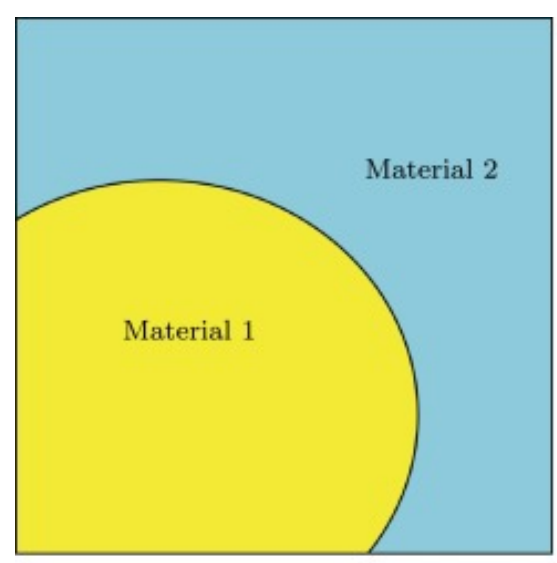

(a)

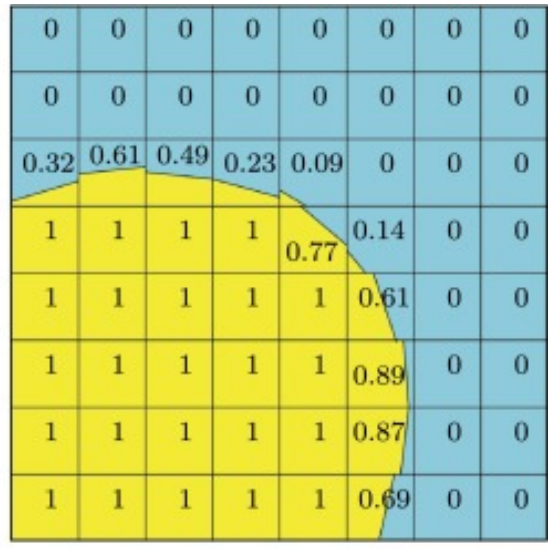

(b)

Figure 4.4: An example of VOF method, where shows the interface between two fluids (a) and is the approximation of the fluid interface in a grid mesh of a computational domain (b). Source: Pathak and Raessi (2016).

- $\alpha_{q}=1$, the cell is full (of the $q^{\text {th }}$ fluid);

- $0<\alpha_{q}<1$ The cell contains the interface between the $q^{\text {th }}$ fluid and the other fluid.

The density and viscosity applying VOF method for each cell can be computed as

$$
\begin{aligned}
& \rho=\sum_{q=1}^{2} \alpha_{q} \rho_{q} \\
& \mu=\sum_{q=1}^{2} \alpha_{q} \mu_{q}
\end{aligned}
$$

\subsection{Implementation of boundary conditions}

Generally, all CFD problems define initial boundary conditions of a computational domain (Figure 4.5). The most common boundary conditions are: inlet, outlet, wall, and symmetry (VERSTEEG; MALALASEKERA, 2007).

\subsubsection{Inlet boundary condition}

The total pressure at inlet boundary conditions is given by

$$
p_{\text {in }}=\frac{1}{2} \mathbf{U}_{\text {in }}^{2}+\left(\rho-\rho_{0}\right)|\vec{g}|[\widehat{g} \cdot(\mathbf{b}-\mathbf{a})]
$$

where $\mathbf{a}$ is any point on the free surface and $\mathbf{b}$ is the position vectors in the center of the surface of an element, $\mathbf{U}_{\text {in }}^{2}$ is a mean velocity vector at inlet boundary condition, $|\vec{g}|$ is 


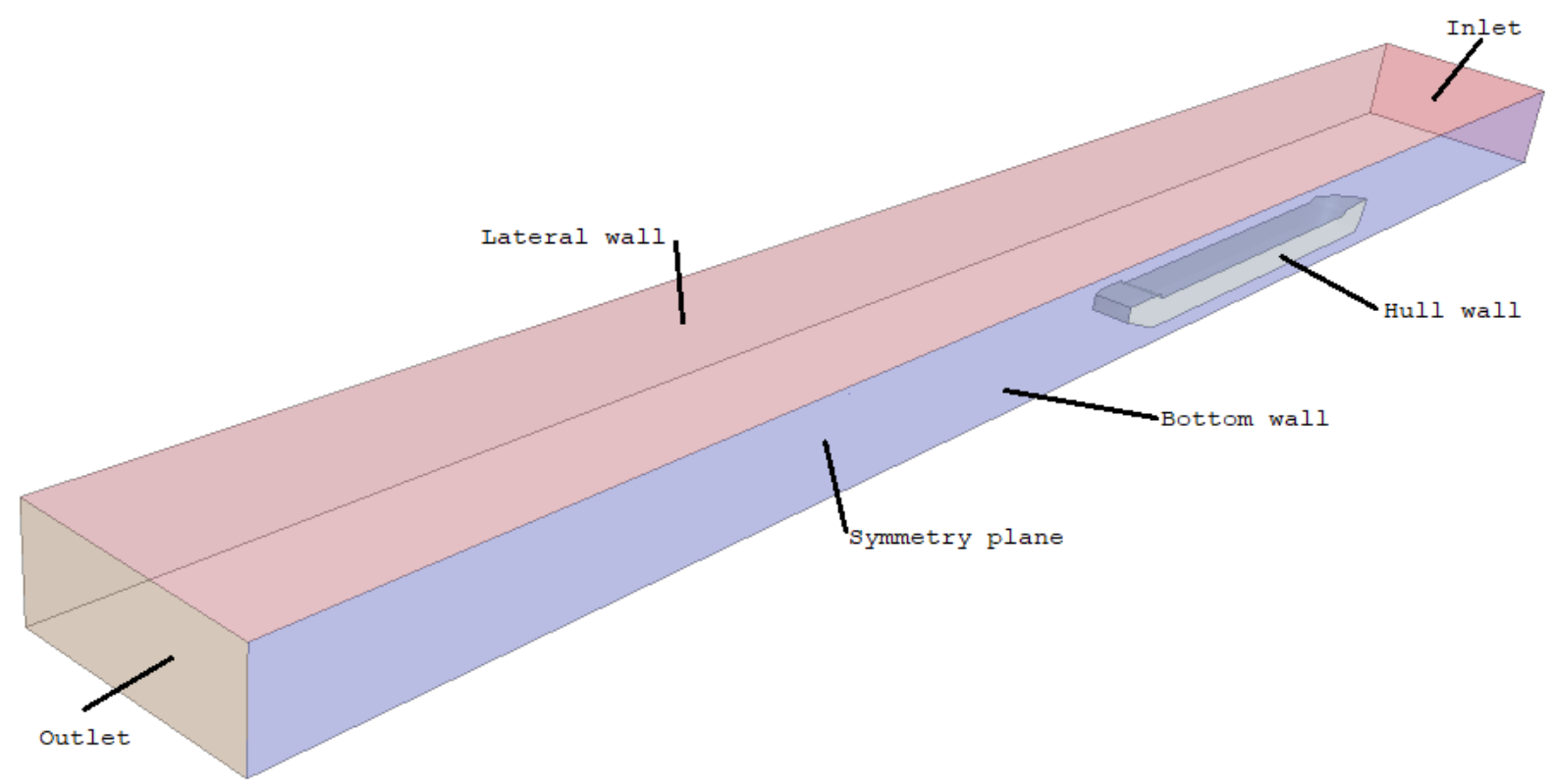

Figure 4.5: Boundary domain to imposes the boundary conditions in a control-volume. Source: Author.

the gravity magnitude, $\widehat{g}$ is the unity vector of gravity, and $\rho_{0}$ is the reference density.

The approximation of the TKE and $\varepsilon$ at inlet are represented by (VERSTEEG; MALALASEKERA, 2007; ANSYS, 2017)

$$
\begin{aligned}
k_{\text {in }} & =\frac{3}{2}\left(\mathbf{U}_{\text {in }} I\right)^{2}, \\
\varepsilon_{\text {in }} & =C_{\mu} \frac{\rho k^{2}}{\mu}\left(\frac{\mu_{t}}{\mu}\right)^{-1},
\end{aligned}
$$

where $C_{\mu}$ is an empirical constant specified in the turbulence model (determined in the section 4.6). $I$ is the turbulence intensity, defined as the ratio of the velocity fluctuations $u_{i}^{\prime}$ to the mean flow velocity $U_{i}$, represented by

$$
I \equiv \frac{u_{i}^{\prime}}{U_{i}}
$$

The turbulent viscosity ratio $\frac{\mu_{t}}{\mu}$ is directly proportional to the turbulent Reynolds number

$$
R e_{t} \equiv \frac{k^{2}}{\varepsilon \nu}
$$

and the turbulence parameters are: $1<\frac{\mu_{t}}{\mu}<10$. 


\subsubsection{Outlet boundary condition}

The pressure at outlet boundary condition is taken equal to the static or atmospheric pressure

$$
p_{\text {out }}=\left(\rho-\rho_{0}\right)|\vec{g}|(\widehat{g} \cdot(\mathbf{b}-\mathbf{a})) .
$$

The flow often reaches a fully developed state in the flow direction if the outlet of the computational domain is chosen far from geometric disturbance. Thus, we can put an exit surface assuming the gradients of all variables are equal to zero in the flow direction (LAUNDER; SPALDING, 1972; VERSTEEG; MALALASEKERA, 2007; DEWAN, 2011; JI, 2013). Thus,

$$
\frac{\partial U_{\text {out }}}{\partial n}=0, \quad \frac{\partial k_{\text {out }}}{\partial n}=0, \quad \frac{\partial \varepsilon_{\text {out }}}{\partial n}=0
$$

where $U_{\text {out }}, k_{\text {out }}$ and $\varepsilon_{\text {out }}$ are variables at outlet flow and $n$ is the normal vector of the surface.

\subsubsection{Wall boundary condition}

The region near to the wall can be modeled by means of the near-wall treatment. This approach does not include the wall, where the no-slip condition is adopted, which can lead to unsatisfactory results for the $k-\varepsilon$ turbulence model.

The no-slip condition implies that the velocity components and the gradients of the pressure, TKE and $\varepsilon$ are equal to zero

$$
U_{\text {wall }} \cdot \mathbf{n}=0, \quad \frac{\partial P_{\text {wall }}}{\partial \mathbf{n}}=0, \quad \frac{\partial k_{\text {wall }}}{\partial \mathbf{n}}=0,
$$

where $\mathbf{n}$ is the local coordinate normal to the wall. Also, the velocity fluctuation $u_{i}^{\prime}$ is zero. Thus, the value of TKE can be computed as (DURBIN; Pettersson Rief, 2011; JI, 2013)

$$
k_{\text {wall }}=\frac{1}{2} \overline{\left|u_{i}^{\prime}\right|^{2}}=0
$$

The adoption of the $k-\varepsilon$ turbulence model closes to the wall at High Reynolds Number (HRN). The law-of-the-wall for mean velocity and TKE on standard wall functions yields

$$
\begin{aligned}
& u_{Q}^{+}=\frac{U_{Q}}{u_{\tau}}=\frac{1}{\kappa} \ln \left(E y_{Q}^{+}\right) \\
& k_{Q}=\frac{u_{\tau}^{2}}{\sqrt{C_{\mu}}}
\end{aligned}
$$


where $u_{Q}^{+}$is the dimensionless velocity, $y_{Q}^{+}$is the dimensionless distance from the wall (for $30<y_{Q}^{+}<500$, it satisfies the equation in the logarithmic region), $E$ is the empirical constant (wall roughness parameter), equivalent to 9.793 for smooth walls, $\kappa$ is the von Kármán constant (equal to 0.4187), $U_{Q}$ is the mean velocity of the fluid at the walladjacent cell centroid $Q, y_{Q}$ is the distance from the centroid of the wall-adjacent cell to the wall $\mathbf{B}$ (Figure 4.6) and $u_{\tau}$ is the friction or shear velocity, represented as

$$
u_{\tau}=\sqrt{\frac{\tau_{\mathrm{wall}}}{\rho}}
$$

where $\tau_{\text {wall }}$ is the shear stress at the wall.
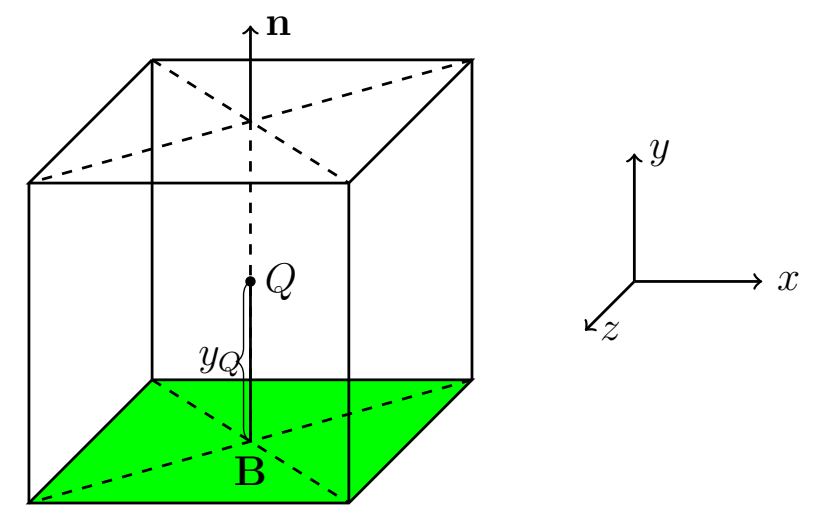

Figure 4.6: Calculation of distance $y_{Q}$ between node $Q$ and the surface on the wall $\mathbf{B}$. Source: Ji (2013).

For $k-\varepsilon$ model, the wall function developed by Launder and Spalding (1974) is different. In order to avoid confusion in the nomenclature, the equation (4.56) according to $y_{Q}^{+}$ for $k-\varepsilon$ model and its variables are represented by

$$
\begin{aligned}
& u_{Q}^{*}=\frac{1}{\kappa} \ln \left(E y_{Q}^{*}\right) \\
& y_{Q}^{*}=\frac{C_{\mu}^{\frac{1}{4}} \sqrt{k_{Q}}}{\nu}
\end{aligned}
$$

where $\nu$ is the kinematic viscosity of the fluid. The equations (4.56) and (4.59) (that correspond to the logarithm-law) are adopted when $\log y_{Q}^{+}$and $\log y_{Q}^{*}$ present values larger that 11.225. Otherwise, the relationships between $u_{Q}^{+}$and $y_{Q}^{+}\left(\right.$also $u_{Q}^{*}$ and $y_{Q}^{*}$ ) are expressed by

$$
u_{Q}^{+}=y_{Q}^{+} \quad u_{Q}^{*}=y_{Q}^{*}
$$

as illustrated in the Figure 4.7, where the plot is divided in three sub-regions: viscous sub-layer $(y+<5)$, buffer layer $(y+<30)$, and log-law layer $(30 \leq y+\leq 500)$. 


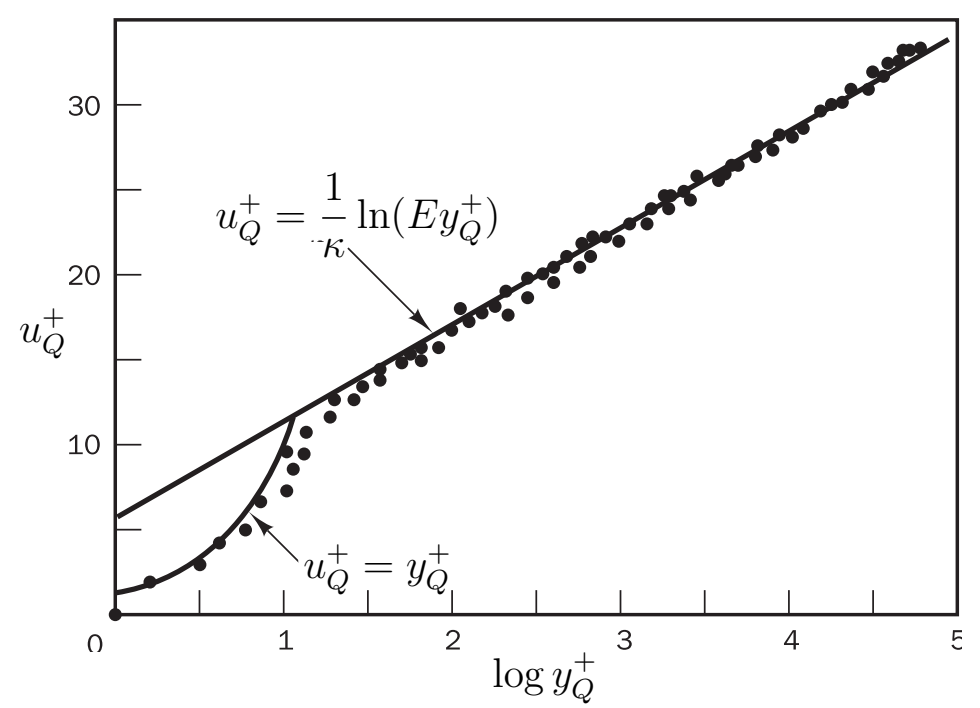

Figure 4.7: Velocity distribution near a solid wall. Source: Schlichting (1979); Versteeg and Malalasekera (2007).

The production of the kinetic energy $P_{k}$ and the dissipation rate $\varepsilon$ at the wall-adjacent cells are

$$
\begin{aligned}
P_{k} & \approx \tau_{\text {wall }} \frac{\partial U}{\partial y}=\tau_{\text {wall }} \frac{\tau_{\text {wall }}}{\kappa \rho C_{\mu}^{\frac{1}{4}} k_{Q}^{\frac{1}{2}} y_{Q}}, \\
\varepsilon_{Q} & =\frac{C_{\mu}^{\frac{3}{4}} k_{Q}^{\frac{3}{2}}}{\kappa y_{Q}}
\end{aligned}
$$

where $\tau_{\text {wall }}$ is the shear stress in the wall, formulated as

$$
\tau_{\text {wall }}=\mu \frac{U_{Q}}{y_{Q}} .
$$

At Low Reynolds Number (LRN), the equation (4.56) is not valid for $\log y_{Q}^{+}<11.225$ or $y_{Q}^{+}<30$, and the equations above mentioned for the wall boundary conditions cannot be used (VERSTEEG; MALALASEKERA, 2007).

\subsubsection{Symmetry boundary condition}

At this boundary condition, the gradients of all flow properties normal to the symmetry plane are taken equal to zero (DEWAN, 2011), i.e.,

$$
\frac{\partial \mathbf{U}_{\mathrm{sym}}}{\partial \mathbf{n}}=0, \quad \frac{\partial k_{\mathrm{sym}}}{\partial \mathbf{n}}=0, \quad \frac{\partial \varepsilon_{\mathrm{sym}}}{\partial \mathbf{n}}=0,
$$

where $\mathbf{U}_{\text {sym }}, k_{\text {sym }}$ and $\varepsilon_{\text {sym }}$ are variables located at symmetry plane. 


\subsection{Finite Volume Method}

The Finite Volume ${ }^{6}$ Method (FVM) is a numerical method of discretization ${ }^{7}$ that allows solve partial differential equations (PDE) applied to conservation laws. Is similar to the Finite Element Method (FEM) or the Finite Difference Method (FDM) and uses integral formulations of conservation laws and does not require a structured grid mesh.

Consider the unsteady conservation equation for transport of a fluid property $\varphi$ in a cell volume $V$ as follows ${ }^{8}$ (VERSTEEG; MALALASEKERA, 2007; CD-adapco, 2014)

$$
\int_{V} \frac{\partial}{\partial t}(\rho \varphi) d V+\oint \rho \varphi \mathbf{u} \cdot d \mathbf{A}=\oint \Gamma_{\varphi} \nabla \varphi \cdot d \mathbf{A}+\int_{V} S_{\varphi} d V
$$

where $\mathbf{u}$ is the velocity vector, $\mathbf{A}$ is the surface area vector, $\Gamma_{\varphi}$ is the diffusion coefficient for $\varphi, \nabla \varphi$ is the gradient of $\varphi$ and $S_{\varphi}$ is the source of $\varphi$ per unit volume. A practical interpretation of the equation (4.66) is provided in words (CD-adapco, 2014),

- The first term is time rate of change of fluid property $\varphi$ inside the cell (transient term);

- The second term is the net rate of decrease of fluid property $\varphi$ across the cell boundaries due to convection (convection term);

- The third term is the net rate of increase of fluid property $\varphi$ across the cell boundaries due to diffusion (diffusion term);

- The fourth term is the generation/destruction of fluid property $\varphi$ inside the cell (source term).

The Figures 4.8 and 4.9 show the position of the variables in each cell in a structured mesh in 2D. The pressure acts on the center $p$ for each cell and the components of the velocities $u_{i, j}$ are evaluated in the center of the faces. The nomenclature is: $\mathrm{O}$ is the center of the cell; N, S, E, W are the center of the coordinates adjacent at north, south, east and west; n, s, e, w are points of the north, south, east and west center faces of the cell respectively.

\footnotetext{
${ }^{6}$ Finite volume refers to the element, cell or volume-control of a grid mesh.

${ }^{7}$ Set of small elements or cells.

${ }^{8}$ The second and third term (convection and diffusion) is rewritten as

$$
\begin{gathered}
\oint \rho \varphi \mathbf{u} \cdot d \mathbf{A}=\int_{V} \nabla \cdot(\rho \varphi \mathbf{u}) d V=\int_{\mathbf{A}} \mathbf{n} \cdot(\rho \varphi \mathbf{u}) d \mathbf{A}, \\
\oint \Gamma_{\varphi} \nabla \varphi \cdot d \mathbf{A}=\int_{V} \nabla \cdot\left(\Gamma_{\varphi} \nabla \varphi\right) d V=\int_{\mathbf{A}} \mathbf{n} \cdot\left(\Gamma_{\varphi} \cdot \varphi\right) d \mathbf{A} .
\end{gathered}
$$
}




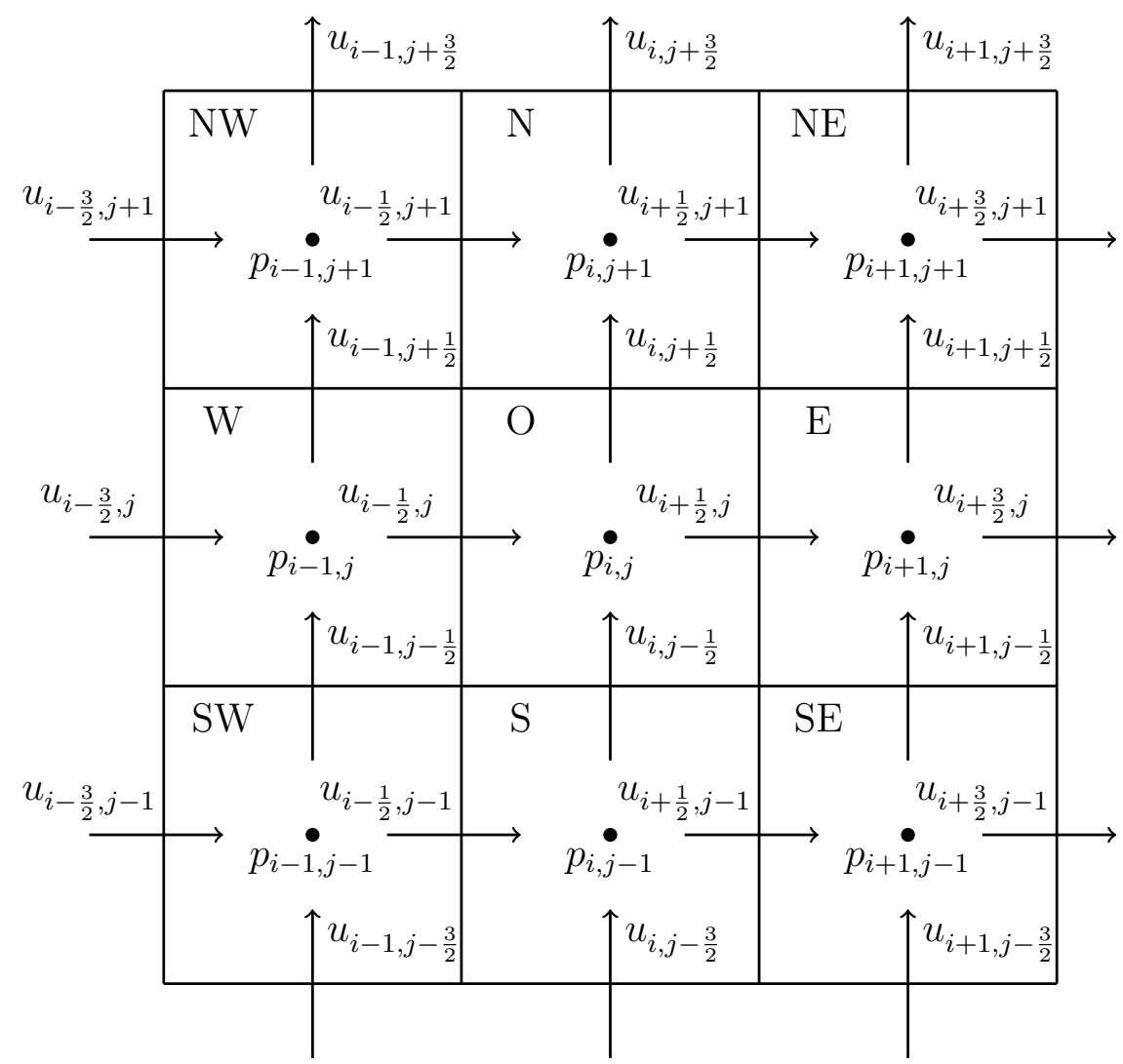

Figure 4.8: Positions of the variables for each cell in a structured mesh. Source: Author.

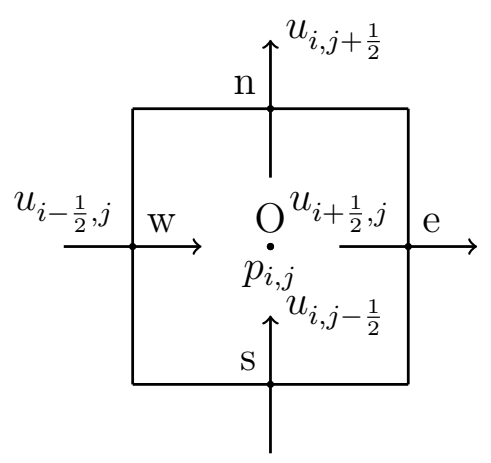

Figure 4.9: Positions of the variables of a cell in 2D. Source: Author.

In discrete form, each term of the equation (4.66) can be rewritten

$$
\begin{aligned}
\int_{V} \frac{\partial}{\partial t}(\rho \varphi) d V & =\frac{\partial}{\partial t} \rho \varphi V, \\
\oint \rho \varphi \mathbf{u} \cdot d \mathbf{A} & =\sum_{f}^{N_{\text {faces }}} \rho_{f} \mathbf{u}_{f} \varphi_{f} \cdot \mathbf{A}_{f}, \\
\oint \Gamma_{\varphi} \nabla \varphi \cdot d \mathbf{A} & =\sum_{f}^{N_{\text {faces }}} \Gamma_{\varphi} \nabla \varphi_{f} \cdot \mathbf{A}_{f}, \\
\int_{V} S_{\varphi} d V & =S_{\varphi} V .
\end{aligned}
$$


Thus

$$
\frac{\partial}{\partial t} \rho \varphi V+\sum_{f}^{N_{\text {faces }}} \rho_{f} \mathbf{u}_{f} \varphi_{f} \cdot \mathbf{A}_{f}=\sum_{f}^{N_{\text {faces }}} \Gamma_{\varphi} \nabla \varphi_{f} \cdot \mathbf{A}_{f}+S_{\varphi} V
$$

where $N_{\text {faces }}$ is the number of faces enclosing each cell, $\varphi_{f}$ is the value of $\varphi$ convected through face $f, \rho_{f} \mathbf{u}_{f} \cdot \mathbf{A}_{f}$ is the mass flow through the face ${ }^{9}, \mathbf{u}_{f}$ is the velocity vector through the face, $\mathbf{A}_{f}$ is the area of face $f$ and $\nabla \varphi_{f}$ is the gradient of $\varphi$ at face $f$. The terms of the transport equation are explained in the following subsections except for source term expressed in the equation (4.70) which is the simplest formulation consistent with a second-order discretization (CD-adapco, 2014).

\subsubsection{Transient term}

The transient term could be discretized temporally. First-order temporal discretization scheme (Euler implicit form) is used in this study. This involves the integration over a time step $\Delta t$ and is given by

$$
\frac{\partial}{\partial t} \rho \varphi V=\frac{(\rho \varphi V)^{n+1}-(\rho \varphi V)^{n}}{\Delta t}
$$

where $n+1$ is the next time level $t+\Delta t, n$ is the current time level $t$.

\subsubsection{Convection term}

In this subsection, an explanation is provided regarding only one type of interpolation using spatial discretization schemes applied to the convection term. In the Figure 4.10 a one-dimensional form is illustrated. The integration of the total flux of the convection term, viewed in the equation (4.68), is rewritten as

$$
\sum_{f}^{N_{\text {faces }}} \rho_{f} \mathbf{u}_{f} \varphi_{f} \cdot \mathbf{A}_{f}=\sum_{f}^{N_{\text {faces }}}(\dot{m} \varphi)_{f}=\left(\dot{m}_{f} \varphi\right)_{e}-\left(\dot{m}_{f} \varphi\right)_{w} .
$$

\subsubsection{2nd order upwind scheme}

The scheme depends on the flow direction and is used in this study. Also, it is less dissipative but not bounded. In the Figure 4.10 shows the value $\varphi$ of a fluid property

\footnotetext{
${ }^{9}$ The mass flow rate measures the mass of the fluid passing a point in the system per unit time. Is calculated as

$$
\dot{m}=\rho \dot{V}=\rho \mathbf{u} \cdot A
$$

where $\dot{V}$ is the volume flow rate.
} 
obtained by means of a 2nd order upwind extrapolation. The estimation of $\varphi$ on east face of a finite volume can be computed

$$
\varphi_{e} \approx \begin{cases}\frac{3}{2} \varphi_{O}-\frac{1}{2} \varphi_{W} & \text { if } u>0 \\ \frac{3}{2} \varphi_{E}-\frac{1}{2} \varphi_{E E} & \text { if } u \leq 0\end{cases}
$$

assuming a regular mesh (i.e. $\Delta x$ is constant).

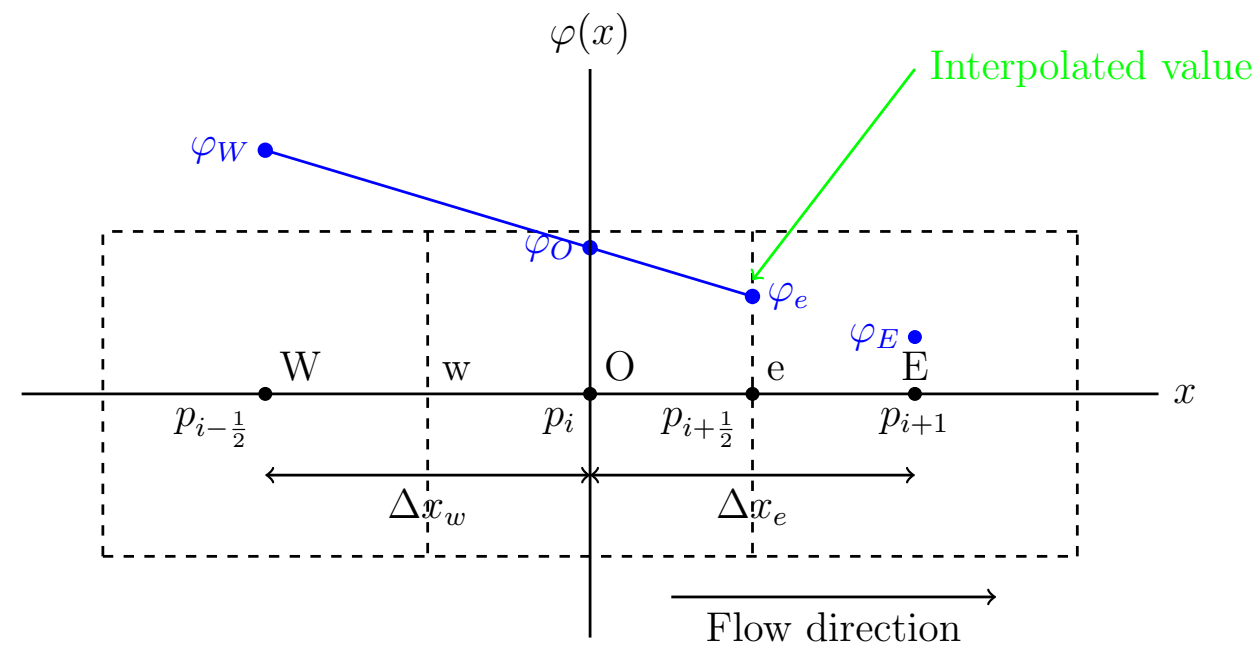

Figure 4.10: Interpolation profile of the 2nd Order Upwind Scheme. Source: Iaccarino (2004).

This discretization scheme was described initially for finite difference discretization by Warming and Beam (1976) and Hodge, Stone and Miller (1979). Later, it was implemented for finite volume by Tamamidis and Assanis (1993) as an explicit transient scheme, and by Thompson and Wilkers (1982) as a steady state implicit version (NORRIS, 2000).

\subsubsection{Diffusion term}

The diffusion term uses the interpolation function of central differentiating and does not cause stability problems to the simulation (MALISKA, 1995; CD-adapco, 2014; ANSYS, 2017). The integration of the total flux of diffusion, expressed in the equation (4.69), is rewritten as

$$
\sum_{f}^{N_{\text {faces }}} \Gamma_{\varphi} \nabla \varphi_{f} \cdot \mathbf{A}_{f}=\left(\Gamma_{\varphi} A_{f}\right)_{e} \frac{\varphi_{E}-\varphi_{O}}{\Delta x_{e}}-\left(\Gamma_{\varphi} A_{f}\right)_{w} \frac{\varphi_{O}-\varphi_{W}}{\Delta x_{w}} .
$$

In $S T A R-C C M+$, the secondary gradient (or cross-diffusion) contribution is used, essential for maintaining accuracy on non-orthogonal meshes (CD-adapco, 2014). 


\subsection{Numerical procedure}

The Semi-Implicit Method for Pressure Linked Equations (SIMPLE) is used to complement the numerical procedure that is described in the Figure 4.11. This method, developed by Patankar and Spalding (1972), is a segregated algorithm of iterative procedure for the calculation of pressure and velocity fields (VERSTEEG; MALALASEKERA, 2007). The flowchart of this procedure illustrates the following steps:

1. Read initial data;

2. Discretize and solve RANS equation using updated values of pressure to compute the intermediate velocity field;

3. Discretize and solve the pressure correction using the intermediate velocity field obtained recently;

4. Correct the pressure and the velocity field using the pressure-correction obtained in the previous step;

5. Discretize and solve scalar equation $\varphi$;

6. Return to step 2 in case of converges;

7. If the current time simulation is different to the maximum time simulation, return to step 2 . 


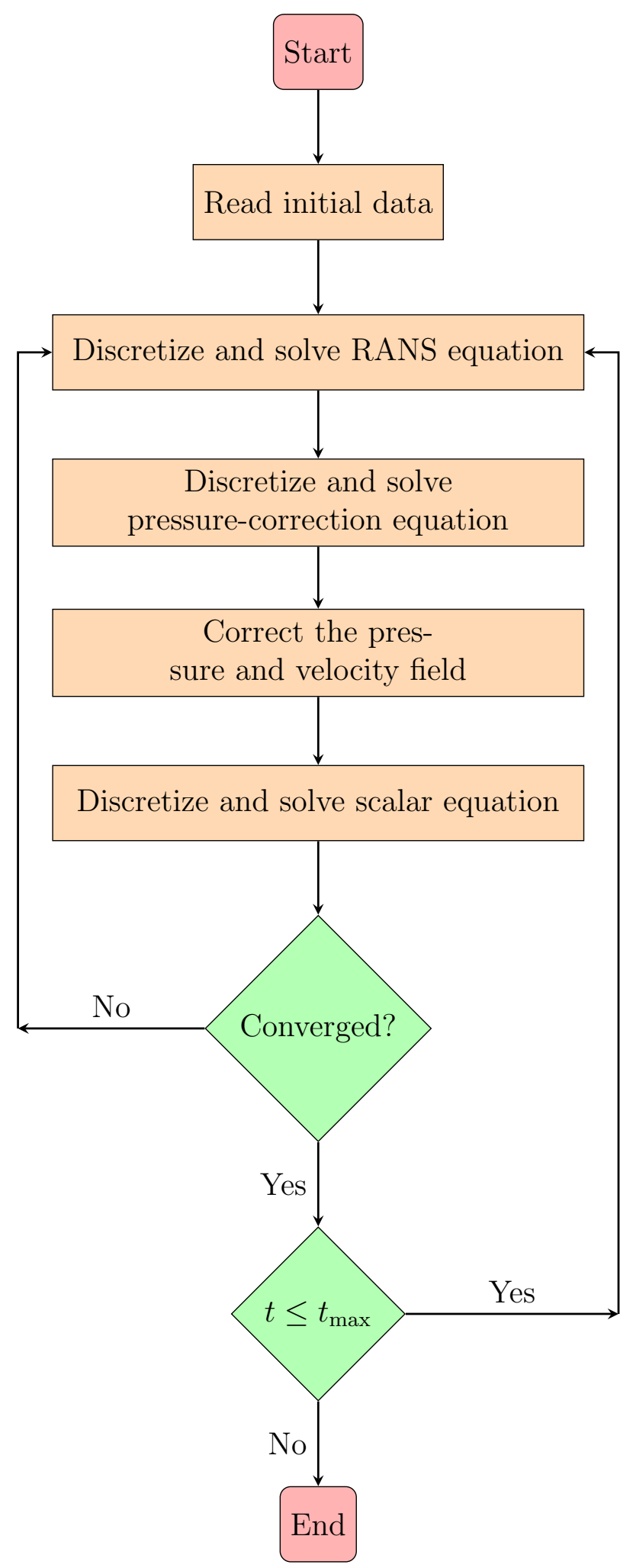

Figure 4.11: Numerical procedure in the $S T A R-C C M+$ solver. Source: Author. 


\section{APPLICATION TO THE SELF-PROPELLED INLAND VESSEL INTENDED FOR THE OPERATION IN THE MAGDALENA RIVER LOW COURSE}

This chapter presents the methodology applied on the ship resistance calculation. For this purpose, a model which was tested and provided by the IPT was used. This model was digitally modeled and, subsequently, was carried out a comparative analysis based on the original IPT model and the CAD modeled hull. In this study, the mesh applied for the geometry, the boundary conditions and the solver parameters, as well as the results are presented and visualized.

\subsection{Methodology}

In the method, the market in which the vessel will operate, the physical restrictions of the river and the data obtained from existing inland vessels are considered. Once the hull design is chosen, the hull resistance is calculated by three ways. The first is the experimental test evaluated in the towing tank on IPT. The second is the empirical procedure (explained in the chapter 3 ) and is accomplished inside the parameters. The third is the procedure using CFD (Figure 5.1). The mesh is generated with the design of the geometry domain. Later, initial physical conditions are configured. Before running the solution (explained in the chapter 4), the time step and the maximum simulation time must be determined. After that, the results are analyzed and the experimental results are compared to the empirical results. The above are described in the Figure 5.2.

\subsection{Experimental test in model scale}

Consists of placing the model in a towing tank with a carriage that travels along the basin. The Figure 5.3 shows an example of a test of an inland vessel in shallow water 


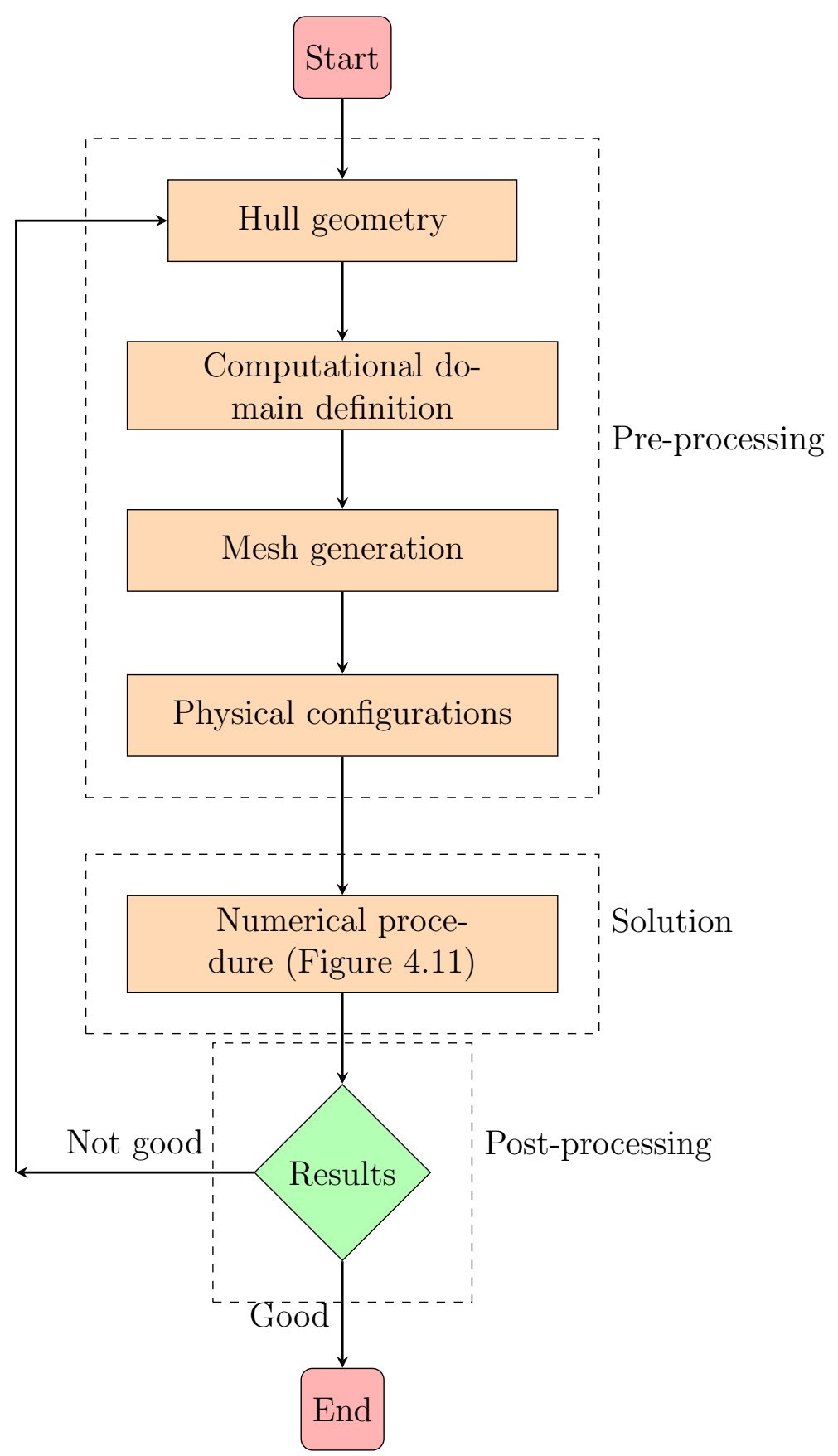

Figure 5.1: CFD procedure. Source: Author.

condition realized at Ghent University.

The geometrical and physical properties must be extrapolated to real scale. The way to do that is the similitude analysis that is composed by three aspects: geometric, kinematic and dynamic. 


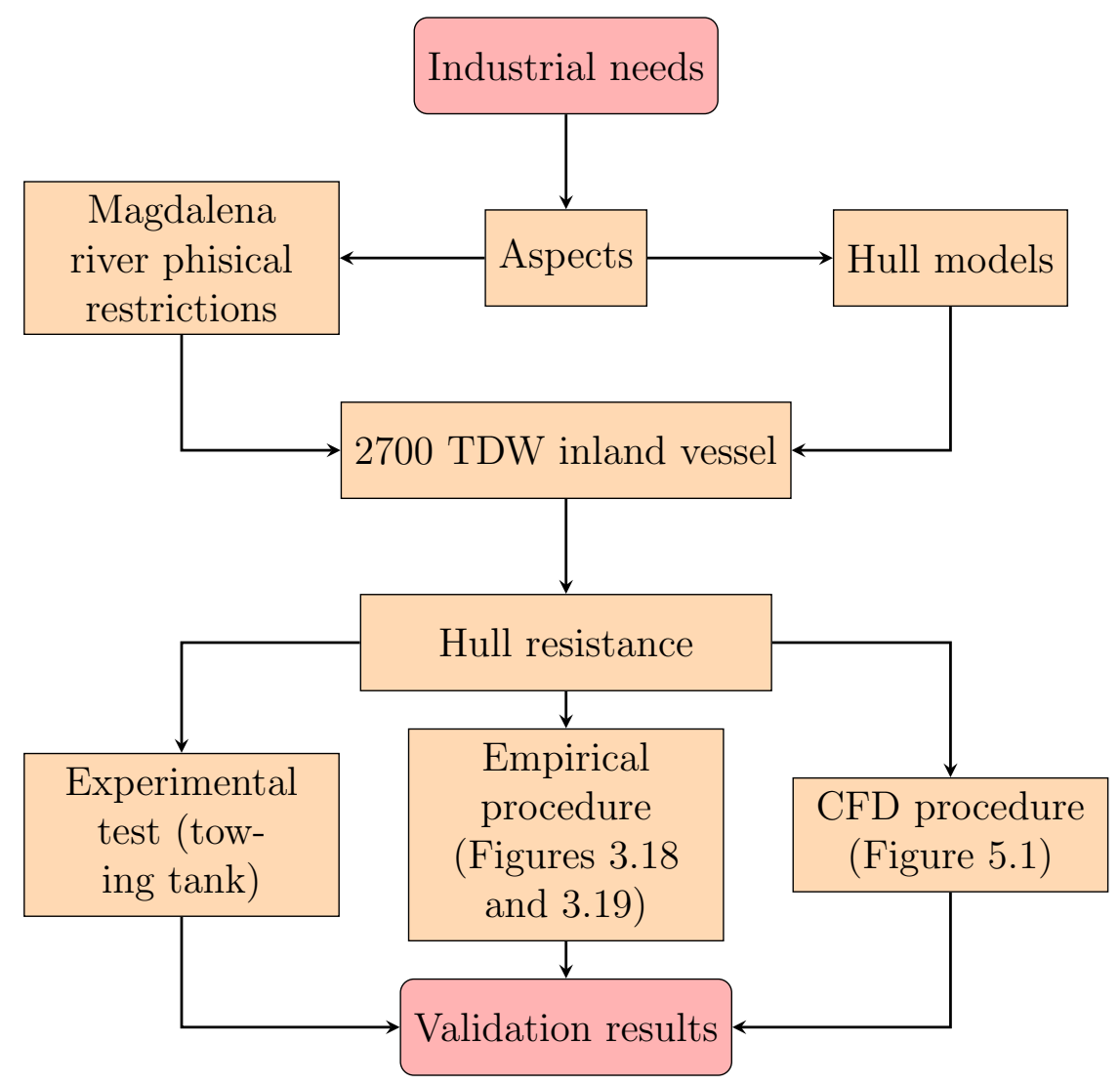

Figure 5.2: General methodology. Source: Author.

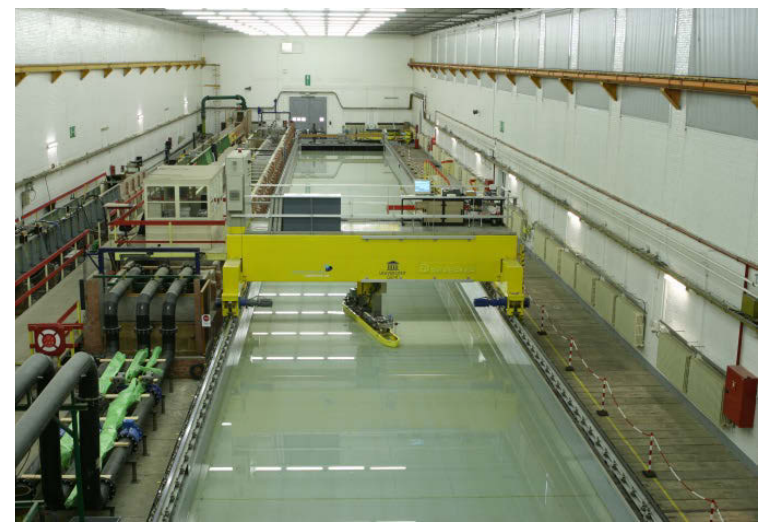

(a) General view of the towing tank

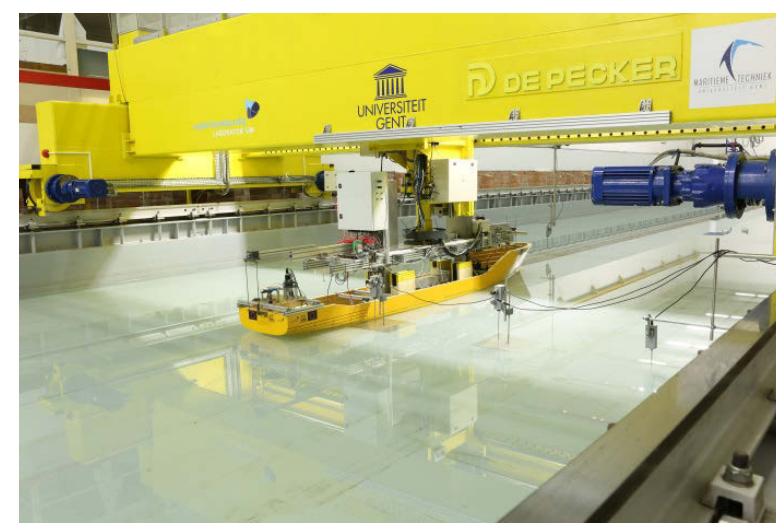

(b) General layout

Figure 5.3: Resistance test in shallow water condition at Ghent University. Source: Delefortrie, Geerts and Vantorre (2016).

\subsubsection{Geometric similarity}

Consists of two objects (model and prototype) of different dimensions which are similar as these have the same scale ratio. This type of similarity is applied to objects with area 
and volume, such as a wing shown in the Figure 5.4. The scale ratio is defined as,

$$
\Xi=\frac{d_{p}}{d_{m}}, \quad \Xi^{2}=\frac{d_{p}^{2}}{d_{m}^{2}}, \quad \Xi^{3}=\frac{d_{p}^{3}}{d_{m}^{3}},
$$

where $d_{p}$ and $d_{m}$ are the dimensional lengths of the prototype and the model respectively.

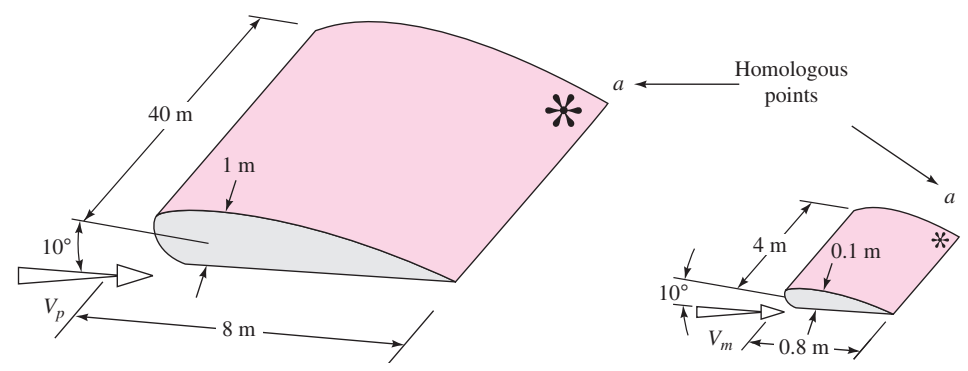

Figure 5.4: Example of geometric similarity in model testing. Left, prototype; right, scale model. Source: White (2011).

\subsubsection{Kinematic similarity}

The velocity of the flow at any point in the model must have the same direction as the velocity of the flow in the prototype. It means, the motions of the systems must be similar as illustrated in the Figure 5.5.

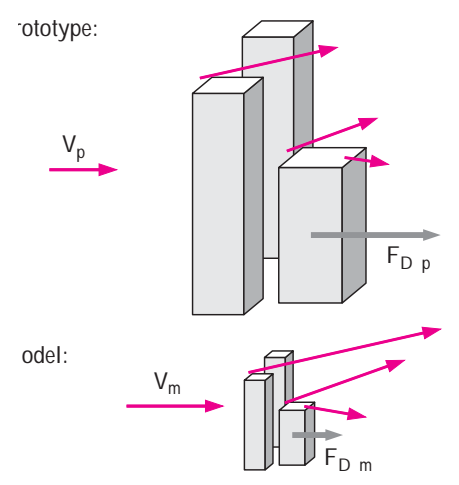

Figure 5.5: Example of kinematic similarity in model testing. Top, prototype; bottom, scale model. Source: Çengel and Cimbala (2006).

\subsubsection{Dynamic similarity}

The force and pressure coefficients of the model and prototype should be identical. It implies that the dimensionless parameters, such as Reynolds and Froude numbers, must be equal. 
If the values of the Reynolds number are equal for different characteristic lengths of the prototype and the model, the velocity of the model will be high and, as a result, the evaluation in the towing tank will be impossible. On the other hand, the Froude number similarity could be used because the velocity of the model must be less than the velocity of the prototype. In the Figure 5.6 shows an experiment, where the prototype and model are identical homogeneous force.
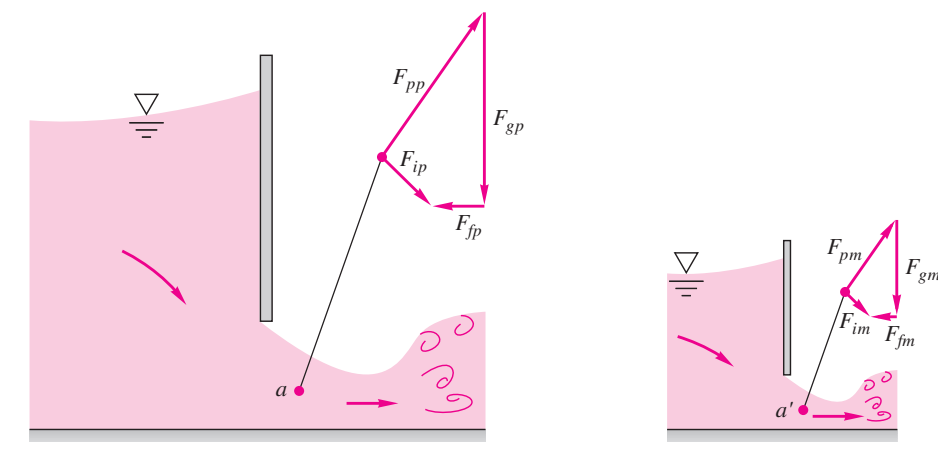

Figure 5.6: Example of dynamic similarity in model testing. Left, prototype; right, scale model. Source: White (2011).

\section{$5.3 \quad$ Hull modeling}

The hull geometry can be described through lines-plan. This plan is composed by the sheer profile (in perspective view which is divided in sections); the body plan (that shows the half symmetrical sections in the fore and aft); and the half-breadth plan (top view) which displays the half symmetrical sections (port and starboard side) at each waterline (levels of hull draft). In the Figure 5.7 illustrates an example of a lines-plan.

The offsets are the representation of the lines plan in numbers organized in tables (that provide the coordinates of the points the sum of which results in the formation of the hull's lines). The original hull model designed by IPT is composed by 137 sheers and 7 waterlines, described in the Figures B.1 and B.2. These offsets are adapted digitally, using the portable software FREE!ship (ENGELAND, 2006). This program uses a simple modeling, creating interpolation points for lines and the generation of surfaces, observed in Figure 5.8. Also, it was possible the analysis of the lines-plan that is generated digitally (Figure 5.9) and is compared with the original lines-plan of the hull, including their dimensions (Table 5.1). 


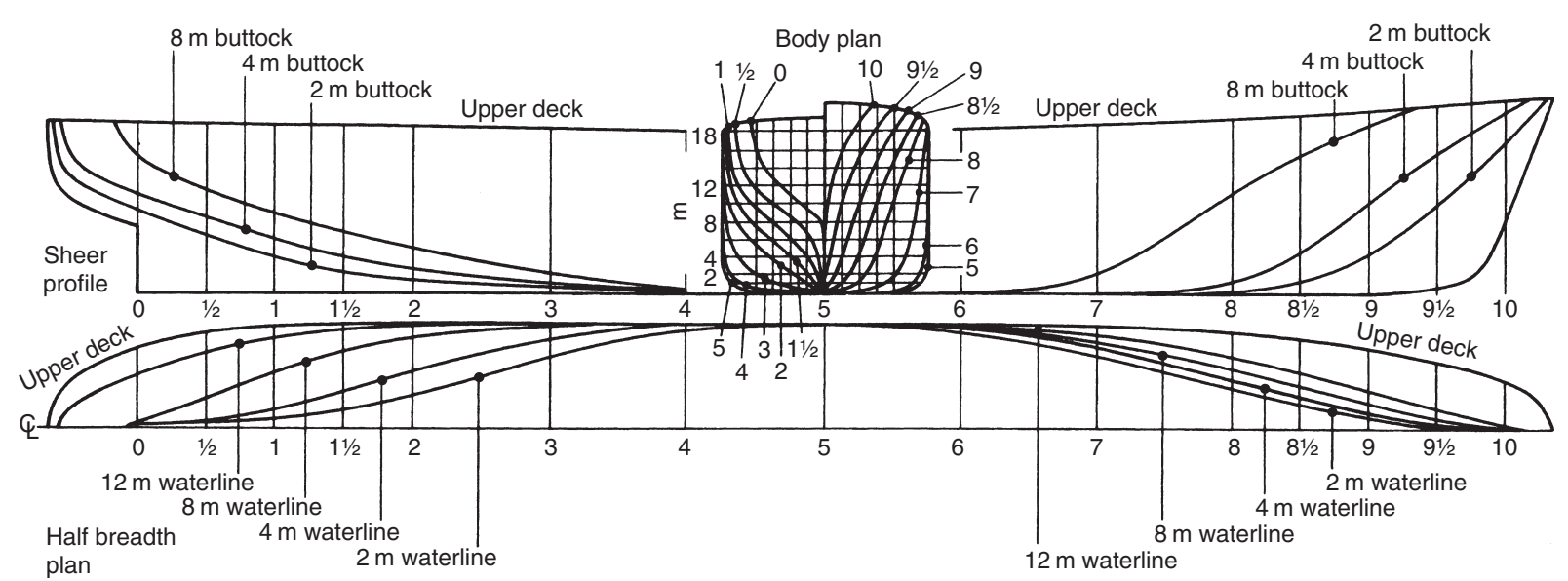

Figure 5.7: Example of a lines-plan. Source: Tupper (2004).

\begin{tabular}{lrrr} 
Variable & Model IPT & Model author & Difference (\%) \\
\hline$L_{\mathrm{WL}}(\mathrm{m})$ & 4.193 & 4.203 & -0.238 \\
$B(\mathrm{~m})$ & 0.725 & 0.725 & 0.000 \\
$T(\mathrm{~m})$ & 0.160 & 0.160 & 0.000 \\
$S_{w s}\left(\mathrm{~m}^{2}\right)$ & 3.911 & 4.076 & -4.048 \\
$\Lambda\left(\mathrm{m}^{3}\right)$ & 0.445 & 0.438 & 1.598 \\
\hline
\end{tabular}

Table 5.1: Comparison of model hulls. Source: Author.

\subsection{Geometry and mesh}

Is important to define the volume of the computational domain for the simulation of inland vessel's resistance. The boundary condition of the symmetry is considered for the reduction of the computational process.

The size of the computational domain volume is one of the aspects that influence the simulation solution and the user defines the limits. If the computational domain is small, the flow is not represented and the simulation diverges. On the other hand, if the domain is larger, the simulation is consuming time and needs more power process without implying significantly better results.

In the Figure 5.10 shows the boundary conditions of the computational domain considered in this study and is similar to those used by Liu et al. (2017). The length is almost 4 times the $L_{\mathrm{WL}}$, and the width of the IPT towing tank. The height is $0.8 \mathrm{~m}$, where 0.3 $\mathrm{m}$ corresponds to the water depth. The geometry of this domain is described in the Table 5.2 . 

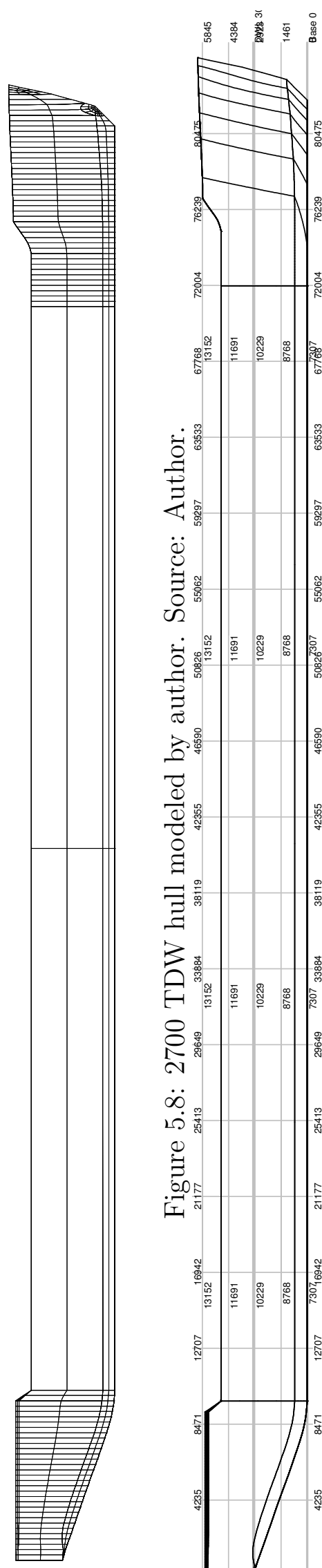

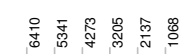
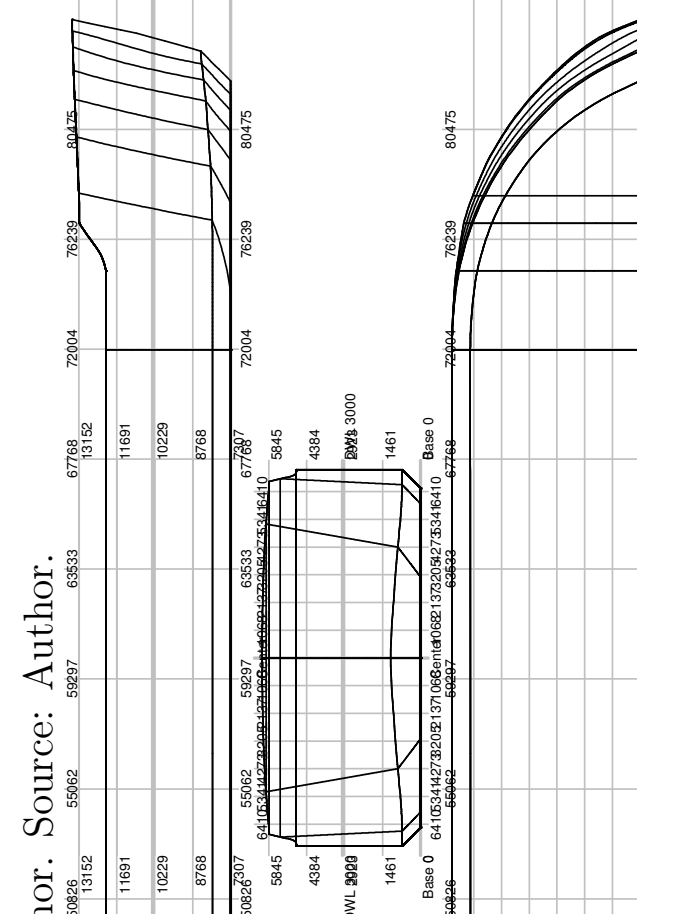

富

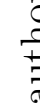
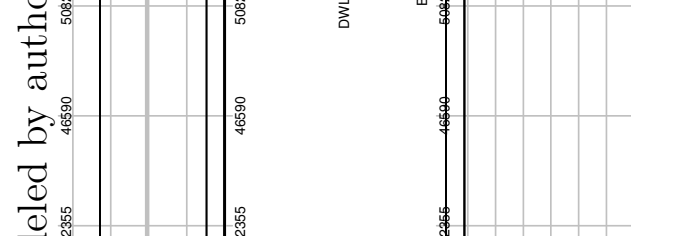

ن்

突

0
0
0
0
0
0

.

$\exists$

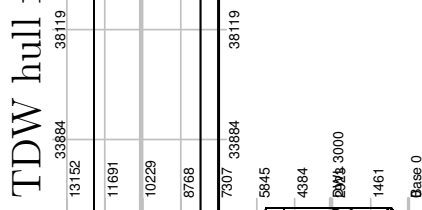

$\stackrel{8}{5}$

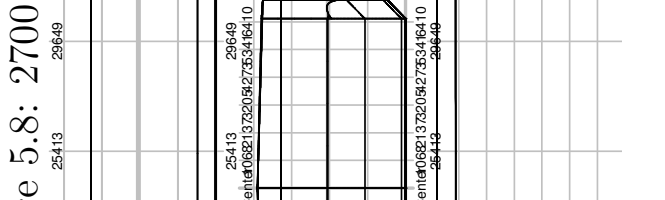

$\stackrel{0}{\exists}$
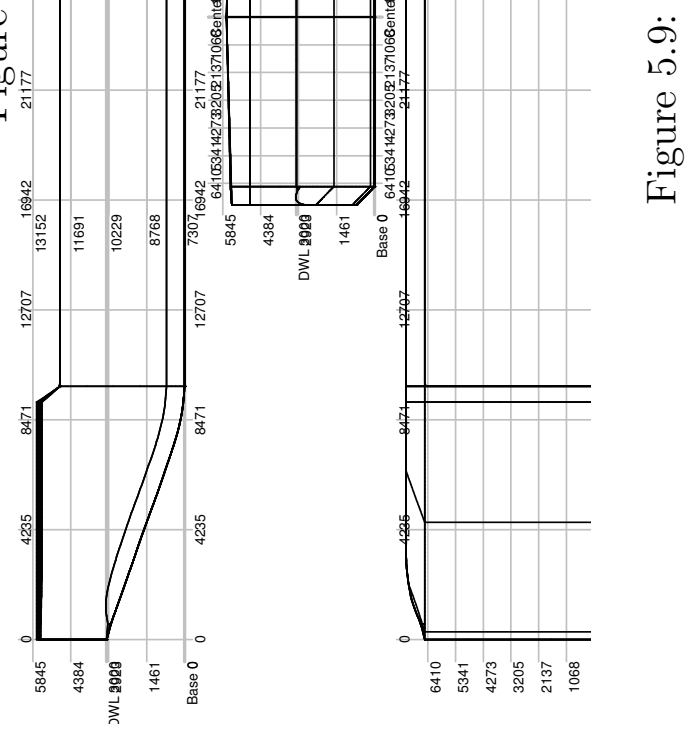

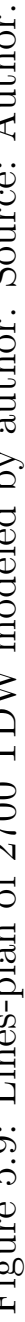




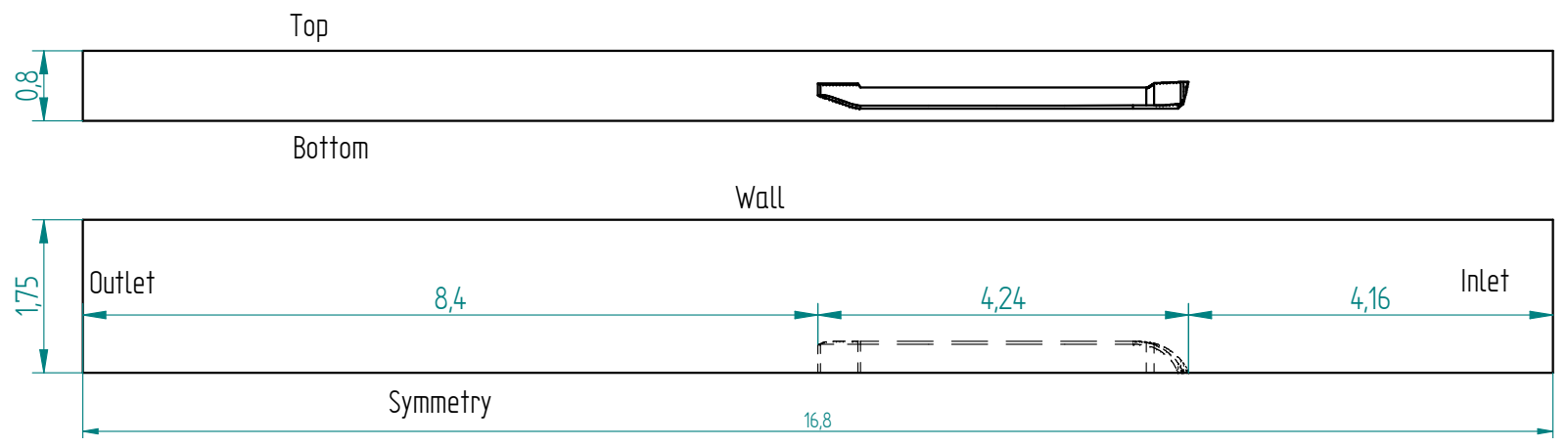

Figure 5.10: Boundary conditions of the domain. Source: Author.

\begin{tabular}{lcc} 
& $L_{\mathrm{WL}}$ & Dimension domain $(\mathbf{m})$ \\
\hline Length of vessel & 1.00 & 4.24 \\
Behind & 1.98 & 8.40 \\
Forward & 0.98 & 4.16 \\
Side & 0.41 & 1.75 \\
High & 0.19 & 0.80 \\
\hline
\end{tabular}

Table 5.2: Dimensions of the computational domain geometry. Source: Author.

\subsubsection{Mesh}

After defining the geometry of the computational domain, the mesh is realized, which it is divided into surface mesh and volume. The $S T A R-C C M+(\mathrm{CD}$-adapco, 2014) software allows the creation of unstructured surface mesh and structured volume mesh.

For this study, it is important to discretize the regions of greatest interest, where the modification of the cell size is refined. The remainder of volume of the computational domain is maintained at base size of the cell. The regions around the hull are important because pressure and shear forces are obtained through the model, followed by the free surface due to the tracking of waves. Six regions of refined mesh are defined in the Table 5.3 and is illustrated in the Figure 5.11.

The advantages of the structured mesh are the algorithms of discretization and implementation in a computationally efficient manner. Their difficulties are the mesh generation of regions with multi-block shapes and the time required to produce a mesh for extremely complex forms in the computational domain (ANWER, 2016).

The base cell size, used for the computational domain, was 1.36 meters. For the vessel hull mesh, the isotropic prism (where the size of the cells side is equal) was used with $5.3125 \mathrm{E}-3$ meters (base cell size divided 256 times), equivalent to $0.39 \%$.

For the rest of the refined regions, the anisotropic prism is used. For the estimation 


\begin{tabular}{lrrr} 
Region & $\begin{array}{r}\text { Length } \\
(\mathbf{m})\end{array}$ & $\begin{array}{r}\text { Width } \\
(\mathbf{m})\end{array}$ & $\begin{array}{r}\text { Height } \\
(\mathbf{m})\end{array}$ \\
\hline Hull - Block & 4.11 & 0.40 & 0.35 \\
Hull - Cylinder & 0.40 & 0.40 & 0.40 \\
Bottom - Block & 5.00 & 1.75 & 0.14 \\
Bottom - Cylinder & 1.75 & 1.75 & 1.75 \\
Free surface - Thin & 16.80 & 1.75 & 0.20 \\
Free surface - Very thin & 16.80 & 1.75 & 0.10 \\
\hline
\end{tabular}

Table 5.3: Dimensions of refined regions. Source: Author.

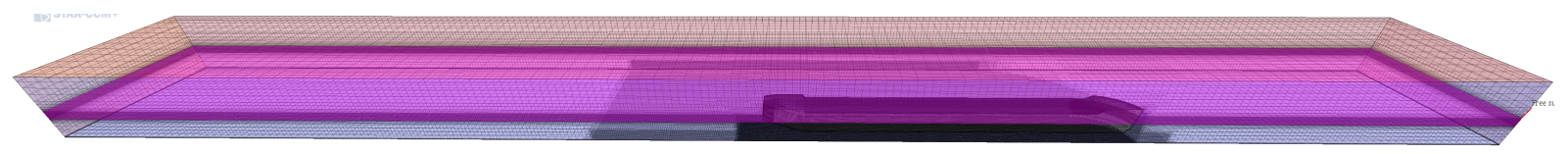

(a) Free surface zone

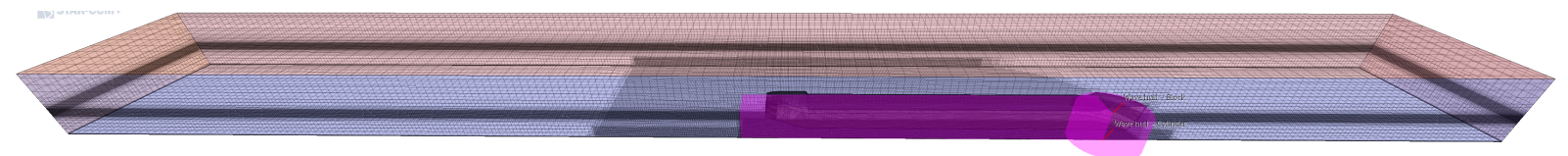

(b) Hull zone

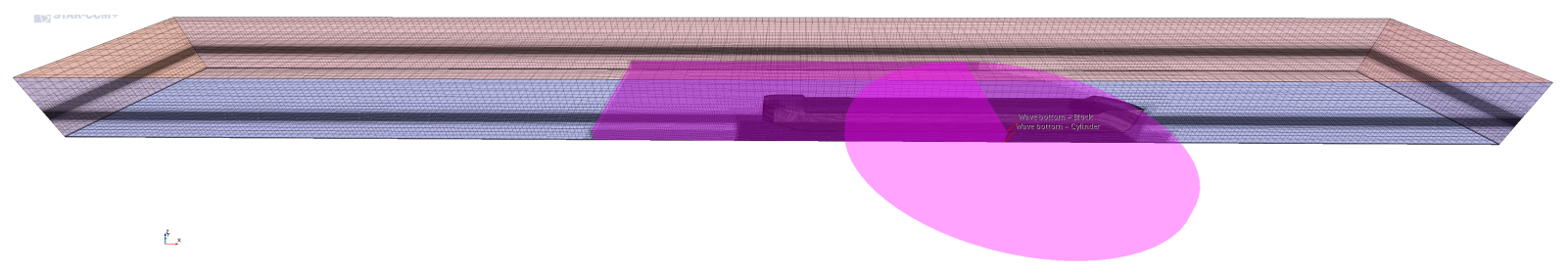

(c) Bottom zone

Figure 5.11: Refined mesh zones (in pink) in the computational domain. Source: Author.

of the cell size in the axes $x$ and $y$ for the free surface region, the wavelength $\lambda$ generated by the inland vessel is calculated and is defined as (MOLLAND; TURNOCK; HUDSON, 2011)

$$
v_{\text {model }}^{2}=\frac{g \lambda}{2 \pi} \tanh \left(\frac{2 \pi h}{\lambda}\right)
$$

Ji et al. (2012) recommends using 10 points per length of the transverse waves. The value of the cell size for both axes is $2.125 \mathrm{E}-2$ meters, because the velocity reference is $0.576 \mathrm{~m} / \mathrm{s}$. The cell size in $z$ axe applied on the bottom and free surface-thin regions is equivalent to 5.3125E-3 meters; the free surface in the very thin region is sized at 2.65625E-3 meters and allows tracking and locating the free surface using VOF method. The visualization of the computational domain mesh described above is illustrated in the Figures 5.12 and 5.13, similar to those by Liu et al. (2017), and the Table 5.4 is detailed the cell size of each region. 


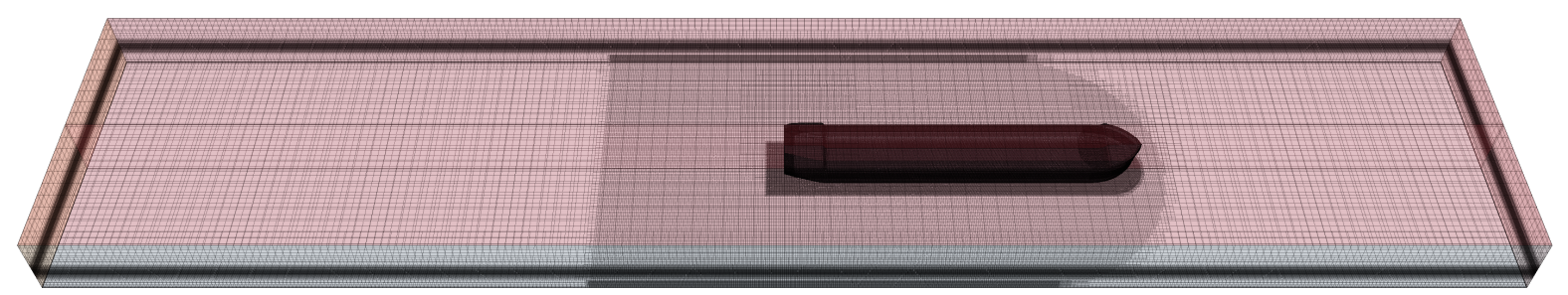

Figure 5.12: Overview of the mesh in the computational domain. Source: Author.

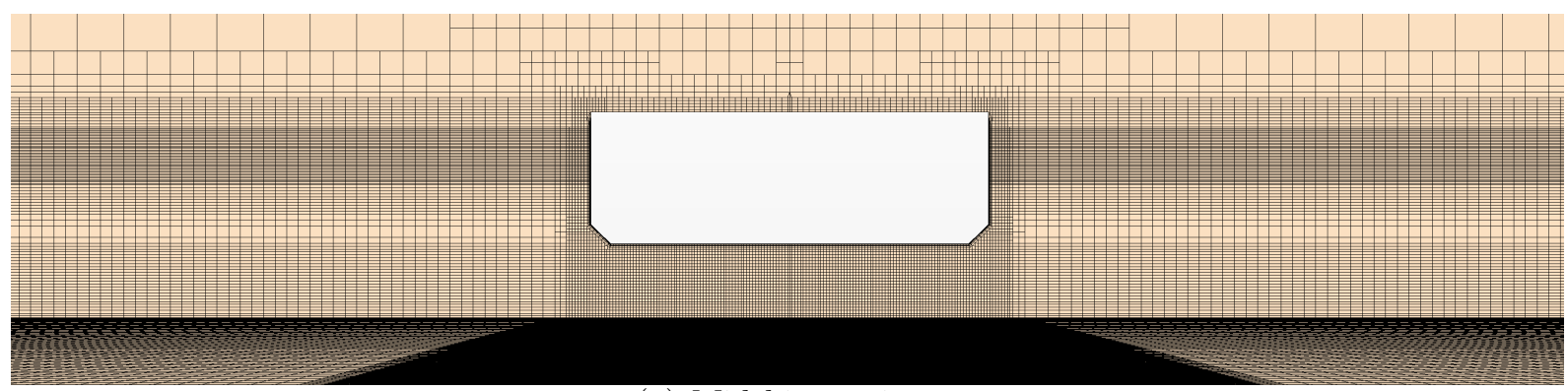

(a) Midship section

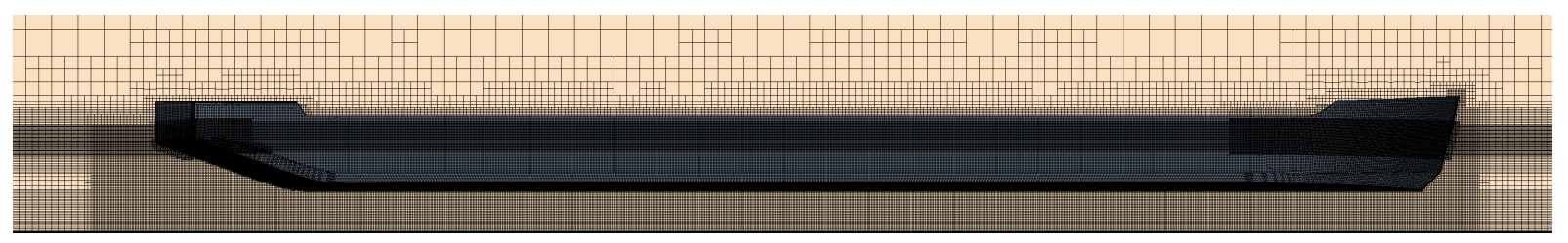

(b) Longitudinal section at symmetry

Figure 5.13: Grid structure around the vessel. Source: Author.

\begin{tabular}{llrrr} 
& & \multicolumn{3}{c}{ Cell size (m) } \\
Region & Trimmer & $x$ & $y$ & $z$ \\
\hline Hull - Block & Isotropic & $5.31250 \mathrm{E}-3$ & $5.31250 \mathrm{E}-3$ & $5.31250 \mathrm{E}-3$ \\
Hull - Cylinder & Isotropic & $5.31250 \mathrm{E}-3$ & $5.31250 \mathrm{E}-3$ & $5.31250 \mathrm{E}-3$ \\
Bottom - Block & Anisotropic & $2.12500 \mathrm{E}-2$ & $2.12500 \mathrm{E}-2$ & $5.31250 \mathrm{E}-3$ \\
Bottom - Cylinder & Anisotropic & $2.12500 \mathrm{E}-2$ & $2.12500 \mathrm{E}-2$ & $5.31250 \mathrm{E}-3$ \\
Free surface - Thin & Anisotropic & $2.12500 \mathrm{E}-2$ & $2.12500 \mathrm{E}-2$ & $5.31250 \mathrm{E}-3$ \\
Free surface - Very thin & Anisotropic & $2.12500 \mathrm{E}-2$ & $2.12500 \mathrm{E}-2$ & $2.65625 \mathrm{E}-3$ \\
\hline
\end{tabular}

Table 5.4: Configuration of the mesh in refined regions. Source: Author.

\subsubsection{Boundary layer mesh}

The boundary layer is important because the near-wall flow solution allows the determination of forces and flow features that depend on the velocity gradients (CD-adapco, 2014). In previous chapter it was explained how the near-all treatment works in the wall of the boundary condition and, in this study, is applied only on the hull vessel and on the wall bottom of the computational domain.

Some aspects are taken into account in the generation of prism mesh. One is the 
boundary thickness, and can be determined according to ITTC (2014),

$$
y=\frac{y^{+} L_{\mathrm{mod}}}{\operatorname{Re}_{L} \sqrt{\frac{C_{f}}{2}}},
$$

where $L_{\text {mod }}$ is the length of the inland vessel model and $R e_{L}$ is the Reynolds number of the ship model. The value corresponds only to the first thickness layer and the user chooses the value of $y+$. For the finite mesh, $y+\leq 1$; and for tick mesh, $30 \leq y+\leq 100$, equivalent to logarithmic profile. In $S T A R-C C M+$, the all $y+$ wall treatment is chosen by default.

Another aspect is the stretch factor, that is represented as the ratio between the thickness of a cell layer and the thickness of the preceding layer. For example, the prism layer is 1 unit and stretch factor is 2, the thickness of the next layer is 2 units, continuing the other next layers that would give values of 4, 8, 16 and so on. An example is illustrated in the Figure 5.14. In appendix C, an algorithm generated in MATLAB is created to determine the total thickness prism layer. In the Figure 5.15 and the Table 5.5 are detailed the properties of the prism layer for the hull and wall bottom in the computational domain. The hull stern and hull deck are not applied, and do not affect the calculation of the resistance.

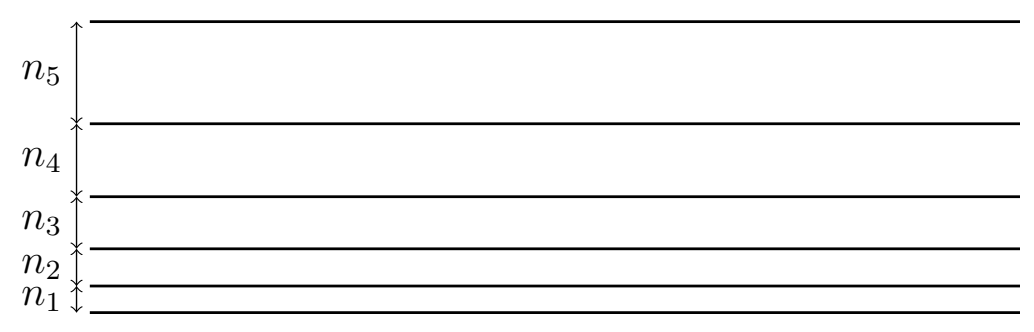

Figure 5.14: Representation of prismatic mesh for boundary layer. Source: Author.

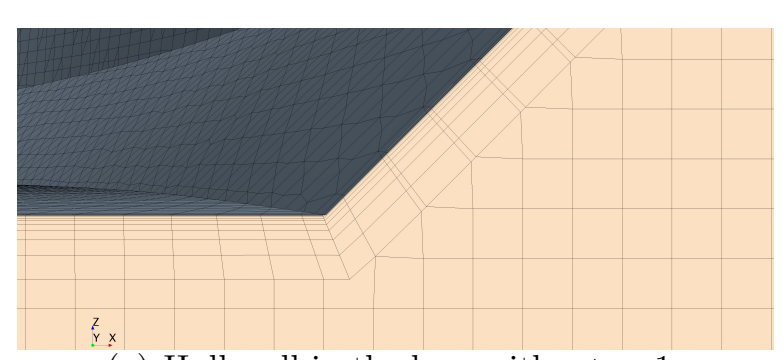

(a) Hull wall in the bow with $y+=1$

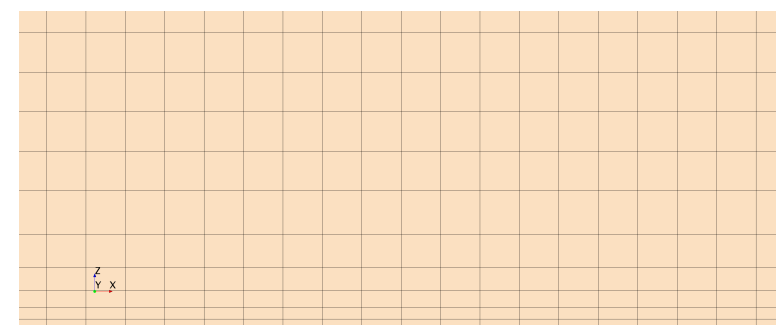

(b) Wall bottom in the computational domain with $y+=30$

Figure 5.15: Prism layer mesh. Source: Author. 


\begin{tabular}{lrr} 
Parameter & Hull vessel & Bottom domain \\
\hline$y+$ & 1 & 30 \\
First prism layer $(\mathrm{m})$ & $2.4994 \mathrm{E}-5$ & 0.0011 \\
Stretch factor & 1.59 & 1.4 \\
Number of layers & 11 & 5 \\
Total thickness layer & 0.0069 & 0.00125 \\
\hline
\end{tabular}

Table 5.5: Parameters of the prism layer of the mesh. Source: Author.

\subsection{Boundary conditions}

The settings for the boundary conditions must be carefully defined according to the test conditions made in the towing tank of the IPT. First, the VOF Waves for the simulation of the gravity waves on a light fluid and a heavy fluid interface are defined. Provides field functions that are used to initialize the VOF calculations (CD-adapco, 2014). In this study, the type of VOF Waves that will be used is flat, because represents a plane of calm water. In the Table 5.6 shows the properties of VOF Waves, where the point on water level defines the position of the water surface; the vertical direction represents the normal vector to the water surface; current is the velocity of the heavy fluid; wind is the velocity of the light fluid; light and heavy fluid density are required for the hydrostatic field function, created automatically with the waves, and the values for the water and the air are determined by default. The variable $u$ stands for the velocity which gains four different values $(0.576,0.691,0.806$ and $0.921 \mathrm{~m} / \mathrm{s})$, for the calculation of the resistance, and its vector direction is negative. These configurations are visualized in the Figure 5.16. The heavy and the light fluids corresponds to the water and the air.

\begin{tabular}{lr} 
Variables & Value \\
\hline Point on water level $(\mathrm{m})$ & {$[0.0,0.0,0.0]$} \\
Vertical direction & {$[0.0,0.0,1.0]$} \\
Current $(\mathrm{m} / \mathrm{s})$ & {$[-u, 0.0,0.0]$} \\
Wind $(\mathrm{m} / \mathrm{s})$ & {$[-u, 0.0,0.0]$} \\
Light fluid density $\left(\mathrm{kg} / \mathrm{m}^{3}\right)$ & 1.18415 \\
Heavy fluid density $\left(\mathrm{kg} / \mathrm{m}^{3}\right)$ & 997.561 \\
\hline
\end{tabular}

Table 5.6: Properties of Flat VOF Wave on $S T A R-C C M+$. Source: Author.

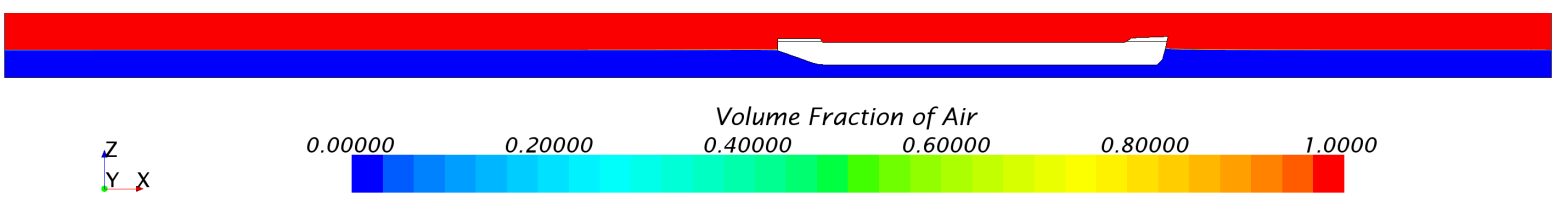

Figure 5.16: Free surface in flat state, with the volume fraction of water (blue) and air (red). Source: Author. 
The boundary conditions of the computational domain are configured and detailed in the Table 5.7 and the Figure 5.10. The velocities are defined at inlet, wall banks, top and wall bottom and correspond to field function of Flat VOF Wave. A numerical damping with length of $8.5 \mathrm{~m}$ is applied at inlet and outlet planes to remove wave reflections and avoid the interaction of the true wave field generated by the vessel of the model, visualized in the Figure 5.17. The prism layer on bottom wall is configured only with $y+=30$ and the hull wall on stern and deck of the vessel is not applied.

\begin{tabular}{|c|c|c|}
\hline Boundary & Condition & Properties \\
\hline Inlet & Velocity inlet & $\begin{array}{l}\text { Normal velocity with volume fraction of water } \\
\text { and air. Damping wave reflections avoided. }\end{array}$ \\
\hline Outlet & Pressure outlet & $\begin{array}{l}\text { Volume fraction of water and air, Damping } \\
\text { wave reflections avoided. }\end{array}$ \\
\hline Wall banks & Wall & No-slip condition and motion: $x$-velocity. \\
\hline Top & Velocity inlet & $\begin{array}{l}\text { Volume fraction of water and air. Motion: } x \text { - } \\
\text { velocity. }\end{array}$ \\
\hline Bottom & Wall & $\begin{array}{l}\text { No-slip condition and motion: } x \text {-velocity. } \\
\text { Prism layer mesh with } y+=30 .\end{array}$ \\
\hline Symmetry & Symmetry & Default. \\
\hline Vessel hull & Wall & No-slip condition and smooth wall (default). \\
\hline Vessel stern and deck & Wall & $\begin{array}{l}\text { No-slip condition and smooth wall (default). } \\
\text { No prism layer. }\end{array}$ \\
\hline
\end{tabular}

Table 5.7: Boundary conditions properties configured on STAR-CCM+. Source: Author.

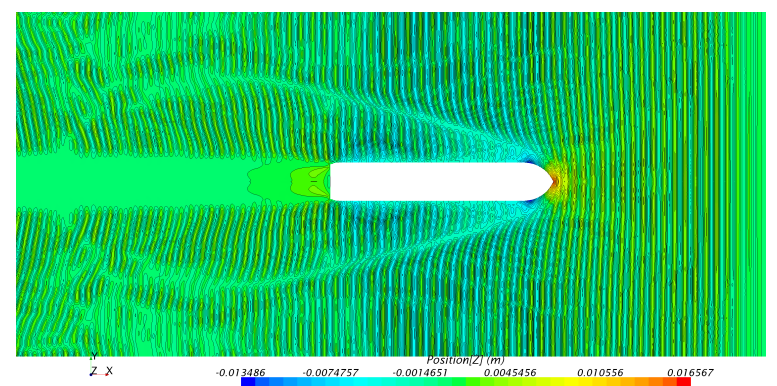

(a) No numerical damping

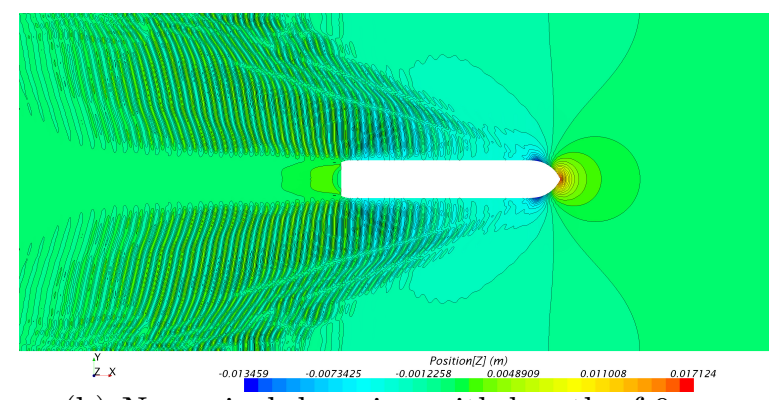

(b) Numerical damping with length of $9 \mathrm{~m}$

Figure 5.17: Numerical damping on $S T A R-C C M+$, where no numerical damping (a) affects the true waves generated by the inland vessel model, unlike numerical damping with length of $8.5 \mathrm{~m}$ applied only at inlet and outlet boundary conditions (b). Source: Author.

\subsection{Solver parameters, monitoring and plotting}

Solver is defined by three parameters: time step, maximum iteration numbers and maximum physical time. 
Time step could be determined by the Courant number, represented by

$$
C_{o}=\frac{v \Delta t}{\Delta x}
$$

where $v$ is the velocity of the fluid, $\Delta t$ is the time step and $\Delta x$ is the length interval. In this study, $\Delta x$ is defined as $2.125 \mathrm{E}-2 \mathrm{~m}$ and $v$ is the minimum velocity of the vessel.

The Courant number must be less that or equal to 1. According to ITTC (2014) the equation of the time step is

$$
\Delta t=0.05-0.01 \frac{L_{\mathrm{mod}}}{v} .
$$

However, for flows in confined water, a significantly smaller time step introduced by Liu et al. (2017), which is used in this study, is represented as

$$
\Delta t \leq 0.002 \frac{L_{\mathrm{mod}}}{v} .
$$

The definition of the maximum iteration number is not established. Checking the journal scientific papers, the average value of iteration is 10 per time step and is chosen in this study. The maximum physical time depends of the simulation results, where the variable of vessel resistance could be stable. Analyzing the results, 120 seconds is enough, as shown in the Figure 5.18. The total iteration process is completed after 80,000 iterations.

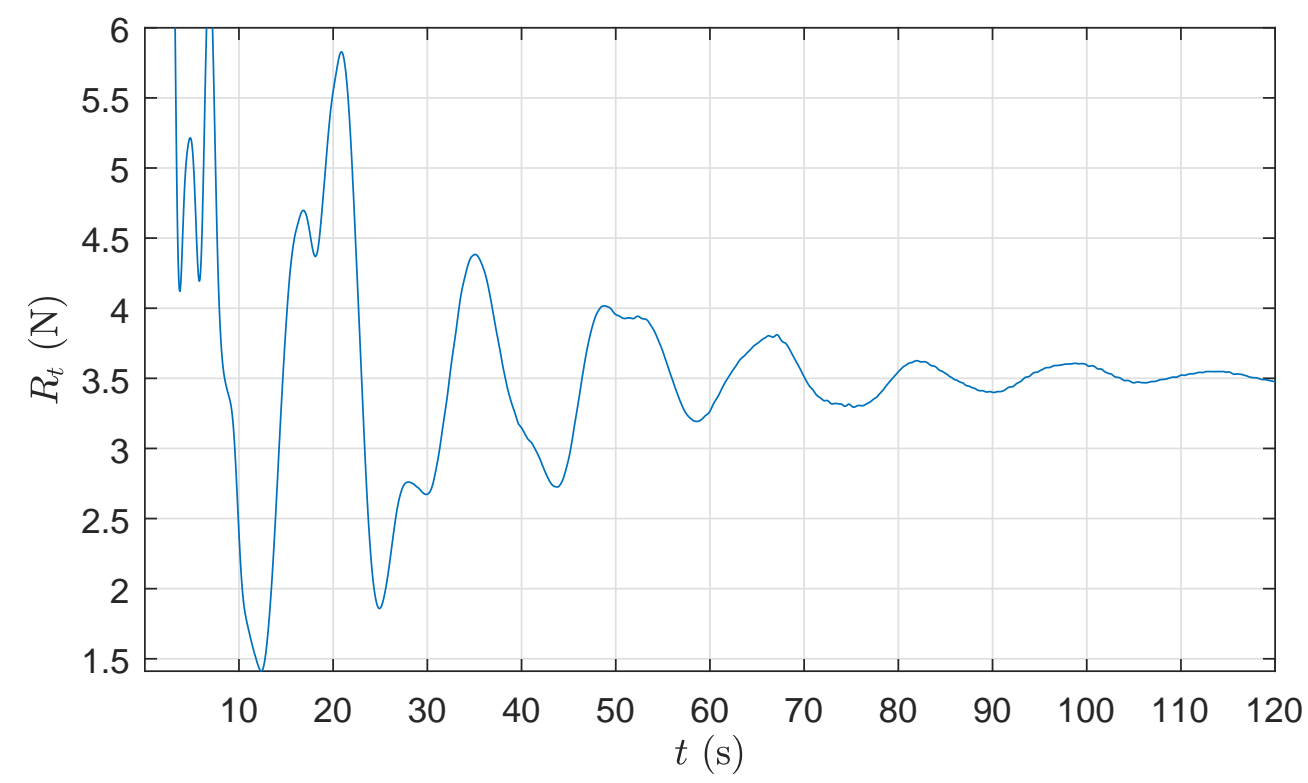

Figure 5.18: Physical time simulation of the 2700 TDW inland vessel performed on STAR$C C M+$ at $v=0.576 \mathrm{~m} / \mathrm{s}$. Source: Author.

Plots and visualization are analyzed for the interpretation of the results after the 
simulation is finished. The plot of the residuals is a convergence analysis and the smaller the residual values, the higher convergence of the simulation with the experimental results. The Figure 5.19 shown an example of the residuals, where is simulated the inland vessel at $0.921 \mathrm{~m} / \mathrm{s}$. Initially, the variables of the residuals start with values equal to 1 . During process, some variables drop to three levels. The ideal is that all the variables must be in lower levels than $1 \cdot 10^{-2}$. Therefore, the results in CFD simulation could close the experimental results. The description of the residuals (continuity, $x$-movement, $y$ movement, $z$-movement, TKE, TDR and water) is contained in the Table 5.8.

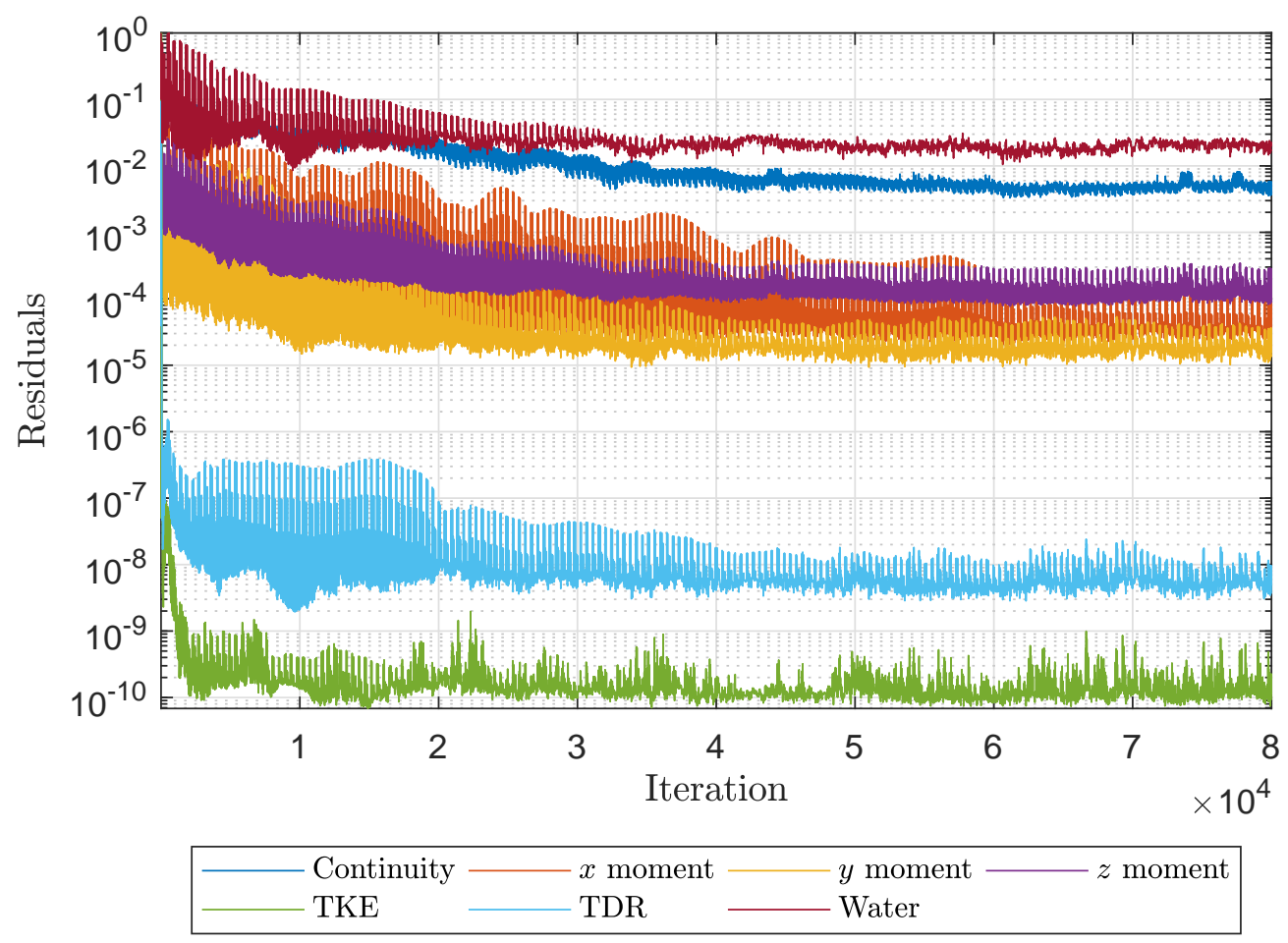

Figure 5.19: Plot of residuals of the 2700 TDW inland vessel performed on STAR-CCM+ at $v=0.921 \mathrm{~m} / \mathrm{s}$. Source: Author.

\begin{tabular}{ll} 
Residual & Description \\
\hline Continuity & How much left to close the continuity equations. \\
$x$ moment & Quantity movement in $x$ axis \\
$y$ moment & Quantity movement in $y$ axis \\
$z$ moment & Quantity movement in $z$ axis \\
TKE & Residuals referent to $k$ parameter of the Reynolds average of the \\
& $k-\varepsilon$ model turbulence \\
TDR & Residuals of the Turbulent Dissipation Rate. \\
Water & Oscillation of water on the simulation, generating wave system. \\
\hline
\end{tabular}

Table 5.8: Definition of residuals. Source: CD-adapco (2014). 


\subsubsection{Cluster specifications}

For the execution of the numerical simulation, the cluster available on TPN is used. The cluster is a set of computers united that work together as a one computer. TPN clusters are based on GNU/Linux operating system. The specifications is described in the Tables 5.9 and 5.10. In this study, The SGI cluster is used for the numerical simulation and is executed 2 nodes with 40 cores and 256 GB of RAM memory. The total simulation CPU time for each velocity was 5.5 days.

\section{Cluster SGI}

\begin{tabular}{ll}
\hline Total nodes & 48. \\
Processor & Intel(R) Xeon(R) CPU E5-2680 v2 @2.80GHz, 10 cores. Total pro- \\
& cessors: 960. Total cores: 9600. \\
Total Teraflops & 28.416 (theoretical), 21.000 (Linkpack). \\
RAM memory & 128 GB per nodes. Total: 6 TB. \\
Storage & 148 TB. \\
\hline
\end{tabular}

Table 5.9: SGI cluster specifications on TPN. Source: Author, in collaboration with TPN.

\begin{tabular}{ll} 
Cluster 1 & \\
\hline Blades & $\begin{array}{l}192 \text { X6175 in water-cooled C48 racks delivering about 15 TFlops of } \\
\text { processing. }\end{array}$ \\
Processor & Intel Nehalem 2.80GHz. Total cores: 1536. \\
RAM memory & $4.5 \mathrm{~TB}$. \\
Storage & $150 \mathrm{~TB}$. \\
\hline Cluster 2 & \\
\hline Total servers & 16 X4440 \\
Processor & AMD Shangai $2.66 \mathrm{GHz}, 256$ cores. \\
RAM memory & 1 TB. \\
Total Teraflops & $\begin{array}{l}2 \text { of generic processing and almost } 30 \text { of vector processing in simple } \\
\text { precision. }\end{array}$ \\
\end{tabular}

Table 5.10: Sun microsystems (Oracle) cluster specifications on TPN. Source: Author, in collaboration with TPN.

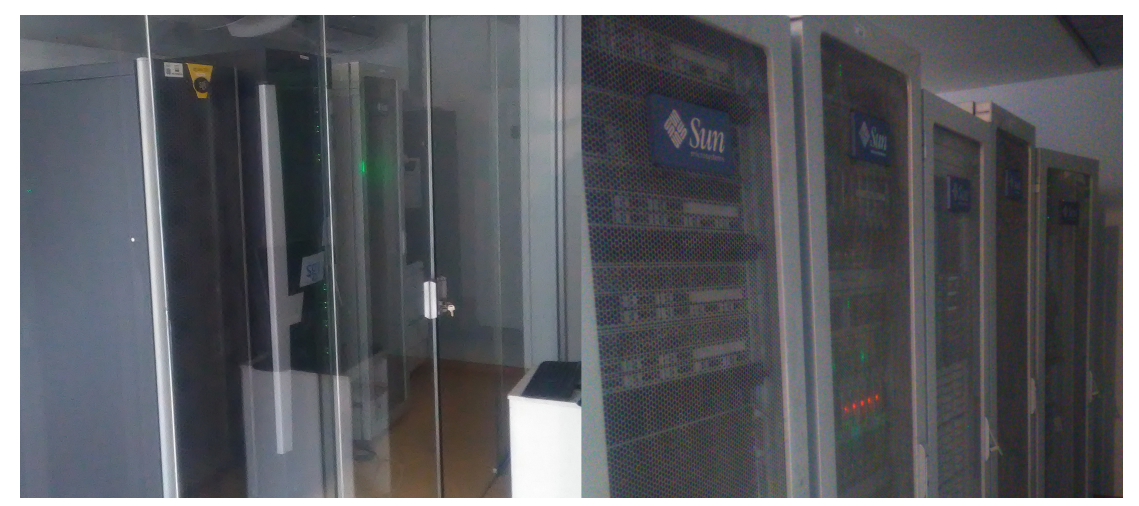

Figure 5.20: TPN clusters. Source: Author. 


\section{$5.7 \quad$ Results}

The comparisons between the empirical methods (for large and medium rivers) and the numerical methods with the experimental result are made and observed in the Figure 5.21, where the numerical method and the empirical method for medium rivers are accurately close to the experimental results.

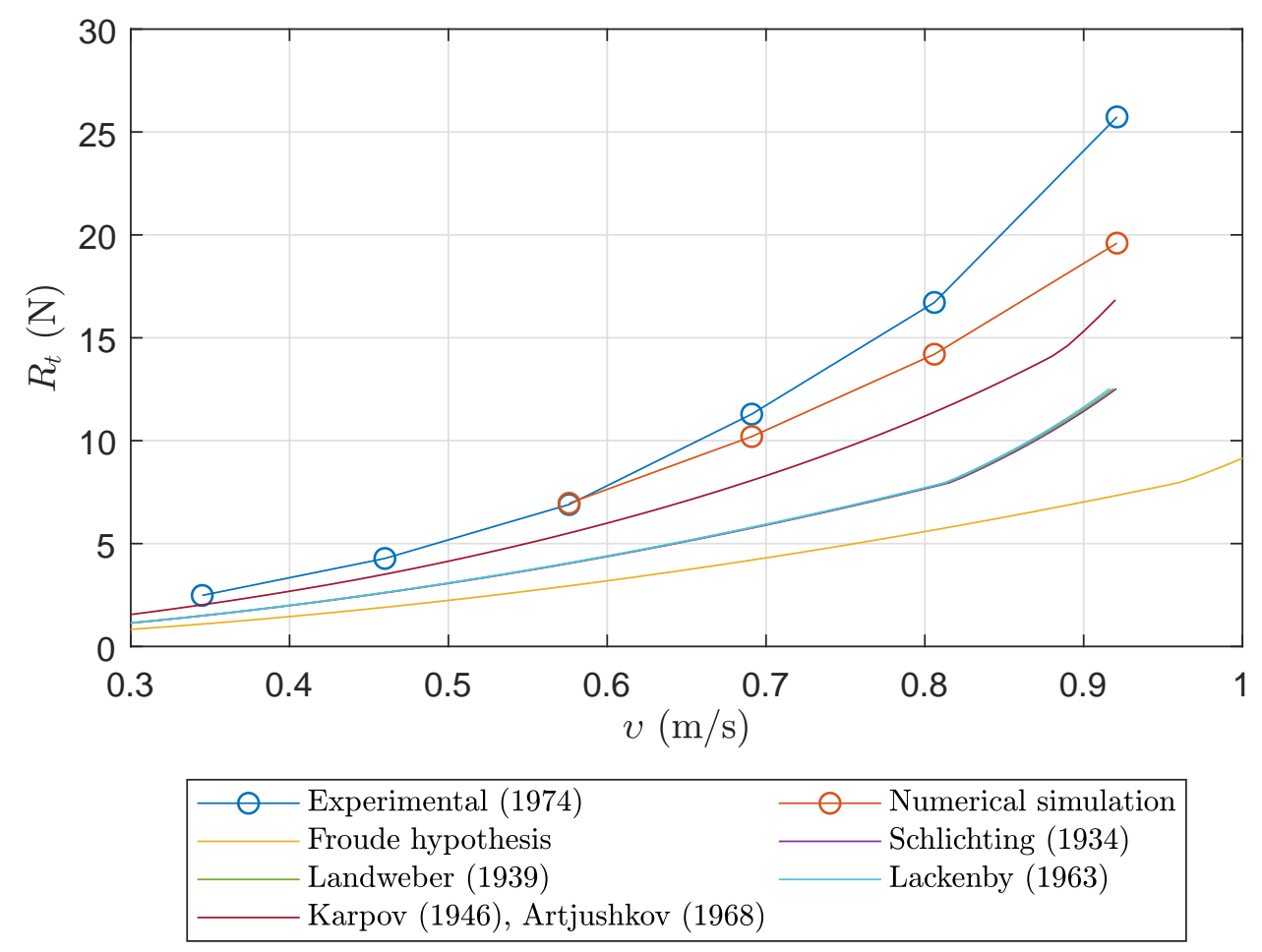

Figure 5.21: Comparison of methods with 2700 TDW inland vessel. Source: Author.

The values obtained from the application of empirical methods applicable for large river operation do not offer, in this study, an accurate prediction of the vessel resistance. The calculation of the coefficient forces are observed in the Figure B.5, where the frictional coefficient resistance are calculated with Reynolds number from $3.5 \cdot 10^{-3}$ to $1.7 \cdot 10^{-3}$. The residual resistance coefficient with infinite velocity is calculated, and the results is constant with $10^{3} C_{r}=0.345$ with length Froude number values up to 0.15. From $\operatorname{Fr}_{L}=0.15$, $10^{3} C_{r}$ the values goes up to 3.5. The values of the loss in velocities (Figure B.4) using Schlichting's method are between $14.93 \%\left(v_{\infty}=0.345 \mathrm{~m} / \mathrm{s}\right)$ and $15.50 \%\left(v_{\infty}=0.921\right.$ $\mathrm{m} / \mathrm{s}$ ). For Lackenby's method, the loss in velocities are between $15.21 \%$ and $15.90 \%$. In the Figure B.6 are shown the comparison of the ship resistance, where the residuary resistance are more higher in shallow waters than in deep waters, because of various factors like the influence of the walls (lateral and bottom), high waves resistance values and other effects. 
The values of the vessel resistance using empirical methods for medium rivers are in better agreement with the experimental results. The velocities $v_{1}$ and $v_{2}$ are calculated from Karpov's diagram (Figure B.7) and are higher than $v_{\infty}$ (maximum of $12.5 \%$ approximately). In the Figure B.8 shows the coefficient forces for middle rivers. The values of the frictional resistance coefficient are higher in comparison with this variable for large rivers. The calculation of the residuary resistance coefficient is constant with value equal to 2.54 and from $F r_{L}=0.15$ this coefficient varies until 2.85. Raven (2012) affirms that the most used empirical methods to estimate shallow water resistance for inland vessels have a very weak theoretical and empirical basis. He recommends the development of new prediction methods that correct separately the components of the total resistance (LINDE et al., 2017).

The results of the numerical method are more accurate at the beginning, but the velocity are higher and the discrepancies appear, described in the Table 5.11. The relative error is necessary to observe the discrepancy between the approximation values and the exact values, and is represented by

$$
E_{r}=\frac{F_{m}-F_{\mathrm{CFD}}}{F_{m}}
$$

where $F_{m}$ is the model resistance that is tested experimentally and $F_{\mathrm{CFD}}$ is the resistance that is calculated numerically.

\begin{tabular}{l|rrr|rr} 
& \multicolumn{3}{|c}{$R_{t}(\mathrm{~N})$} & \multicolumn{2}{c}{ Relative error (\%) } \\
$v(\mathrm{~m} / \mathrm{s})$ & Experimental & CFD & Empirical & CFD & Empirical \\
\hline 0.576 & 6.8941 & 6.9600 & 5.8256 & -0.9563 & 15.4988 \\
0.691 & 11.2875 & 10.2000 & 8.5450 & 9.6342 & 24.2968 \\
0.806 & 16.7105 & 14.2000 & 12.0895 & 15.0236 & 27.6533 \\
0.921 & 25.7228 & 19.6000 & 17.8585 & 23.8031 & 30.5657 \\
\hline
\end{tabular}

Table 5.11: Comparison of numerical and empirical method with experimental results. Source: Author.

The Figure 5.22 shows the numerical results of the hull resistance for each velocity and the behavior is the same. At the beginning, the values are higher and, over time, the resistances are stabilized around 100 seconds.

\subsubsection{Verification of results}

Four meshes with number of elements between 2,231,629 and 10,060,010 were used for the analysis of the grid dependence study simulated in STAR-CCM+. In the Table 5.12 is presented the number of the mesh and the total resistance of the inland vessel. 


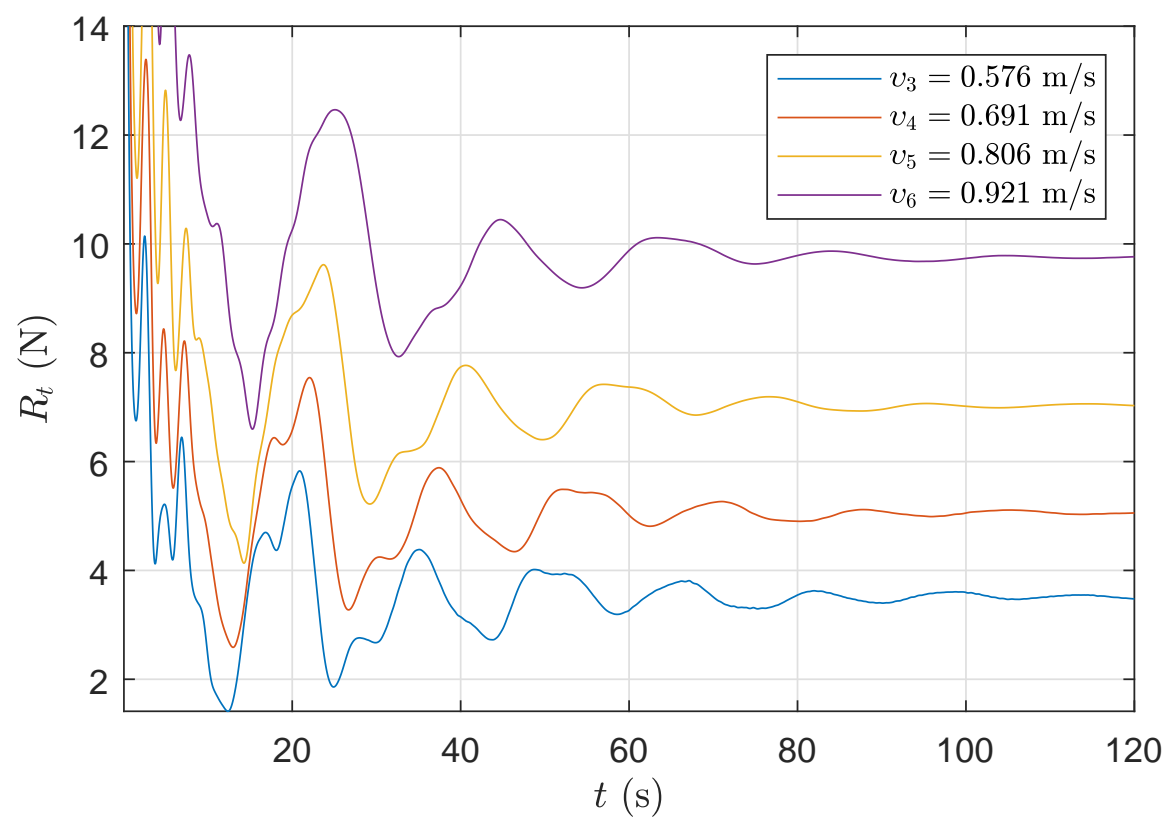

Figure 5.22: Total resistance results of 2700 TDW inland vessel calculated numerically, where the values are half of inland vessel vessel. Source: Author.

The calculation of the resistance for each mesh are shown in the Figure 5.23a, and the difference of the calculated values comparing to the mesh number 1 is illustrated in the Figure 5.23b.

\begin{tabular}{lrr} 
Mesh number $\left(N_{i}\right)$ & Number of cells & Total Resistance $\left(R_{t}\right)$ \\
\hline 1 & 10066010 & 6.946 \\
2 & 8307654 & 6.954 \\
3 & 6080167 & 6.998 \\
4 & 2231629 & 7.044 \\
\hline
\end{tabular}

Table 5.12: Number of cell in the mesh used in the grid dependence study of 2700 TDW inland vessel at $v=0.576 \mathrm{~m} / \mathrm{s}$. Source: Author.

For the discretization errors, the Grid Convergence Index (GCI) will be used, developed by Roache (1998) and described by Celik et al. (2008). This method is recommended by American Society of Mechanical Engineers (ASME) and American Institute of Aeronautics and Astronautics (AIAA) (LINDE et al., 2017).

Checking the articles where the method is used, a constant refinement ratio is represented in the equation (2.1). The fine grid $\left(N_{1}\right)$ consist of approximately 10.07 million cells; the medium grid $\left(N_{2}\right)$ contains about 8.31 million cells; and about 6.08 million cells in the coarse grid $\left(N_{3}\right)$. The solution changes between two successive grids $\iota_{21}$ for 


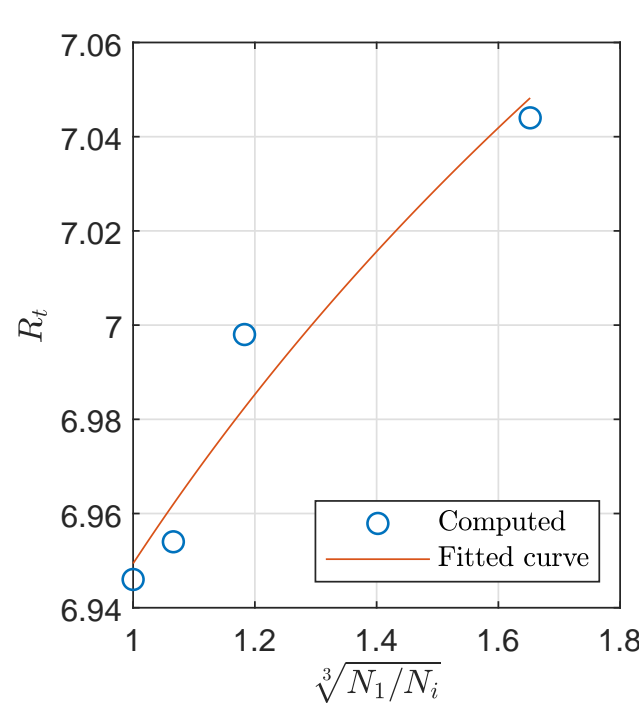

(a) Total resistance

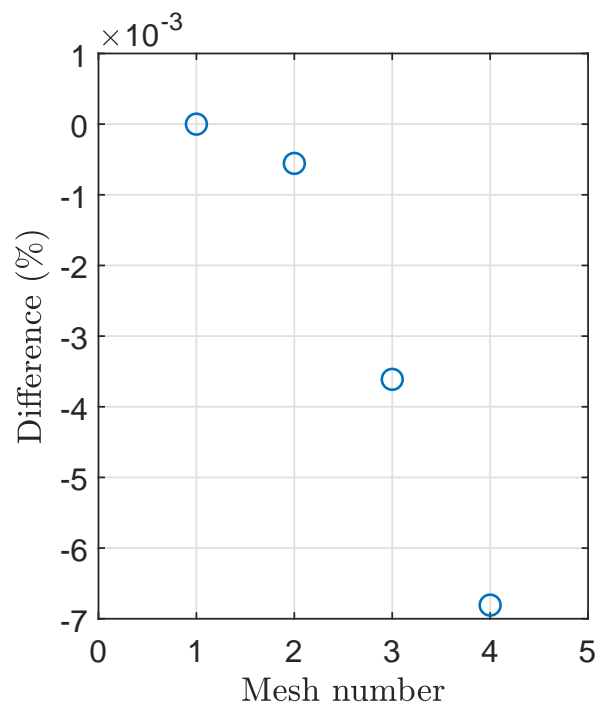

(b) Difference between the meshes

Figure 5.23: Convergence of the total resistance with grid refinement of the 2700 TDW inland vessel performed on $S T A R-C C M+$ at $v=0.576$. Source: Author.

medium-fine meshes and $\iota_{32}$ for coarse-medium meshes are defined as

$$
\iota_{32}=\phi_{3}-\phi_{2}, \quad \phi_{2}-\phi_{1},
$$

where $\phi_{1}, \phi_{2}, \phi_{3}$ are the solutions for fine, medium and coarse $k$ th input parameters. The apparent order $\Upsilon$ of the method is represented by

$$
\Upsilon=\frac{1}{\ln \left(r_{k}\right)}|\ln | \frac{\iota_{32}}{\iota_{21}}||
$$

The extrapolated values could be determinate by

$$
\phi_{\mathrm{ext}}^{21}=\left(r_{k} \phi_{1}-\phi_{2}\right)\left(r_{k}^{\Upsilon}-1\right)
$$

The approximate relative error between medium-fine $e_{a}^{21}$ and coarse-medium $e_{a}^{32}$ solution and the extrapolate relative error between $e_{\text {ext }}^{21}$ and $e_{\text {ext }}^{32}$ are computed as

$$
\begin{aligned}
e_{a}^{21} & =\left|\frac{\phi_{1}-\phi_{2}}{\phi_{1}}\right|, \\
e_{\mathrm{ext}}^{21} & =\left|\frac{\phi_{\mathrm{ext}}^{12}-\phi_{2}}{\phi_{\mathrm{ext}}^{12}}\right| .
\end{aligned}
$$

Finally, the fine-GCI is calculated by

$$
G C I_{\text {fine }}^{21}=\frac{1.25 e_{a}^{21}}{r^{\Upsilon}-1}
$$


The total resistance $R_{t}$ of the vessel is compose of two components: the frictional $R_{f}$ and the pressure $R_{p}$ resistances. The computed values of the resistance and its components of the fine, medium and coarse grids are shown in the Table 5.13. The results of $e_{a}^{21}$ demonstrates that all the resistance have a too small approximate errors. Later, the $G C I_{\text {fine }}^{21}$ values in all resistances are no more than $1 \%$. To maintain the an affordable computational cost, the medium grid is chosen since the errors calculated in all grid set are low.

\begin{tabular}{lrrr} 
Parameter & $R_{p}(\mathrm{~N})$ & $R_{f}(\mathrm{~N})$ & $R_{t}(\mathrm{~N})$ \\
\hline$\phi_{1}$ & 4.3800 & 2.5650 & 6.9450 \\
$\phi_{2}$ & 4.4910 & 2.5634 & 6.9544 \\
$\phi_{3}$ & 4.4320 & 2.5660 & 6.9980 \\
$p$ & 3.7962 & 1.4009 & 4.4272 \\
$\phi_{\text {ext }}^{21}$ & 0.6612 & 1.7025 & 0.7881 \\
$e_{a}^{21}(\%)$ & 0.0025 & 0.0006 & 0.0014 \\
$e_{\text {ext }}^{21}(\%)$ & 5.6244 & 0.5066 & 7.8124 \\
$G C I_{\text {fine }}^{21}(\%)$ & 0.0012 & 0.0012 & 0.0005 \\
\hline
\end{tabular}

Table 5.13: Grid convergence parameters. Source: Author.

\subsubsection{Calculation of the properties}

The following subsections is presented results of the calculation of the properties of the 2700 TDW inland vessel. Pressure coefficient, skin friction coefficient, dimensionless wall distance and wave pattern are visualized. Finally, the wetted surface is illustrated.

In the Figure 5.24a is shown the cross sections that are used to present the results. According to this figure, three transverse cross sections trace along the hull at $x=0.200$ $\mathrm{m}, x=2.000 \mathrm{~m}$ and $x=4.000 \mathrm{~m}$; three longitudinal cross sections trace along the hull at $y=0.005 \mathrm{~m}, y=0.200 \mathrm{~m}$ and $y=0.350 \mathrm{~m}$; and two longitudinal cross sections are located outside of the hull at $y=0.920 \mathrm{~m}$ and $y=1.500 \mathrm{~m}$. In the Figure 5.24b is illustrated the longitudinal cross section in $z$ axis to measure the velocity magnitude and pressure distribution between the hull and wall bottom at $z=-0.240 \mathrm{~m}$.

\subsubsection{Pressure coefficient}

In the Figure 5.25 shows the contour plots of the pressure coefficient on the inland vessel hull. The significant higher pressure is observed for lowest velocity (a). For highest velocity, the pressure is low between the hull and the wall bottom $(\mathrm{d})$. Contour blue color corresponds the air flow. 


\begin{tabular}{l}
$y=1.500$ \\
\hline$y=0.920$ \\
\hline$y=0.350 \quad x=0.200$ \\
$y=0.200$
\end{tabular}

(a) $x-y$ axis

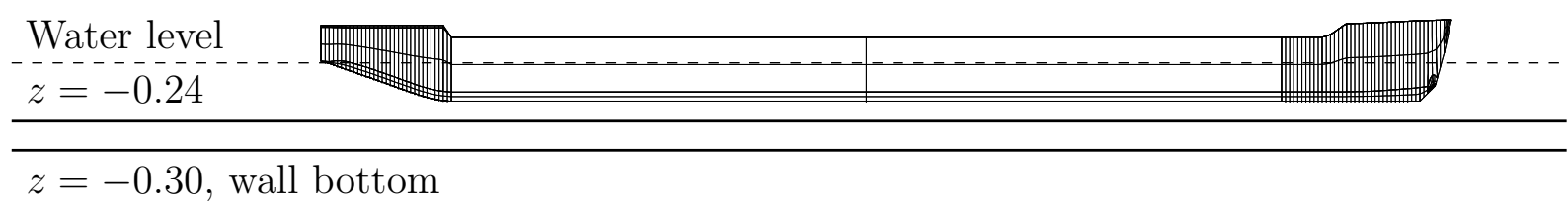

(b) $z-y$ axis

Figure 5.24: Cross sections in scale model at different $x, y$ and $z$ coordinates axis used in the illustrations of the results. The origin point of the computational domain is marked by $\mathrm{O}$, and its position in all coordinate axis is zero $(z=0 \mathrm{~m}$ in the water surface). Source: Author.

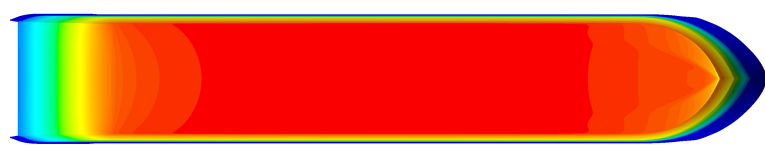

(a) $v=0.576 \mathrm{~m} / \mathrm{s}$

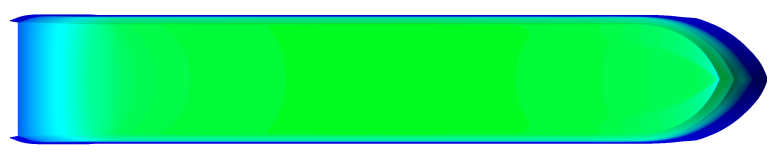

(c) $v=0.806 \mathrm{~m} / \mathrm{s}$

0.044275

3.6412

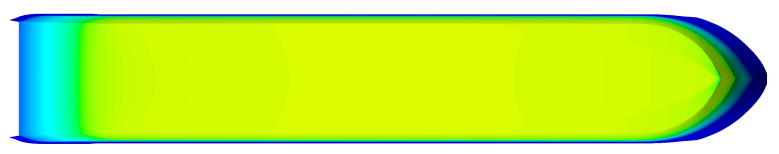

(b) $v=0.691 \mathrm{~m} / \mathrm{s}$

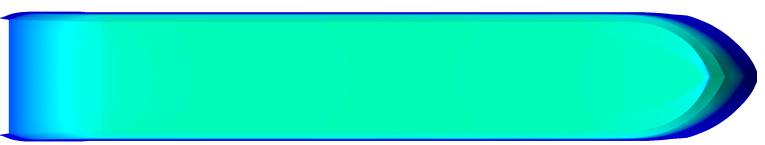

(d) $v=0.921 \mathrm{~m} / \mathrm{s}$

5.4839

Figure 5.25: Contour plots of the pressure coefficient on the inland vessel hull performed on STAR-CCM+. Source: Author.

In the Figure 5.26 are shown the longitudinal cross section of the pressure coefficient on the inland vessel hull. At $y=0.005 \mathrm{~m}$ and $y=0.200 \mathrm{~m}$, the values are similar, but the coefficient is low at the end of the hull beam. The values are more 9 in case of low velocity, and almost 3.5 in case to higher velocity. In the Figure 5.27 are shown the transverse cross section of the pressure coefficient on the inland vessel hull. The values are low at stern but higher at bow and midsection. The plot of these values take the hull geometry form. 


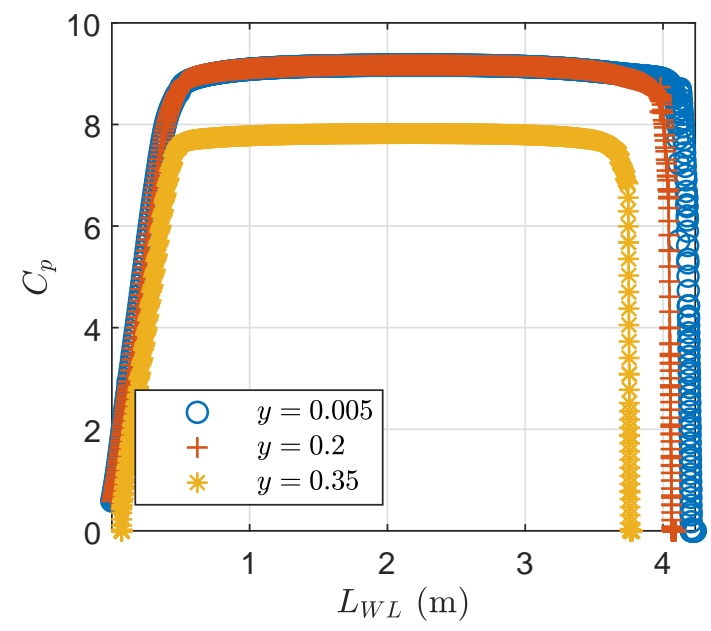

(a) $v=0.576 \mathrm{~m} / \mathrm{s}$

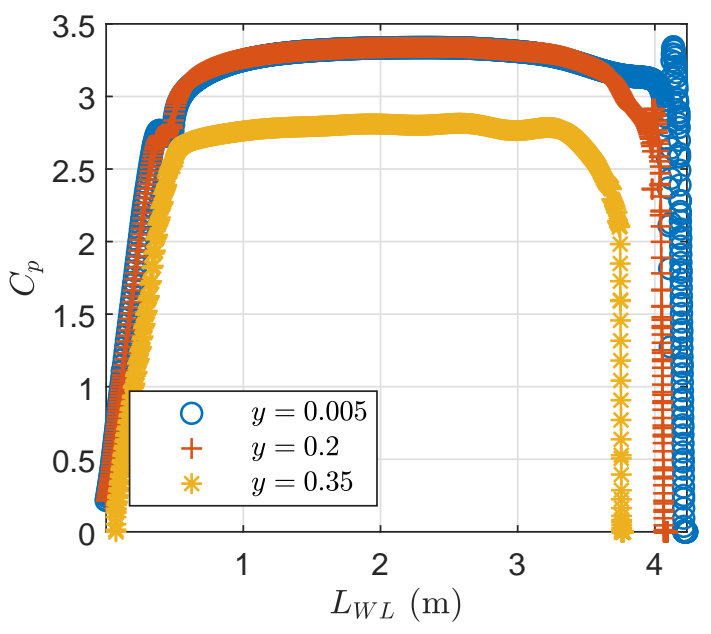

(b) $v=0.921 \mathrm{~m} / \mathrm{s}$

Figure 5.26: Longitudinal cross section of the pressure coefficient on the inland vessel hull at lowest (a) and highest (b) velocities performed on STAR-CCM+. Source: Author.

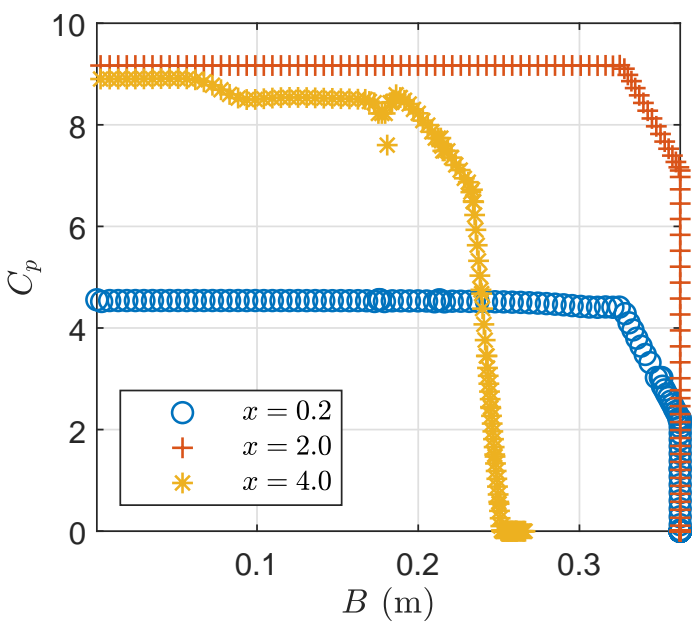

(a) $v=0.576 \mathrm{~m} / \mathrm{s}$

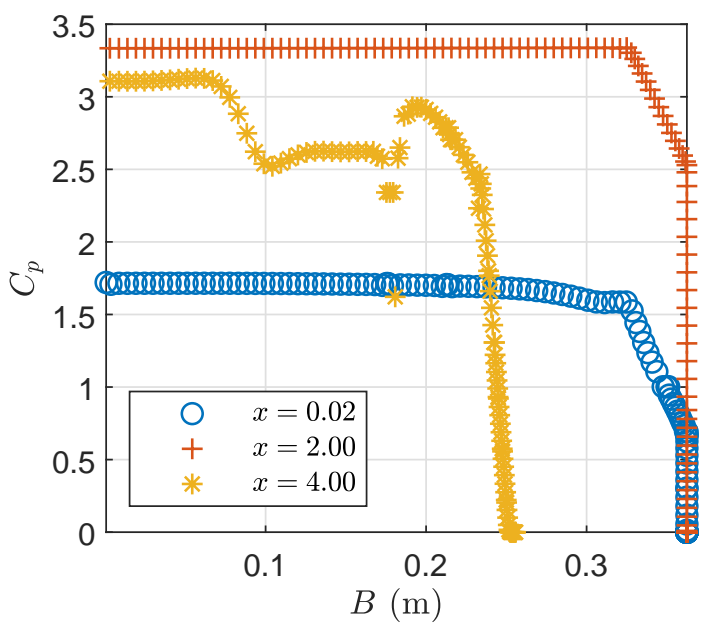

(b) $v=0.921 \mathrm{~m} / \mathrm{s}$

Figure 5.27: Transverse cross section of the pressure coefficient on the inland vessel hull at lowest (a) and highest (b) velocities performed on STAR-CCM+. Source: Author.

\subsubsection{Skin friction coefficient}

In the Figure 5.28 shows the contour plots of the skin friction coefficient on the inland vessel hull. It can be observed that the contour of this coefficient is the same for different velocities, and it is illustrated in the Figures 5.29 and 5.30, where the behavior is similar. The values are maintained in less that 0.01 except in the bow zone, where the values are high. 


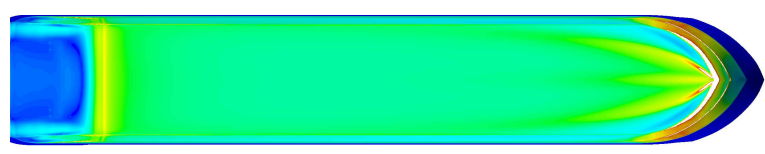

(a) $v=0.576 \mathrm{~m} / \mathrm{s}$

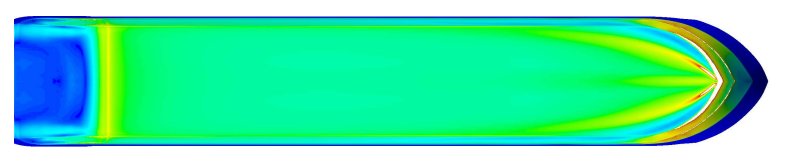

(c) $v=0.806 \mathrm{~m} / \mathrm{s}$

$8.2586 e-07$

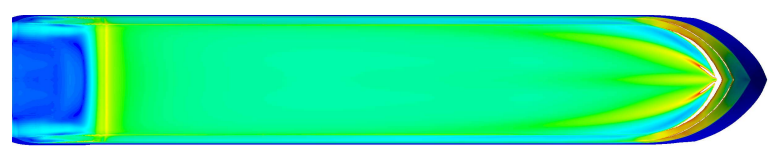

(b) $v=0.691 \mathrm{~m} / \mathrm{s}$

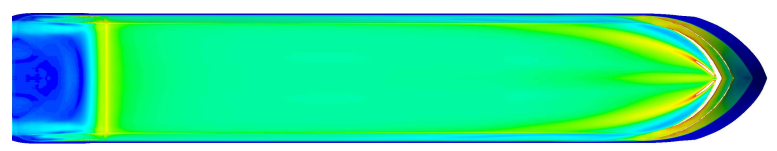

(d) $v=0.921 \mathrm{~m} / \mathrm{s}$

$0.0060003 \quad 0.0080002$ 0.010000

Figure 5.28: Contour plots of the skin friction coefficient on the inland vessel hull performed on STAR-CCM+. Source: Author.

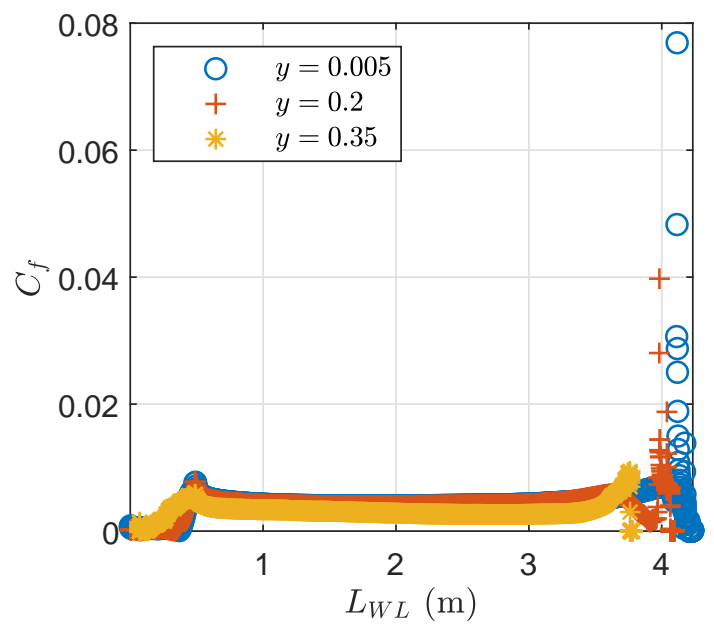

(a) $v=0.576 \mathrm{~m} / \mathrm{s}$

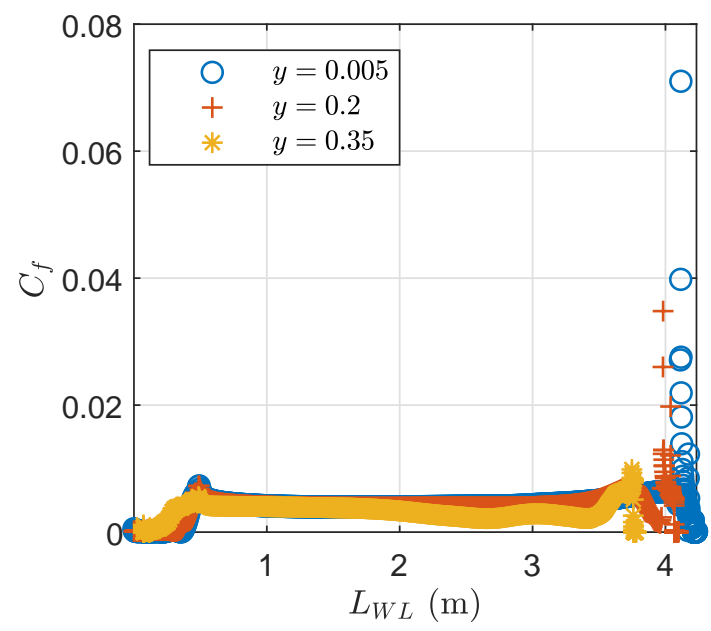

(b) $v=0.921 \mathrm{~m} / \mathrm{s}$

Figure 5.29: Longitudinal cross section of the skin friction coefficient on the inland vessel hull at lowest (a) and highest (b) velocities performed on STAR-CCM+. Source. Author.

\subsubsection{Dimensionless wall distance $y+$}

In the Figure 5.31 shows the contour plots of the dimensionless wall distance on the inland vessel hull. The high values of $y+$ greater than 1 are market in white and it happens in the inland vessel bow. This is because the value of the distance $y$ is based on low velocities and it can be used for highest velocities. However, the distance $y$ can be calculated for different velocities without affecting the numerical simulation results. These measures are observed in the Figures 5.32 and 5.33, where in inland vessel bow is higher in all velocities. The choosing of the first thickness of the prism layer $y+$, the region of the air were not taken account. 


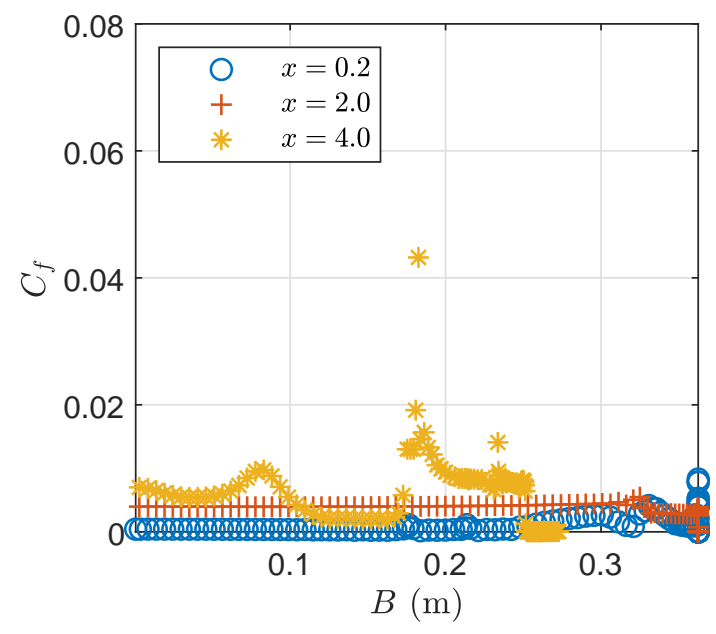

(a) $v=0.576 \mathrm{~m} / \mathrm{s}$

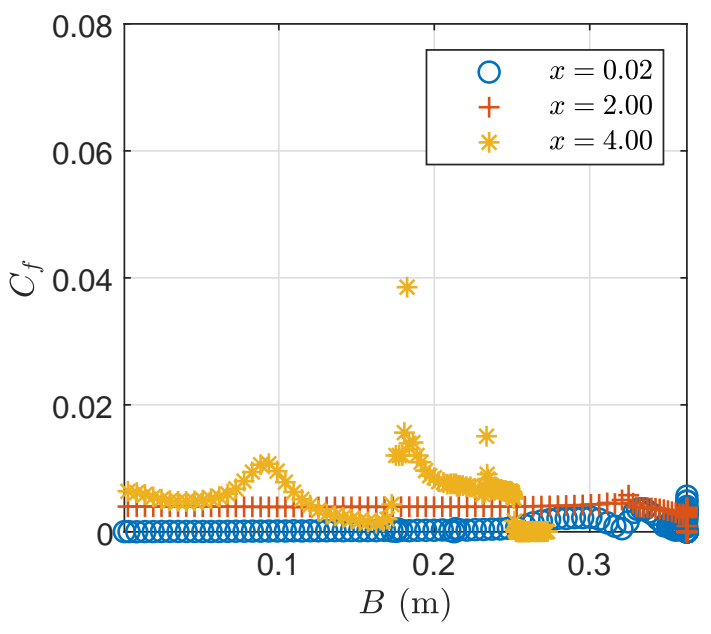

(b) $v=0.921 \mathrm{~m} / \mathrm{s}$

Figure 5.30: Longitudinal cross section of the skin friction coefficient on the inland vessel hull at lowest (a) and highest (b) velocities performed on STAR-CCM+. Source. Author.

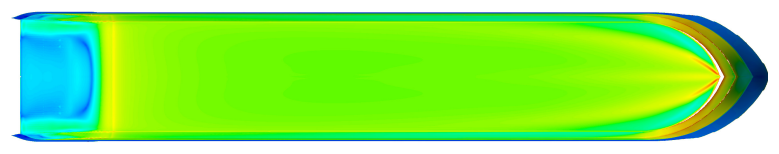

(a) $v=0.576 \mathrm{~m} / \mathrm{s}$

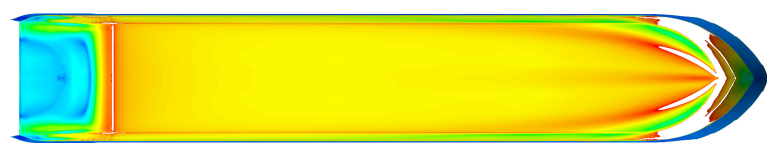

(c) $v=0.806 \mathrm{~m} / \mathrm{s}$

0.019381

0.21551

0.41163

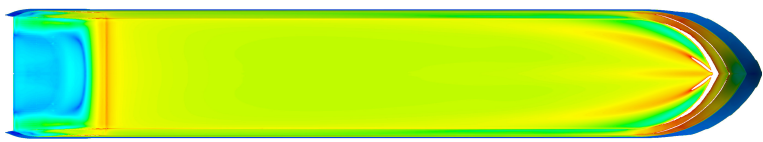

(b) $v=0.691 \mathrm{~m} / \mathrm{s}$

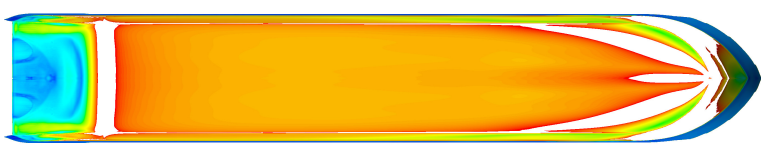

(d) $v=0.921 \mathrm{~m} / \mathrm{s}$

0.60775

1.0000

Figure 5.31: Contour plots of the dimensionless wall distance $y+$ on the inland vessel hull performed on STAR-CCM+. Source. Author.

\subsubsection{Wave pattern}

The wave pattern is generated by the hull of the inland vessel for each velocity, visualized in the Figure 5.34, showing the Kelvin waves system which consists of transverse and divergent waves, and its angulation is titled up to 19 degrees. The presence of the walls causes reflection of the waves. The wave height was measured in the longitudinal cross section outside in the hull and is illustrated in the Figure 5.35. This measure was captured by the mesh created on $S T A R-C C M+$. At lowest velocity, there are more oscillations that highest velocity. Another observation is the level of the water surface at inlet, where is not initiates at origin level. Its mean that the computational domain must be bigger, approximately six times the length of the inland vessel in $x$-direction. 


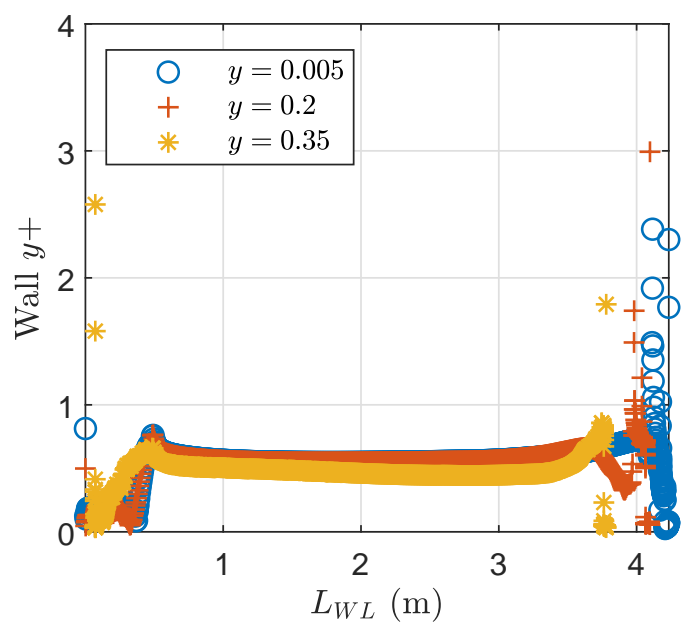

(a) $v=0.576 \mathrm{~m} / \mathrm{s}$

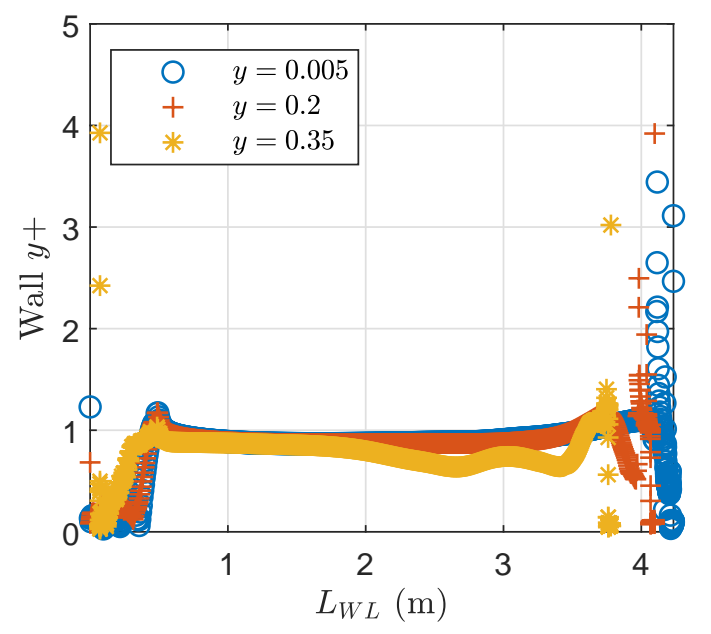

(b) $v=0.576 \mathrm{~m} / \mathrm{s}$

Figure 5.32: Longitudinal cross section of the dimensionless wall $y+$ on the inland vessel hull at lowest (a) and highest (b) velocities performed on STAR-CCM+. Source: Author.

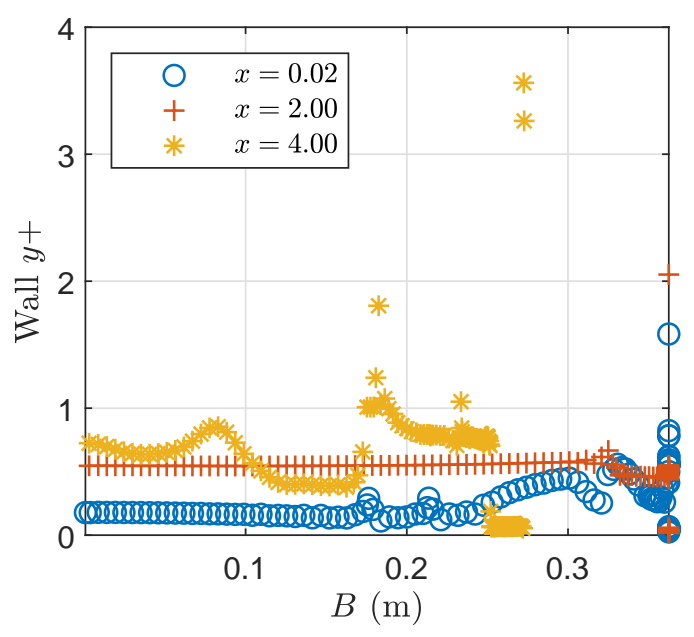

(a) $v=0.921 \mathrm{~m} / \mathrm{s}$

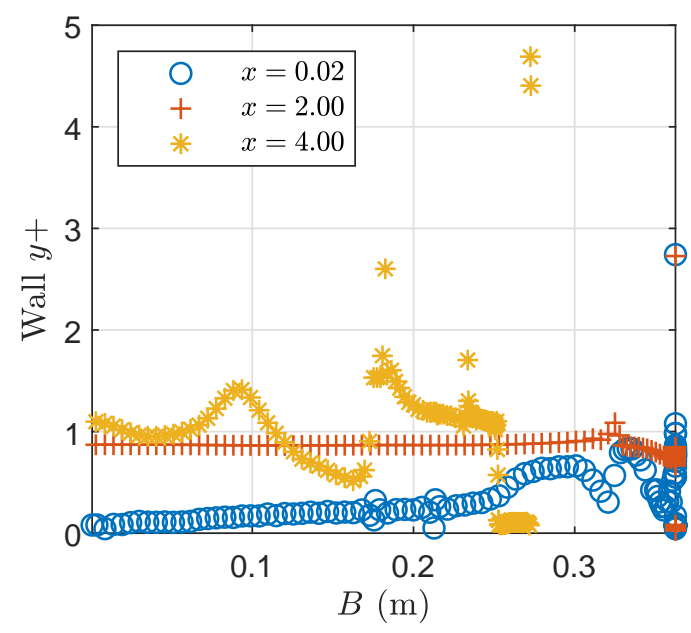

(b) $v=0.921 \mathrm{~m} / \mathrm{s}$

Figure 5.33: Transverse cross section of the dimensionless wall $y+$ on the inland vessel hull at lowest (a) and highest (b) velocities performed on STAR-CCM+. Source: Author.

\subsubsection{Velocity and pressure distribution}

In the Figures 5.36 and 5.37 shows the contour of the velocity distribution of the water in the computational domain. From the symmetry view, there is higher velocity between the hull and the wall bottom. From the top view, there is low velocity distribution of the water at the bow and stern. The space between the wall and the hull there is changes of the velocity distribution of the water.

In the Figures 5.38 and 5.39 shows the contour of the pressure distribution of the 


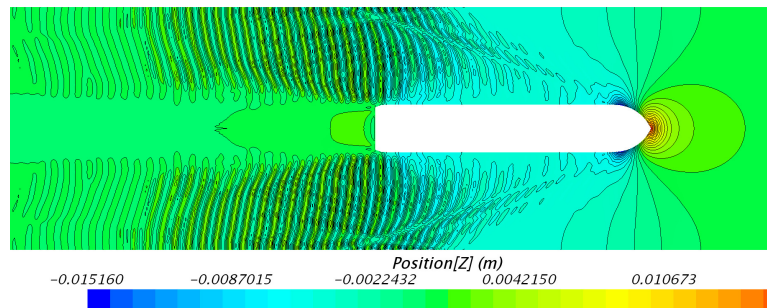

(a) $v=0.576$

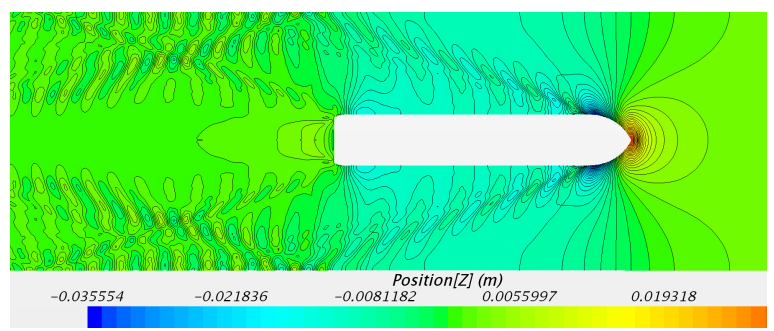

(c) $v=0.806$

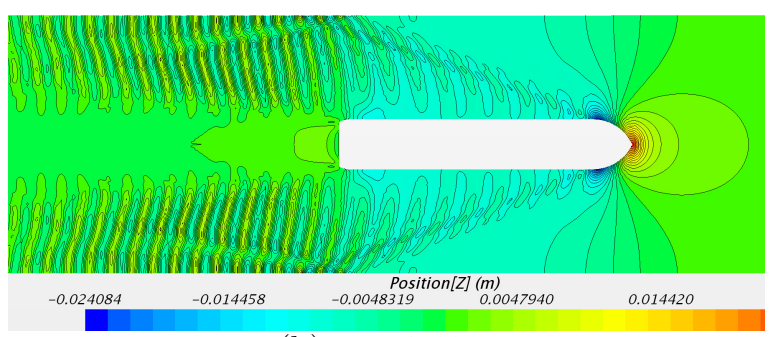

(b) $v=0.691$

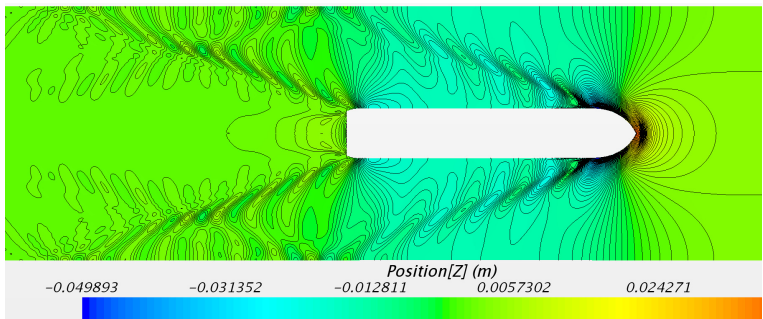

(d) $v=0.921$

Figure 5.34: Wave pattern generated by 2700 TDW inland vessel performed on STAR$C C M+$. Source: Author.
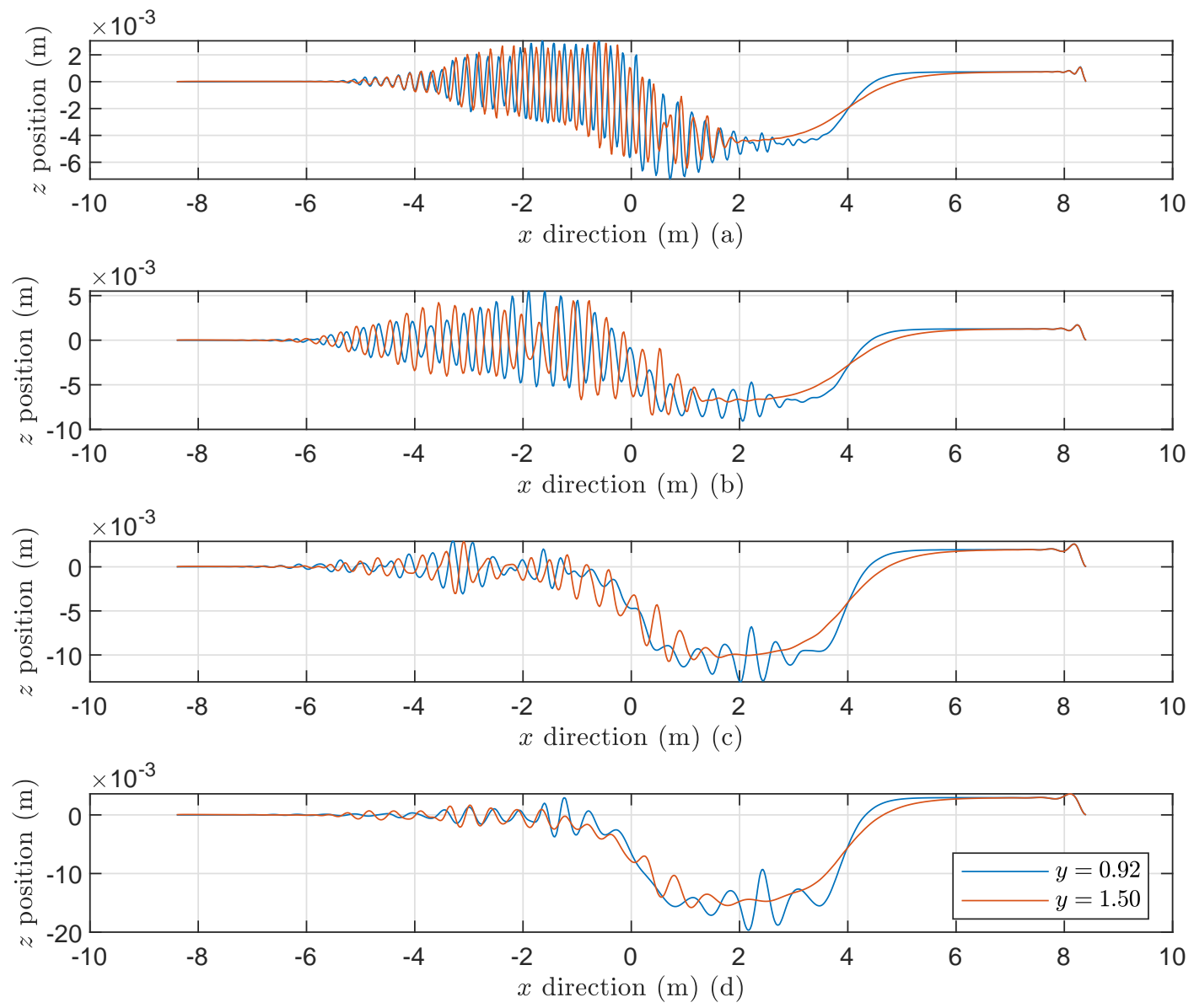

Figure 5.35: Longitudinal cross section of the wave height generated by 2700 TDW inland self-propelled vessel measured in different transversal cross sections at (a) $v=0.576$, (b) $v=0.691,(\mathrm{c}) v=0.806$ and (d) $v=0.921$ performed on STAR-CCM+. Source: Author. 


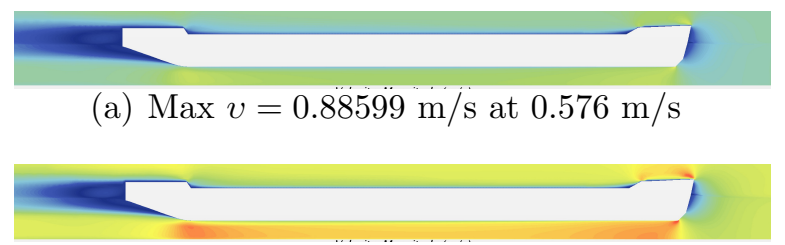

(c) $\operatorname{Max} v=1.2914 \mathrm{~m} / \mathrm{s}$ at $0.806 \mathrm{~m} / \mathrm{s}$

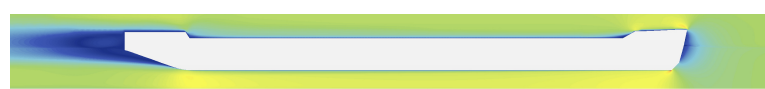

(b) $\operatorname{Max} v=1.0878 \mathrm{~m} / \mathrm{s}$ at $0.691 \mathrm{~m} / \mathrm{s}$

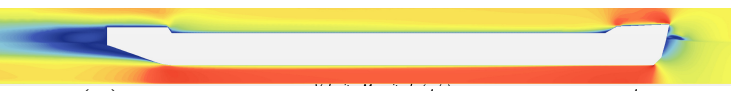

(d) Max $v=1.1487 \mathrm{~m} / \mathrm{s}$ at $0.921 \mathrm{~m} / \mathrm{s}$
0.00000
0.28974
$0.57947^{\circ}$
0.86921
1.1589
1.4487

Figure 5.36: Velocity magnitude on the computational domain (symmetry view) performed on STAR-CCM+. Source: Author.

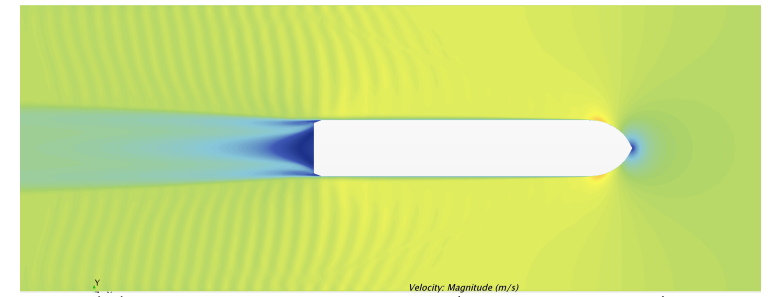

(a) $\operatorname{Max} v=0.77472 \mathrm{~m} / \mathrm{s}$ at $0.576 \mathrm{~m} / \mathrm{s}$

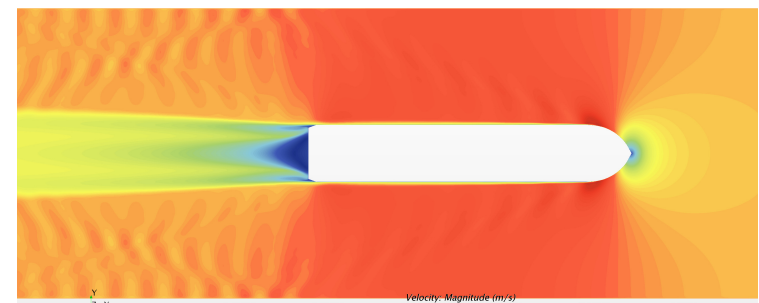

(c) $\operatorname{Max} v=1.0793 \mathrm{~m} / \mathrm{s}$ at $0.806 \mathrm{~m} / \mathrm{s}$

$\begin{array}{lll}0.00000 & 0.23529 & 0.47057\end{array}$

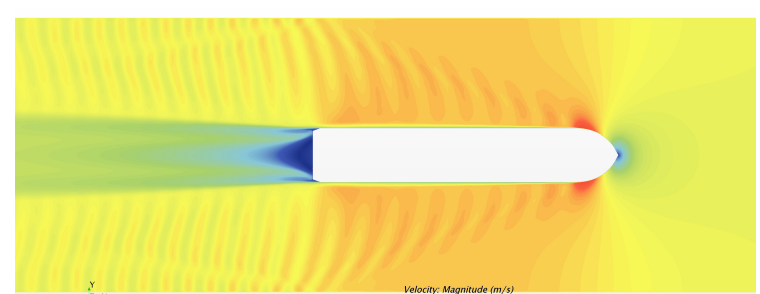

(b) $\operatorname{Max} v=0.94712 \mathrm{~m} / \mathrm{s}$ at $0.691 \mathrm{~m} / \mathrm{s}$

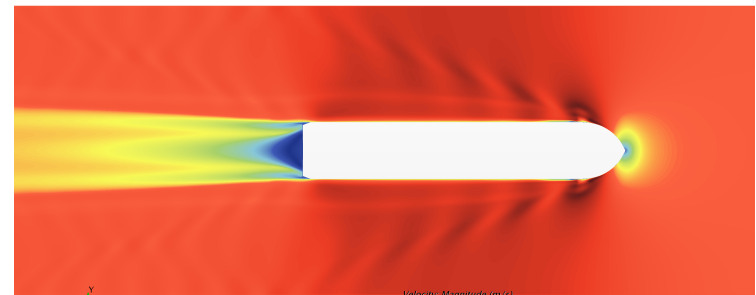

(d) $\operatorname{Max} v=1.1764 \mathrm{~m} / \mathrm{s}$ at $0.921 \mathrm{~m} / \mathrm{s}$

0.70586

0.94115

1.1764

Figure 5.37: Velocity magnitude of of the water generated by 2700 TDW inland vessel at different velocities (top view) performed on $S T A R-C C M+$. Source: Author.

water and air in the computational domain. From the symmetry view, the air flow is marked in blue. There is higher pressure between the hull and wall bottom and there is no changes of the pressure. From the top view, there is significant changes between the wall and the hull. The faster the ship navigates the pressures increase. At the bow, the value of this variable is higher.

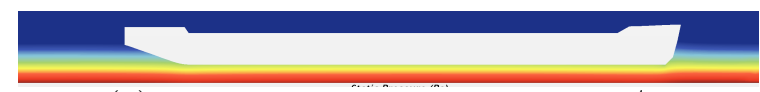

(a) $\operatorname{Max} p=2972.7 \mathrm{~Pa}$ at $0.576 \mathrm{~m} / \mathrm{s}$

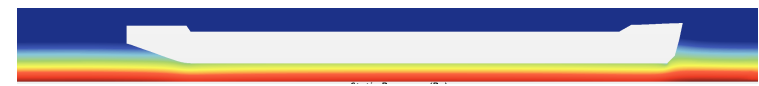

(c) $\operatorname{Max} p=3017.2 \mathrm{~Pa}$ at $0.806 \mathrm{~m} / \mathrm{s}$

604.98

1215.7

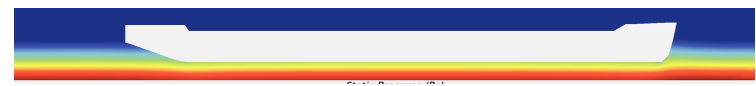

(b) $\operatorname{Max} p=2992.6 \mathrm{~Pa}$ at $0.691 \mathrm{~m} / \mathrm{s}$

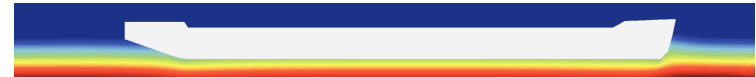

(d) Max $p=3047.8 \mathrm{~Pa}$ at $0.921 \mathrm{~m} / \mathrm{s}$

1826.4

2437.1

3047.8

Figure 5.38: Pressure distribution of the air and water on the computational domain (symmetry view) performed on $S T A R-C C M+$. Source: Author. 
(a) Min $p=144.63 \mathrm{~Pa}, \operatorname{Max} p=455.77 \mathrm{~Pa}$ at $0.576 \mathrm{~m} / \mathrm{s}$

(c) Min $p=0.47628 \mathrm{~Pa}, \operatorname{Max} p=607.50 \mathrm{~Pa}$ at $0.806 \mathrm{~m} / \mathrm{s}$

0.32479 (d) Min $p=0.32479 \mathrm{~Pa}, \operatorname{Max} p=702.41 \mathrm{~Pa}$ at $0.921 \mathrm{~m} / \mathrm{s}$

421.58

562.00

Figure 5.39: Pressure distribution of the water generated by 2700 TDW inland vessel at different velocities (top view) performed on $S T A R-C C M+$. Source: Author.

These effects are agreement with the Bernoulli's principle, explained in the chapter 3. The effect where the velocity of the water is higher between the hull and the bottom wall causing low pressure at this area is called squat. This behavior was measured in the Figure 5.40.
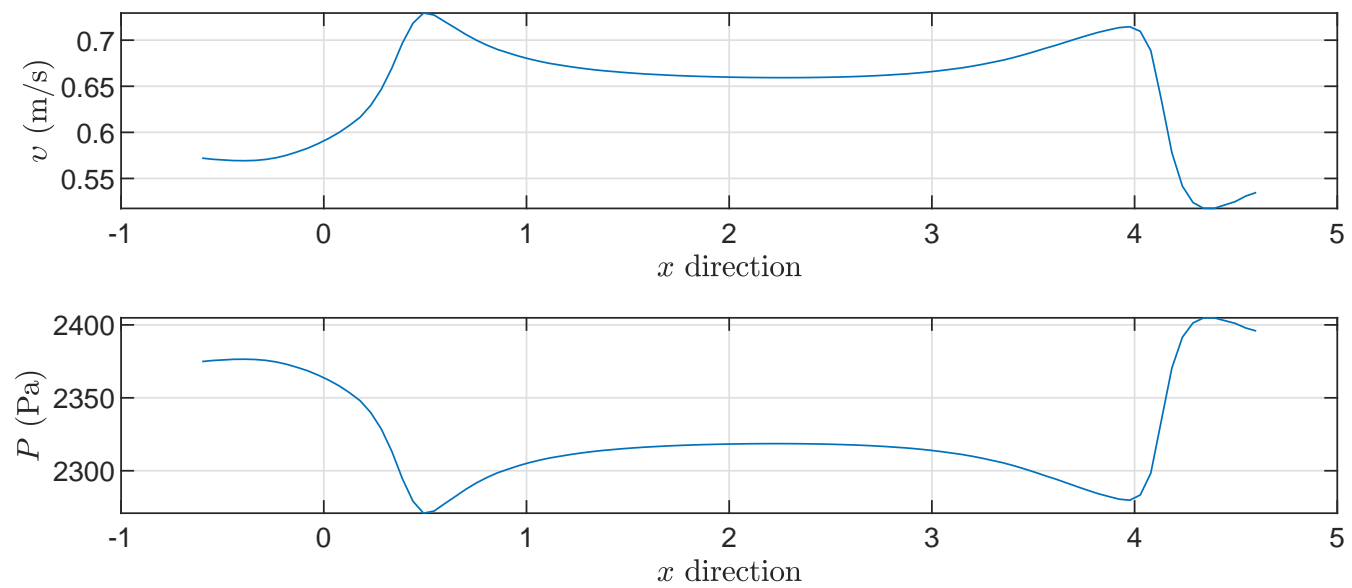

Figure 5.40: Longitudinal cross section of the velocity and the pressure distribution between the hull and wall bottom performed on $S T A R-C C M+$ on $z=-0.24 \mathrm{~m}$ at $v=0.576$ $\mathrm{m} / \mathrm{s}$. Source: Author. 


\subsubsection{Wetted surface of the hull}

In the Figure 5.41 is shown the wetted surface area of the hull obtained from CFDsimulation. From IPT (1974), there is no measurement of the wetted surface for different velocities, thus, it is difficult to make measurements for this variable and there is no conclusions to describe these results.

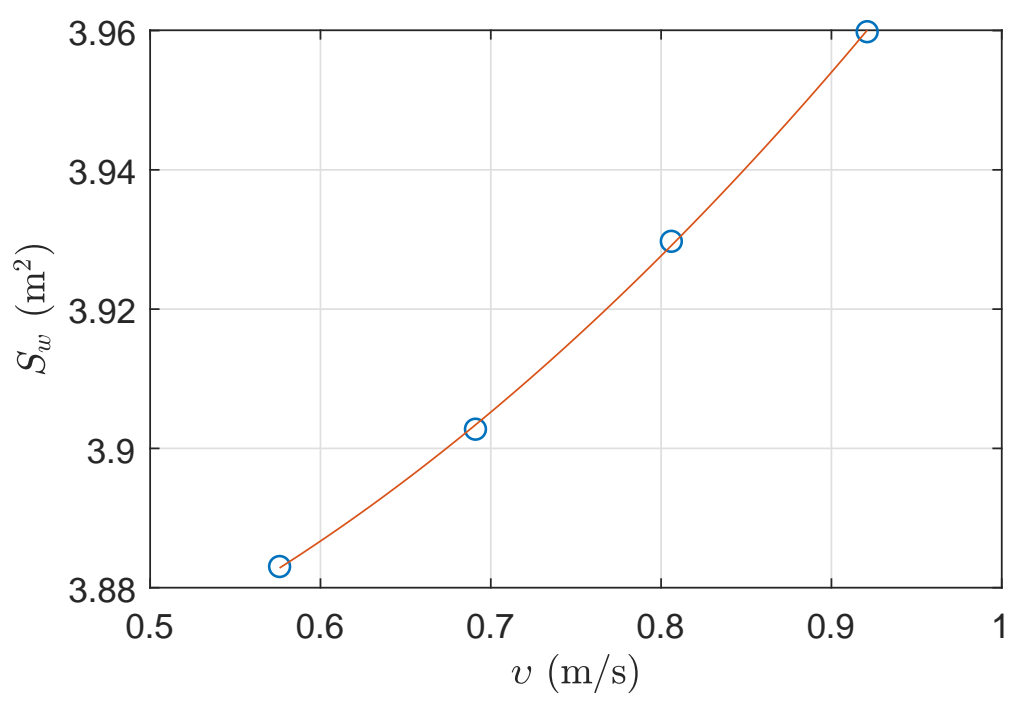

Figure 5.41: Wetted surface area of the 2700 TDW inland self-propelled vessel performed on $S T A R-C C M+$ at different velocities. Source: Author. 


\section{CONCLUSIONS}

The problem solution by CFD allows the collecting data that are difficult to obtain from the experimental tests, for example, the velocity distribution of the water in the computational domain and the streamlines around the hull. The use of CFD can realize the corrections and improvements of the hull in the process design. This is no mean that the experimental test could be replaced by CFD simulation despite the numerical simulations must be faster or cost less.

The conclusions of this study could be listed as follows:

- The formulations for the empirical procedure were satisfactory only in case of vessel navigating in middle rivers in which case the most appropriate is the Karpov's and Artjushkov's method.

- In the case of other methods used in barge operating in large rivers, the width of the affluent is not taken into account, implying less velocity loss. The wave resistance is not taken account instead of residuary resistance is used. Also, the formulations for the application to this shallow water effects are not satisfied for the inland vessel hull in this study.

- The results of the inland vessel resistance by numerical simulation are satisfactory only in case of low speeds. As the speed increases, the relative error also increases up to $18 \%$.

- The GCI applied in the mesh convergence criteria allow the choosing of the number of mesh in the numerical solution. The errors are too small, and the medium grid is chosen to simulate the ship resistance and calculate its properties at different velocities.

- The calculation properties by CFD allow the inside analysis of the performance of the inland vessel that the experimental analysis could be not measured. Is very 
important the comparison of the numerical and the experimental results of some variables, as example, the wetted surface of the hull.

The numerical simulation results can be corrected with more precision in order to obtain results similar to those obtained in cases of navigation in shallow waters. For this purpose, it is important to present the future work, specifying aspects that must be analyzed.

\subsection{Future analysis}

All difficulties found during the development of this research could be listed as follows:

- Execution of test in reduced scale of the 2700 TDW inland vessel for obtaining the analysis as skinage and trim. Also, it must be calculating some measure variables as length of the vessel in waterline, wetted surface area, inclination angle, etc.

- Improves and optimizes the inland vessel hull geometry in bow and stern based on reference as Rotteveel, Hekkenberg and Ploeg (2017) and Tabaczek and Zawiślak (2018).

- Modification of the computational domain size (at last 6.5 times of $L_{\mathrm{WL}}$ of the ship model in $x$ coordinate and 1.2 times of $L_{\mathrm{WL}} z$ coordinate from free surface of the water) and more elements in the grid mesh distribution (approximately 22 million), specially on the free surface and the space between the ship hull and the wall bottom.

- Apply the GCI criteria for the highest velocity imputing parameters (time step or cell size of the mesh) according to Linde et al. (2017).

- Application of the propulsion analysis, where it will study the propeller design and the power required to push the self-propelled inland vessel using CFD software with semi-empirical approach and its validation in model scale.

- Comparison of the experimental and semi-empirical approaches with others CFD software as STAR-CCM+, ANSYS Fluent, OPEN Foam and Nektar++. The relative error must be, at last, increase up to $5 \%$.

- News semi-empirical formulations of the shallow waters that implies the analysis of maneuverability, stability, hull dimensions, skinage, trim and others according to Raven (2012). 


\section{REFERENCES}

ACOSTA-LOPERA, O. D.; CABRERA-TOVAR, J. H. Conceptual Design of an Inland Water Ship Self-Propelled for Coal Transportation to Navigability of the Magdalena River Low Section (in Spanish). 89 p. Thesis (BSc.) — UTB, 2014.

ANSYS. ANSYS Fluent R18.1 user guide. Canonsburg, PA, United States: ANSYS, Inc., 2017.

ANWER, S. F. Basics of Mesh Generation. In: TEQIP School on Computational Methods in Engineering Applications. Kanpur, India: IITK, 2016. Available at: 〈http://www.iitk.ac.in/tkic/workshop/FEM/ppt.php〉.

ARTJUSHKOV, L. Wall Effect Correction for Shallow Water Model Tests. Transactions of North East Coast Institution of Engineers and Shipbuilders, v. 85, n. 2, p. 35-42, 1968.

BARAKAT, H. Z.; CLARK, J. A. Analytical and Experimental study of the Transient Laminar Natural Convection Flows in Partially Filled Liquid Containers. In: 3rd IHTC. Chicago, United States: IHTC, 1966. p. 152-162.

BATCHELOR, G. An Introduction of Fluid Dynamics. Cambridge, United Kingdom: Cambridge University Press, 1967. 615 p.

Bernal Duffo, E. Magdalena River: Primordial scenario of the Fatherland (in Spanish). Credencial Historia, Bogotá, D.C., Colombia, 2013. Available at: 〈http://www.banrepcultural.org/biblioteca-virtual/credencial-historia/numero-282/ el-rio-magdalena-escenario-primordial-de-la-patria.

BERTRAM, V. Practical Ship Hydrodynamics. Oxford, United Kingdom: ButterworthHeinemann, 2000. 270 p.

BOUWMEESTER, J. et al. Recent studies on Push - Towing as a base for Dimensioning Waterways. In: 24th International Navigation Congress. Brussels, Belgium: PIANC, 1977.

Bureau Voorlichting Binnenvaart. Inland Shipping in Numbers (in Dutch). Blue Magazine, Rotterdam, The Netherlands, p. 11, 2011.

Bureau Voorlichting Binnenvaart. Types of Vessels. n.d. Available at: 〈https:// www.bureauvoorlichtingbinnenvaart.nl/inland-navigation-promotion/basic-knowledge/ types-of-vessels $\rangle$.

Castro Pinzón, C. Páramo de las Papas. In: PÉREZ, R. M. (Ed.). Holy Water (in Spanish). Bogotá, D.C., Colombia: Semana, 2017. ch. 3. Available at: 〈http://especiales.semana.com/agua-bendita/paramopapas.html〉.

CD-adapco. STAR-CCM+ Version 9.06 User Guide. Melville, United States: CD-adapco, 2014. 14041 p. 
CELIK, I. B. et al. Procedure for Estimation and Reporting of Uncertainty Due to Discretization in CFD Applications. Journal of Fluids Engineering, v. 130, n. 7, 2008.

ÇENGEL, J. A.; CIMBALA, J. M. Fluid Mechanics: Fundamentals and Applications. 1st. ed. New York, United States: McGraw-Hill, 2006. 929 p.

COURANT, R.; ISAACSON, E.; REES, M. On the Solution of Nonlinear Hyperbolic Differential Equations by Finite Differences. Communications on Pure and Applied Mathematics, v. 5, n. 3, p. 243-255, 1952.

DELEFORTRIE, G.; GEERTS, S.; VANTORRE, M. The Towing Tank for Manoeuvres in Shallow Water. In: ULICZKA, K. et al. (Ed.). 4th MASHCON. Hamburg, Germany: Bundesanstalt für Wasserbau, 2016. p. 266-235.

DEWAN, A. Tackling Turbulent Flows in Engineering. Berlin, Germany: Springer, 2011. $124 \mathrm{p}$.

DURBIN, P. A.; Pettersson Rief, B. A. Statistical Theory and Modeling for Turbulent Flows. 2nd. ed. Chichester, United Kingdom: John Wiley \& Sons, 2011. 357 p.

Encyclopædia Britannica. Canals and Inland Waterways. In: DAVIES, E. A. J.; MARSH, C. M. (Ed.). Encyclopcedia Britannica Ultimate Reference Suite. Chicago, United States: Encyclopædia Britannica, Inc., 2015a.

Encyclopædia Britannica. Fluid. In: Encyclopædia Britannica Ultimate Reference Suite. Chicago, United States: Encyclopædia Britannica, Inc., 2015b.

Encyclopædia Britannica. Froude Number (Fr). In: Encyclopædia Britannica Ultimate Reference Suite. Chicago, United States: Encyclopædia Britannica, Inc., 2015c.

Encyclopædia Britannica. Magdalena River. In: Encyclopcedia Britannica Ultimate Reference Suite. Chicago, United States: Encyclopædia Britannica, Inc., 2015d.

Encyclopædia Britannica. Navier-Stokes Equation. In: HOSCH, W. L. (Ed.). Encyclopadia Britannica Ultimate Reference Suite. Chicago, United States: Encyclopædia Britannica, Inc., 2015e.

Encyclopædia Britannica. Reynolds number. In: Encyclopædia Britannica Ultimate Reference Suite. Chicago, United States: Encyclopædia Britannica, Inc., $2015 f$.

ENGELAND, M. v. FREE!ship Manual. Boston, United States: FREE!ship Project, 2006. 57 p.

EULER, L. General Principles Concerning the Motion of Fluids (in French). Mémoires de lLacadémie des Sciences et des Belles-Lettres de Berlin, n. 11, p. 217-273, 1755.

FIELDING, S. M. Laminar Boundary Layer Theory. Duham, United Kingdom: Durham University, 2005. Available at: 〈https://community.dur.ac.uk/suzanne.fielding/teaching. html $\rangle$.

FORTUNA, A. d. O. Computational Techniques for Fluid Dynamics: Basic Concepts and Applications (in Portuguese). 2nd. ed. São Paulo, Brazil: EDUSP, 2012. 552 p. 
GENTRY, R. A.; MARTIN, R. E.; DALY, B. J. An Eulerian Differencing Method for Unsteady Compressible Flow problems. Journal of Computational Physics, v. 1, n. 1, p. 87-118, 1966.

GEORGAKAKI, A.; SORENSON, S. C. Report on Collected Data and Resulting Methodology for Inland Shipping. Lyngby, Denmark: Department of Mechanical Engineering, DTU, 2004. 110 p.

GULDHAMMER, H. E.; HARVALD, S. A. Ship Resistance Effect of Form and Principal Dimensions. Copenhagen, Denmark: Akademisk Forlag, 1974.

HARVALD, S. A. Resistance and Propulsion of Ships. New York, United States: John Wiley \& Sons, 1983. 353 p.

HIRSCH, C. Numerical Computation of Internal and External Flows: The Fundamentals of Computational Fluid Dynamics. 2nd. ed. Oxford, United Kingdom: ButterworthHeinemann, 2007. 680 p.

HIRT, C.; NICHOLS, B. Volume of Fluid (VOF) Method for the Dynamics of Free Boundaries. Journal of Computational Physics, v. 39, n. 1, p. 201-225, 1981.

HODGE, J. K.; STONE, A. L.; MILLER, T. E. Numerical Solution for Airfoils near Stall in optimized Boundary-Fitted Curvilinear Coordinates. AIAA Journal, v. 17, n. 5, p. $458-464,1979$.

IACCARINO, G. Lectures in Computational Methods in Fluid Dynamics using commercial CFD Codes. Stanford, United States: Stanford University, 2004. Available at: 〈https://web.stanford.edu/class/me469b/index.html〉.

IPT. Resistance Test of Inland Vessel 2700 Self-propelled in Shallow Waters (in Portuguese). São Paulo, Brazil, 1974. 9 p.

ITTC. Proceedings of the 11th ITTC Conference. Madrid, Spain: ITTC, 1957. 347 p.

ITTC. Proceedings of the 18th ITTC Conference. Kobe, Japan: ITTC, 1987. 502 p.

ITTC. Recommended Procedures and Guidelines. Lyngby, Denmark: ITTC, 2014.

JANSEN, P.; SCHIJF, J. The Relation between the form of Cross Section, the method of Revetment and the Distribution of the Water Velocities in a Waterway. In: Proceedings of 18th International Navigation Congress. Rome, Italy: PIANC, 1953. p. 175-197.

JI, S. C. 3D Numerical Modelling of Shipwaves and associated Sediment Transport (in French). 130 p. Thesis (PhD) — UTC, 2013.

JI, S. C. et al. 3-D numerical simulation of convoy-generated waves in a restricted waterway. Journal of Hydrodynamics, Publishing House for Journal of Hydrodynamics, v. 24, n. 3 , p. $420-429,2012$.

KARPOV, A. Calculation of Ship Resistance in Restricted Waters (in Russian). TRUDY GII. T. IV, v. 2, 1946.

LACKENBY, H. The Effect of Shallow Water on Ship Resistance. The Shipbuilder and the Marine Engine-Builder, v. 70, n. 672, 1963. 
LANDWEBER, L. Test of a Model in Restricted Channels. Washington, D.C., United States: DTMB, 1939. 32 p.

LATORRE, R.; LUTHRA, G.; TANG, K. Improvement of Inland Waterway Vessel and Barge Tow Performance: Translations of selected Chinese, German and Russian Technical Articles (Report No. 249). Ann Arbor, United States: Department of Naval Architecture and Marine Engineering, College of Engineering, University of Michigan, 1982. $73 \mathrm{p}$.

LAUNDER, B. E.; SPALDING, D. B. Lectures in Mathematical Models of Turbulence. London, United Kingdom: Academic Press, 1972. 169 p.

LAUNDER, B. E.; SPALDING, D. B. The Numerical Computation of Turbulent Flows. Computer Methods in Applied Mechanics and Engineering, v. 3, n. 2, p. 269-289, 1974.

LEWIS, E. V. (Ed.). Principles of Naval Architecture. 2. ed. Jersey City, United States: SNAME, 1988. 327 p.

LINDE, F. et al. Three-dimensional Numerical Simulation of Ship Resistance in Restricted Waterways: effect of Ship Sinkage and Channel Restriction. Journal of Waterway, Port, Coastal, Ocean Engineering, v. 143, n. 1, p. 1-11, 2017.

LIU, Y. et al. Numerical Predictions of Hydrodynamic Forces and Squat of Ships in Confined Waters. In: LIU, G.; HAN, X.; LI, Z. (Ed.). Proceedings of the 8th ICCM. Guilin, Guangxi, China: Scientech Publisher LLC, 2017. p. 1095-1110.

MALISKA, C. R. Heat Transfer and Computational Fluid Mechanics (in Portuguese). Rio de Janeiro, Brazil: LTC Editora S.A., 1995. 424 p.

MENTER, F. R. Zonal Two Equation $k-\omega$ Turbulence Models for Aerodynamic Flows. In: 23rd Fluid Dynamics, Plasmadynamics, and Lasers Conference. Orlando, United States: AIAA, 1993. p. 21.

Merriam-Webster. The Merriam-Webster's Collegiate Dictionary. 11th. ed. Springfield (MA), United States: Merriam-Webster, Inc., 2004. 939 p.

Ministry of Transport - Colombia. Transportation in Numbers - Statistics 2017 (in Spanish). Bogotá, D.C., Colombia, 2018. 107 p.

MOLlAnD, A. F.; TURNOCK, S. R.; HUDSON, D. A. Ship Resistance and Propulsion. New York, United States: Cambridge University Press, 2011. 537 p.

MOLLAND, A. F.; WILSON, P.; TAUNTON, D. Resistance Experiments on a Systematic Series of High Speed Displacement Monohull and Catamaran forms in Shallow Water. Transactions of the Royal Institution of Naval Architects. Part A: International Journal of Maritime Engineering, v. 2, n. 146, p. 19-38, 2004.

NAVIER, C.-L.-M.-H. Memory on the Laws of the Movement of Fluids (in French). Mémoires de l'Académie Royale des Sciences Paris, n. 6, p. 389-416, 1822.

NOH, W.; WOODWARD, P. SLIC (Simple Line Interface Calculation). In: VOOREN, A. van de; ZANDBERGEN, P. (Ed.). Proceedings of the 5th International Conference on Numerical Methods in Fluid Dynamics. Berlin, Germany: Springer, 1976. Lecture Notes in Physics, v. 59, p. 330-340. 
NORRIS, S. E. A Parallel Navier-Stokes Solver for Natural Convection and Free Surface Flow. 229 p. Thesis (Ph.D.) — University of Sydney, 2000.

PATANKAR, S. V.; SPALDING, D. B. A calculation Procedure for Heat, Mass and Momentum Transfer in Three-Dimensional Parabolic Flows. International Journal of Heat and Mass Transfer, v. 15, n. 10, p. 1787-1806, 1972.

PATHAK, A.; RAESSI, M. A Three-Dimensional Volume-of-Fluid Method for reconstructing and advecting Three-Material Interfaces forming Contact Lines. Journal of Computational Physics, Elsevier Inc., v. 307, p. 550-573, 2016.

PletChER, R. H.; TANNEHILL, J. C.; ANDERSON, D. A. Computational Fluid Mechanics and Heat Transfer. 3rd. ed. Boca Raton, United States: CRC Press, 2013. $740 \mathrm{p}$.

POMMIER, M.; SELMI, M. Optimization of the Section of a Navigation Channel, study by Mathematical and Physical models. La Houille Blanche, n. 2, 1981.

POMPÉE, P.-J. About Modelling Inland Vessels Resistance and Propulsion and Interaction Vessel - Waterway. Key Parameters driving Restricted/Shallow Water Effects (Paper 180). In: PIANC. 7th International PIANC-SMART Rivers Conference. Buenos Aires, Argentina: PIANC, 2015.

RAVEN, H. C. A Computational Study of Shallow-Water Effects on Ship Viscous Resistance. In: Proceedings of 29th Symposium on Naval Hydrodynamics. Gothenburg, Sweden: Chalmers University of Technology, 2012.

REYNOLDS, O. An Experimental Investigation of the Circumstances Which Determine Whether the Motion of Water Shall Be Direct or Sinuous, and of the Law of Resistance in Parallel Channels. Philosophical Transactions of the Royal Society of London., v. 174, p. 935-982, 1883.

REYNOLDS, O. On the Dynamical Theory of Incompressible Viscous Fluids and the Determination of the Criterion. Philosophical Transactions of the Royal Society of London. (Serie A.), v. 186, p. 123-164, 1895.

RICHARDSON, L. F. The Approximate Arithmetical Solution by Finite Differences of physical problems involving Differential Equations, with an application to the Stresses in a Masonry Dam. Philosophical Transactions of the Royal Society A, v. 210, n. 459-470, p. 307-357, 1910.

ROACHE, P. J. Verification and Validation in Computational Science and Engineering. Albuquerque, United States: Hermosa Publications, 1998. 464 p.

ROTTEVEEL, E.; HEKKENBERG, R.; PLOEG, A. van der. Inland Ship Stern Optimization in Shallow Water. Ocean Engineering, Elsevier Ltd., v. 141, p. 555-569, 2017.

RUNCHAL, A.; WOLFSHTEIN, M. Numerical Integration Procedure for the Steady State Navier-Stokes Equations. Journal of Mechanical Engineering Science, v. 11, n. 5, p. $445-453,1969$. 
SAVEY, P. Hydraulic Phenomena related to the Passage of a Boat in a Canal. In: The defense of Banks, Canals and Rivers (in French). Paris, France: ENPC, 1977. ch. 2.

SCHIJF, J. Protection of Embankments and Bed in Inland and Maritime Waters, and in Overflows or Weirs (in French). In: Proceedings of 17th International Navigation Congress. Lisbon, Portugal: PIANC, 1949. p. 61-78.

SCHLICHTING, H. Boundary-Layer Theory. 7nd. ed. New York, United States: McGraw-Hill, 1979. 817 p.

SCHLICHTING, O. Ship Resistance in Water of Limited Depth - Resistance of Seagoing Vessels in Shallow Water (in German). Janhrbuch der Schiffbautechnischen Gesellshaft, v. 35 , p. 127-148, 1934.

SHIH, T.-H. et al. A new $k-\epsilon$ Eddy Viscosity Model for High Reynolds Number Turbulent Flows. Computers and Fluids, v. 24, n. 3, p. 227-238, 1995.

STOKES, G. G. On the Theories of the Internal Friction of Fluids in Motion and of the Equilibrium and Motion of Elastic Solids. Transactions of the Cambridge Philosophical Society, v. 8, p. 287-305, 1845.

STULL, R. Meteorology for Scientists and Engineers. 2. ed. Pacific Grove, United States: Brooks/Cole, 2000. 502 p.

TABACZEK, T.; ZAWIŚLAK, M. Hull Resistance of An Inland Waterway Vessel in Model Scale and in Full Scale. Polish Maritime Research, v. 25, n. s1, p. 80-84, 2018.

TAMAMIDIS, P.; ASSANIS, D. N. Evaluation of Various High-Order-Accuracy Schemes with and without Flux Limiters. International Journal for Numerical Methods in Fluids, v. 16, n. 10, p. 931-948, 1993.

TENAUD, R. Model tests and Mathematical models for the Study of the Passage of Pushed Convoys in a Canal and Defenses of the Banks (in French). In: Proceedings of 24h International Navigation Congress. Leningrad, Russia: PIANC, 1977.

THOMPSON, C.; WILKERS, N. Experiments with Higher-Order Finite Difference Formulae. Harwell, Oxfordshire, United Kingdom, 1982.

TU, J.; YEOH, G.-H.; LIU, C. Computational Fluid Dynamics: A Practical Approach. 2nd. ed. Oxford, United Kingdom: Butterworth-Heinemann, 2008. 480 p.

TUPPER, E. C. Introduction to Naval Architecture. 4th. ed. Oxford, United Kingdom: Butterworth-Heinemann, 2004. 446 p.

VERSTEEG, H. K.; MALALASEKERA, W. An Introduction to Computational Fluid Dynamics, The Finite Volume Methods. 2nd. ed. Harlow, United Kingdom: Pearson Education Limited, 2007. 503 p.

WARMING, R.; BEAM, R. M. Upwind Second-Order Difference Schemes and Applications in Aerodynamic Flows. AIAA Journal, v. 14, p. 1241-1249, 1976.

WHITE, F. M. Viscous Fluid Flow. 2nd. ed. New York: McGraw-Hill, 1991. 614 p. 
WHITE, F. M. Fluid Mechanics. 7th. ed. New York, United States: McGraw-Hill, 2011. $862 \mathrm{p}$.

WILCOX, D. C. Reassessment of the Scale-Determining Equation for Advanced Turbulence Models. AIAA Journal, v. 26, n. 11, p. 1299-1310, 1988.

WILCOX, D. C. Turbulence Modeling for CFD. 2nd. ed. La Cañada, United States: DCW Industries, Inc., 1998. 540 p.

YAKHOT, V. et al. Development of Turbulence Models for Shear Flows by a Double Expansion Technique. Physics of Fluids, v. 4, n. 7, p. 1510-1520, 1992. 


\section{APPENDIX A - GRAPHICS AND TABLES}

This appendix shows the graphics of residuary resistance coefficient, made by Guldhammer and Harvald (1974). Also, the table of Georgakaki and Sorenson (2004) is included for generation of a code made in MATLAB.

\begin{tabular}{|c|c|c|}
\hline Factor & Value & Limits \\
\hline$\alpha^{*}$ & 1 & $x<0.2$ \\
\hline$\alpha^{*}$ & $\begin{array}{l}\left(1.072817327-2.95517983 x+2.677257924 x^{2}-0.34935866 x^{3}+\right. \\
\left.0.242040284 \ln (y / 10)+0.09728855(\ln (y / 10))^{2}\right) /(1- \\
2.65876522 x+2.128572396 x^{2}+0.196411142 \ln (y / 10)+ \\
\left.0.05573344(\ln (y / 10))^{2}-0.01424796(\ln (y / 10))^{3}\right)\end{array}$ & $0.2<x<0.75$ \\
\hline$\alpha^{*}$ & $\begin{array}{l}\left(1.016019336+12.53814509 \ln x+53.26949464(\ln x)^{2}+\right. \\
\left.74.73282869(\ln x)^{3}+0.001376743 \ln (y / 10)\right) /(1+ \\
12.31125171 \ln x+52.09394682(\ln x)^{2}+72.79361228(\ln x)^{3}- \\
0.00395828 \ln (y / 10))\end{array}$ & $0.75<x<0.9$ \\
\hline$\alpha^{*}$ & 1 & $x>0.9$ \\
\hline$\alpha^{* *}$ & $\begin{array}{l}\left(0.951498465+0.090322144 \ln y-0.02585333(\ln y)^{2}+\right. \\
\left.0.003378671(\ln y)^{3}-2.05546622 x+1.088478007 x^{2}\right) /(1+ \\
0.03275693 \ln y-0.0036447(\ln y) 2-2.17156612 x+ \\
\left.1.407458972 x^{2}-0.18634398 x^{3}\right)\end{array}$ & $\alpha^{* *}<1$ \\
\hline$V_{\infty} / V^{\prime}$ & $\begin{array}{l}(1.201296612-0.24893659 y+0.753380571 \ln z+ \\
\left.0.004502733(\ln (z))^{2}\right) /\left(1-0.21424821 y-0.00366378 y^{2}+\right. \\
\left.0.000121814 y^{3}+0.708479783 \ln z\right)\end{array}$ & \\
\hline$\Delta C_{r}$ & $\begin{array}{l}0.001\left(-0.10885912+0.023641012 y-0.00248865 y^{2}+\right. \\
\left.0.0000856328 y^{3}-0.02474568 \ln z-0.00476151(\ln z)^{2}\right) /(1- \\
0.03640844 y+0.001560549 y^{2}+1.696914134 \ln z+ \\
\left.0.943623478(\ln z)^{2}+0.194816129(\ln z)^{3}\right)\end{array}$ & \\
\hline
\end{tabular}

Table A.1: Equations for the approximation of factors $\alpha^{*}, \alpha^{* *}, V_{\infty} / V^{\prime}$ and $\Delta C_{r}$. Parameters: $x=F_{h}, y=h / T, z=B / b$. Source: Georgakaki and Sorenson (2004). 


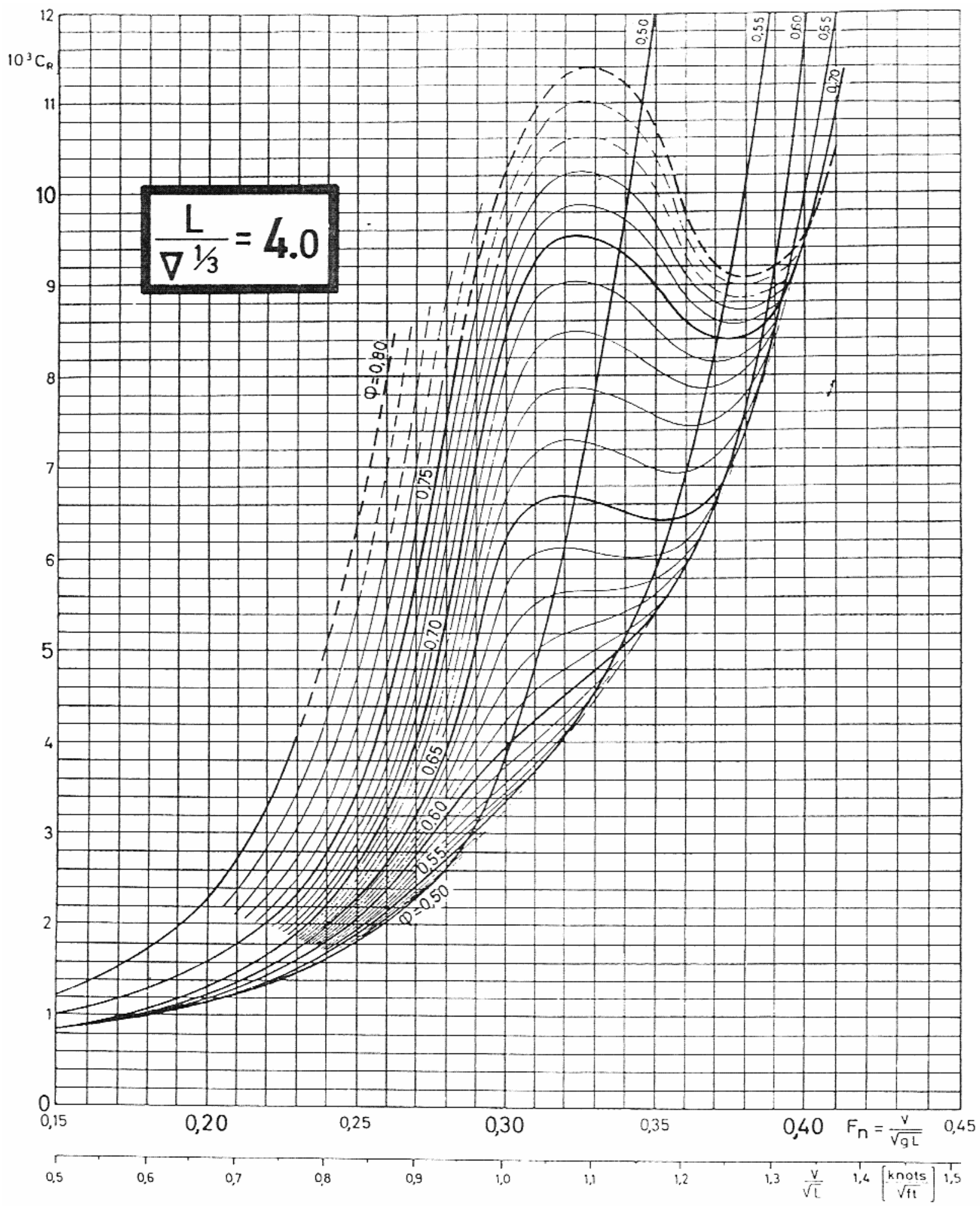

Figure A.1: Residuary resistance coefficient versus length Froude number for different values of longitudinal prismatic coefficient. $M=4$.0. Source: Harvald (1983). 


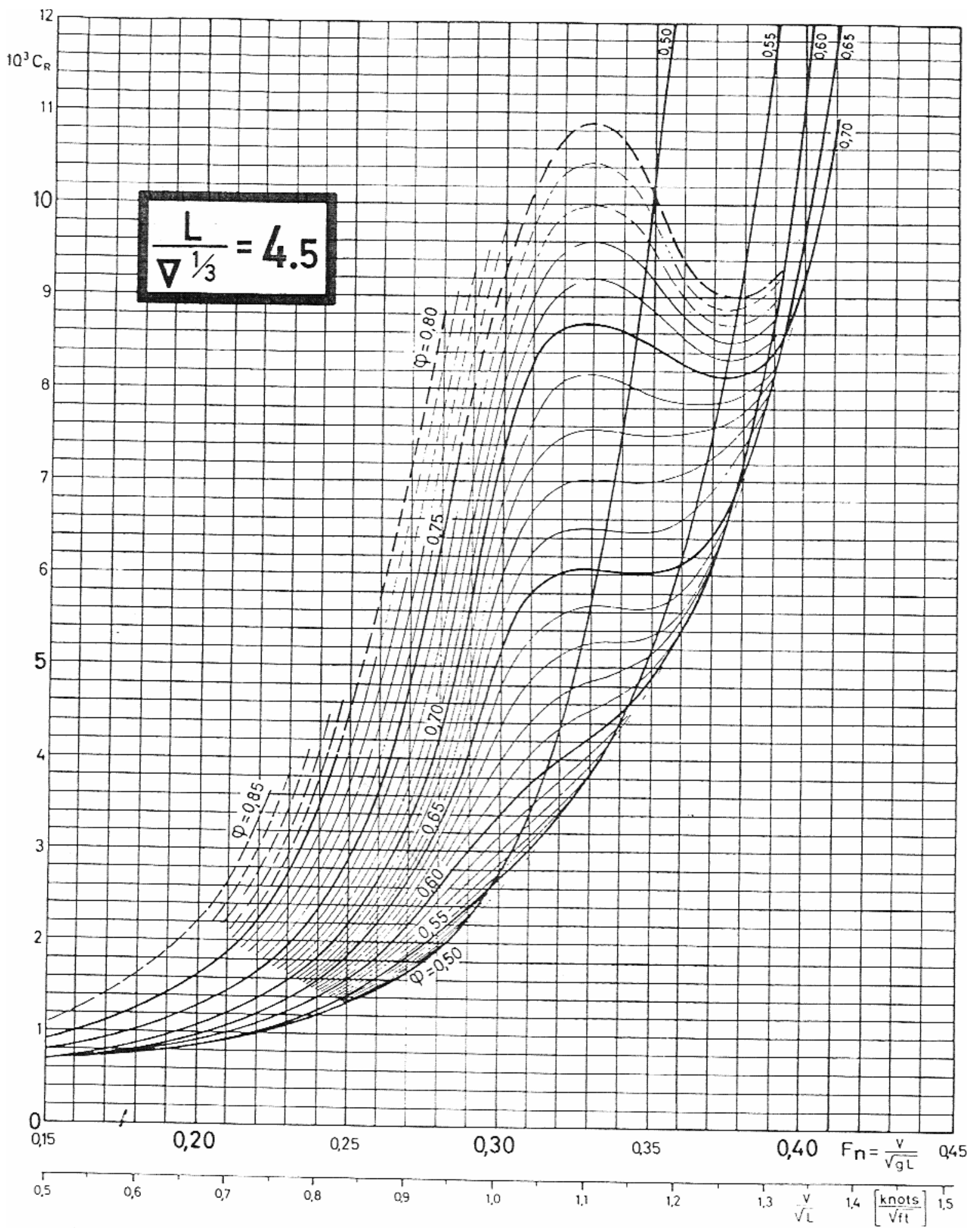

Figure A.2: Residuary resistance coefficient versus length Froude number for different values of longitudinal prismatic coefficient. $M=4.5$. Source: Harvald (1983). 


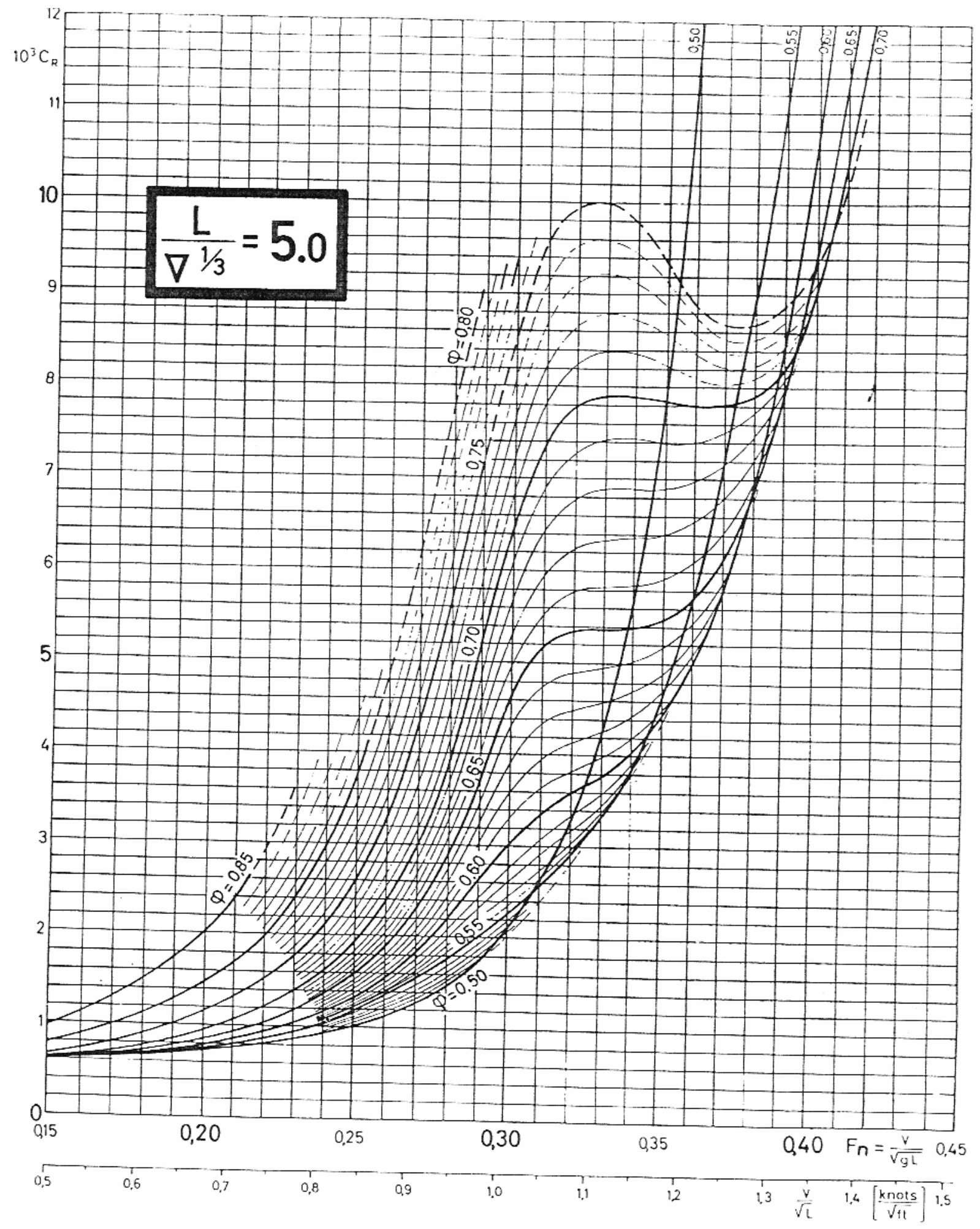

Figure A.3: Residuary resistance coefficient versus length Froude number for different values of longitudinal prismatic coefficient. $M=5.0$. Source: Harvald (1983). 


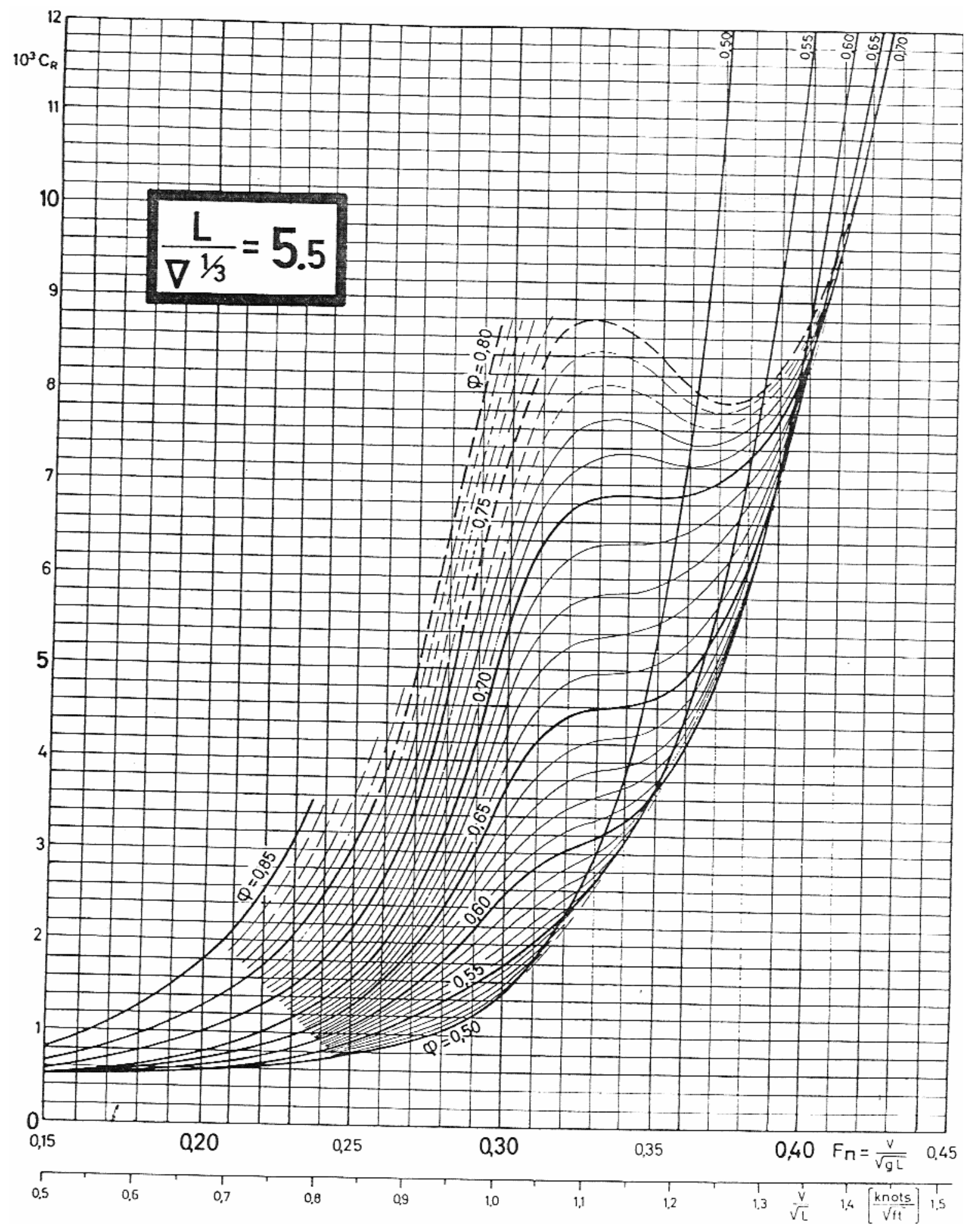

Figure A.4: Residuary resistance coefficient versus length Froude number for different values of longitudinal prismatic coefficient. $M=5.5$. Source: Harvald (1983). 


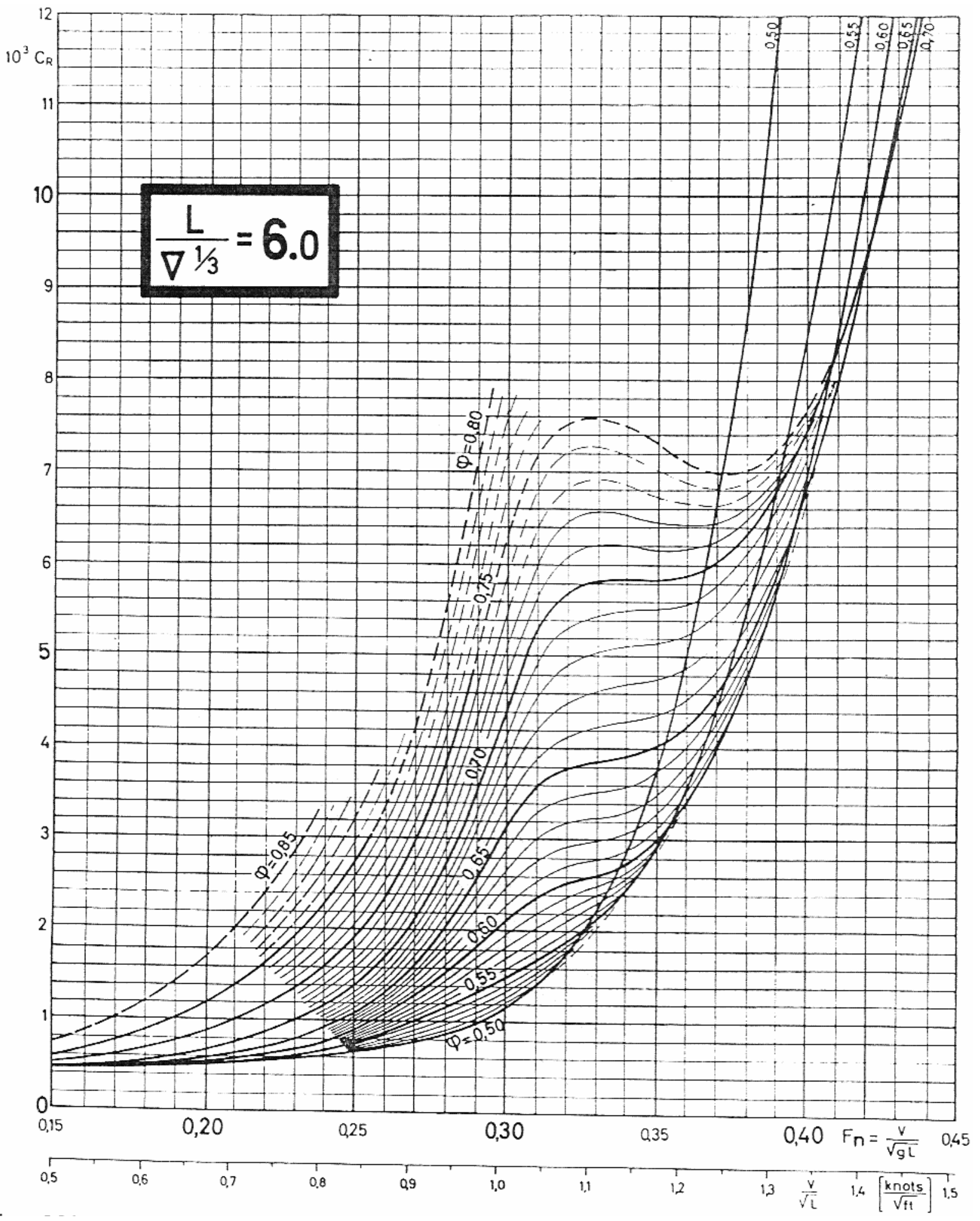

Figure A.5: Residuary resistance coefficient versus length Froude number for different values of longitudinal prismatic coefficient. $M=6.0$. Source: Harvald (1983). 


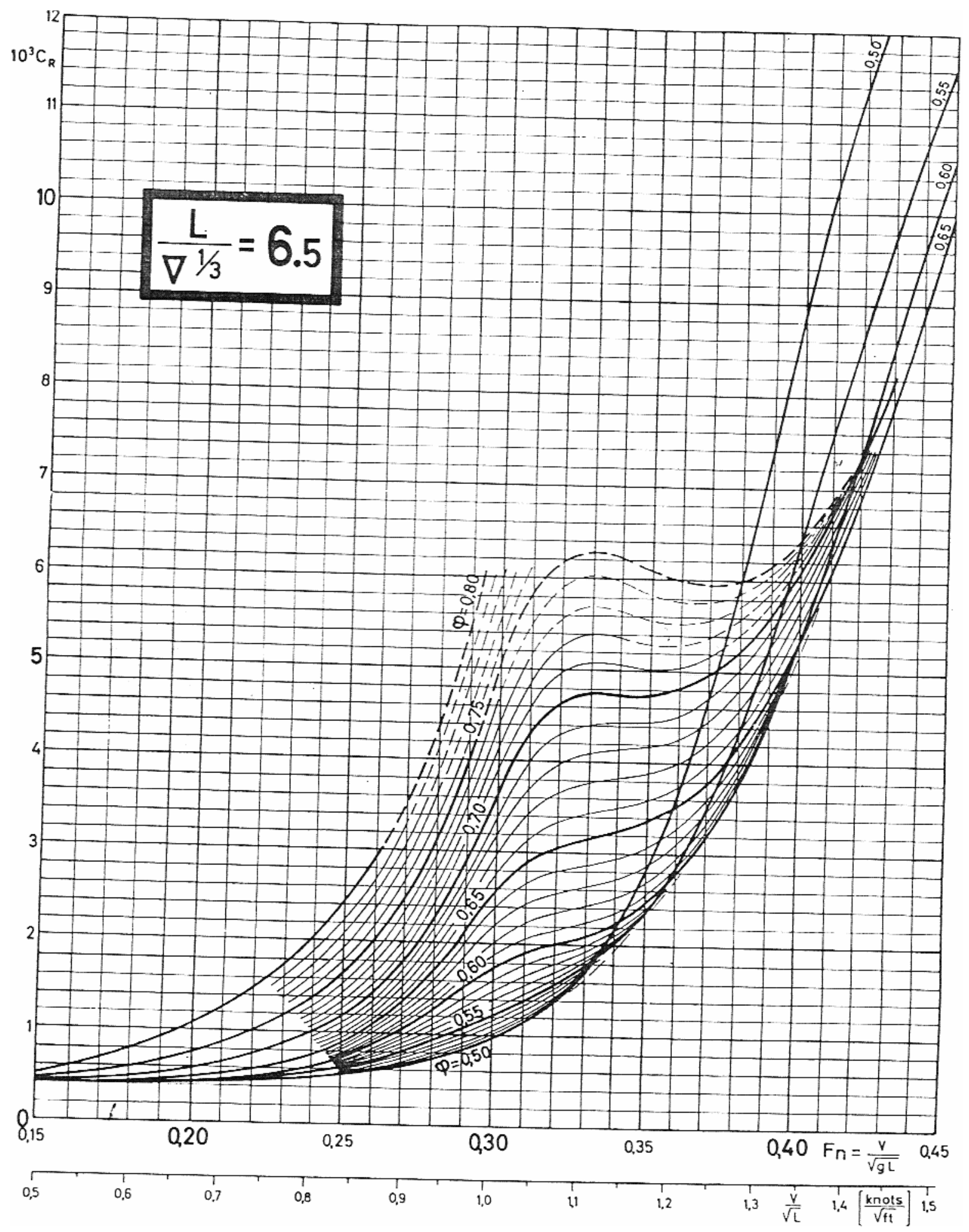

Figure A.6: Residuary resistance coefficient versus length Froude number for different values of longitudinal prismatic coefficient. $M=6.5$. Source: Harvald (1983). 


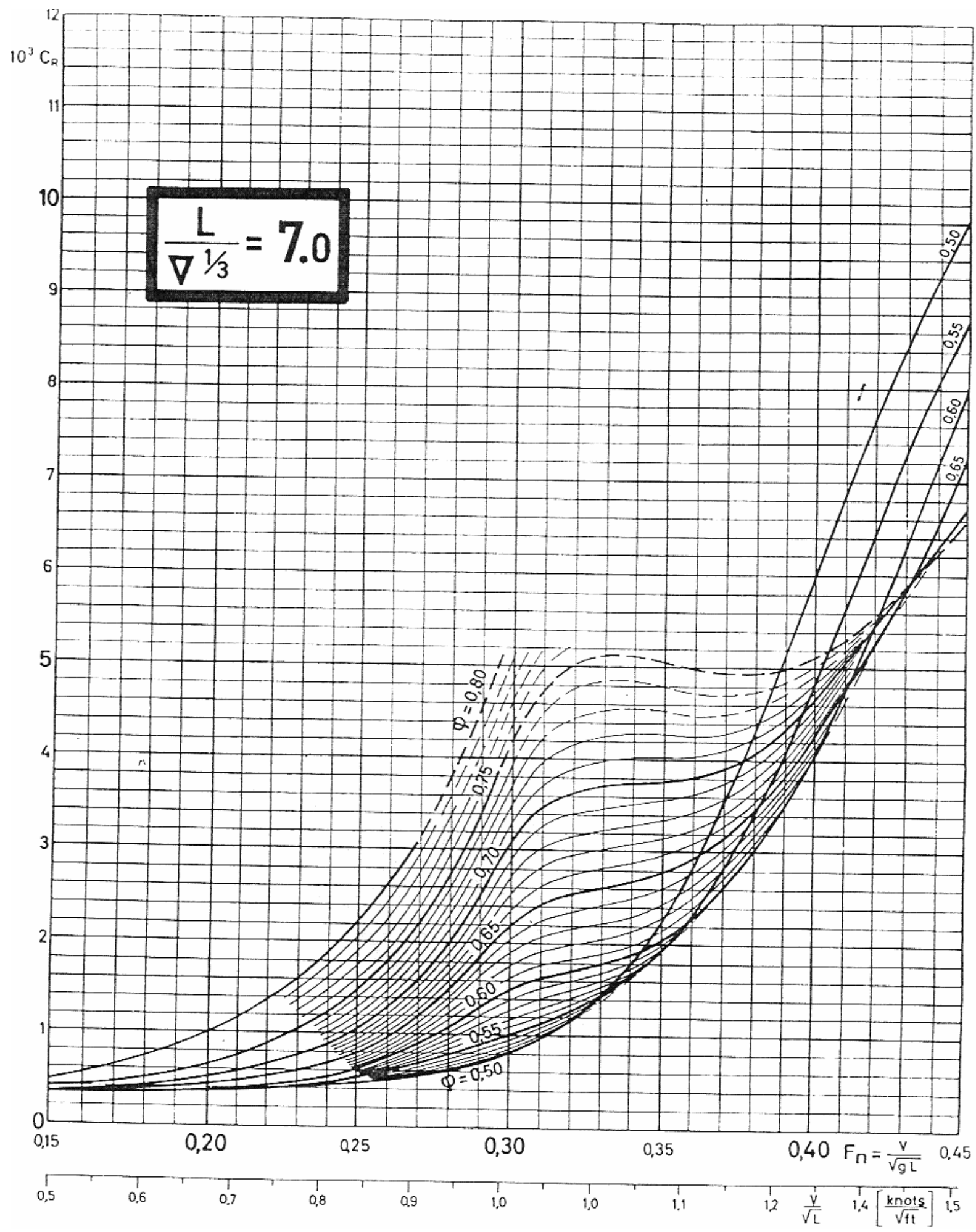

Figure A.7: Residuary resistance coefficient versus length Froude number for different values of longitudinal prismatic coefficient. $M=7.0$. Source: Harvald (1983). 


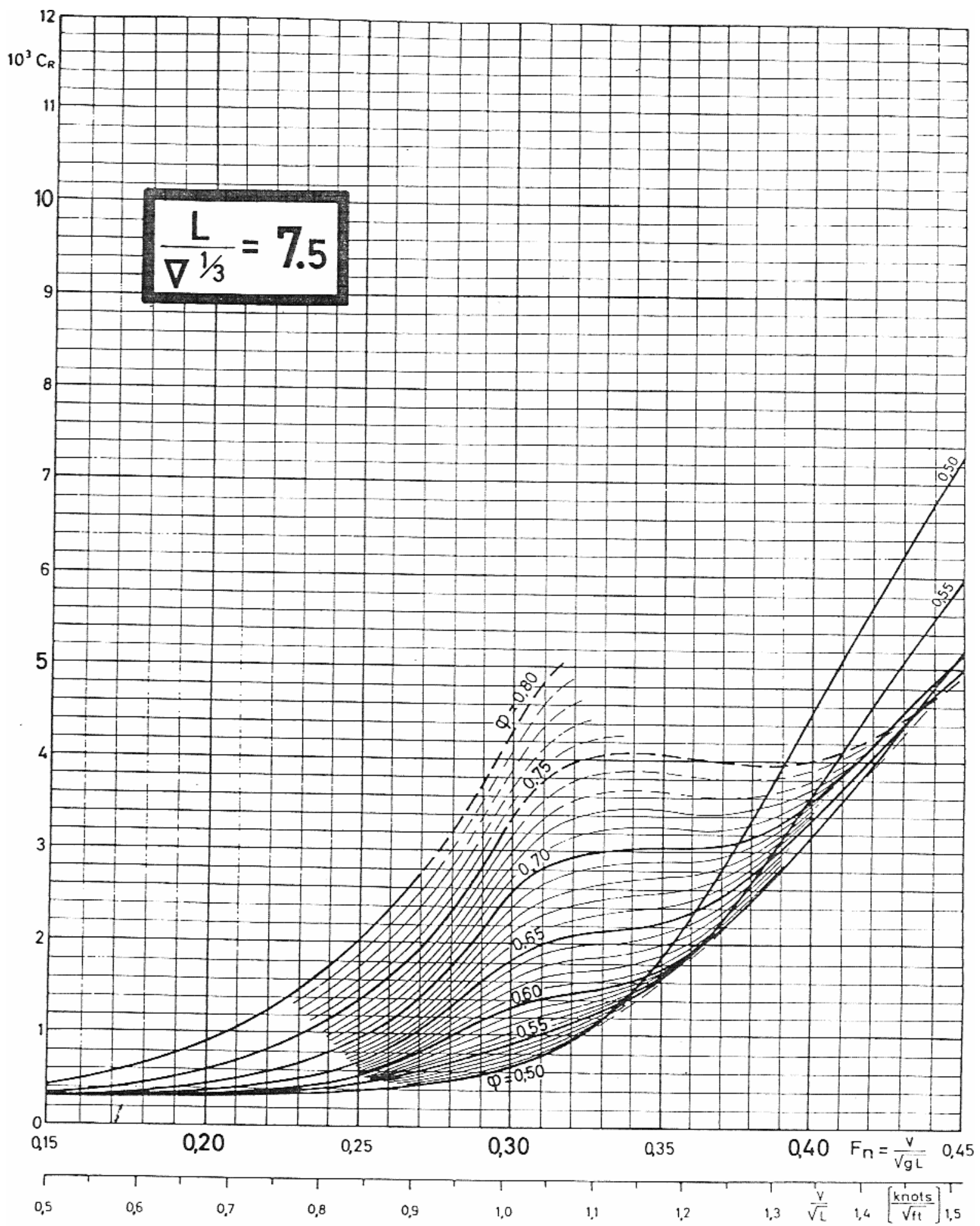

Figure A.8: Residuary resistance coefficient versus length Froude number for different values of longitudinal prismatic coefficient. $M=7.5$. Source: Harvald (1983). 


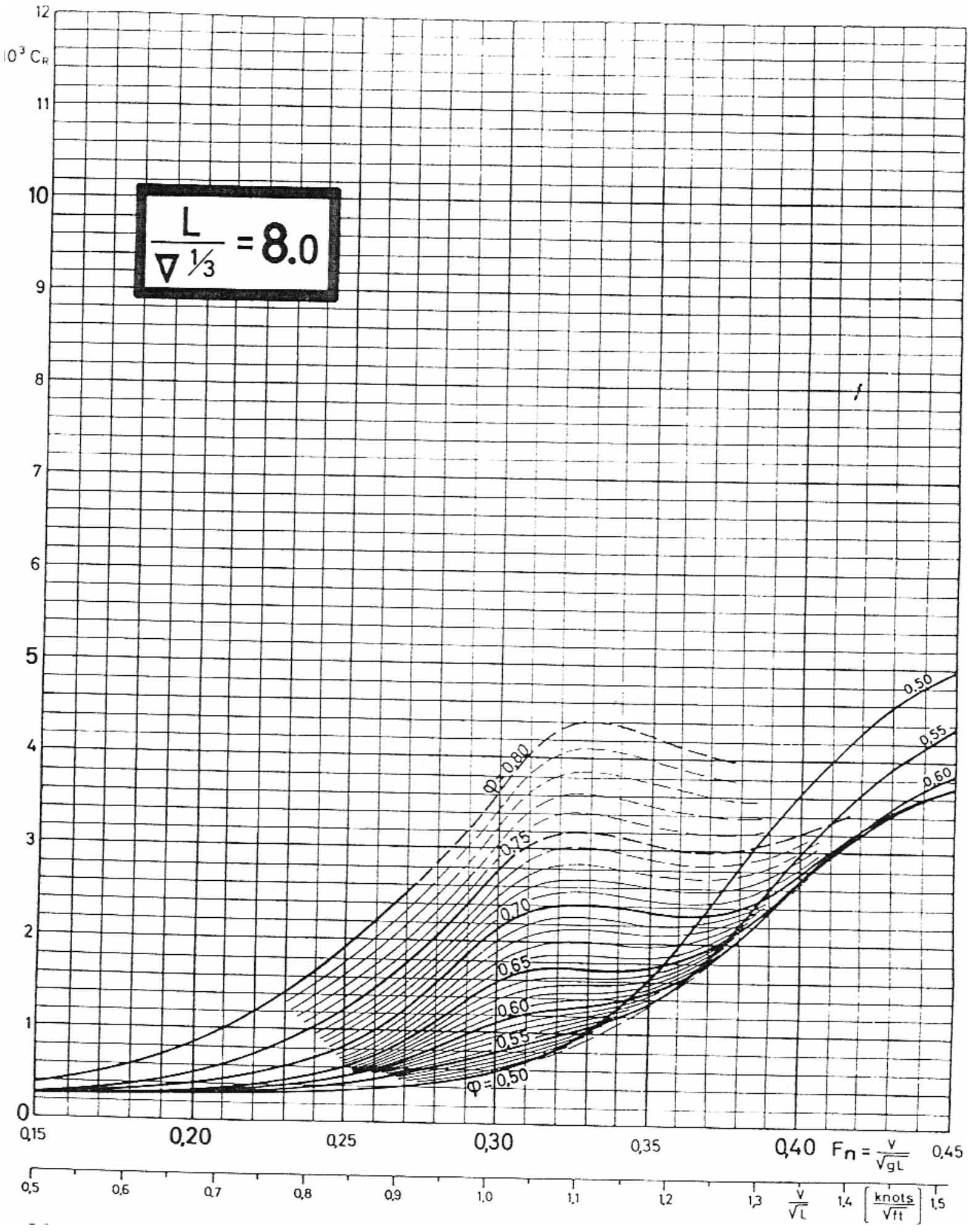

Figure A.9: Residuary resistance coefficient versus length Froude number for different values of longitudinal prismatic coefficient. $M=8.0$. Source: Harvald (1983). 


\section{APPENDIX B - RESULTS OF THE 2700 TDW INLAND VESSEL RESISTANCE IN SHALLOW WATERS}

In this appendix is presented the offset of the vessel, the original lines plan, the characteristic of the model in test condition and resistance results, made by IPT (1974). Also, is shown the empirical results of the ship model.

\begin{tabular}{lrr} 
Characteristic & Full scale & Model scale \\
\hline Water line length $(\mathrm{m})$ & 83.86 & 4.193 \\
Beam $(\mathrm{m})$ & 14.50 & 0.725 \\
Displacement $\left(\mathrm{m}^{3}\right)$ & 3560.00 & 0.445 \\
Draft $(\mathrm{m})$ & 3.20 & 0.160 \\
Wetted surface $\left(\mathrm{m}^{2}\right)$ & 1564.40 & 3.911 \\
\hline
\end{tabular}

Table B.1: Characteristics of 2700 TDW inland vessel in full and in model scale. Source: IPT (1974)

\begin{tabular}{lr} 
Characteristic & Value \\
\hline Model scale & 0.05 \\
Turbulence coefficient & 0.00 \\
Number of test & 6 \\
Temperature $(\mathrm{C})$ & 21.6 \\
Water density $\left(\mathrm{kg} \cdot \mathrm{s}^{2} / \mathrm{m}^{4}\right)$ & 201.75 \\
Viscosity $\left(\mathrm{m}^{2} / \mathrm{s}\right)$ & $0.96895 \mathrm{E}-06$ \\
Roughness coefficient & $0.40 \mathrm{E}-03$ \\
Block factor & 1.00 \\
Form factor & 1.00 \\
\hline
\end{tabular}

Table B.2: Characteristics of experimental test. Source: IPT (1974) 


\begin{tabular}{lcrrrrrr} 
Test & $\begin{array}{l}v_{\text {model }} \\
(\mathrm{m} / \mathrm{s})\end{array}$ & \multicolumn{1}{l}{$\begin{array}{l}R_{\text {model }} \\
(\mathrm{kgf})\end{array}$} & \multicolumn{1}{l}{$\begin{array}{l}v_{\text {ship }} \\
(\mathrm{knot})\end{array}$} & \multicolumn{1}{l}{$\begin{array}{l}R_{\text {ship }} \\
(\mathrm{kgf})\end{array}$} & $\mathrm{EHP}$ & \multicolumn{1}{c}{$\mathrm{EHP} / \Lambda$} \\
$\left(\mathrm{EHP} / \mathrm{m}^{3}\right)$ & $R e_{\text {model }}$ \\
\hline 1 & 0.345 & 0.253 & 3.00 & 1,712 & 35 & $0.991 \mathrm{E}-02$ & $0.149 \mathrm{E}+07$ \\
2 & 0.460 & 0.436 & 4.00 & 2,979 & 81 & $0.230 \mathrm{E}-01$ & $0.199 \mathrm{E}+07$ \\
3 & 0.576 & 0.703 & 5.00 & 4,879 & 167 & $0.470 \mathrm{E}-01$ & $0.249 \mathrm{E}+07$ \\
4 & 0.691 & 1.151 & 6.00 & 8,192 & 337 & $0.948 \mathrm{E}-01$ & $0.299 \mathrm{E}+07$ \\
5 & 0.806 & 1.704 & 7.00 & 12,312 & 591 & $0.166 \mathrm{E}+00$ & $0.349 \mathrm{E}+07$ \\
6 & 0.921 & 2.623 & 8.00 & 19,330 & 1,061 & $0.298 \mathrm{E}+00$ & $0.399 \mathrm{E}+07$ \\
\hline Test & $U$ & $C_{\nu_{\text {model }}}$ & $C_{\nu_{\text {model }}}$ & $C_{w}$ & $C_{t_{\text {model }}}$ & $C_{\nu_{\text {ship }}}$ & $C_{t_{\text {ship }}}$ \\
& $\sqrt{L_{p p}}$ & & $(15 \mathrm{C})$. & & & & \\
\hline 1 & 0.181 & $0.409 \mathrm{E}-02$ & $0.421 \mathrm{E}-02$ & $0.658 \mathrm{E}-02$ & $0.108 \mathrm{E}-01$ & $0.244 \mathrm{E}-02$ & $0.901 \mathrm{E}-02$ \\
2 & 0.241 & $0.387 \mathrm{E}-02$ & $0.399 \mathrm{E}-02$ & $0.646 \mathrm{E}-02$ & $0.105 \mathrm{E}-01$ & $0.236 \mathrm{E}-02$ & $0.882 \mathrm{E}-02$ \\
3 & 0.301 & $0.372 \mathrm{E}-02$ & $0.383 \mathrm{E}-02$ & $0.694 \mathrm{E}-02$ & $0.108 \mathrm{E}-01$ & $0.230 \mathrm{E}-02$ & $0.924 \mathrm{E}-02$ \\
4 & 0.362 & $0.360 \mathrm{E}-02$ & $0.371 \mathrm{E}-02$ & $0.852 \mathrm{E}-02$ & $0.122 \mathrm{E}-01$ & $0.225 \mathrm{E}-02$ & $0.108 \mathrm{E}-01$ \\
5 & 0.422 & $0.351 \mathrm{E}-02$ & $0.361 \mathrm{E}-02$ & $0.968 \mathrm{E}-02$ & $0.133 \mathrm{E}-01$ & $0.221 \mathrm{E}-02$ & $0.119 \mathrm{E}-01$ \\
6 & 0.482 & $0.342 \mathrm{E}-02$ & $0.352 \mathrm{E}-02$ & $0.121 \mathrm{E}-01$ & $0.156 \mathrm{E}-01$ & $0.218 \mathrm{E}-02$ & $0.143 \mathrm{E}-01$ \\
\hline
\end{tabular}

Table B.3: Experimental results of 2700 TDW inland vessel resistance test for condition 2. Source: IPT (1974)

\begin{tabular}{|c|c|c|c|c|c|c|c|c|}
\hline \multirow{2}{*}{\multicolumn{3}{|c|}{$\begin{array}{lc}x & y \\
\text { Station } 0.0000\end{array}$}} & $x$ & $y$ & $z$ & $x$ & $y$ & $z$ \\
\hline & & & \multicolumn{3}{|c|}{ Station 4.2355} & \multicolumn{3}{|c|}{ Station 8.4710} \\
\hline 0.0000 & 0.0000 & 5.0250 & 4.2355 & 0.0000 & 1.5624 & 8.4710 & 0.0000 & 0.1538 \\
\hline 0.0000 & 0.0000 & 5.7000 & 4.2355 & 1.6325 & 1.5624 & 8.4710 & 1.6325 & 0.1538 \\
\hline 0.0000 & 1.6325 & 5.6625 & 4.2355 & 3.2650 & 1.5624 & 8.4710 & 3.2650 & 0.1538 \\
\hline 0.0000 & 3.2650 & 5.6250 & 4.2355 & 4.8975 & 1.5624 & 8.4710 & 4.8975 & 0.1538 \\
\hline 0.0000 & 4.8975 & 5.5875 & 4.2355 & 6.5300 & 1.5624 & 8.4710 & 6.5300 & 0.1538 \\
\hline 0.0000 & 6.5300 & 5.5500 & 4.2355 & 6.7100 & 1.7381 & 8.4710 & 6.7100 & 0.3294 \\
\hline 0.0000 & 6.5300 & 4.9125 & 4.2355 & 6.8900 & 1.9138 & 8.4710 & 6.8900 & 0.5049 \\
\hline 0.0000 & 6.5300 & 4.2750 & 4.2355 & 7.0700 & 2.0895 & 8.4710 & 7.0700 & 0.6805 \\
\hline 0.0000 & 6.5300 & 3.6375 & 4.2355 & 7.2500 & 2.2651 & 8.4710 & 7.2500 & 0.8561 \\
\hline 0.0000 & 6.5300 & 3.0000 & 4.2355 & 7.2500 & 3.0739 & 8.4710 & 7.2500 & 2.0170 \\
\hline 0.0000 & 4.8975 & 3.0000 & 4.2355 & 7.2500 & 3.8826 & 8.4710 & 7.2500 & 3.1780 \\
\hline 0.0000 & 3.2650 & 3.0000 & 4.2355 & 7.2500 & 4.6913 & 8.4710 & 7.2500 & 4.3390 \\
\hline 0.0000 & 1.6325 & 3.0000 & 4.2355 & 7.2500 & 5.5000 & 8.4710 & 7.2500 & 5.5000 \\
\hline 0.0000 & 0.0000 & 3.0000 & 4.2355 & 5.4375 & 5.5500 & 8.4710 & 5.4375 & 5.5500 \\
\hline 0.0000 & 0.0000 & 3.6750 & 4.2355 & 3.6250 & 5.6000 & 8.4710 & 3.6250 & 5.6000 \\
\hline 0.0000 & 0.0000 & 4.3500 & 4.2355 & 1.8125 & 5.6500 & 8.4710 & 1.8125 & 5.6500 \\
\hline 0.0000 & 0.0000 & 5.0250 & 4.2355 & 0.0000 & 5.7000 & 8.4710 & 0.0000 & 5.7000 \\
\hline \multicolumn{3}{|c|}{ Station 12.7065} & \multicolumn{3}{|c|}{ Station 16.9420} & \multicolumn{3}{|c|}{ Station 21.1775} \\
\hline 12.7065 & 0.0000 & 0.0000 & 16.9420 & 0.0000 & 0.0000 & 21.1775 & 0.0000 & 0.0000 \\
\hline 12.7065 & 1.6327 & 0.0000 & 16.9420 & 1.6331 & 0.0000 & 21.1775 & 1.6334 & 0.0000 \\
\hline 12.7065 & 3.2655 & 0.0000 & 16.9420 & 3.2662 & 0.0000 & 21.1775 & 3.2668 & 0.0000 \\
\hline
\end{tabular}

Table B.4 - Offset of 2700 TDW inland vessel. Source: Author. Continued on next page 
Continued from previous page

\begin{tabular}{|c|c|c|c|c|c|c|c|c|}
\hline$x$ & $y$ & $z$ & $x$ & $y$ & $z$ & $x$ & $y$ & $z$ \\
\hline 12.7065 & 4.8982 & 0.0000 & 16.9420 & 4.8992 & 0.0000 & 21.1775 & 4.9003 & 0.0000 \\
\hline 12.7065 & 6.5309 & 0.0000 & 16.9420 & 6.5323 & 0.0000 & 21.1775 & 6.5337 & 0.0000 \\
\hline 12.7065 & 6.7107 & 0.1726 & 16.9420 & 6.7117 & 0.1728 & 21.1775 & 6.7128 & 0.1730 \\
\hline 12.7065 & 6.8905 & 0.3452 & 16.9420 & 6.8912 & 0.3456 & 21.1775 & 6.8918 & 0.3459 \\
\hline 12.7065 & 7.0702 & 0.5179 & 16.9420 & 7.0706 & 0.5184 & 21.1775 & 7.0709 & 0.5189 \\
\hline 12.7065 & 7.2500 & 0.6905 & 16.9420 & 7.2500 & 0.6912 & 21.1775 & 7.2500 & 0.6918 \\
\hline 12.7065 & 7.2500 & 1.7179 & 16.9420 & 7.2500 & 1.7184 & 21.1775 & 7.2500 & 1.7189 \\
\hline 12.7065 & 7.2500 & 2.7452 & 16.9420 & 7.2500 & 2.7456 & 21.1775 & 7.2500 & 2.7459 \\
\hline 12.7065 & 7.2500 & 3.7726 & 16.9420 & 7.2500 & 3.7728 & 21.1775 & 7.2500 & 3.7730 \\
\hline 12.7065 & 7.2500 & 4.8000 & 16.9420 & 7.2500 & 4.8000 & 21.1775 & 7.2500 & 4.8000 \\
\hline 12.7065 & 5.4375 & 4.8000 & 16.9420 & 5.4375 & 4.8000 & 21.1775 & 5.4375 & 4.8000 \\
\hline 12.7065 & 3.6250 & 4.8000 & 16.9420 & 3.6250 & 4.8000 & 21.1775 & 3.6250 & 4.8000 \\
\hline 12.7065 & 1.8125 & 4.8000 & 16.9420 & 1.8125 & 4.8000 & 21.1775 & 1.8125 & 4.8000 \\
\hline 12.7065 & 0.0000 & 4.8000 & 16.9420 & 0.0000 & 4.8000 & 21.1775 & 0.0000 & 4.8000 \\
\hline \multicolumn{3}{|c|}{ Station 25.4130} & \multicolumn{3}{|c|}{ Station 29.6485} & \multicolumn{3}{|c|}{ Station 33.8840} \\
\hline 25.4130 & 0.0000 & 0.0000 & 29.6485 & 0.0000 & 0.0000 & 33.8840 & 0.0000 & 0.0000 \\
\hline 25.4130 & 1.6338 & 0.0000 & 29.6485 & 1.6341 & 0.0000 & 33.8840 & 1.6344 & 0.0000 \\
\hline 25.4130 & 3.2675 & 0.0000 & 29.6485 & 3.2682 & 0.0000 & 33.8840 & 3.2689 & 0.0000 \\
\hline 25.4130 & 4.9013 & 0.0000 & 29.6485 & 4.9023 & 0.0000 & 33.8840 & 4.9033 & 0.0000 \\
\hline 25.4130 & 6.5350 & 0.0000 & 29.6485 & 6.5364 & 0.0000 & 33.8840 & 6.5378 & 0.0000 \\
\hline 25.4130 & 6.7138 & 0.1731 & 29.6485 & 6.7148 & 0.1733 & 33.8840 & 6.7158 & 0.1735 \\
\hline 25.4130 & 6.8925 & 0.3463 & 29.6485 & 6.8932 & 0.3466 & 33.8840 & 6.8939 & 0.3469 \\
\hline 25.4130 & 7.0713 & 0.5194 & 29.6485 & 7.0716 & 0.5199 & 33.8840 & 7.0719 & 0.5204 \\
\hline 25.4130 & 7.2500 & 0.6925 & 29.6485 & 7.2500 & 0.6932 & 33.8840 & 7.2500 & 0.6939 \\
\hline 25.4130 & 7.2500 & 1.7194 & 29.6485 & 7.2500 & 1.7199 & 33.8840 & 7.2500 & 1.7204 \\
\hline 25.4130 & 7.2500 & 2.7463 & 29.6485 & 7.2500 & 2.7466 & 33.8840 & 7.2500 & 2.7469 \\
\hline 25.4130 & 7.2500 & 3.7731 & 29.6485 & 7.2500 & 3.7733 & 33.8840 & 7.2500 & 3.7735 \\
\hline 25.4130 & 7.2500 & 4.8000 & 29.6485 & 7.2500 & 4.8000 & 33.8840 & 7.2500 & 4.8000 \\
\hline 25.4130 & 5.4375 & 4.8000 & 29.6485 & 5.4375 & 4.8000 & 33.8840 & 5.4375 & 4.8000 \\
\hline 25.4130 & 3.6250 & 4.8000 & 29.6485 & 3.6250 & 4.8000 & 33.8840 & 3.6250 & 4.8000 \\
\hline 25.4130 & 1.8125 & 4.8000 & 29.6485 & 1.8125 & 4.8000 & 33.8840 & 1.8125 & 4.8000 \\
\hline 25.4130 & 0.0000 & 4.8000 & 29.6485 & 0.0000 & 4.8000 & 33.8840 & 0.0000 & 4.8000 \\
\hline \multicolumn{3}{|c|}{ Station 38.1195} & \multicolumn{3}{|c|}{ Station 42.3550} & \multicolumn{3}{|c|}{ Station 46.5905} \\
\hline 38.1195 & 0.0000 & 0.0000 & 42.3550 & 0.0000 & 0.0000 & 46.5905 & 0.0000 & 0.0000 \\
\hline 38.1195 & 1.6348 & 0.0000 & 42.3550 & 1.6351 & 0.0000 & 46.5905 & 1.6355 & 0.0000 \\
\hline 38.1195 & 3.2696 & 0.0000 & 42.3550 & 3.2702 & 0.0000 & 46.5905 & 3.2709 & 0.0000 \\
\hline 38.1195 & 4.9043 & 0.0000 & 42.3550 & 4.9054 & 0.0000 & 46.5905 & 4.9064 & 0.0000 \\
\hline 38.1195 & 6.5391 & 0.0000 & 42.3550 & 6.5405 & 0.0000 & 46.5905 & 6.5418 & 0.0000 \\
\hline 38.1195 & 6.7168 & 0.1736 & 42.3550 & 6.7179 & 0.1738 & 46.5905 & 6.7189 & 0.1740 \\
\hline 38.1195 & 6.8946 & 0.3473 & 42.3550 & 6.8952 & 0.3476 & 46.5905 & 6.8959 & 0.3480 \\
\hline
\end{tabular}

Table B.4 - Offset of 2700 TDW inland vessel. Source: Author. Continued on next page 
Continued from previous page

\begin{tabular}{|c|c|c|c|c|c|c|c|c|}
\hline$x$ & $y$ & $z$ & $x$ & $y$ & $z$ & $x$ & $y$ & $z$ \\
\hline 38.1195 & 7.0723 & 0.5209 & 42.3550 & 7.0726 & 0.5214 & 46.5905 & 7.0730 & 0.5219 \\
\hline 38.1195 & 7.2500 & 0.6946 & 42.3550 & 7.2500 & 0.6952 & 46.5905 & 7.2500 & 0.6959 \\
\hline 38.1195 & 7.2500 & 1.7209 & 42.3550 & 7.2500 & 1.7214 & 46.5905 & 7.2500 & 1.7219 \\
\hline 38.1195 & 7.2500 & 2.7473 & 42.3550 & 7.2500 & 2.7476 & 46.5905 & 7.2500 & 2.7480 \\
\hline 38.1195 & 7.2500 & 3.7736 & 42.3550 & 7.2500 & 3.7738 & 46.5905 & 7.2500 & 3.7740 \\
\hline 38.1195 & 7.2500 & 4.8000 & 42.3550 & 7.2500 & 4.8000 & 46.5905 & 7.2500 & 4.8000 \\
\hline 38.1195 & 5.4375 & 4.8000 & 42.3550 & 5.4375 & 4.8000 & 46.5905 & 5.4375 & 4.8000 \\
\hline 38.1195 & 3.6250 & 4.8000 & 42.3550 & 3.6250 & 4.8000 & 46.5905 & 3.6250 & 4.8000 \\
\hline 38.1195 & 1.8125 & 4.8000 & 42.3550 & 1.8125 & 4.8000 & 46.5905 & 1.8125 & 4.8000 \\
\hline 38.1195 & 0.0000 & 4.8000 & 42.3550 & 0.0000 & 4.8000 & 46.5905 & 0.0000 & 4.8000 \\
\hline \multicolumn{3}{|c|}{ Station 50.8260} & \multicolumn{3}{|c|}{ Station 55.0615} & \multicolumn{3}{|c|}{ Station 59.2970} \\
\hline 50.8260 & 0.0000 & 0.0000 & 55.0615 & 0.0000 & 0.0000 & 59.2970 & 0.0000 & 0.0000 \\
\hline 50.8260 & 1.6358 & 0.0000 & 55.0615 & 1.6361 & 0.0000 & 59.2970 & 1.6365 & 0.0000 \\
\hline 50.8260 & 3.2716 & 0.0000 & 55.0615 & 3.2723 & 0.0000 & 59.2970 & 3.2730 & 0.0000 \\
\hline 50.8260 & 4.9074 & 0.0000 & 55.0615 & 4.9084 & 0.0000 & 59.2970 & 4.9094 & 0.0000 \\
\hline 50.8260 & 6.5432 & 0.0000 & 55.0615 & 6.5446 & 0.0000 & 59.2970 & 6.5459 & 0.0000 \\
\hline 50.8260 & 6.7199 & 0.1742 & 55.0615 & 6.7209 & 0.1743 & 59.2970 & 6.7219 & 0.1745 \\
\hline 50.8260 & 6.8966 & 0.3483 & 55.0615 & 6.8973 & 0.3486 & 59.2970 & 6.8980 & 0.3490 \\
\hline 50.8260 & 7.0733 & 0.5225 & 55.0615 & 7.0736 & 0.5230 & 59.2970 & 7.0740 & 0.5235 \\
\hline 50.8260 & 7.2500 & 0.6966 & 55.0615 & 7.2500 & 0.6973 & 59.2970 & 7.2500 & 0.6980 \\
\hline 50.8260 & 7.2500 & 1.7225 & 55.0615 & 7.2500 & 1.7230 & 59.2970 & 7.2500 & 1.7235 \\
\hline 50.8260 & 7.2500 & 2.7483 & 55.0615 & 7.2500 & 2.7486 & 59.2970 & 7.2500 & 2.7490 \\
\hline 50.8260 & 7.2500 & 3.7742 & 55.0615 & 7.2500 & 3.7743 & 59.2970 & 7.2500 & 3.7745 \\
\hline 50.8260 & 7.2500 & 4.8000 & 55.0615 & 7.2500 & 4.8000 & 59.2970 & 7.2500 & 4.8000 \\
\hline 50.8260 & 5.4375 & 4.8000 & 55.0615 & 5.4375 & 4.8000 & 59.2970 & 5.4375 & 4.8000 \\
\hline 50.8260 & 3.6250 & 4.8000 & 55.0615 & 3.6250 & 4.8000 & 59.2970 & 3.6250 & 4.8000 \\
\hline 50.8260 & 1.8125 & 4.8000 & 55.0615 & 1.8125 & 4.8000 & 59.2970 & 1.8125 & 4.8000 \\
\hline 50.8260 & 0.0000 & 4.8000 & 55.0615 & 0.0000 & 4.8000 & 59.2970 & 0.0000 & 4.8000 \\
\hline \multicolumn{3}{|c|}{ Station 63.5325} & \multicolumn{3}{|c|}{ Station 67.7680} & \multicolumn{3}{|c|}{ Station 72.0035} \\
\hline 63.5325 & 0.0000 & 0.0000 & 67.7680 & 0.0000 & 0.0000 & 72.0035 & 0.0000 & 0.0000 \\
\hline 63.5325 & 1.6368 & 0.0000 & 67.7680 & 1.6372 & 0.0000 & 72.0035 & 1.6374 & 0.0000 \\
\hline 63.5325 & 3.2736 & 0.0000 & 67.7680 & 3.2743 & 0.0000 & 72.0035 & 3.2748 & 0.0000 \\
\hline 63.5325 & 4.9105 & 0.0000 & 67.7680 & 4.9115 & 0.0000 & 72.0035 & 4.9122 & 0.0000 \\
\hline 63.5325 & 6.5473 & 0.0000 & 67.7680 & 6.5486 & 0.0000 & 72.0035 & 6.5496 & 0.0000 \\
\hline 63.5325 & 6.7230 & 0.1747 & 67.7680 & 6.7240 & 0.1748 & 72.0035 & 6.7247 & 0.1750 \\
\hline 63.5325 & 6.8986 & 0.3493 & 67.7680 & 6.8993 & 0.3497 & 72.0035 & 6.8998 & 0.3500 \\
\hline 63.5325 & 7.0743 & 0.5240 & 67.7680 & 7.0747 & 0.5245 & 72.0035 & 7.0749 & 0.5250 \\
\hline 63.5325 & 7.2500 & 0.6986 & 67.7680 & 7.2500 & 0.6993 & 72.0035 & 7.2500 & 0.7000 \\
\hline 63.5325 & 7.2500 & 1.7240 & 67.7680 & 7.2500 & 1.7245 & 72.0035 & 7.2500 & 1.7250 \\
\hline 63.5325 & 7.2500 & 2.7493 & 67.7680 & 7.2500 & 2.7497 & 72.0035 & 7.2500 & 2.7500 \\
\hline
\end{tabular}

Table B.4 - Offset of 2700 TDW inland vessel. Source: Author. Continued on next page 
Continued from previous page

\begin{tabular}{rrr|rrr|rrr}
\hline$x$ & $y$ & $z$ & $x$ & $y$ & $z$ & $x$ & $y$ & $z$ \\
\hline 63.5325 & 7.2500 & 3.7747 & 67.7680 & 7.2500 & 3.7748 & 72.0035 & 7.2500 & 3.7750 \\
63.5325 & 7.2500 & 4.8000 & 67.7680 & 7.2500 & 4.8000 & 72.0035 & 7.2500 & 4.8000 \\
63.5325 & 5.4375 & 4.8000 & 67.7680 & 5.4375 & 4.8000 & 72.0035 & 5.4375 & 4.8000 \\
63.5325 & 3.6250 & 4.8000 & 67.7680 & 3.6250 & 4.8000 & 72.0035 & 3.6250 & 4.8000 \\
63.5325 & 1.8125 & 4.8000 & 67.7680 & 1.8125 & 4.8000 & 72.0035 & 1.8125 & 4.8000 \\
63.5325 & 0.0000 & 4.8000 & 67.7680 & 0.0000 & 4.8000 & 72.0035 & 0.0000 & 4.8000 \\
\hline \multicolumn{6}{c}{ Station 76.2390} & \multicolumn{6}{|c}{ Station 80.4745} & & & \\
\hline 76.2390 & 0.0000 & 0.0000 & 80.4745 & 0.0000 & 0.0000 & & & \\
76.2390 & 1.4864 & 0.0000 & 80.4745 & 0.7824 & 0.0000 & & & \\
76.2390 & 2.9729 & 0.0000 & 80.4745 & 1.5648 & 0.0000 & & & \\
76.2390 & 4.4593 & 0.0000 & 80.4745 & 2.3471 & 0.0000 & & & \\
76.2390 & 5.9458 & 0.0000 & 80.4745 & 3.1295 & 0.0000 & & & \\
76.2390 & 6.1282 & 0.1750 & 80.4745 & 3.4147 & 0.2171 & & & \\
76.2390 & 6.3107 & 0.3500 & 80.4745 & 3.6999 & 0.4341 & & & \\
76.2390 & 6.4931 & 0.5250 & 80.4745 & 3.9851 & 0.6512 & & & \\
76.2390 & 6.6756 & 0.7000 & 80.4745 & 4.2703 & 0.8683 & & & \\
76.2390 & 6.7334 & 1.8756 & 80.4745 & 4.4927 & 2.1390 & & & \\
76.2390 & 6.7913 & 3.0513 & 80.4745 & 4.7150 & 3.4097 & & & \\
76.2390 & 6.8491 & 4.2269 & 80.4745 & 4.9373 & 4.6804 & & & \\
76.2390 & 6.9070 & 5.4026 & 80.4745 & 5.1596 & 5.9511 & & & \\
76.2390 & 5.1802 & 5.4026 & 80.4745 & 3.8697 & 5.9511 & & & \\
76.2390 & 3.4535 & 5.4026 & 80.4745 & 2.5798 & 5.9511 & & & \\
76.2390 & 1.7267 & 5.4026 & 80.4745 & 1.2899 & 5.9511 & & & \\
76.2390 & 0.0000 & 5.4026 & 80.4745 & 0.0000 & 5.9511 & & & \\
\hline
\end{tabular}

Table B.4: Offset of 2700 TDW inland vessel. Source: Author. 


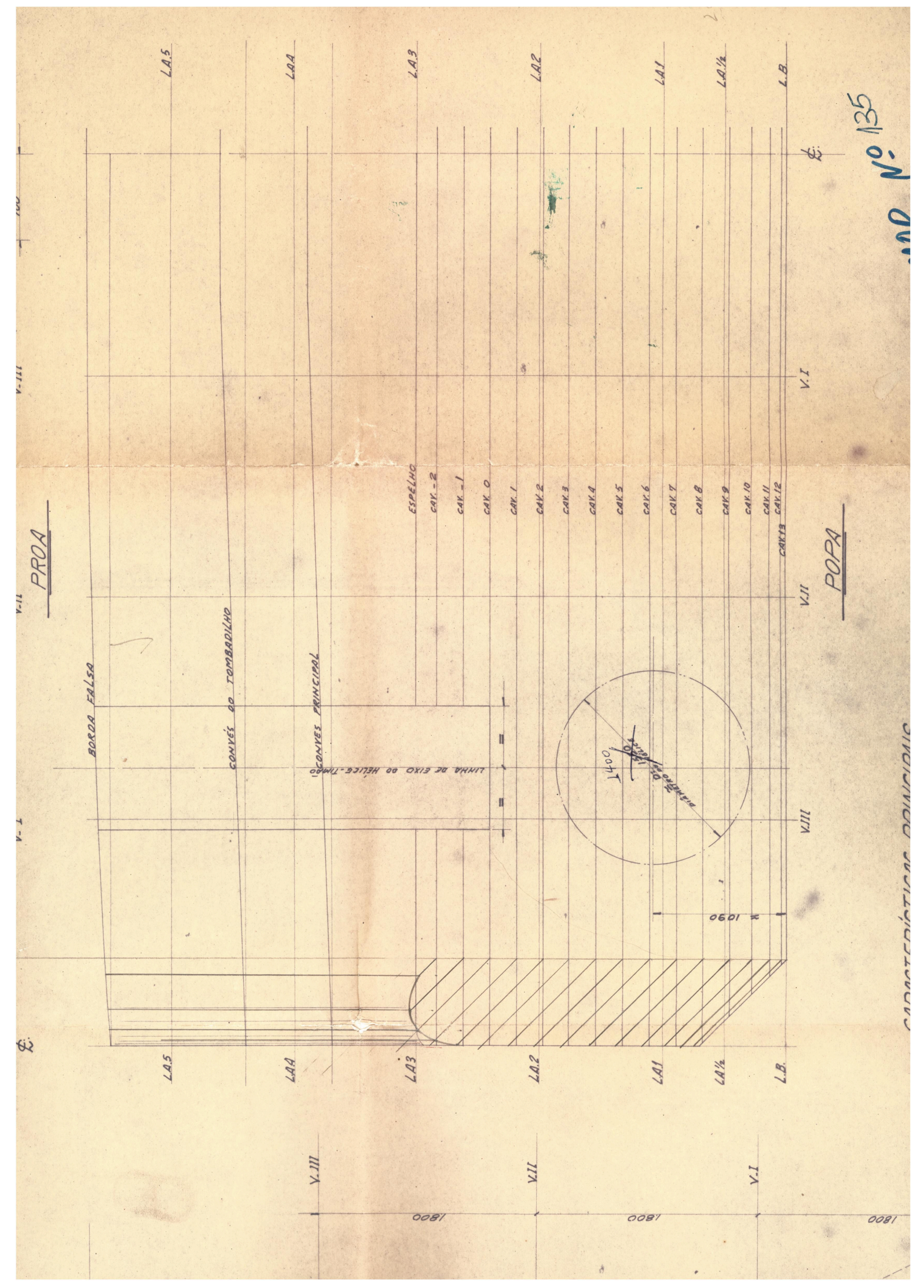

Figure B.1: 2700 TDW original inland vessel lines-plan (stern view). Source: (IPT, 1974). 


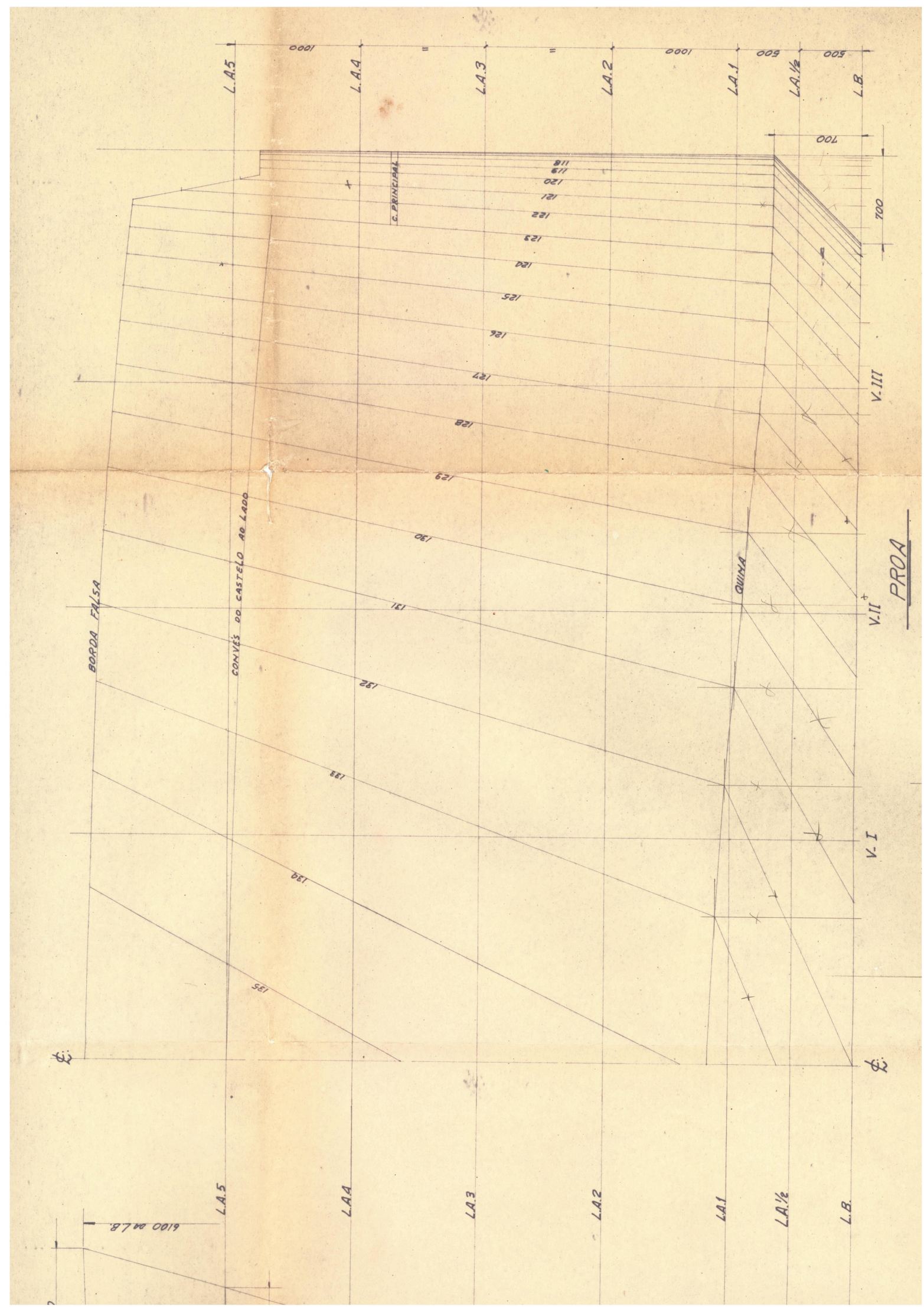

Figure B.2: 2700 TDW inland vessel original lines-plan (bow view). Source: (IPT, 1974). 


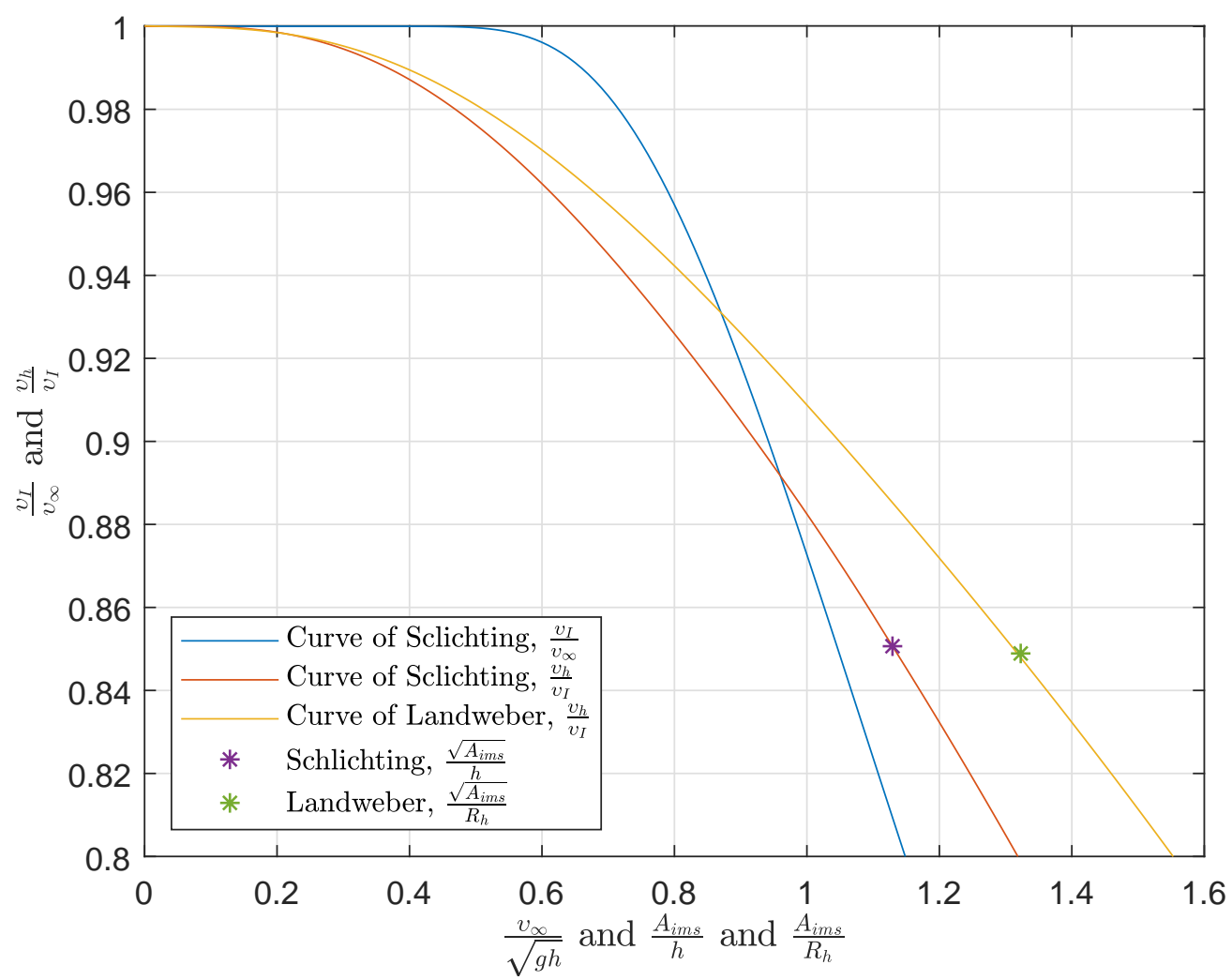

Figure B.3: Schlichting's curves applied to 2700 TDW inland vessel, where is indicated the values of $A_{i m s}^{1 / 2} / h$ and $A_{i m s}^{1 / 2} / R_{h}$ of the ship. Source: Author.

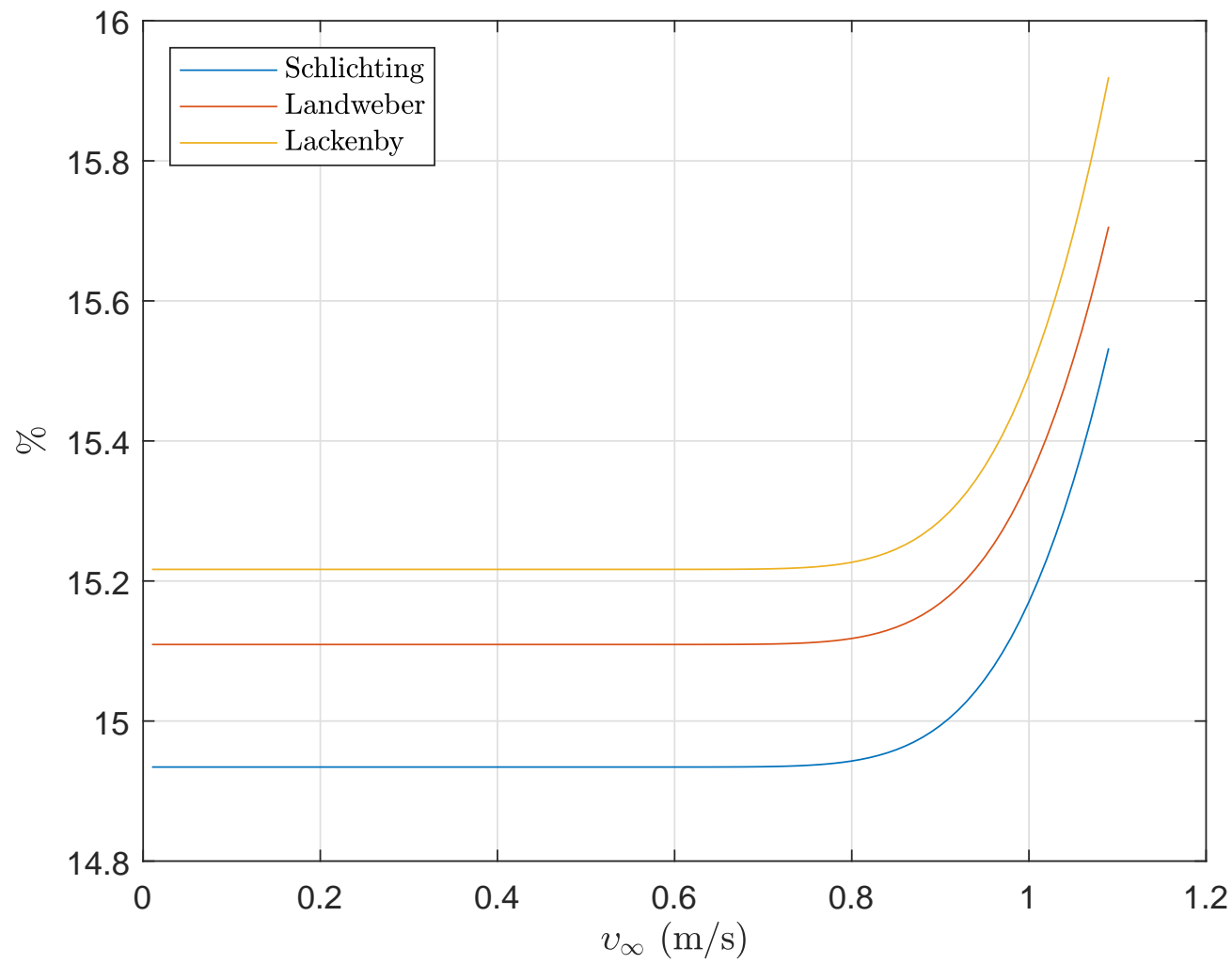

Figure B.4: Loss in velocities using empirical method for large rivers applied to 2700 TDW inland vessel. Source: Author. 

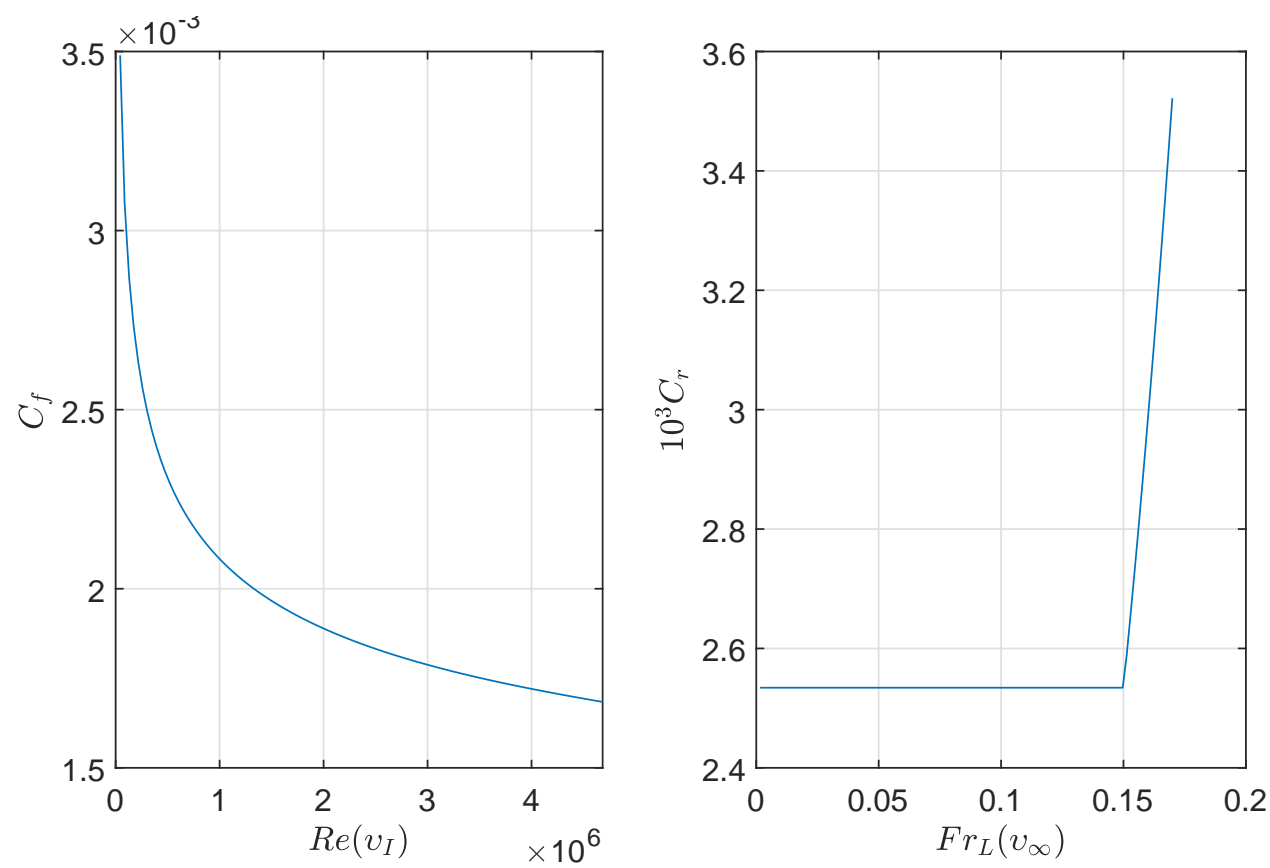

Figure B.5: Coefficient forces for large rivers of the 2700 TDW inland vessel. Source: Author.

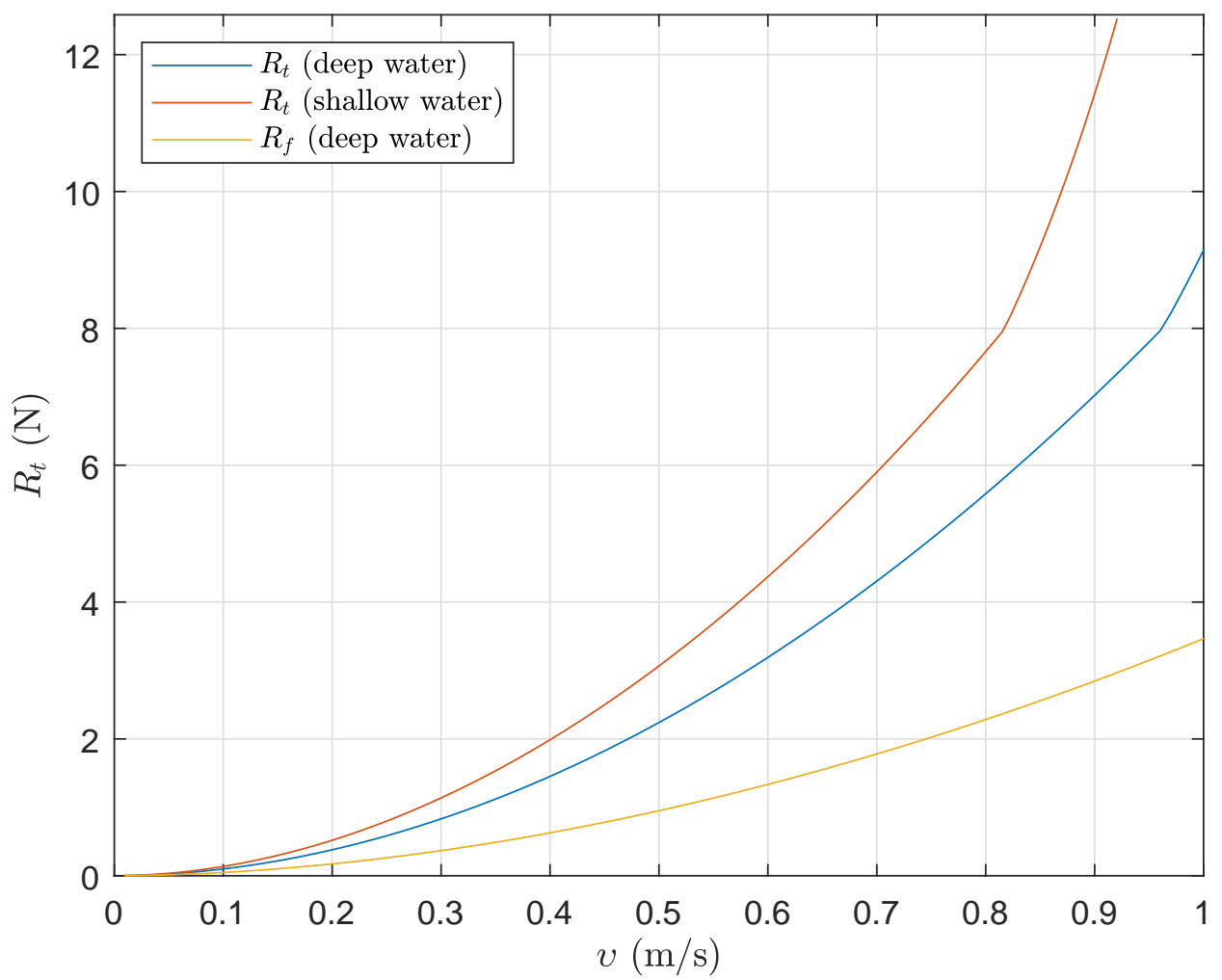

Figure B.6: Total resistance using Schlichting's method in comparison with Froude hypothesis ship resistance of the 2700 TDW inland vessel. Source: Author. 

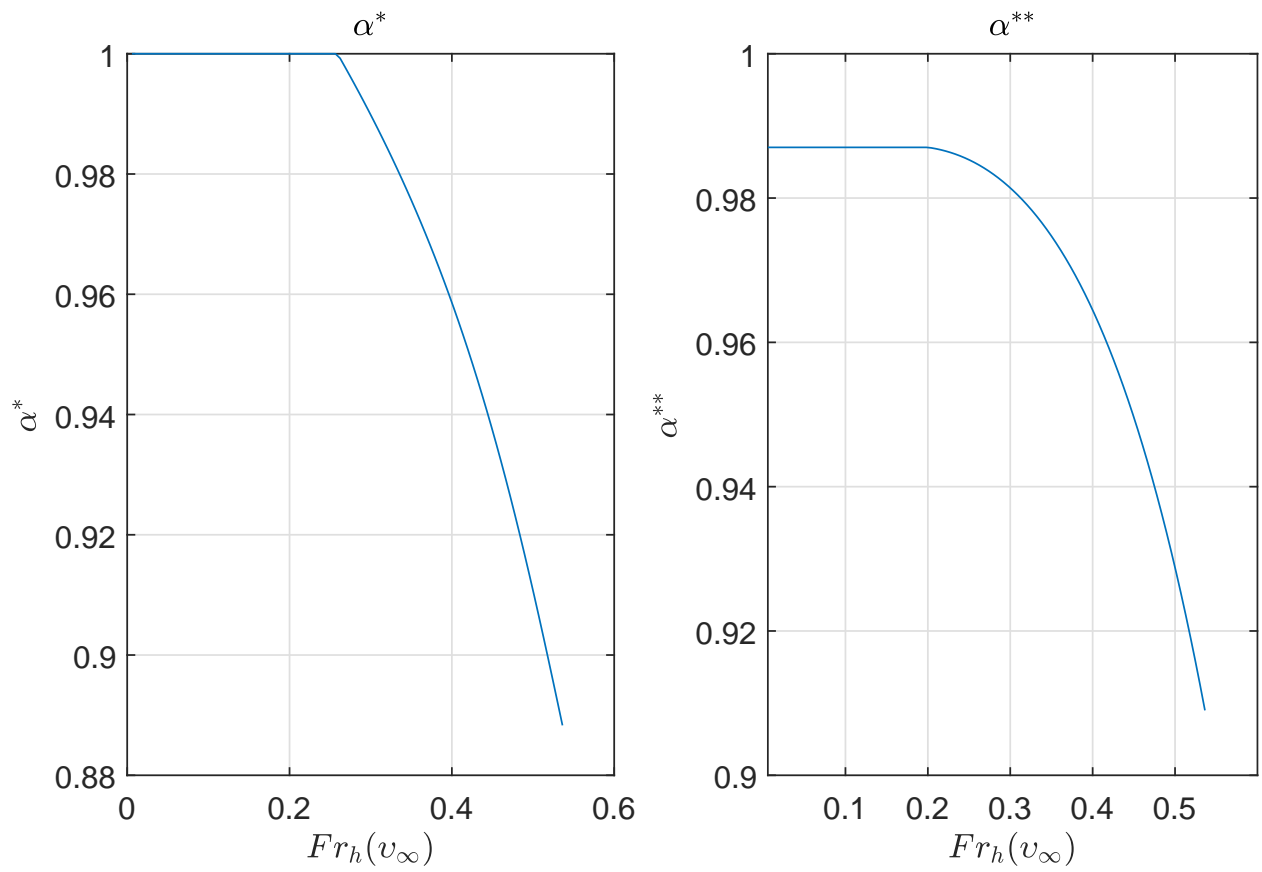

Figure B.7: Karvop's diagrams for 2700 TDW inland vessel.
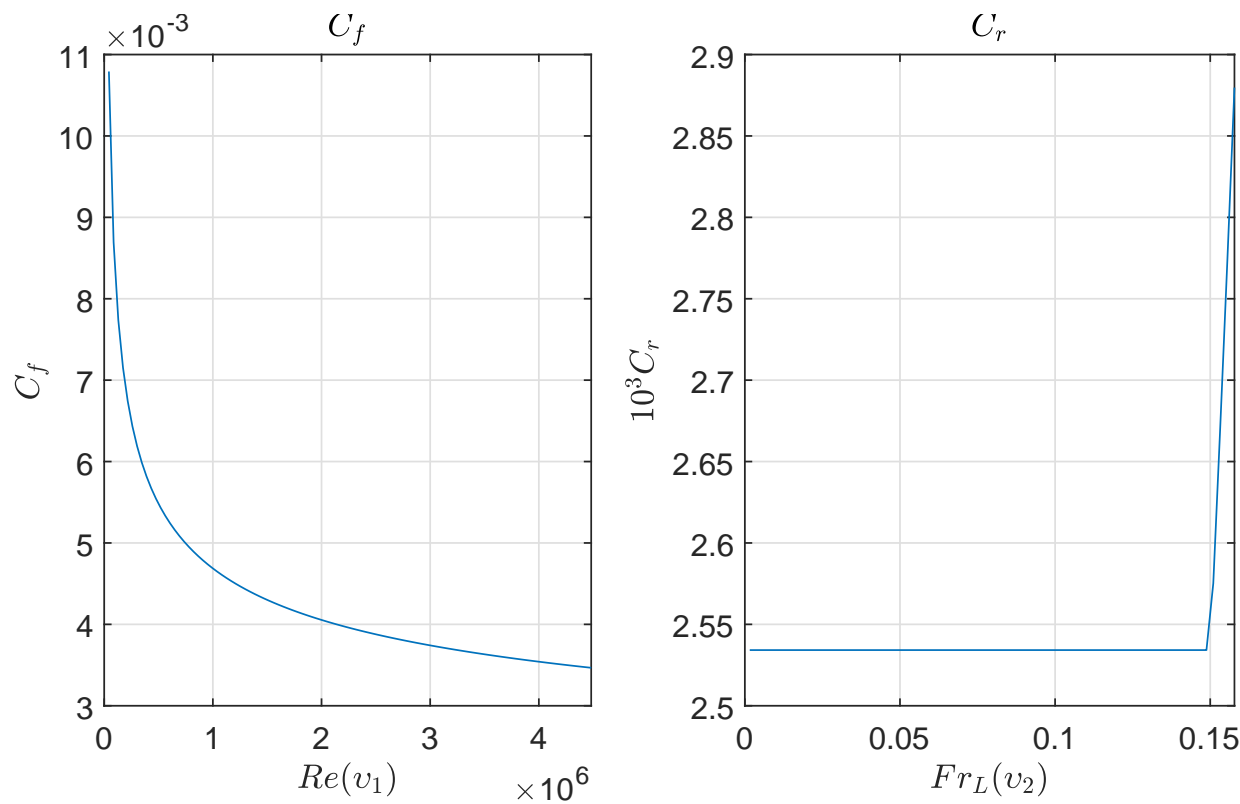

Figure B.8: Coefficient forces for middle rivers of the 2700 TDW inland vessel. Source: Author. 


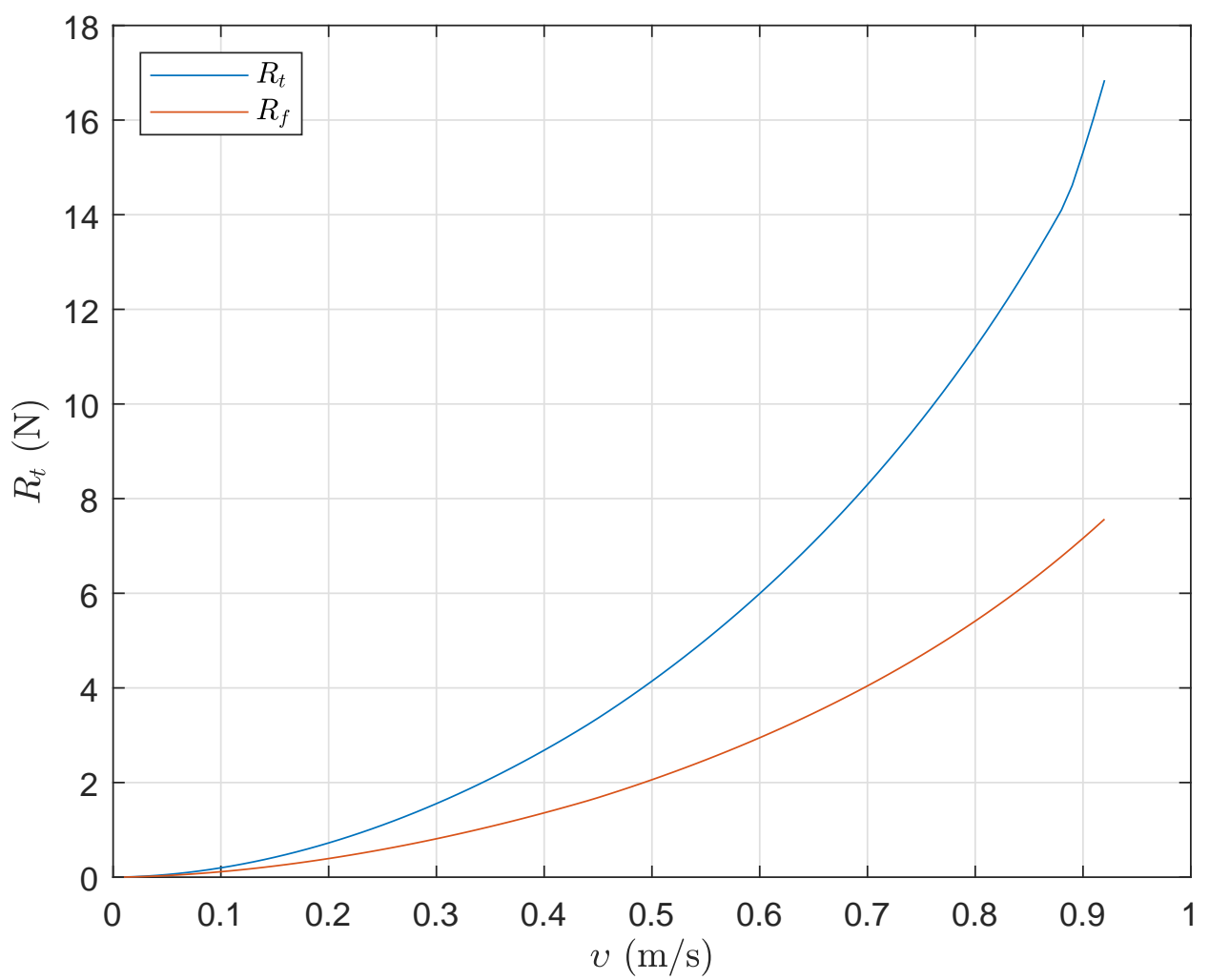

Figure B.9: Total forces for middle rivers of the 2700 TDW inland vessel. Source: Author. 


\section{APPENDIX C - CODES}

In this appendix is shown the codes made on MATLAB.

\section{C.1 Schlichting's method}

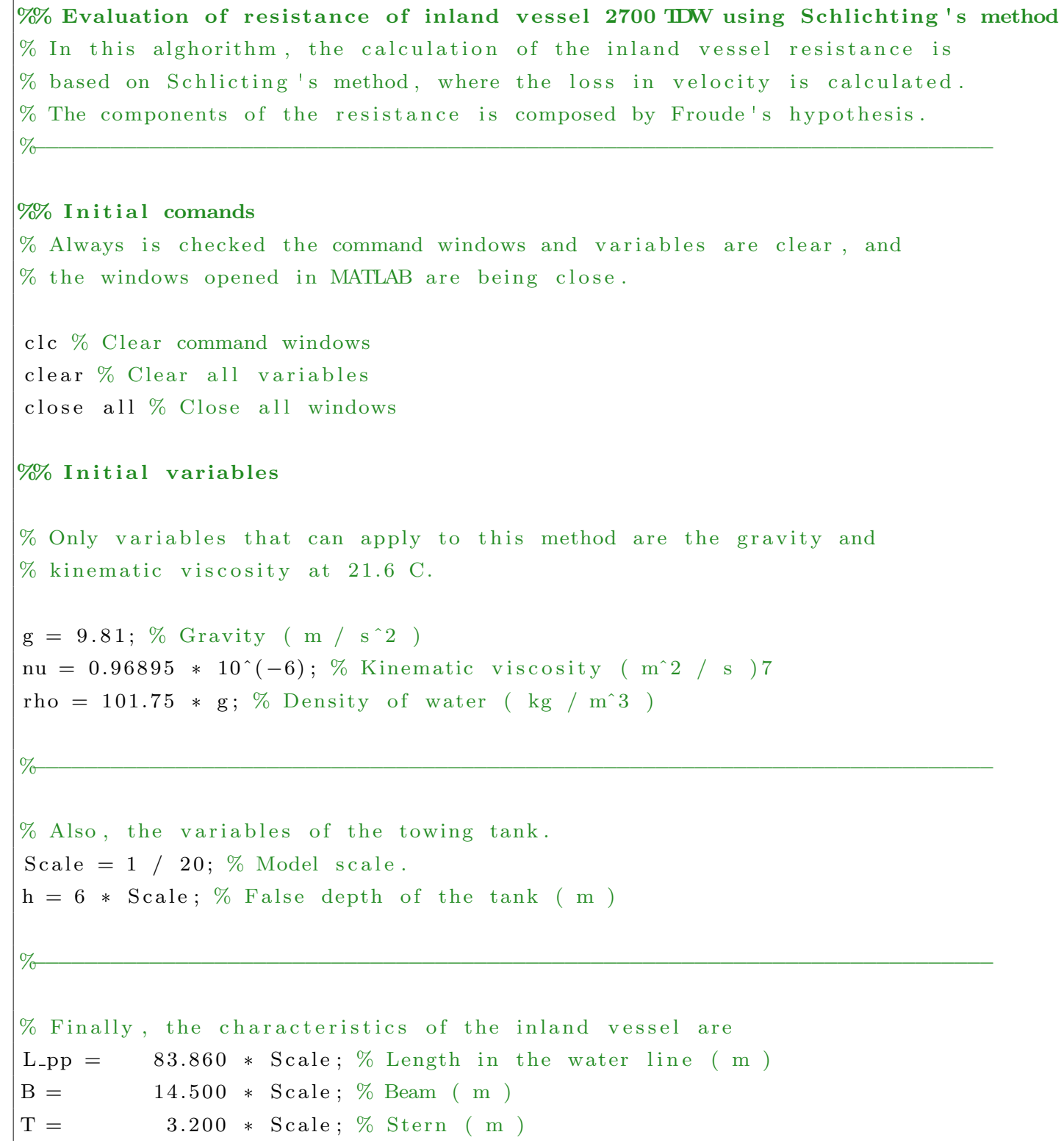




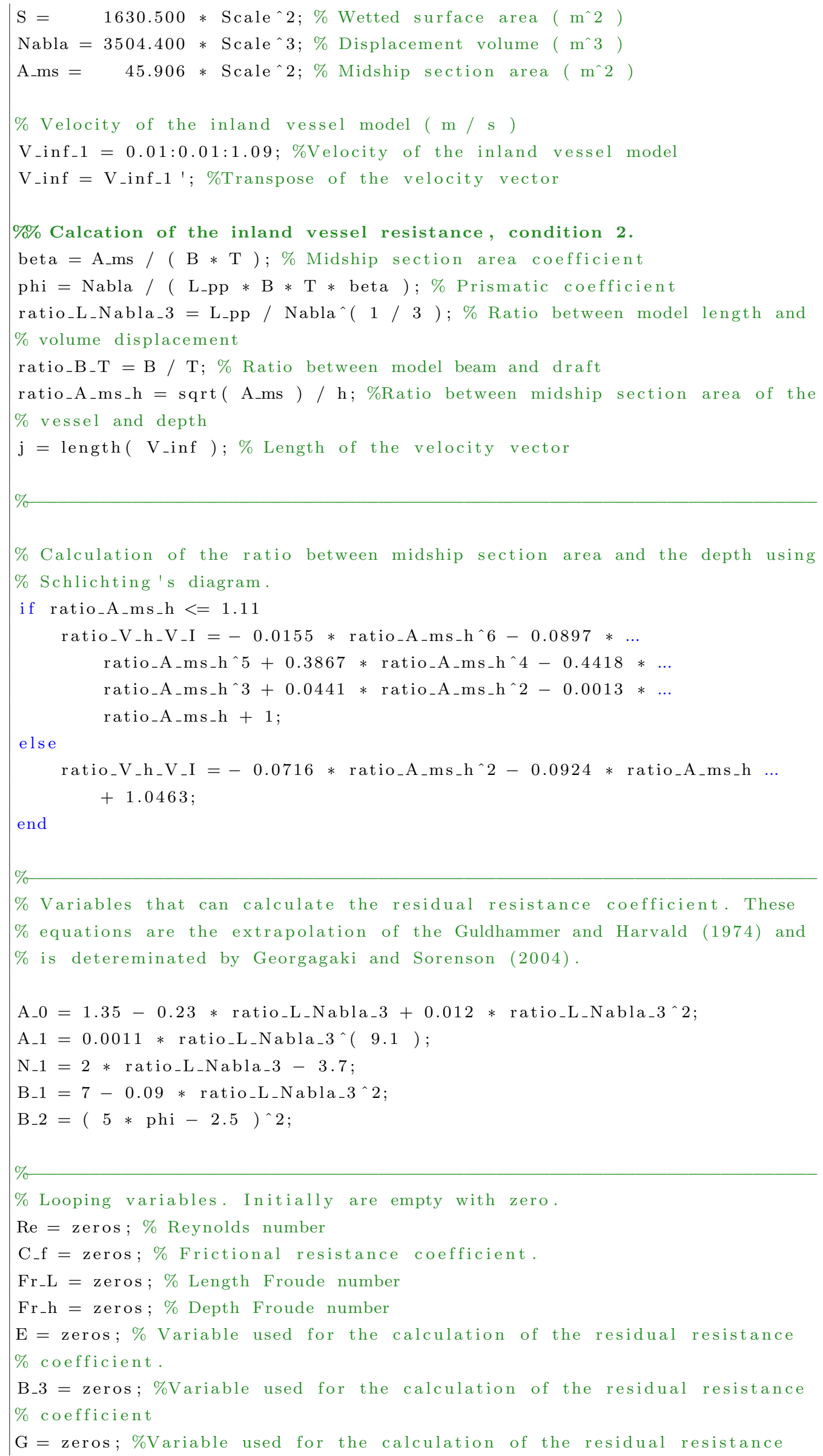




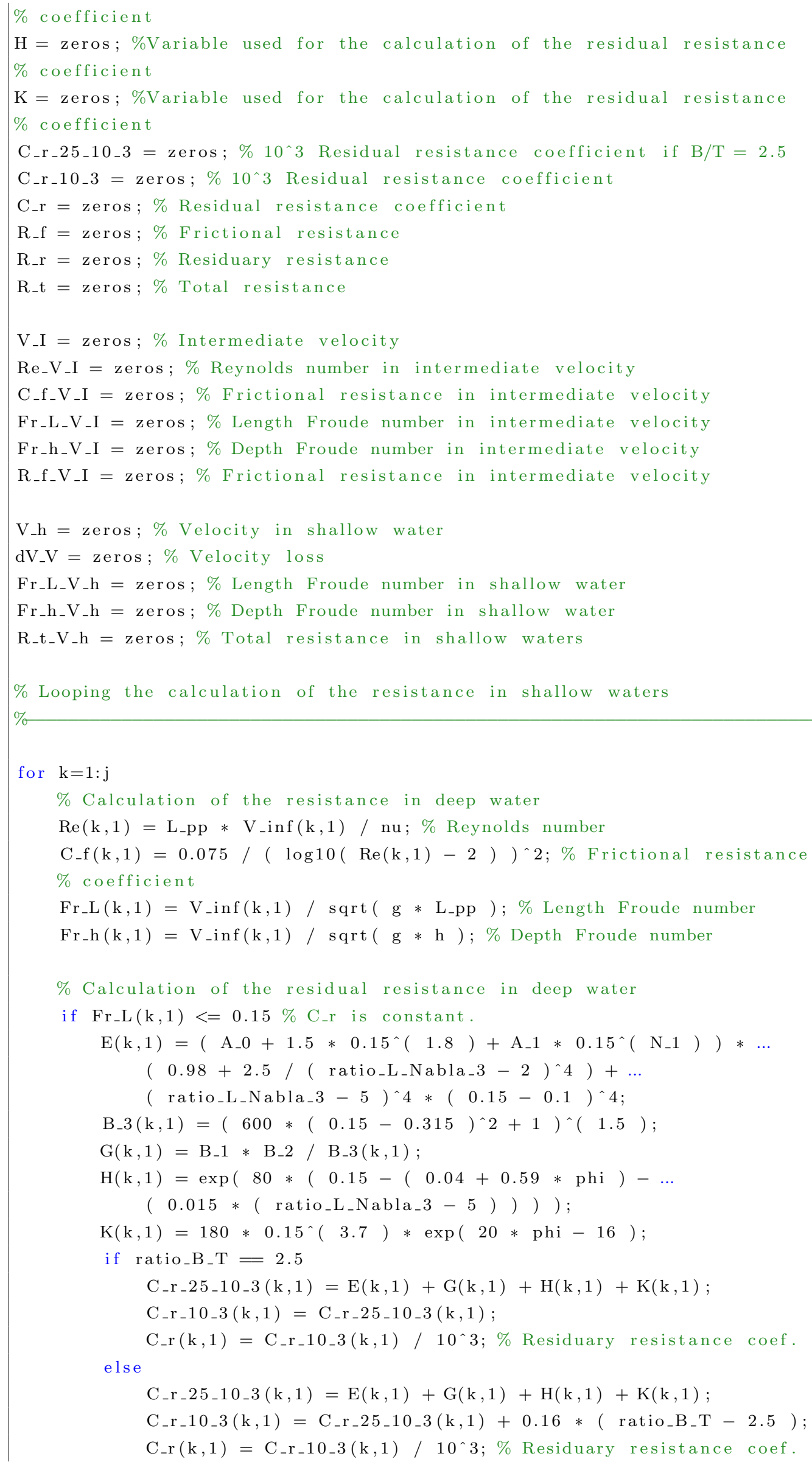




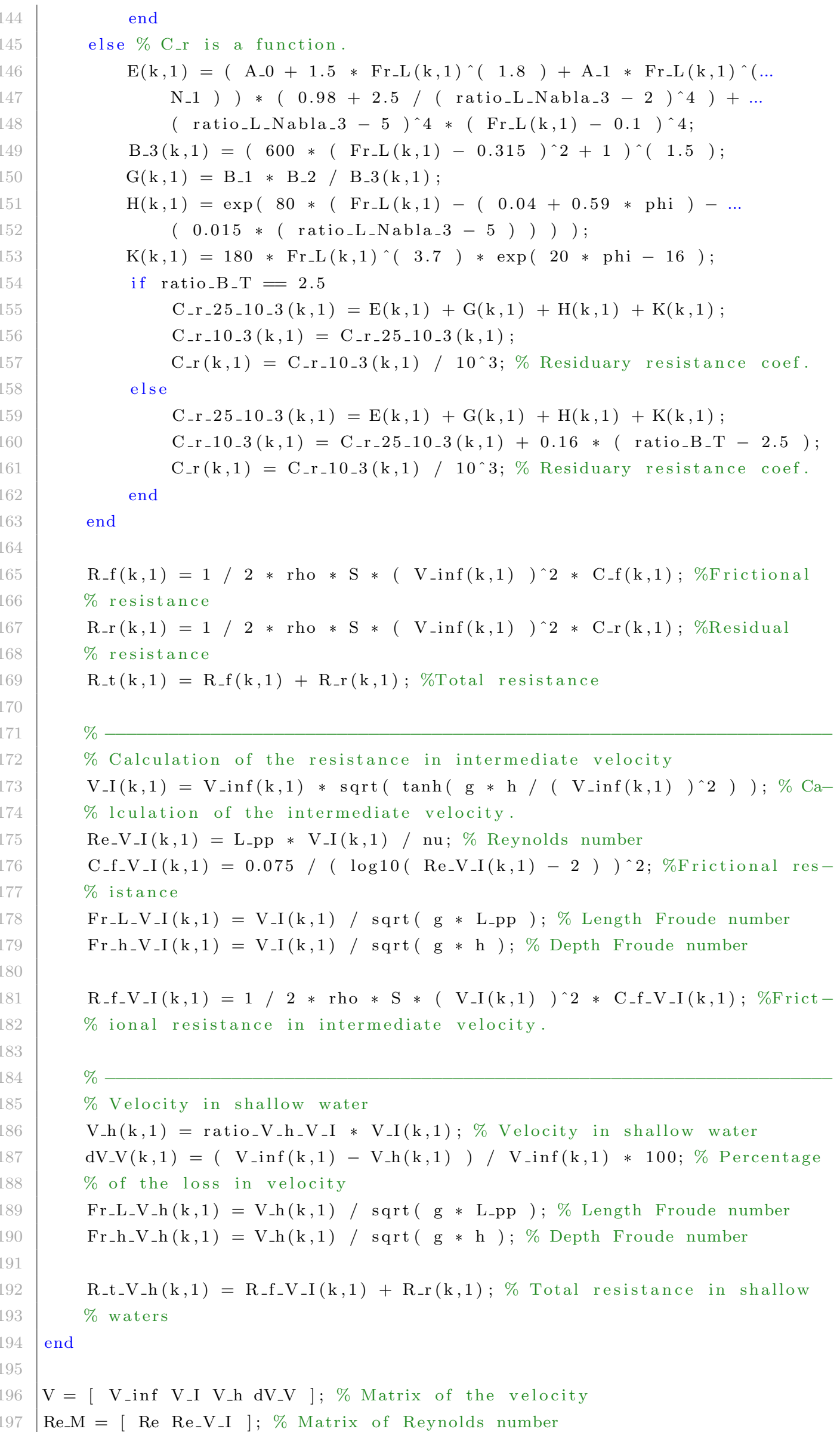


$\mathrm{C}_{-} \mathrm{M}=\left[\mathrm{C}_{-} \mathrm{f} \mathrm{C}_{-} \mathrm{f} \_\mathrm{V} \_\mathrm{I} \mathrm{C}_{-} \mathrm{r}\right] * 10^{\wedge} 3 ; \%$ Matrix of the resistance coefficients $\mathrm{Fr}_{-} \mathrm{L}_{-} \mathrm{M}=\left[\mathrm{Fr}_{-} \mathrm{L} \mathrm{Fr}_{-} \mathrm{L}_{-} \mathrm{V}_{-} \mathrm{I} \mathrm{Fr}_{-} \mathrm{L}_{-} \mathrm{V}_{-} \mathrm{h}\right] ; \%$ Matrix of length Froude number Fr_h_M = [ Fr_h Fr_h_V_I Fr_h_V_h ]; \% Matrix of depth Froude number

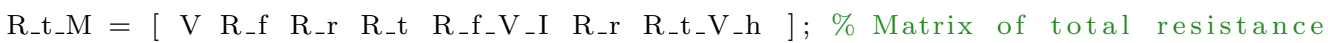

$\% \%$ Cuves of velocities ratios for calculating resistance in shallow waters $\mathrm{i}=0$;

$\mathrm{x}_{-} 2=0: 0.01: 1.6$;

$\mathrm{x}_{-} 1=\operatorname{zeros}\left(\operatorname{length}\left(\mathrm{x}_{-} 2\right), 1\right)$;

$\mathrm{y}_{-} \mathrm{Sch}_{-} \mathrm{f}=\operatorname{zeros}\left(\operatorname{length}\left(\mathrm{x}_{-} 2\right), 1\right)$;

$\mathrm{y}_{-} \mathrm{Sch}_{-} \mathrm{c}=\operatorname{zeros}\left(\right.$ length $\left.\left(\mathrm{x}_{-} 2\right), 1\right)$;

$y_{-}$Landweber_c $=$zeros $\left(\operatorname{length}\left(x_{-} 2\right), 1\right)$;

for $\mathrm{x}=\mathrm{x}_{-} 2$

$\mathrm{i}=\mathrm{i}+1$;

$\mathrm{x}_{-} 1(\mathrm{i},:)=\mathrm{x}$;

$\mathrm{y}_{-} \mathrm{Sch}_{-} \mathrm{f}(\mathrm{i},:)=\operatorname{sqrt}\left(\tanh \left((1 / \mathrm{x})^{\wedge} 2\right)\right)$;

\%schlichting 's curve

if $\mathrm{x}<=1.11$

$\mathrm{y} \_S c h \_c(\mathrm{i},:)=-0.0155 * \mathrm{x}^{\wedge} 6-0.0897 * \mathrm{x}^{\wedge} 5+0.3867 * \mathrm{x}^{\wedge} 4 \ldots$

$-0.4418 * \mathrm{x}^{\wedge} 3+0.0441 * \mathrm{x}^{\wedge} 2-0.0013 * \mathrm{x}+1$;

els e

$\mathrm{y} \_S c h \_c_{-}(\mathrm{i},:)=-0.0716 * \mathrm{x}^{\wedge} 2-0.0924 * \mathrm{x}+1.0463 ;$

end

\%Landweber's curve

if $\mathrm{x}<=1.56$

$\mathrm{y}_{\text {_Landweber_c }}(\mathrm{i},:)=0.0269 * \mathrm{x}^{\wedge} 6-0.1664 * \mathrm{x}^{\wedge} 5+0.38267 \ldots$

$* \mathrm{x}^{\wedge} 4-0.3729 * \mathrm{x}^{\wedge} 3+0.0429 * \mathrm{x}^{\wedge} 2-0.0045 * \mathrm{x}+1.0001$;

els e

$\mathrm{y}_{\text {_Landweber_c }}(\mathrm{i},:)=-0.1406 * \mathrm{x}^{\wedge} 2-0.2077 * \mathrm{x}+0.8177$;

end

end

$\%$ Displaying in command window

$\%$ In this section, is displayed the results of the resistance calulation of

$\%$ the 2700 TDW inland vessel.

disp ('Evaluation of resistance of inland vessel 2700 TDW using method of Schlichting') disp $(1$

disp ('Scale')

disp (Scale)

disp ('Length of waterline - L_pp (m)')

disp ( L_pp)

disp ('Beam - B (m)')

disp (B)

$\operatorname{disp}\left({ }^{\prime}\right.$ Draft $\left.-\mathrm{T}(\mathrm{m}){ }^{\prime}\right)$

$\operatorname{disp}(\mathrm{T})$

disp ('Wetted surface of the hull-S (m^2)') 
disp $(\mathrm{S})$

disp ('Displacement - Nabla (m^3) ')

disp (Nabla)

disp ('Midship section area - A_ms ( $\left.\mathrm{m}^{\wedge} 2\right)$ ')

disp (A_ms)

disp ('Depth of the tank (m)')

disp $(h)$

disp ('Midship section area coefficient - beta')

disp ( beta)

disp ('Prismatic coefficient - phi')

disp ( phi )

disp('Ratio between model length and volume displacement _ L_pp / Nabla^3')

disp ( ratio_L_Nabla_3)

disp ('Ratio between model beam and draft $-\mathrm{B} / \mathrm{T}^{\prime}$ )

disp ( ratio_B_T )

disp ('Ratio between Midship section area and depth - sqrt (A_ms) / h')

disp (ratio_A_ms_h)

disp('Ratio between velocity in shallow water and intermediate velocity - V_h / V_I')

disp ( ratio_V_h_V_I )

disp ('Velocity $(\mathrm{m} / \mathrm{s})$ ')

disp ( $\quad$ V_inf V_I V_h Losses (\%)')

disp (V)

disp ('Reynolds number - Re in function of ')

disp ( $\quad V_{-}$inf $\left.\quad V_{-} I^{\prime}\right)$

disp (Re_M)

disp ('Resistance coefficient * 10^3')

disp ( $\quad$ C_f $\left.\quad C_{-} f_{-} V_{-} I \quad C_{-} r^{\prime}\right)$

$\operatorname{disp}(\mathrm{C} M)$

disp ('Length Froude number - Fr_L in function of ')

disp ( $\quad V_{-}$inf $\left.\quad V_{-} I \quad V_{-}{ }^{\prime}\right)$

disp (Fr_L_M )

disp ('Depth Froude number - Fr_h in function of')

disp ( $\quad V_{-}$inf $\left.\quad V_{-} I \quad V_{-}{ }^{\prime}\right)$

disp ( Fr_h_M )

disp ('Total resistance $R_{-} t$ ')

$\operatorname{disp}(1$

Total resistance

(N) 


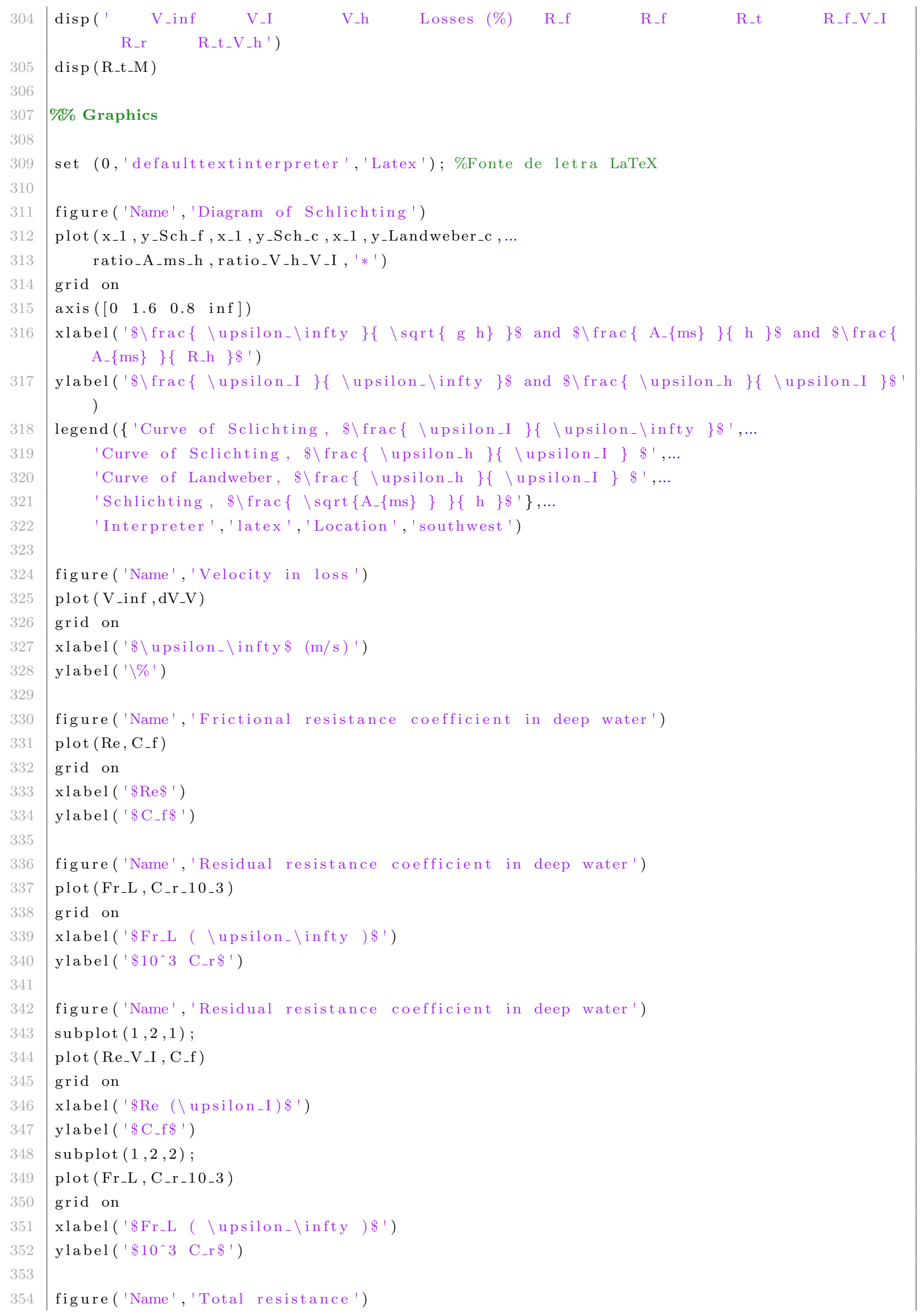




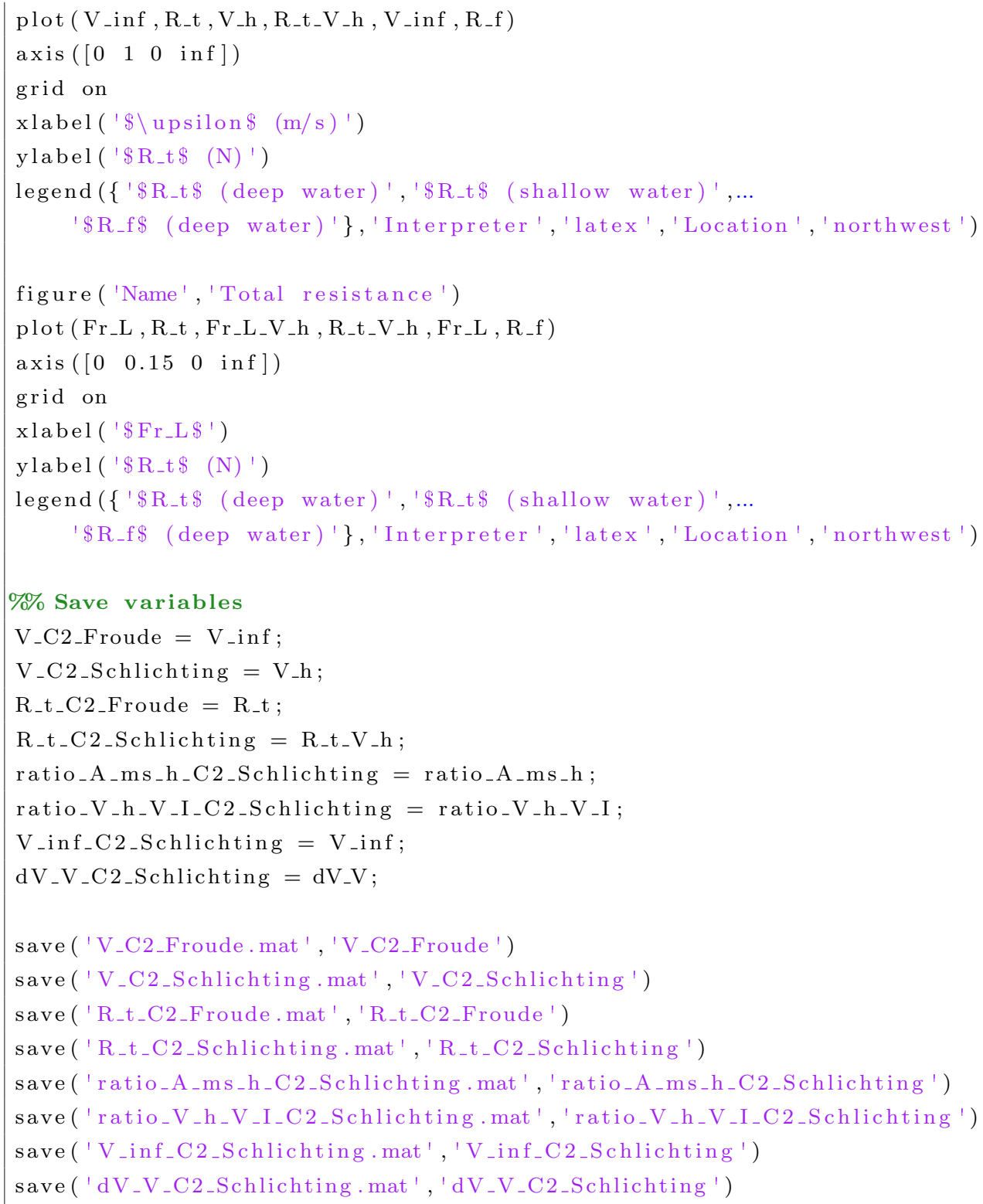

\section{C.2 Karpov's and Artjuskov's method}

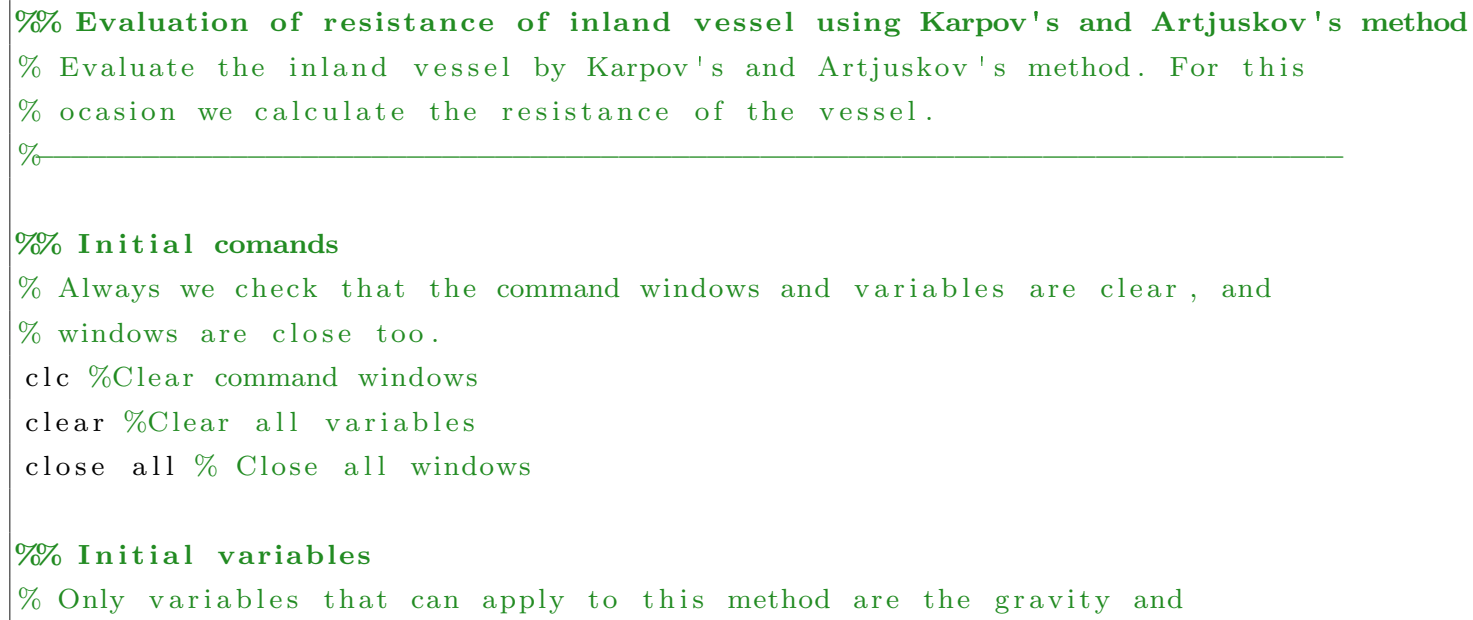




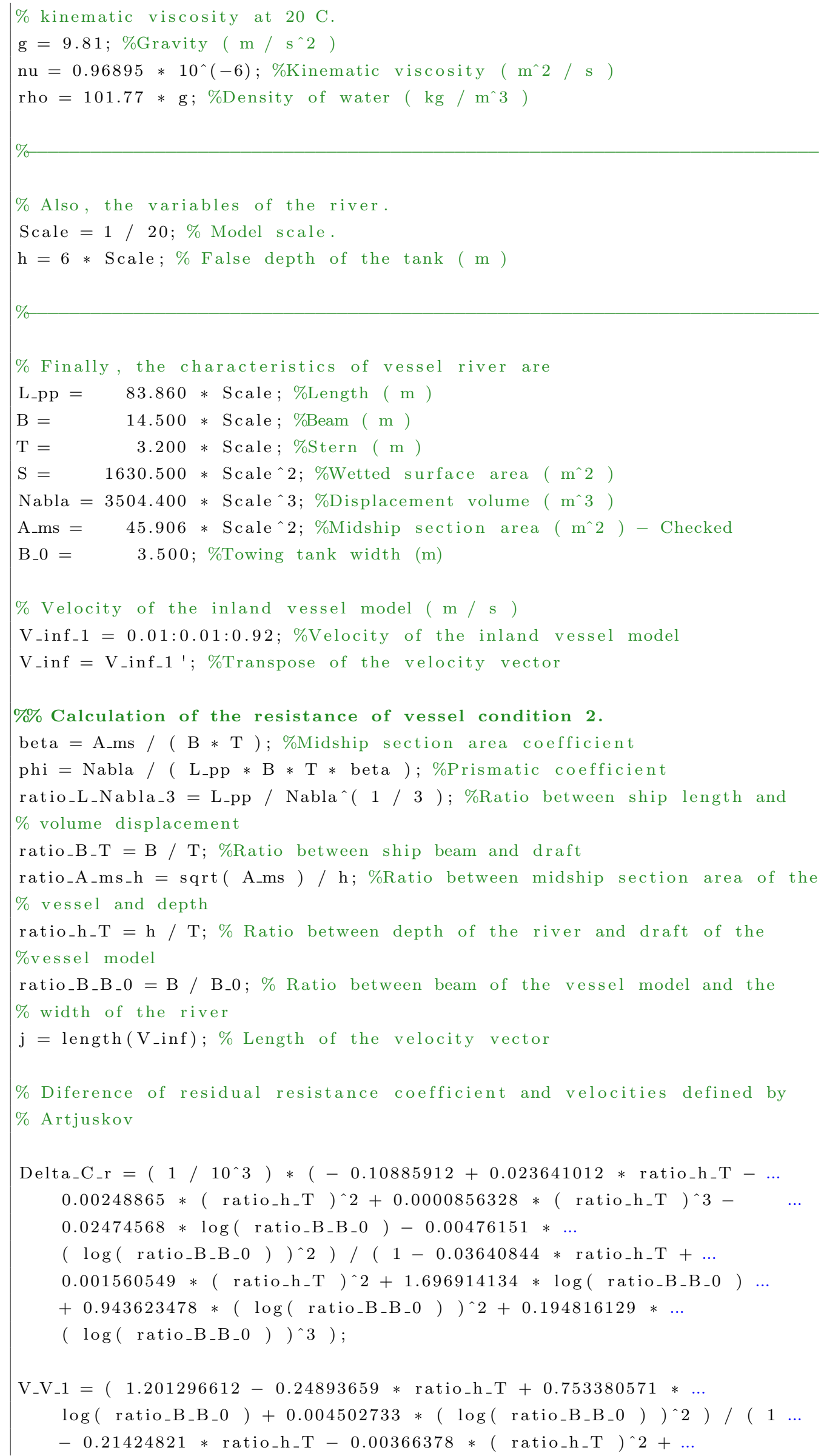


$0.000121814 *($ ratio_h_T $) \wedge 3+0.708479783 * \log ($ ratio_B_B_0 $)) ;$ $\%$

\% Variables that can calculate the residual resistance coefficient. These $\%$ equations are the extrapolation of the Guldhammer and Harvald (1974) and $\%$ is detereminated by Georgagaki and Sorenson (2004).

A_0 $=1.35-0.23 *$ ratio_L $L_{-} \mathrm{Nabla}_{-} 3+0.012 *$ ratio_L $L_{-} \mathrm{Nabla}_{-}{ }^{\wedge} 2$;

A_1 $=0.0011 *$ ratio_L_Nabla_3^ $(9.1)$;

$\mathrm{N}_{-} 1=2 *$ ratio_L_Nabla_ $3-3.7$;

$\mathrm{B} \__{-}=7-0.09 *$ ratio_L_ $\mathrm{L}_{-} \mathrm{Nabla}_{-} 3^{\wedge} 2$

B_2 $=(5 * \text { phi }-2.5)^{\wedge} 2$; $\%$

\% Looping variables. Initially are empty with zero.

Fr_L $=$ zeros; \% Length Froude number

Fr_h $=$ zeros; \% Depth Froude number

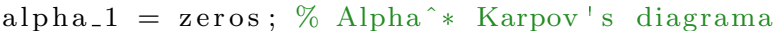

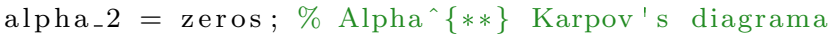

V_1 = zeros; \% Velocity 1 by Karpov

V_2 = zeros; \% Velocity 2 by Karpov

$\operatorname{Re}=$ zeros; \% Reynolds number

$\mathrm{C}_{-} \mathrm{f}=$ zeros; $\%$ Frictional resistance coefficient

$\mathrm{E}=$ zeros; $\%$ Variable used for the calculation of the residual resistance

$\%$ coefficient.

B_3 = zeros; \% Variable used for the calculation of the residual resistance $\%$ coefficient

$\mathrm{G}=$ zeros; $\%$ Variable used for the calculation of the residual resistance $\%$ coefficient.

$\mathrm{H}=$ zeros; $\%$ Variable used for the calculation of the residual resistance $\%$ coefficient.

$\mathrm{K}=$ zeros $; \%$ Variable used for the calculation of the residual resistance $\%$ coefficient.

C_r_25_10_3 = zeros; $\%$ 10^3 Residual resistance coefficient if $\mathrm{B} / \mathrm{T}=2.5$

C_r_10_3 = zeros; $\%$ 10^3 Residual resistance coefficient

C_r $=$ zeros; \% Residual resistance coefficient

$\mathrm{R}_{-} \mathrm{f}=$ zeros $; \%$ Frictional resistance

$\mathrm{R}_{-} \mathrm{r}=$ zeros; $\%$ Residuary resistance

$\mathrm{R}_{-} \mathrm{t}=$ zeros; $\%$ Total resistance

\% Looping the calculation of the resistance in shallow waters $\%$

for $\mathrm{k}=1: \mathrm{j}$

$\operatorname{Fr}_{-} \mathrm{h}(\mathrm{k}, 1)=\mathrm{V}_{-} \inf (\mathrm{k}, 1) / \operatorname{sqrt}(\mathrm{g} * \mathrm{~h}) ; \%$ Depth Froude number $\%$

\% Alphas diagrams defined by Karpov

$\% \mathrm{Alpha}^{\wedge} *$

if $\mathrm{Fr}_{-} \mathrm{h}(\mathrm{k}, 1)<0.2$

alpha_1 $(\mathrm{k}, 1)=1$; 


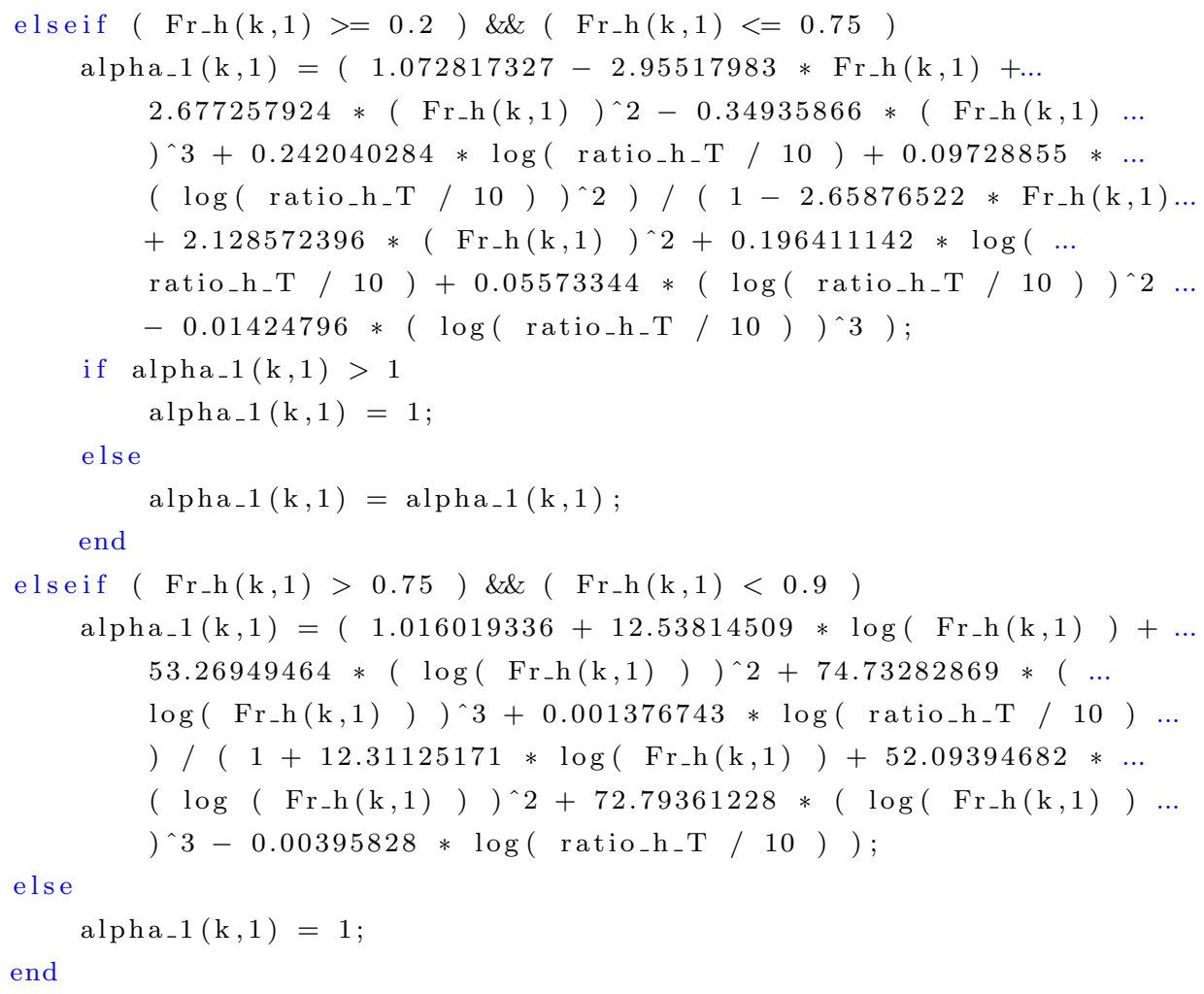


$\operatorname{Re}(\mathrm{k}, 1)=\mathrm{L}_{-} \mathrm{pp} * \mathrm{~V}_{-} 1(\mathrm{k}, 1) / \mathrm{nu} ; \%$ Reynolds number

$\mathrm{C}_{-} \mathrm{f}(\mathrm{k}, 1)=0.075 /(\log 10(\operatorname{Re}(\mathrm{k}, 1))-2)^{\wedge} 2 ; \%$ Frictional resistance $\%$ coefficient

$\%$ Equation for obtain data for residuary resistent coefficient $\%$ obtained by Harvald graphic and improved by Georgakaki and Sorenson

Fr_L $(\mathrm{k}, 1)=\mathrm{V} \_2_{2}(\mathrm{k}, 1) / \operatorname{sqrt}\left(\mathrm{g} * \mathrm{~L}_{-} \mathrm{pp}\right) ; \%$ Length Froude number

if $\operatorname{Fr}_{-} \mathrm{L}(\mathrm{k}, 1)<=0.15 \% \mathrm{C}_{-} \mathrm{r}$ is constant

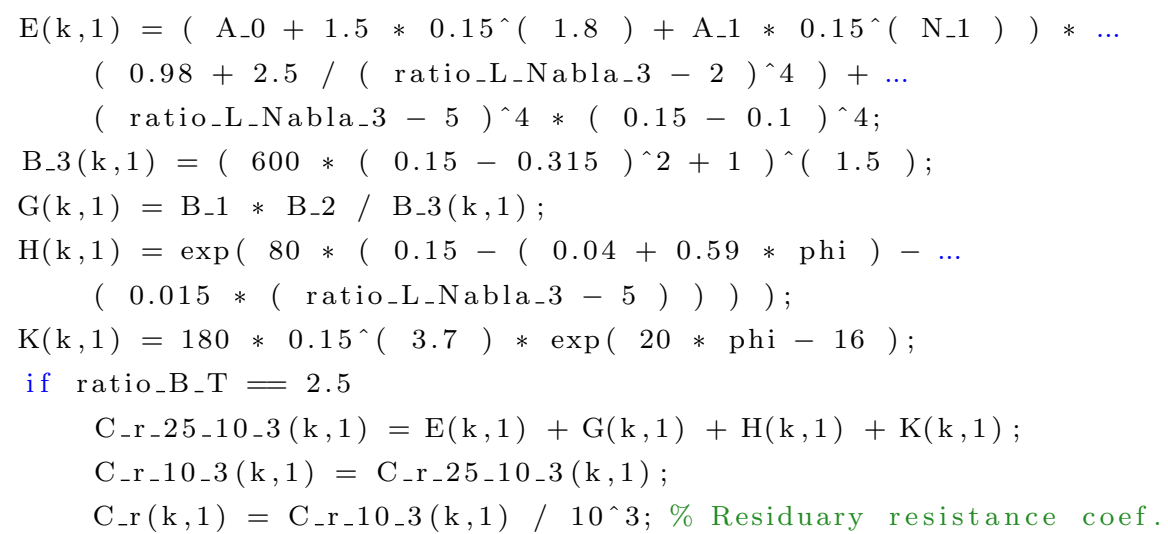
els e

$\mathrm{C}_{\text {_r }} \_25_{-} 10_{\_} 3(\mathrm{k}, 1)=\mathrm{E}(\mathrm{k}, 1)+\mathrm{G}(\mathrm{k}, 1)+\mathrm{H}(\mathrm{k}, 1)+\mathrm{K}(\mathrm{k}, 1) ;$

$\mathrm{C} \_r_{-} 10 \_3(\mathrm{k}, 1)=\mathrm{C}_{-} \mathrm{r}_{-} 255_{-} 10 \_3(\mathrm{k}, 1)+0.16 *\left(\operatorname{ratio}{ }_{-} \mathrm{B} \_\mathrm{T}-2.5\right)$;

C_r $(\mathrm{k}, 1)=\mathrm{C}_{-} \mathrm{r} \_10_{-} 3(\mathrm{k}, 1) / 10^{\wedge} 3 ; \%$ Residuary resistance coef.

end

else \% C_r is a function.

$\mathrm{E}(\mathrm{k}, 1)=\left(\mathrm{A}_{-} 0+1.5 * \mathrm{Fr}_{-} \mathrm{L}(\mathrm{k}, 1) \wedge(1.8)+\mathrm{A}_{-} 1 * \mathrm{Fr}_{-} \mathrm{L}(\mathrm{k}, 1)^{\wedge}(\ldots\right.$

$\left.\left.\mathrm{N}_{-} 1\right)\right) *\left(0.98+2.5 /\left(\mathrm{ratio}_{-} \mathrm{L}_{-} \mathrm{Nabla}-3-2\right) \wedge 4\right)+\ldots$

$($ ratio_L_Nabla_ $3-5) \wedge 4 *\left(\operatorname{Fr}_{-} \mathrm{L}(\mathrm{k}, 1)-0.1\right) \wedge 4$;

B_3 $(\mathrm{k}, 1)=\left(600 *\left(\operatorname{Fr}_{-} L(\mathrm{k}, 1)-0.315\right)^{\wedge} 2+1\right)^{\wedge}(1.5)$;

$\mathrm{G}(\mathrm{k}, 1)=\mathrm{B}_{-} 1 * \mathrm{~B}_{-} 2 / \mathrm{B}_{-} 3(\mathrm{k}, 1)$;

$\mathrm{H}(\mathrm{k}, 1)=\exp \left(80 *\left(\mathrm{Fr}_{-} \mathrm{L}(\mathrm{k}, 1)-(0.04+0.59 * \mathrm{phi})-\ldots\right.\right.$

$(0.015 *($ ratio_L_Nabla_3 - 5 ) ) ) );

$\mathrm{K}(\mathrm{k}, 1)=180 * \mathrm{Fr}_{-} \mathrm{L}(\mathrm{k}, 1) \wedge(3.7) * \exp (20 * \mathrm{phi}-16)$;

if ratio_B_ $\mathrm{T}=2.5$

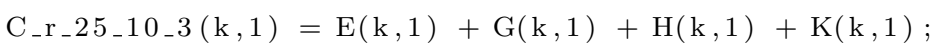

$\mathrm{C}_{-} \mathrm{r}_{-} 10_{-} 3(\mathrm{k}, 1)=\mathrm{C}_{-} \mathrm{r}_{-} 25_{-} 10_{-} 3(\mathrm{k}, 1)$;

C_r $(\mathrm{k}, 1)=\mathrm{C}_{\_} \mathrm{r} \_10_{\_} 3(\mathrm{k}, 1) / 10^{\wedge} 3 ; \%$ Residuary resistance coef. els e

$\mathrm{C}_{-} \mathrm{r}_{-} 25_{-} 10_{-} 3(\mathrm{k}, 1)=\mathrm{E}(\mathrm{k}, 1)+\mathrm{G}(\mathrm{k}, 1)+\mathrm{H}(\mathrm{k}, 1)+\mathrm{K}(\mathrm{k}, 1) ;$

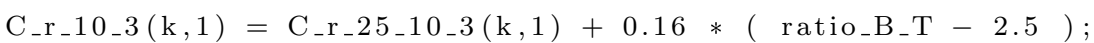

C_r $(\mathrm{k}, 1)=\mathrm{C}_{-} \mathrm{r} \_10_{-} 3(\mathrm{k}, 1) / 10^{\wedge} 3 ; \%$ Residuary resistance coef .

end

end

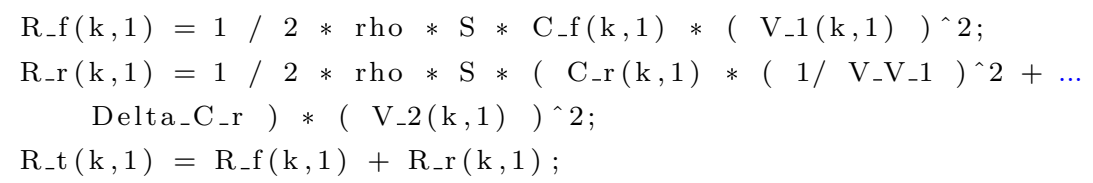
end

alphas $=[$ Fr_h alpha_1 alpha_2 $]$;

$\mathrm{V}=\left[\begin{array}{lll}\mathrm{V} \_ \text {inf } & \mathrm{V}_{-} 1 & \mathrm{~V}_{-} 2\end{array}\right] ;$ 
$\%$ Displaying in command window

disp ('Evaluation of resistance of inland vessel 2700 TDW using method of Karpov and Arjuskov')

disp ('Scale')

disp (Scale)

disp ('Length of waterline - L_pp (m)')

disp ( L_pp)

disp ('Beam - B (m)')

$\operatorname{disp}(B)$

disp ( 'Draft $\left.-\mathrm{T}(\mathrm{m}){ }^{\prime}\right)$

$\operatorname{disp}(\mathrm{T})$

disp ('Wetted surface of the hull - S ( $\left.\mathrm{m}^{\wedge} 2\right)$ ')

$\operatorname{disp}(\mathrm{S})$

disp ('Displacement - Nabla ( $\left.\left.\mathrm{m}^{\wedge} 3\right)^{\prime}\right)$

disp (Nabla)

disp ('Midship section area - A_ms (m^2)')

disp (A_ms)

disp ('Towing tank width - B_0 (m)')

$\operatorname{disp}\left(B_{-} 0\right)$

disp ('Midship section area coefficient - beta')

disp (beta)

disp ('Prismatic coefficient - phi')

disp (phi)

disp ('Ratio between model length and volume displacement _ L_pp / Nabla`3')

disp ( ratio_L_Nabla_$_{-} \mathrm{N}_{\text {) }}$

disp ('Ratio between model beam and draft $-\mathrm{B} / \mathrm{T}$ ')

disp ( ratio_B_T )

disp ('Ratio between Midship section area and depth - sqrt (A_ms) / h')

disp ( $\left.\mathrm{ratio}_{-} \mathrm{A}_{-} \mathrm{ms}_{-} \mathrm{h}\right)$

disp ('Ratio between depth and draft $-\mathrm{h} / \mathrm{T}^{\prime}$ )

disp ( ratio_h_t $)$

disp ('Ratio between beam and width - B / B_0')

disp (ratio_B_B_0 )

disp( 'Changes in residual resistance coefficient - Delta C_r')

disp ( Delta_C_r ) 


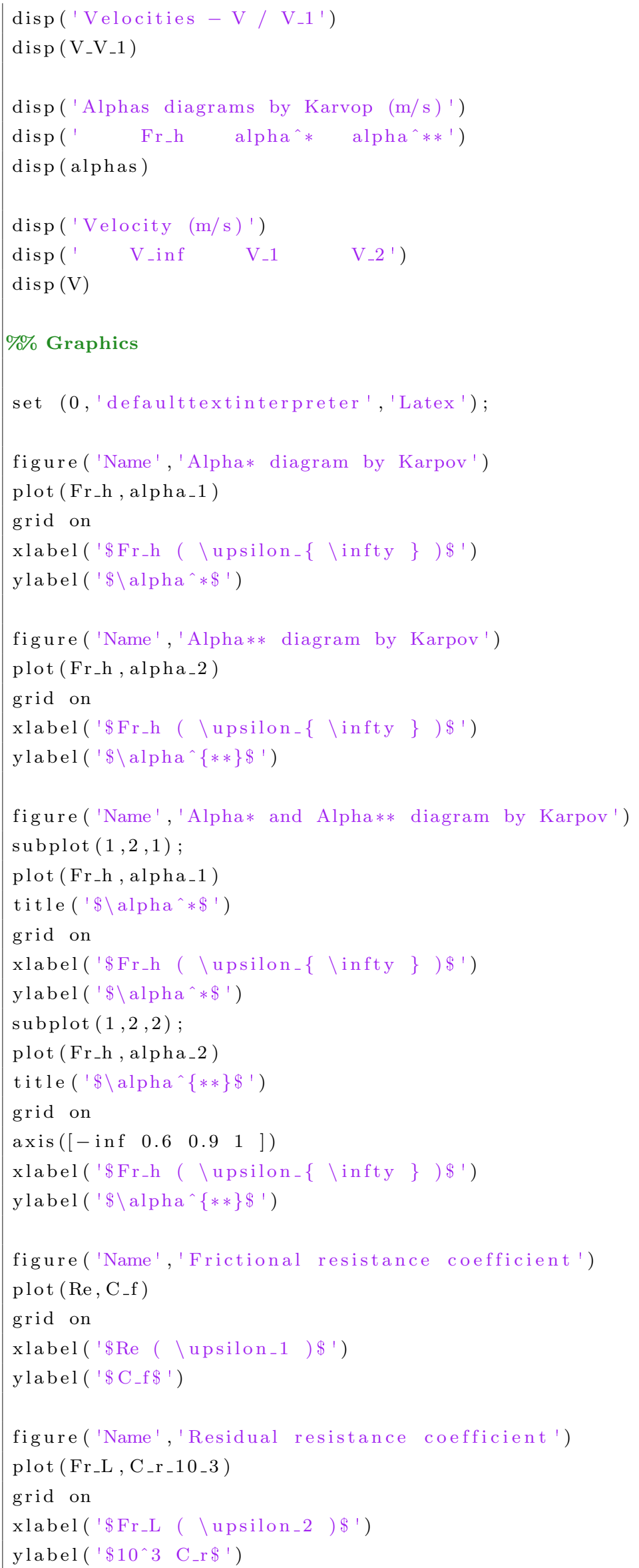




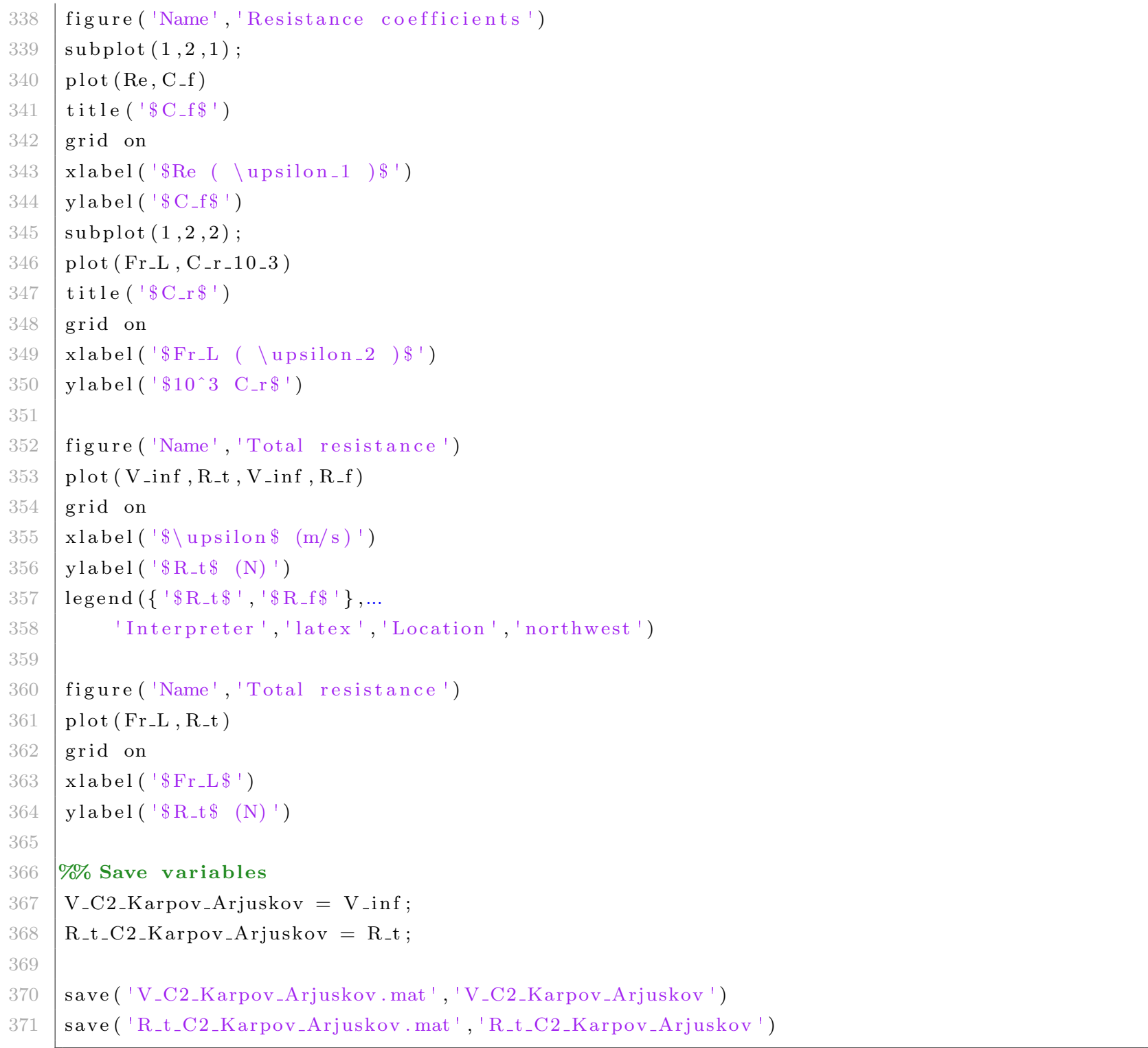

\section{C.3 Total prism layer calculation}

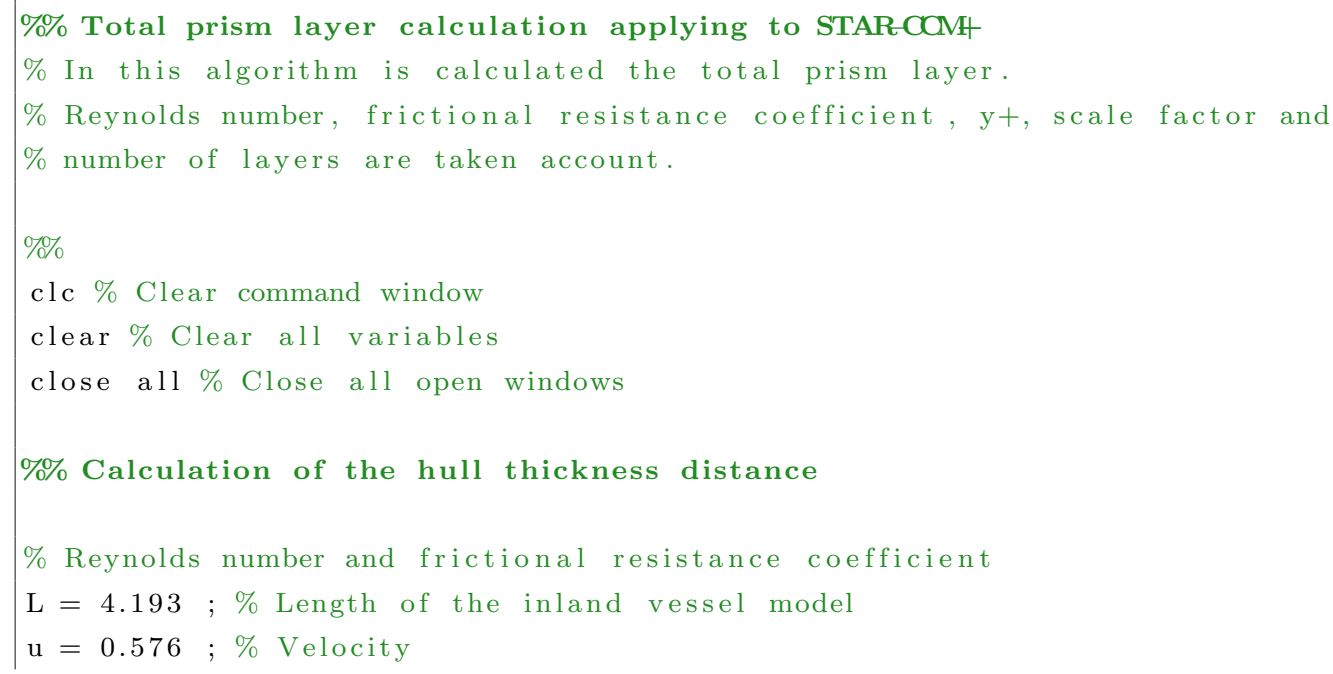




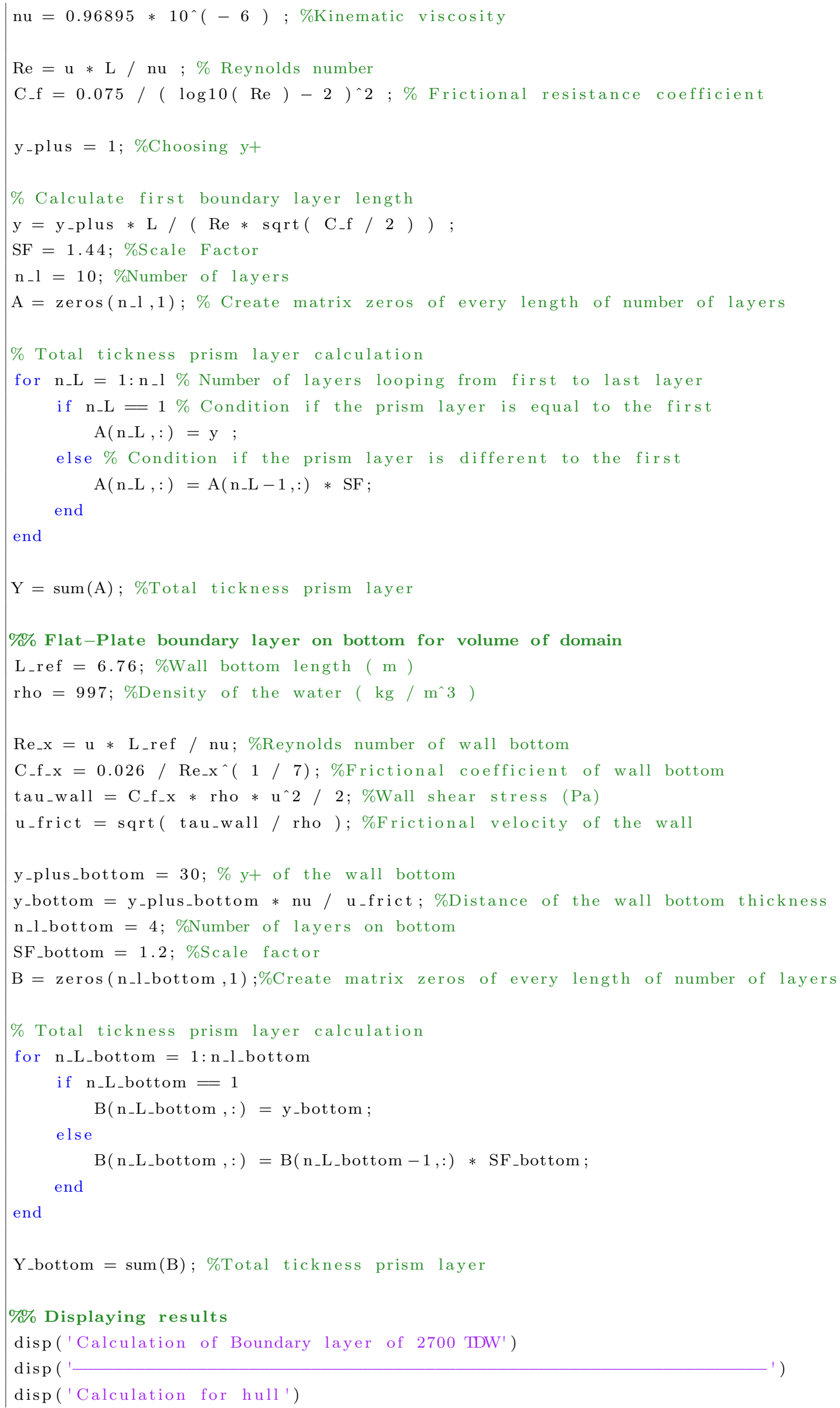




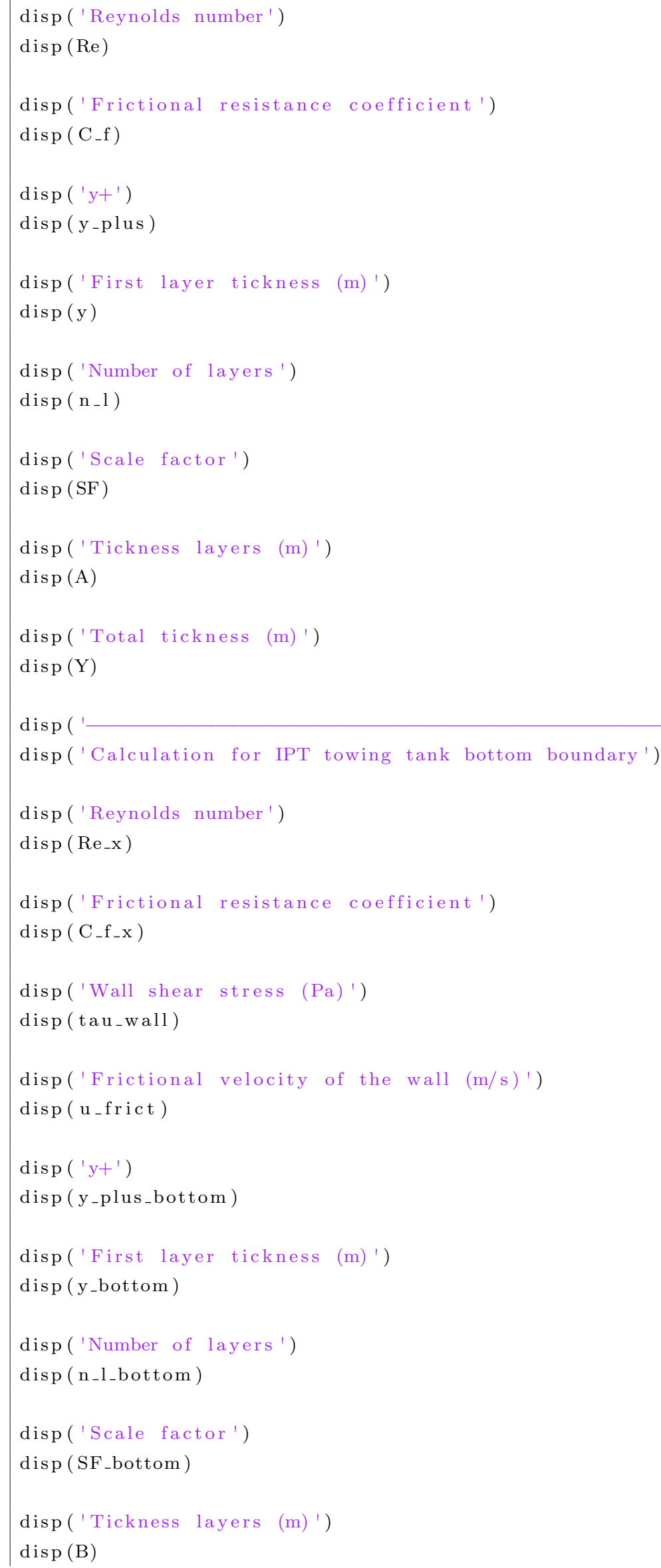


disp ('Total tickness (m) ')

disp (Y_bottom ) 